
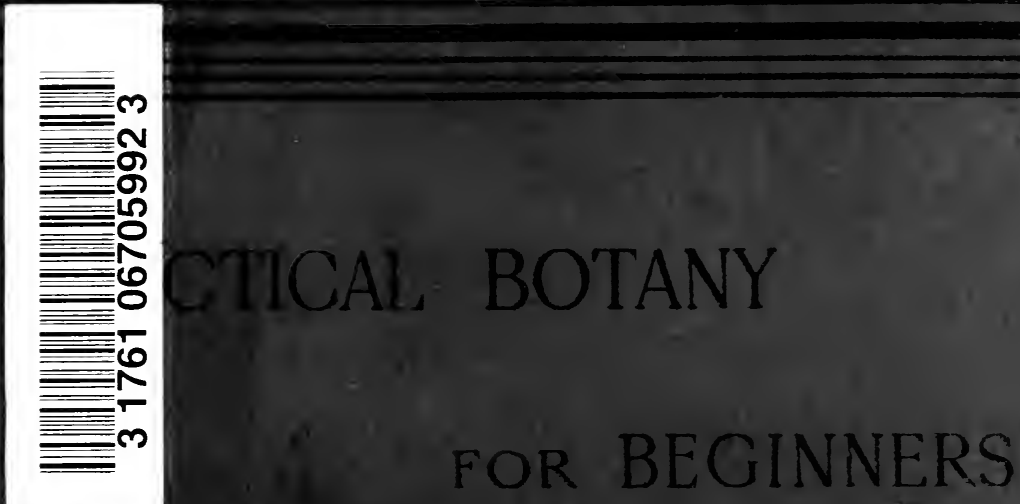

F. ซ. BOHW R 
PRESENTED

TO

THE UNIVERSITY OF TORONTO

Mass macmillan To. 

Digitized by the Internet Archive in 2007 with funding from Microsoft Corporation 


\section{PRACTICAL BOTANY}

FOR

\section{BEGINNERS}


s. 


\section{'RACTICAL BOTANY}

FOR

\section{BEGINNERS}

F. O. BOWER, D.Sc., F.R.S.

REGIUS PROFESSOR OF BOTANY IN THE UNIVERSITY OF GIASGOW

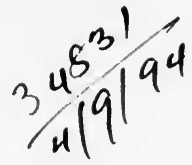

32 O 11000

M A C ILLAN A N CO.

AND NEW YORK

I 894 
Richard Clay and Sons, Limited, LONDON AND BUNGAY. 


\section{PREFACE}

THIS little book contains, in an abridged form, the elementary and more essential parts of the text of the larger Course of Practical Instruction in Botany. It is believed that beginners will find the directions sufficient to guide their first steps in laboratory work. The abridgment has largely consisted in the excision of supplementary descriptions of forms other than those which have been selected as the main types: in so far as that is the case, the publication of this book may be thought to encourage a narrow style of type-teaching.

Type-teaching in Biological Sciences appears at present to be inevitable in elementary classes; it lies chicfly with the teacher to avoid the evils which are apt to arise from it. In order to use this book with proper effect, his knowledge should extend far beyond the area of the work here specifically described, and the larger edition may help him towards 
this end. By grasping every opportunity of comparison of the type selected with allied forms which show differences of detail, he will then be able to guide the pupil to distinguish essentials from secondary details, and to check the dangerous tendency of beginners towards generalisation from too limited an area of fact.

F. O. BOWER.

Gidasgow, April i 894 . 


\section{TABLE OF CONTENTS}

List of Apparatus . . . . . . . . . . . . ${ }^{\text {Page }}$

\section{INTRODUCTORY CHAPTERS.}

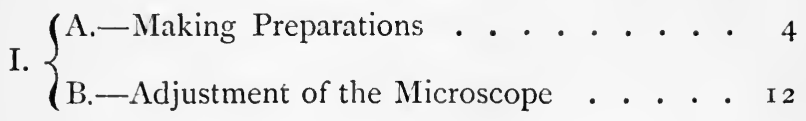

II.-- Practical Exerçises involving Simple Methods . I 7

III.-Common Micro-Chemical Reactions . . . . 24 
PRACTICAL DIRECTIONS FOR THE STUDY OF TYPES PHANEROGAM

I. ANGIOSPERMS.

† VEGETATIVE ORGANS.

STEM-HERBACEOUS TYPE.

Mature . . . . . . . 35

Young . . . . . . . . . 45

Apical Bud . . . . . . . 47

ARBOREOUS TYPE . . . . 52

AQUATIC TYPE...... 67

Sieve Tubes . . . . . . . 70

Laticiferous Tissues . . . . . 73

LEAF-Bifacial Type.

Petiole . . . . . . . . 76

Lamina . . . . . . . . . 77

LEAF-SCARS, AND FALL OF LEAF . . . . 83

Root-Herbaceous Type . . . . . . . . 85

Ligneous Type . . . . . . . . 88

Apex . . . . . . . . . 91

B.-MONOCOTYLEDONS.

STEM-HERBACEOUS TYPE . . . . 95 ARBOREOUS TYPE. . . . . 98

LEAF-Bifacial Type . . . . . . . . 100

RoOT . . . . . . . . . 104

Apex .......... 105

† REPRODUCTIVE ORGANS.

Observations with the Naked Eye 108

DeVElopment of THE Flower . . . II3

Calyx and Coroli.a . . . . . I I 5 
PHANEROGAMÆ (continued).

$\dagger+$ REPRODUCTIVE ORGANS (continued).

The STAMEN PAGE

Carpel and Ovules . . . . . . . . II9

Fertilization . . . . . . . . . 120

Development of the EMBRYo. . . . . I2I

Developanent of THE ENDOSPERM . . . I23

Mature Seed and Embryo.

Dicotyledons . . . . . . . . 125

Monocotyledons . . . . . . . . . 127

RESERVE AND TRANSITORY Materials iN

Seeds, Tubers, \&c. . . . . . . . $12 \mathrm{~S}$

Germination.

Dicotyledons . . . . . . . . . . . 132

Monocotyledons ....... . . 133

II. GYMNOSPERMS.

† VEGETATIVE ORGANS .......... . 134

STEM . . . . . . . . . . . 135

LEAF . . . . . . . . . . . . 143

$\dagger+$ REPRODUCTIVE ORGANS . . . . . . . . I45

Ripe Seed ani) Germination . . . . . . 149

\section{PTERIDOPHYTA.}

A.-LYCOPODINEE.

SELAGINELLA (Heterosporous Type).

SPOROPHYTE ........... 150

OOPHYTE . . . . . . . . . . . . 155

B.-FILICINEA.

NEPHRODIUM (Homosporous Type).

MATURE SPOROPHYTE.

External Characters . . . . . 156

Anatomical. Citaracters to be observed

WITH THE NAKED Eyf, . . . . . 157 
PTERIDOPHYTA (continued).

Microscopic ObSERvations-

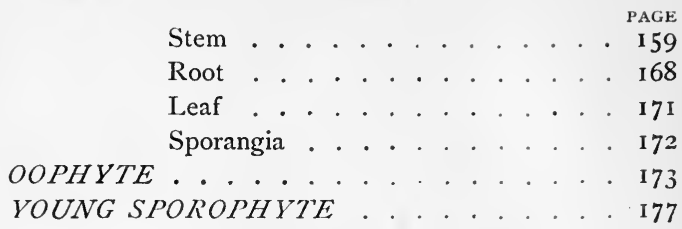

BRYOPHYTA.

A.-MIUSCI.

POLYTRICHUM.

General External Characters . . . I 79

Microscopic INVESTIGATION-

OOPHYTE ........... 180

SPOROPHYTE . . . . . . . 184

B. - HEPATICE.

MARCHANTIA.

General External Charactekrs . . I 89

Microscopic ObServations . . . . . . 190

SPOROPHYTE . . . . . . . . . . 196

\section{THALLOPHY'TA.}

A.-ALGÆ.

FLORIDEA.

POLYSIPHONIA.

PHÆOPHYCEÆ.

FUCUS . . . . . . . . . . 20I

CHARACEE ............... 2I0

CONFERVOIDEA.

IDOGONIUM . . . . . . . . . . 216

SIPHONEE.

VAUCHERIA

CONJUGATE.

SPIROGYRA . . . . . . . . . . 223 
THALLOPHYTA (continued.)

\section{B.-FUNGI.}

BASIDIOMYCETES.

AGARICUS . . . . . . . . . . . . . . . $\begin{array}{r}{ }^{\text {PAGE }} \\ \mathbf{2} 26\end{array}$

ECIDIOMYCETES.

PUCCINIA

ASCOMYCETES.

EUROTIUM

PERONOSPOREE.

PYTHIUM . . . . . . . . . . . $24 \mathrm{I}$

MUCORINEÆ.

MUCOR . . . . . . . . . . . . . . 244

SPORODINIA

Appenix A.-list of Reagents, their Preparation, and Uses . . 249

APPENDix B. - List of the Reactions of Bodies commonly found composing the Tissues of Plants . . . . . . . . . . . . . 264

INDEX . . . . . . . . . . . . . . . 269 



\section{PRACTICAL BOTANY}

FOR

\section{B E G I N N E R S}

The following is a list of apparatus required for ordinary work in the botanical laboratory. The articles marked with an asterisk (*) are absolutely essential to successful work.

I. A pair of fine scissors with sharp points.

2. Fine-pointed forceps.

*3. One or more good razors (see p. 7), and a strop and hone for sharpening them.

4. Scalpels of various sizes: a fine eye-scalpel with a long narrow blade will be found to be very useful.

5. A section-lifter.

*6. Mounted needles.

7. Several fine camels'-hair brushes.

*8. Watch-glasses of various sizes, flattened at the middle of the convex side so as to stand steadily.

*9. Glass or porcelain ointment pots, with lids.

*IO. Test-tubes and beakers.

I I. A spirit-lamp.

12. A black enamelled tile for mounting on.

* 1 3. Glass slides, with ground edges $(3$ in. $X I$ in.).

* I4. Thin cover-glasses, square or circular $\left(\frac{7}{8}\right.$ in. diameter).

*I5. Blotting-paper, cut or torn into small pieces. 
* I6. Drawing-paper or card, with a hard smooth surface, or a note-book of such paper, without lines.

*17. Hard pencils (H. or H.H.H.) and india-rubber.

* I . Gummed labels ( $I$ in. $\times \frac{3}{4}$ in.) for naming slides.

* I9. A coarse duster, and a finer cloth, e.g. an old pockethandkerchief.

20. A rack for keeping slides temporarily, and a bell-glass to cover it.

*21. A simple lens.

*22. A compound microscope. This should be one of the smaller stands with a short tube: such stands of varying merit are to be obtained from most makers. The microscope should be provided with-

$*_{i}$. High and low eye-pieces : the longer is the lower power, the shorter the higher.

*ii. Two objectives, the lower power of about 1 inch focal length. The higher about one-sixth inch or one-eighth inch focal length.

*iii. A micrometer, either adapted to the eye-piece, or a stage micrometer.

iv. A nose-piece to carry two, or, if necessary, more objectives: its use will save much time.

v. A camera lucida for drawing.

*23. A rack or tray to hold small glass-stoppered bottles containing reagents : the following are the reagents which are in most constant use-

*a. Weak glycerine, i.e. Price's pure glycerine diluted with an equal volume of distilled water.

*b. Caustic potash : make a 2 per cent. solution of the solid sticks of caustic potash in distilled water, and filter.

${ }^{*}$ c . Acetic acid : one volume of glacial acetic acid is to be diluted with 99 volumes of distilled water.

*d. Iodine solution : this may be obtained by diluting the liquor iodi of the Pharmacopœia; or as follows: dissolve a small quantity of potassium iodide in distilled water, and add crystals of iodine : if the solution be too deeply coloured it may be diluted with distilled water to the colour of brown sherry. 
*e. Chlor-zinc-iodine (Schulze's solution) may be purchased ready prepared from the dealers in micro-chemical reagents; or it may be prepared as follows :-

(I) Dissolve 110 grms. of zinc in 300 c.c. of pure hydrochloric acid, and evaporate to 150 c.c. (sp. gr. about $\mathrm{I} \cdot 8)$.

(2) Dissolve I2 grms. of $\mathrm{KI}$ in as little water as possible : add $0.15 \mathrm{grm}$. of iodine.

(3) Mix (I) and (2), and filter, if necessary, through asbestos. The solution should have a dark sherry-brown colour.

*f. Solution of aniline chloride : a saturated solution is made in distilled water, filtered, and a few drops of hydrochloric acid added so that it may give a distinctly acid reaction. The solution should be colourless.

*g. A solution of common salt : a 5 per cent. solution, i.e. 5 grms. of salt to 100 c.c. distilled water.

Many other reagents besides these will be required for the work described below ; also substances for permanent mounting and sealing up of slides : their preparation and uses are detailed in the Appendix A.

Care should be taken in the preparation of the reagents: they must be kept pure, and should be renewed occasionally. Glass rods with rounded ends are to be used for removing drops of the reagents from the bottles to the slide, and the rod should always be cleansed before dipping it into a reagent-bottle.

*24. Two wash-bottles such as are in ordinary use in a chemical laboratory: the one should contain alcohol (methylated), the other distilled water. 


\section{I \\ A.-Making Preparations}

I. Preservation of Material.-In many cases it is possible, and even preferable, to use fresh material, but it is often convenient to keep it for a time, since many of the specimens required are only to be obtained at certain seasons of the year : the best liquid for this purpose is ordinary methylated alcohol, in such quantity as completely to cover the material. It must be remembered that this will extract the green colouring matter (chlorophyll) from the material immersed in it, as well as resin and other substances.

II. Hardening.-For the general study of the histology of the mature parts of plants, it is often unnecessary to harden them, for the tissues are usually sufficiently firm to admit of their being cut satisfactorily. In the case of young, or of exclusively parenchymatous tissues, especially those of non-vascular plants, it is necessary to harden them, and for this purpose alcohol may be used.

When it is desired to study the structure of the protoplasm, and of the nucleus, special methods must be employed for hardening them, or rather for fixing them as nearly as possible in the condition in which they are during life. For this purpose one or other of the fluids mentioned below may be used. Care must be taken that the objects shall be of small size, that the quantity of hardening fluid be large relatively to the bulk of the object, and that the fluid have ready access to all parts of it. Large objects should be cut up into pieces of moderate size, so that the reagent may readily gain access to all parts of the tissue. 
The following are the best fluids for this purpose :-

I. Absolute alcohol or methylated spirit.

2. Picric acid (saturated solution in water).

3. Chromic acid $\left(0^{\circ} \mathrm{I}-\mathrm{O}^{\circ} 5\right.$ per cent. solution in water).

4. Osmic acid $(\cdot \mathrm{I}-\mathrm{I} \cdot$ per cent. solution in water).

These reagents are only to be applied to fresh material.

When absolute alcohol is used, the object may be kept in it for an indefinite period. Such treatment generally makes the object brittle ; this may be remedied when the object is to be mounted in glycerine by placing it, for at least twenty-four hours before it is to be cut, in a mixture of glycerine and absolute alcohol in equal parts, leaving it exposed to the air so that the alcohol may gradually evaporate. The glycerine slowly saturates the object and restores its toughness. This can only be done when the sections are to be mounted in glycerine.

When picric or chromic acid is used, the object should be immersed in it until each part of it is thoroughly permeated by the reagent ; the length of time required for this varies with different material, and in the case of chromic acid, with the strength of the solution used, from a few minutes to twenty-four hours or more. The objects must then be washed thoroughly with water: they are then to be placed in dilute methylated spirit (50 per cent.), subsequently in stronger spirit (70 per cent.), and finally in absolute alcohol or strong methylated spirit, which must be changed so long as any colour is still extracted from the objects. They may be preserved in this for future use.

When osmic acid is used, the fixing effect is produced much more rapidly; in the case of simple structures, such as unicellular or filamentous Algæ, a few minutes (5-15) generally suffices; in the case of more complex structures, such as ovules, sporangia, growing points, \&c., the object may be left in the acid till it looks black on the exterior : it must be then well washed with dilute alcohol (50 per cent.), and left in it for some time, and be then removed to 70 per cent. The sections are best mounted in dilute glycerine. In some cases osmic acid 
produces an excessive blackening of the cells, which can be removed by treatment with chlorine-water.

Of the hardening reagents above mentioned absolute alcohol, methylated spirit, and picric or chromic acids are those most generally used.

III. Cutting sections.-In order to investigate the structure of the tissues of a plant or member, it is usually necessary to cut sections, i.e. thin slices, in various directions. To make a complete study of a solid mass of tissue, sections must be cut in three different planes at right angles to one another.

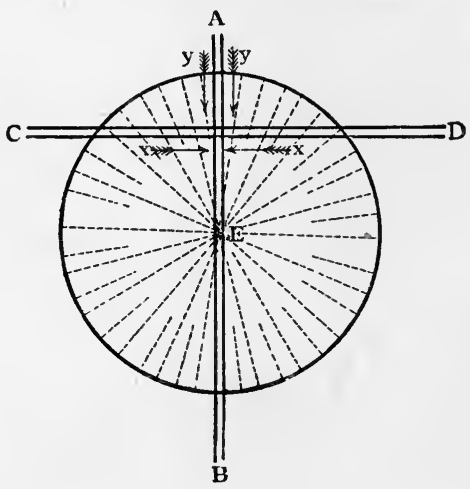

FIG. I

Taking the case of a cylindrical stem, the best way to study its structure would be to cut-

(i.) Transverse sections, in planes at right angles to the organic axis.

(ii.) Radial longitudinal sections, in longitudinal planes including the organic axis.

(iii.) Tangential longitudinal sections, in longitudinal planes which do not include the organic axis.

This may be illustrated by a diagram (Fig. I), which may be taken to represent the transversely cut end of a cylindrical stem, the tissues being arranged with reference to a central point $(E)$ : transverse sections are those which are in transverse 
planes, parallel to the plane of the paper in Fig. I. The line including the central points of successive imaginary transverse sections is the organic axis.

Radial and tangential sections are both in planes vertical to that of the paper in Fig. I : a radial section (A E B) includes the organic axis (E), and a slice of tissue thus cut when examined from a direction indicated by either of the arrows $(x)$ will show in surface view those cell-walls which run radially : a tangential section (C D) does not include the organic axis (E), and such sections when examined from a direction indicated by the arrows $(y y)$ will show the tangential walls in surface view, while the radial walls, previously seen in surface view, would present their cut edges to the observer.

In the case of tangential sections only the central part of the section (i.e. the part near to $y y$ ) is to be examined, for obviously in the more lateral parts of the section (C D) the radial lines are not cut vertically but obliquely.

In all cases the sections must be cut accurately in the plane intended: if the sections be cut obliquely the difficulty of understanding the structure will in almost every case be enormously increased.

A razor of good quality is the best cutting instrument : there is some variety of opinion as to the best form of blade; some prefer a hollow-ground razor, which, though well suited for cutting small sections, will not serve for sections of large area ; for such work a razor with one flat side is recommended. For general use, not only in cutting small objects and soft tissues, but for the every-day work of the laboratory, an ordinary, very slightly hollow-ground razor of good quality will be found the most useful. The razor should be stropped to a smooth edge, and the blade should be carefully protected when not in use : it should never be left open on the work-table, and the blade should always be cleaned after use, since the acid juices of plants are apt to corrode it. It will be found convenient to have a glass of water (or weak spirit when resinous tissues are being cut) on the work-table, into which the blade of the razor may be plunged at once after use; this will prevent immediate corrosion. 
The success of work in the laboratory depends very greatly on due care in the direction of section, and on the condition of the edge of the razor.

All the sections required in the succeeding pages of this book can be made by hand : elementary students are advised to avoid the use of a microtome; they should cultivate that small amount of manual dexterity which will suffice for the successful preparation of such objects as will be described below.

When cutting sections the razor is to be opened so that the blade is in a line with the handle : the object to be cut may be held in the thumb and first finger of the left hand, while the razor is grasped firmly by the four fingers of the right : it may be found convenient to rest the thumb of the right hand on that of the left so as to regulate the movements of the right hand. The edge of the razor is not to be rudely forced through the tissues of the specimen, but a sliding cut is to be made, thus using a considerable length of the edge of the razor : in this way a smoother surface of section is obtained, and the tissues are not displaced as they otherwise might be.

Care must be taken to keep the object and the razor wet during the process of cutting, in order to avoid the entrance of air into the tissue, and to prevent adhesion of the section to the razor. When fresh material is cut, water or very dilute alcohol may be used for this purpose, but if material which has been hardened is cut, it is advisable to use alcohol of the same strength as that in which the material has been preserved.

IV. Embedding.-The objects are frequently so large that they may be held in the hand whilst they are being cut. If they are too small for this, it is convenient to embed them in some substance.

The simplest method is to fix the object into a slit in a piece of pith. Dried elder-pith is the best, and it may be bought ready prepared from the dealers.

When the object to be cut is small, or easily damaged, it is more convenient to embed in some easily fusible substance : by this means also the form of the object is less likely to be distorted in the process of cutting. Various substances, or 
mixtures of substances, are used for this purpose, of which soft paraffin is perhaps the best. Samples of paraffin which vary in hardness and melting point may be obtained from the dealers.

The ordinary method of embedding is to make a cavity in a piece of the substance sufficiently large to contain the object, which, if fresh, must have been previously washed with alcohol to remove all traces of water from its surface. If the object had been previously preserved in alcohol, all superfluous fluid must be removed from the surface with blotting-paper, but care must be taken that the spirit which permeates the tissue shall not evaporate. The object is then placed in the cavity, and without unnecessary delay a small quantity of the embedding substance, melted over a spirit-lamp in a small tinned iron spoon, is poured into the cavity so as to surround and cover the object.

If the object be small, it will be found convenient to heat one end of a thick copper or platinum wire, and with it melt a small cavity, in which the object may be placed in such position as is found convenient.

The sections must not be made until the paraffin is quite cold, and firmly set.

It is important to keep the embedded objects wet with alcohol during the process of cutting, in order to prevent the drying-up of the object, and its consequent contraction away from the substance in which it is embedded.

The sections when cut should be removed at once to a watch-glass containing alcohol or water, by means of a camels'hair brush, or a jet of alcohol or water from a wash-bottle : the thicker sections may then be removed, and the thinnest ones selected for observation.

V. Mounting Objects.-Various specimens, whether sections or objects which may be examined whole, require varied treatment, and the common methods in ordinary use will be described below, and illustrated by experimental exercises (see pp. 17, \&c.); meanwhile a few practical suggestions will be given which are to be observed in all cases, whatever the special method of treatment may be.

1. Study to avoid all unnecessary manipulation of specimens: 
never apply a reagent at haphazard, but only when you have a definite purpose for doing so.

These rules apply specially to staining reagents, which should only be used when their assistance is actually required : the primary end of the anatomical investigations detailed below is not to prepare a number of objects pleasing to the uneducated eye, but to gain a knowledge of the structure of the plant-body as it is in the living state, and this end may as a rule be best attained by the simplest methods.

2. See that the glass slide and the cover-glass are perfectly clean and dry, and show a bright polished surface before using them; they should be cleaned immediately before use, and, after cleaning, their surfaces should not be touched with the fingers, nor should the cover-glass be laid flat on the table, but tilted on its edge.

3. In mounting, whatever the fluid may be, take only so small a drop of it as shall just suffice to fill the space between the slide and the cover-glass, and extend to the margin of the cover: judgment as to the quantity necessary can only be acquired by practice. If too much fluid has been used the excess must be soaked up with slips of blotting-paper, or filter paper.

4. The practice of scrupulous cleanliness cannot be too strongly impressed upon students as the basis of all successful work with the microscope, and it is in the use of fluid reagents that the greatest care is necessary; if too large a quantity be used it is apt to extend to the lowe: surface of the slide, and so to the stage of the microscope : or to be smeared over the upper side of the cover-slip, and may then gain access even to the objective; it is absolutely necessary that both the front lens of the objective, and the upper side of the cover-slip be perfectly clean and dry, also the lower surface of the slide and the stage of the microscope.

5. Having taken a sufficiently small drop of the mounting medium, and having placed the object in it, bring down the coverglass obliquely upon the drop so that one edge of it is first wetted by the medium, then let down the slip gently, so as to allow the medium time to spread out under the cover-slip; this may be 
done either by holding the cover-slip in a pair of clean forceps, or hold the slip by its edges in an oblique position in the finger and thumb of the left hand, while it is supported by a clean needle held in the right; then, the lower side being wetted with the medium, gradually withdraw the needle and thus gently lower the slip. It would be well at first to practise thus lowering the cover-glass over a drop of water, so as to acquire judgment of the quantity of fluid required, and skill in avoiding the inclosure of air-bubbles.

6. One great purpose of the above directions is to avoid the presence of bubbles of air in the medium surrounding the object ; their presence is one of the great difficulties of the beginner, who is therefore advised, in his own interest, to follow carefully the directions above given. In some specimens, especially when fresh, air-bubbles will be found entangled in the tissues, or attached to the outside; a good method for avoiding them in mounting fresh material is to moisten with alcohol (weak alcohol will do) for a few seconds before mounting : by this means the surface of the object will be more thoroughly wetted than would otherwise be the case. Obstinate bubbles may be expelled by heating over a spirit-lamp; but as many objects will not stand such rough treatment, a better method is to exhaust them under the receiver of an airpump.

7. After an object has been mounted it is often necessary to apply to it certain staining, or micro-chemical reagents : this may frequently be done, without removing the object from the slide, by irrigation: successive drops of the reagent are placed on the slide, close to one edge of the cover-slip, special care being taken that the fluid does not spread to the upper side of the cover, while a small piece of blotting-paper is pushed up to the opposite edge of the cover-slip, so that, when it comes in contact with the medium in which the object is mounted, it will soak it up: the space thus vacated by the medium is taken by the reagent, and if the latter be supplied in sufficient quantity, a stream of it will pass under the coverslip and bathe the object. It is obvious that for such a treatment to be successful the medium and the reagent must be 
fluids which will mix. Students are warned against too readily accepting negative evidence as the result of observations by irrigation : the reagent may frequently pass under the cover-slip without permeating the object, or the edges only of a section may be affected : in order to insure the object being bathed by the reagent, it is well to raise the cover-glass gently with a needle, or even to raise the section itself slightly with the point of a needle.

8. Never use more than one cover-slip on a single slide, though several objects may, if small enough, be covered by one slip: the cover-slip should be as nearly as possible in the middle of the slide.

9. Pressure should never be laid on the cover-slip, except in certain special cases : a bad section will not be improved by being squeezed flat, while a good section may be easily rendered worthless by such treatment.

Io. Before putting a slide aside for subsequent observation be sure that the medium used is one which will not evaporate: alcohol, water, and solutions in water, such as iodine solution, aniline sulphate, salt solution, are all liable to evaporation, while chlor-zinc-iodine and glycerine are not.

II. Before putting a slide aside be careful to label it, writing at once on an adhesive label the name of the plant, part, direction of section, and medium in which it is mounted.

\section{B.-Adjustment of the Microscope for Work.}

Before beginning work it should be ascertained that the microscope is in good working order: if it be a stand without rackwork, see that the stage of the microscope is clean, and that the tube moves easily and smoothly; if it does not, take out the tube, and rub it with a clean cloth; if still stiff, apply a. very little mineral oil or vaseline, and rub with a clean cloth till there is no appearance of oil on the tube : it should then work freely. Nothing causes a greater strain on a microscope than neglect of this simple point.

Next see that the lenses are clean; to this end first dust the mirror, and adjust it so as to reflect light through the instrument : 
insert first one eye-piece, then the other : rotate each eye-piece, and if any 'specks be seen to rotate with it they are on the lenses of the eye-piece, and must be removed with a soft chamois leather, or a fine linen or silk cloth (old pockethandkerchief). Carefully examine the front lens of eachobjective, and if any dirt be seen wipe the lens gently with a chamois leather, or fine linen or silk cloth. Glycerine is apt to gain access to the objective in careless hands; when this is the case the lens is to be washed with a jet of distilled water, and carefully dried. Since the lenses are often fixed with balsam, great care must be taken that they should not be smeared with Canada balsam, or Dammar : when this has happened the lens should be gently rubbed with a cloth wetted with a very little benzol, or alcohol. In all cases the cleaning of lenses should be carried out as gently as possible, to avoid destroying their polish.

The best light for microscopic work is that reflected from white clouds in a northern sky, and a window with a northern aspect should be selected. Never use direct sunlight, and avoid using artificial light. If the only available room has a south aspect, a white blind is to be used, so as to cut off direct sunlight, or a piece of white card may be fitted to the surface of the mirror, so as to act as a less perfect reflector.

The body of the microscope should be vertical; with the short microscopes now in use, the oblique position is quite unnecessary, and very inconvenient when mounting in fluid media, or irrigating with fluid reagents.

Always examine an object with a low power first, and afterwards, if necessary, with a higher power. It is a general principle of microscopic practice that observations should be made with the lowest possible power sufficient for distinct vision. Never use the high power unless the object be covered with a coverslip.

When a low power is used a larger hole of the diaphragm below the stage is to be placed opposite the aperture in the stage; when a high powver is used a smaller hole of the diaphragm is necessary, otherwise the definition will not be satisfactory.

Some difficulty will be felt at first in finding the focus. There 
are two adjustments of focus-the coarse and the fine : the latter is never to be used until the focus is approximately found with the coarse adjustment. The coarse adjustment is effected by a sliding tube in the smaller microscopes in general use by students : having drawn this tube out, screw on the low power objective (the one with the larger front lens, focal length about I inch from object), then replace the tube so that the objective is about $I \frac{1}{2}$ inches from the stage, and having adjusted the mirror so as to illuminate the whole field, place some object on a slide at the centre of the stage; hold the slide with the thumb and forefinger of the left hand, while the upper end of the tube is grasped with the right : then slide the tube gradually downwards with a spiral movement, until the object comes dimly into view; then begin to use the fine adjustment, which is worked by a screw with a milled head, the position of which varies in different instruments : this head is to be turned so as to lower the tube, when the object will become clearer, and ultimately be in perfect focus. The focus is to be found in the same way with the high power, but in this case greater care is necessary, since when in focus the objective is nearer to the object : in careless hands the position of focus is apt to be over-stepped, and the objective advanced so as to touch, or even crush, the object: this is to be carefully avoided, as it not only damages the object, but may also ruin the objective.

When the focus has been found, the fine adjustment is to be worked constantly up and down by the right hand during observation; by this means a series of optical sections of the object is brought successively into view, and in this way the observer builds up mentally a conception of the object as a solid body. In so far as an objective lends itself to this it is said to possess good penetration. Meanwhile the forefinger and thumb of the left hand will be at liberty to move the slide on the stage so as to bring into the field of view different parts of the preparation.

Observers should accustom themselves to using both eyes indifferently, and when one eye is being used for observation, the other should be kept open : a little practice will soon overcome any difficulty which may be at first found in doing this.

Care is necessary in removing the slide from the stage, 
especially when the high power has been used : in this case the tube should first be raised so as to remove the objective from close proximity to the stage, and the slide should then be slipped off the stage, not lifted off. Want of attention to these points is apt to result in smearing the objective with glycerine, or other media.

Drawing from the Microscope.-Nothing compels attention to details of an object so successfully as drawing it ; while, as it is impossible to make a drawing of an ill-prepared object, the intention to make a drawing will have its effect upon the care devoted to preparation and mounting. It should be a rule for students to drawe every object they observe, not merely for the sake of the drawings as memoranda, but in order to acquire a habit of close observation.

For drawing, a hard pencil (H.H.H.) is recommended, and it must be cut to a fine point : paper with a hard smooth surface is to be used, or better, a thin drawing card or Bristol board with a hard surface. A decisive style of drawing should be adopted, in which every line is clear, and conveys its own meaning.

For ordinary purposes a freehand drawing will suffice, the scale being as nearly as possible that of the object as it appears under the microscope, or larger, if the object be a complicated one : whatever the scale, the proportion of the several parts is to be scrupulously followed. Coloured chalks, or better, light washes of water-colour, may be used for distinguishing tissues of different character, and in making a series of drawings the same colours should be assigned to corresponding tissues throughout the series.

When drawing cell-walls of appreciable thickness, they should be indicated by a double line ; solid bodies should be shaded so as to give the idea of light coming from one side, and in a series of drawings the side selected should be maintained throughout.

Measurement of objects.-Measurements may be most readily made by means of an eye-piece micrometer, which is a glass slip, fitted into the eye-piece, and having a scale engraved upon it. The value of the divisions of this scale varies with 
the combination of lenses used; accordingly, before the micrometer can be employed in the actual measurement of objects, the value of the divisions must be determined for each combination, and a table of the results should be kept for reference in the case of the microscope. To determine the value of divisions of the scale under a given combination of glasses, a stage micrometer, having lines drawn to $\frac{1}{1000}$ ths of an inch apart, should be placed on the stage, and focused under the objective and eyepiece whose magnifying powers it is desired to measure : the relation of the divisions of the stage micrometer (these intervals being of known value) to those of the eye-piece micrometer is then to be noted. Suppose that the interval between two lines of the stage micrometer covers the intervals between six lines of the eye-piece micrometer, the former being $\frac{1}{1000}$ th of an inch apart, the interval between two lines of the latter (with that combination of lenses) will correspond to $\frac{1}{5000}$ th of an inch, and the linear measurement of any object which fills such an interval under that combination of lenses will be $\frac{7}{5000}$ th of an inch. It is usual to state the size of objects seen under the microscope according to the linear measurement of the diameter. The simpler method of measurement by laying the stage micrometer inverted on the slide carrying the object to be measured, though direct, is open to many objections, and can at best only be used with low powers. 


\section{II}

PRACTICAL EXERCISES ON THE STRUCTURE OF THE VEGETABLE CELL INVOLVING SIMPLE METHODS OF PREPARATION.

Before entering upon the work described below, the preceding pages should be carefully read through, otherwise the beginner will be apt to make serious mistakes in manipulation.

NOTF.-The method of mounting fresh material in water will be used throughout this chapter: it has the following advantages :-

I. It is the simplest possible.

2. The cells are seen unaltered, i.e. in the living state, and it is thus specially suitable for observations on fresh material.

3. When thus mounted the effect upon the living cell of any reagent soluble in water may be observed by irrigation : thus it is the natural starting-point for the study of the microchemical reactions of the living cell.

It is however open to objection on the following grounds :-

I. The slides thus prepared cannot be kept, since the water would evaporate.

2. The refractive index of water being relatively low, the objects do not appear so transparent as in more highly refractive media.

3. Bubbles of air are very apt to be included with the object.

I. The first object to be examined will be the filamentous Alga, Spirogyra. 
This Alga is commonly to be found in summer, growing in stagnant, or slowly flowing, fresh water : it is to be recognised by its bright green colour, and the unbranched filaments irregularly coiled together, and of sufficient size to be distinguished by the naked eye : the whole flocculent mass feels slimy when lifted from the water.

Mount a small quantity of the Spirogyra in water : examine it first under a low power, and observe on one of the largest specimens-

I. That the cylindrical filament is limited by a definite cell-wall.

2. That transverse partitions-septa-which are continuous with the limiting cell-wall, divide the filament into a linear series of cells.

3. That each cell contains a protoplasmic body, the most marked part of which will be one or more spiral chromatophores, coloured bright green by chlorophyll.

In order to study the structure of the protoplasmic body in detail, put on a high power, and, focusing carefully, make the following observations of the filament, which, it is to be remembered, is in the living condition :-

I. Having recognized the smooth colourless cell-wall, note that it is closely invested internally by-

2. A continuous film of colourless protoplasm (the "primordial utricle").

3. That this protoplasmic film surrounds a large central cavity - the vacuole-filled with perfectly transparent cell-sap.

4. That in the peripheral film are embedded one or more green spiral bodies (chromatophores) of flattened form, and very irregular margin, each including numerous lenticular, highly refractive bodies, the pyrenoids.

5. Focusing carefully downwards into the central cavity, a highly refractive, colourless, lens-shaped body is to be seen suspended in a central position by numerous finely granular protoplasmic threads : this body is the nucleus.

$a$. These several points should be made out in the living cell, without treatment with any reagent ; but their observation may be made easier in various ways. Irrigate (p. II) with 
iodine solution, and observe the following results of that treatment :-

I. The cell-wall will not be appreciably altered or stained.

2. The film of protoplasm (primordial utricle) will have stained a pale yellow or brown, and may often be seen to have separated partially or completely from the cell-wall, from which it may now be readily distinguished.

3. The chromatophores will have assumed a dusky colour, while the pyrenoids will be a dark purple.

4. The nucleus will have stained a deep yellow or brown, and inclosed within it one or sometimes two nucleoli may be recognized by their deeper colour, and high refractive power.

$b$. Irrigate a fresh specimen with $2 \frac{1}{2}$ per cent. solution of common salt, and watch the result, which will take some minutes to appear. The protoplasm will gradually separate from the cell-wall, and while the latter retains its form and position, the protoplasm will contract, and rounding itself off, ultimately appear as a more or less irregularly oval or spherical body.

c. Mount a fresh specimen in water, and irrigate with glycerine; the cells will collapse, owing to the sudden abstraction of water of the cell-sap.

$d$. Mount a fresh preparation in water: irrigate with potash solution, and observe that the protoplasmic contents swell and lose their definite outline, and the whole becomes more transparent.

II. The above example of a simple Alga shows cells aggregated in a linear series, constituting a filament : the next specimen illustrates the more complicated arrangement of cells in two dimensions of space, i.e. as a flat plate of tissue. Mount a small prothallus of a Fern (or the thin lateral part of a large one) in water, and examine it under a low power: such Fern prothalli are commonly to be found on the damp surface of soil or flower-pots in ferneries where the air is constantly damp : or they may be readily grown by sowing Fern-spores on moist soil. 
It will be at once obvious that the thin plate of tissue, one layer of cells in thickness, is partitioned off into a number of cells of polygonal form, which are in close connection with one another, so that no spaces intervene between them. Note the green granules (chlorophyll-corpuscles or chloroplasts), which are here to be seen in considerable numbers in each cell.

Examine the preparation under a high power, and distinguish-

I. The cell-walls, which are thin, highly refractive, and of almost uniform width throughout : the extreme margin of the prothallus will be found best adapted for their observation.

2. A colourless film of granular protoplasm (primordial utricle), which is in close apposition to the cell-wall, and surrounds a large central cavity (the vacuole) full of colourless cell-sap : in this protoplasmic film are embedded-

3. The chlorophyll-corpuscles or chloroplasts, which will now be seen to be flattened disk-like bodies.

4. A single, more highly refractive nucleus is to be found in each cell, its position being variable.

Treat the preparation with iodine solution, and observe that -

I. The protoplasm will be stained brown.

2. The chlorophyll-corpuscles, for the most part, a dusky purple.

3. The nucleus will be more deeply stained, and will accordingly be more easily recognized. One or more roundish, highly refractive bodies may be seen in the nucleus (nucleoli).

4. The cell-walls are not stained.

$a$. Treat a fresh preparation with potash solution, and warm gently over a spirit-lamp : observe that the protoplasm, chlorophyll-grains, and nucleus lose their definite outlines, and, undergoing a process of swelling, become at the same time more transparent. This may best be seen in a specimen which has been bleached in alcohol.

b. Mount another preparation in "eau de javelle" (see Appendix A), and observe it at intervals for some minutes: a similar result will be seen, viz. the contents of the cells swell, and the whole tissue becomes more transparent: this is 
especially the case in the region near the apex of the prothallus.

c. Irrigate a fresh specimen with a $2 \frac{1}{2}$ per cent. solution of common salt, and watch the result : it will be seen that the protoplasm contracts, often taking the form of an almost spherical ball, thus separating from the cell-walls with which it was originally in contact: the latter will now appear as a continuous network of partitions dividing the whole prothallus into a number of chambers.

If this preparation be examined under a high power, a number of delicate protoplasmic filaments may be seen connecting the outer surface of the contracted protoplasm with the cell-wall: this indicates that the two bodies are not merely in apposition in the living cell, but are closely connected.

A cell in this state is said to be plasmolytic: the contraction is due to the withdrawal of water from the cell-sap by the salt solution, this withdrawal not being compensated for by the entrance of salt solution into the vacuole. The salt solution diffuses through the cell-wall, and occupies the space between the cell-wall and the contracted primordial utricle, but it cannot pass through the primordial utricle to any considerable extent.

On washing the section with water, the plasmolytic cells gradually reassume their normal appearance.

From such observations as these it is concluded that the passage of substances in solution into or out of the protoplasm is controlled by the primordial utricle so long as the cell is living.

III. These osmotic properties of the cell can be easily studied in cells which have coloured cell-sap, such as those of the garden Beet : this will at the same time serve as a first exercise in cutting sections from a solid mass of tissue.

Cut a tranverse section (p. 6) of a piece of a fresh beet-root sufficiently thin to be transparent, but of such thickness that at least some of the cells shall remain uninjured, and mount in water: observe-

I. The thin cell-walls. 
2. The layer of protoplasm (primordial utricle), which lines the cell-wall.

3. The red cell-sap filling the cavity of the cell (vacuole). Note that the red sap does not escape from uninjured cells.

a. Examine a similar section which has been dipped for a moment into alcohol, and thus killed; the red sap diffuses out of the cells : hence it is evident that though the colouring-matter does not diffuse out of a living cell, it diffuses readily out of a dead cell.

b. Mount another section in water, and run some $2 \frac{1}{2}$ per cent. salt solution under the cover-slip; it will be seen that the red sap collects as rounded deeply-coloured bodies in the centre of the cells. This is due, as in the previous cases, to the contraction of the primordial utricle. Wash out the salt solution with water, and some at least of the plasmolyzed cells will gradually reassume their original appearance.

IV. In order to observe the movements of protoplasm in the living cell, mount in water a rootlet of Trianea Bogotensis, or, if that be not available, of Hydrocharis morsus-rane; in fact, any plant in which the root hairs can be obtained free, and uninjured, will do, aquatic plants being most suitable : examine first with a low power, and note the solid cylindrical body of the root with its conical apex: its surface is studded, except near to the apex, by transparent cylindrical out-growths-the root-hairs. Neglecting the body of the root, focus under the high power upon one of these hairs, and observe-

I. The thin, smooth cell-wall.

2. The granular protoplasm constituting the primordial utricle which lines it, and surrounds the large central vacuole, from which it is separated by an irregular inner surface.

Focusing carefully upon the granules in the protoplasm, these may be seen to be in motion, being carried along by a streaming movement of the protoplasm (rotation). By gently warming the slide on the palm of the hand, or over a lamp, the movement may be accelerated.

Heat the slide over a spirit-lamp to boiling point : the movements will, on examination, be seen to have stopped, the cell having been killed by the high temperature. 
Treat another preparation, in which active movement is going on, with iodine solution : the movement will be arrested, the cell being killed : the protoplasm will be stained brown.

Similar movements of rotation are to be seen more or less clearly in living cells generally, and are easily observed in cells of the leaf of Vallisneria spiralis, Elodea canadensis, and especially well in the large internodal cells of Nitella, \&c.

More complicated movements are to be seen in various hairs, and notably in those which cover the base of the stamens in species of Tradescantia. Remove a few of the hairs from a stamen of an open flower, and mount them in water. Observe under a low power the moniliform hairs, each composed of a row of barrel-shaped cells. Focus the high power upon one of these cells, and note the limiting cell-wall, and protoplasmic lining : threads or bridles of protoplasm, irregularly disposed, pass from the peripheral protoplasm towards the centrally disposed, spherical nucleus.

Examination of these threads will disclose movements of the protoplasm in various directions : these more complicated movements are collectively termed circulation. The hairs should be treated as above directed in the case of the roothairs, to show that the movement depends upon the life of the cell. 


\section{- III}

COMMON MICRO-CHEMICAL REACTIONS.

A FEW further practical exercises will now be given, involving the use of common methods and reagents, and leading to a fuller knowledge of the appearance and reactions of the parts of the cell, and of some of the bodies commonly contained in it.

\section{Cell-walls.}

\section{A. Cellulose Walls.}

Take some ordinary unbleached "cotton wool," which consists of unicellular hairs from the surface of the seed of the cotton plant (Gossypium). Moisten first with alcohol, and then soak in water.

$a$. Mount a small quantity in water, and examine first with a low, and then with a high power : observe-

1. The long, filamentous, unicellular hairs, which compose the "cotton wool," coiled irregularly together.

2. The rather thick, highly-refractive and colourless cellwall.

3. The remains of granular protoplasm, which may still be seen within.

b. Soak a small quantity of the cotton for a few minutes in iodine solution in a watch-glass, mount in iodine solution, and note the cell-walls stained slightly yellow.

c. Mount a small quantity of the cotton which has been thoroughly soaked with iodine, in a single small drop of concentrate sulphuric acid diluted with an equal volume of water : the greatest care is to be observed in the use of this reagent, 
so that it shall not gain access to the stage, or the objective; only a very small quantity is to be used, and the slide should be washed in water directly the observation has been made. A low power will suffice to show that-

I. The cell-walls swell greatly, and in an irregular form, and ultimately lose their sharp contour.

2. They assume a blue colour. This colouring is often not uniform, and this reaction, though trustworthy as positive evidence of the presence of cellulose where the blue colour is obtained, is not secure as proving the absence of cellulose if the blue colour be not seen.

d. Mount a fresh piece of the soaked cotton in chlor-zinciodine, and observe that the cell-wall stains a more or less distinct blue or a pinkish violet according to circumstances : the protoplasm, of which a small quantity may remain in the hairs, stains yellow.

$e$. Mount still another small quantity of the soaked cotton in acid solution of aniline sulphate, and observe that the cell-walls do not stain.

$f$. One of the most characteristic reactions of cellulose may be observed as follows :-

Prepare an ammoniacal solution of cupric hydrate (see Appendix A) : take, in a pair of forceps, a small quantity of cotton-wool, and immerse it in the fluid : it will be seen that the separate hairs of the cotton lose their identity, coalesce into a gelatinous mass, and are finally dissolved.

The solution, and antecedent swelling of the walls may be observed on a slide under the microscope if a very small quantity of the cotton-wool be mounted in the solution.

These reactions may be repeated on other tissues, e.g. the endosperm of the Date. (See larger edition, p. 38.)

\section{B. Lignified walls.}

For the reactions of lignified walls the wood of the Pine will serve : for instance, sections may be cut from an ordinary wooden match. Having cut thin transverse sections, soak them first in alcohol to remove bubbles of air : mount one of them in glycerine, and observe under a high power the very regular network of cell- 
walls, which are of almost uniform thickness, and are colourless or slightly yellow : protoplasm is practically absent in this tissure.

$a$. Treat a fresh section with iodine solution, and note that the walls stain distinctly yellow.

b. Mount a section thus thoroughly stained with iodine in a single drop of sulphuric acid : no blue colour is produced, the walls swell as do the cellulose walls, but their colour is brownish.

c. Mount a fresh section in chlor-zinc-iodine; the walls stain yellow, with no trace of blue.

$d$. Mount another section in acid solution of aniline sulphate : the lignified walls stain yellow.

By means of the above reactions a lignified wall may be distinguished from a cellulose wall.

\section{Corky Walls.}

Cut thin sections from a piece of common bottle cork : soak them first in alcohol, in order to remove air bubbles, and then in water : mount a thin section in water, or dilute glycerine, and note under a low power the regular arrangement of the tissue, and the thin, pale yellowish or brown cell-walls, with sharp definition and the absence of cell-contents.

$a$. Treat a section with iodine solution: the walls stain yellow.

b. Treat another section with chlor-zinc-iodine: the walls stain yellow or brown.

c. Treat as above directed (p. 24), with iodine and sulphuric acid : the walls are yellow or brown, and do not swell, but retain their sharp outline.

d. Treat a fresh section with Schulze's macerating fluid (see Appendix A), and warm gently at first : the corky walls turn yellow: then boil vigorously (this should be done at some distance from the microscope, as the fumes given off are apt to attack the metal), and on cooling re-examine : the corky walls, if the reaction be complete, will be found to have lost their definite outline, and to have run together into irregular viscid drops of ceric acid, which is in some measure soluble in the mixture when hot, and is reprecipitated on cooling. 
This reaction may with advantage be performed in the bulk, by cutting some shavings of cork, and boiling them for some minutes in Schulze's macerating fluid : the y will be seen to lose shape, and coalesce into a viscid mass : this is soluble in warm alcohol, benzol, \&c.

\section{Protoplasm and Nucleus.}

The protoplasm of the cell, and the nucleus, may be observed in the living condition as described in the preceding chapter; but in order to recognize the more minute details, and in order to make permanent preparations of these bodies, more complicated methods of treatment are necessary.

The protoplasm and nucleus must be first fixed and hardened (see above, p. 4) : the best hardening agent is absolute alcohol ; if picric acid be used it must be very completely washed out from the tissues before staining.

Harden the young flowering stem of a conımon Hyacinth, not more than three or four inches in length, in alcohol : cut longitudinal sections of the basal portion of it, and stain with Kleinenberg's hæmatoxylin (see Appendix A) till the sections are deeply coloured, then wash thoroughly with absolute alcohol in a watch-glass : transfer them (drying off all superfluous alcohol with blotting-paper) to oil of cloves, or turpentine and creosote (see Appendix A), in which they should be left for some minutes, so that the fluid may thoroughly permeate them : then mount in Canada balsam dissolved in benzol.

Examine sections thus treated under a high power, and observe the chief bulk of the tissue to consist of square or oblong cells of considerable size : the following parts are to be recognized-

1. The cell-wall, which is uniformly thin and is stained.

2. The protoplasmic lining or primordial utricle, which is also stained.

3. A large central vacuole, which is not stained, and is usually traversed by fine bridles of slightly stained granular protoplasm : these suspend in a central position-

4. The deeply stained nucleus : it may be observed in many cases that the nucleus does not occupy a central position, but 
is embedded in the peripheral protoplasm, while the whole cell-cavity is occupied by a large vacuole.

Examining the nucleus more closely there may be distinguished-

$a$. Deeply stained fibrillæ, forming apparently a convoluted coil, or a reticulum : this is the chromatin.

$b$. An unstained matrix in which the fibrillæ are embeddedthe achromatin.

Pith of a very young shoot of the Elder will also serve as good material for these observations; the young shoot should be treated as above directed, and longitudinal sections will afford similar results. As an alternative method of preparation, which has the advantage of simplicity, stain the sections from material hardened in alcohol, with a solution of methyl green in weak acetic acid, wash with weak acetic acid, and mount in dilute glycerine : the nucleus only is distinctly stained in this case, but the results are as a whole less satisfactory than when the former method is used.

\section{Starch.}

a. Scrape the freshly-cut surface of a Potato tuber lightly with a knife, and mount a small quantity of the scrapings in water : examine first with a low, and then under a high power, and observe scattered through the water a large number of somewhat ovoid, colourless, bright-looking, i.e. highly refractive bodies: these are starch-grains; near to one end, which is usually slightly pointed, is a round clear spot, the hilum. The grain will show a stratified structure: the layers of stratification near the hilum are almost circular and concentric; the more external layers are excentric and elliptical, and are wider on the side further from the hilum ; many of them between the hilum and the broader end of the grain are incomplete; hence the layers are more numerous between the hilum and the broad end than between the hilum and the pointed end of the grain.

Here and there may be seen a compound grain, consisting of two small grains in contact by their broad ends, and invested by several layers common to both.

b. Sections should also be cut from the Potato so as to show the starch-grains in situ in the cells. The razor should be 
wetted with water, and one section (the thinnest cut) should be mounted in water : a section which runs out to a thin edge will be found to be best: examine under a high power, and observe-

I. The numerous starch-grains as before.

2. The thin cell-walls partitioning off the cells which are of considerable size, and each of them may contain a large number of starch-grains.

3. The protoplasm, which is so scanty as often to escape observation.

c. Mount a small quantity of starch-grains in water as before, and irrigate with iodine solution: the starch granules will stain a more or less deep blue according to the strength of the solution : this is the characteristic reaction of starch.

d. Treat another preparation of starch with strong chlor-zinciodine : the starch-grains will as before assume a blue colour, but they also swell, and lose their bright, high refractive properties. This fact is to be borne in mind when treating tissues containing starch with this reagent.

e. Mount a fresh slide of starch in water, and irrigate with solution of potash : observe that as the reagent gains access to the granules they swell, and at the same time assume a dull appearance, their high refractive power being lost as they take up additional water of imbibition under the influence of the reagent. Now wash out the potash thoroughly with water, and irrigate the preparation with iodine solution : the swollen grains will still stain blue, though much paler than before, showing that the swelling with potash does not fundamentally alter the nature of the starch.

$f$. Mount some fresh starch in water, and heat it over a spirit-lamp till it boils : on examining under the microscope, the grains will be seen to have swollen and lost their high refractive power, forming starch-paste : staining with iodine will produce the blue colour, and show that they are only swollen, not dissolved : compare the effect of potash. A temperature of about $65^{\circ} \mathrm{C}$. is sufficient to cause this swelling.

$g$. Digest starch-grains in saliva for some hours at a temperature of about $45^{\circ}-55^{\circ} \mathrm{C}$. Examine them subsequently 
under the microscope : they will be found to have lost their high refractive power. Stain with iodine: they give a pale blue or yellowish colour.

IV. Chloroplasts, or chlorophyll-corpuscles.

Mount a fresh Fern prothallus in water, and note as in the last chapter the several parts of the cells which compose it, and especially the green chlorophyll-corpuscles, which are usually of discoid form, sharply defined from the surrounding colourless protoplasm.

Observe here and there granules of oval or biscuit-shaped outline : these are stages in the process of division, by which means the chlorophyll-corpuscles increase in number. Drawings of a series of such forms should be made so as to illustrate the process of division.

Treat with alcohol; the green colouring substance (chlorophyll) will be seen to be dissolved out of the granules, but they will retain the same definite outline as before. For further details as to chlorophyll see below.

The various other bodies, which are found either having definite form (such as aleurone grains), or in solution in the cell-sap (such as inulin), will be described as opportunity offers, later in the book : a special section at the end of the description of the Angiosperms will be devoted to the study of the nutritive materials stored in seeds and fruits. The reactions by which the bodies commonly found as components of the plant-body may be recognized, are stated concisely in Appendix B at the end of the book.

\section{Remarks on Staining, Clearing, and Permanent Mounting.}

staining.-It is often useful to stain sections in order to bring out certain points in their structure, or to distinguish between bodies of nearly the same refractive index and appearance, but of different nature. A very large number of colouring matters have been used for this purpose, some of which are mentioned in Appendix A: a very few of them will suffice for ordinary laboratory work, and none are ever to be used without a definite purpose. 
Staining is best performed by placing a few drops of the staining fluid in a watch-glass, and immersing the sections in it. The exact strength of the fluid, and the time of exposure of the sections to its action varies in each case, and must be ascertained by preliminary trials. As a rule, when differentiated staining is desired, the best results are obtained by using a dilute solution, and by exposing the sections for a long time to its action; after staining and before mounting for observation it is as a rule necessary to wash the sections in order to remove the superfluous staining fluid; when the staining substance is dissolved in alcohol, the sections are to be washed out with alcohol; when dissolved in water they are to be washed with water: in the case of iodine staining this need not be done, as these colourings fade rapidly when the staining fluid is removed.

Clearing the Preparations.-If it is not desired to observe the details of structure of the protoplasm or of the nucleus, the best clearing agent for ordinary use is a solution of potash, either in water or alcohol.

The clearing action of potash is due to the swelling of various parts of the cells and their contents, so that they become more transparent ; at the same time it dissolves many of the granules in the protoplasm, and saponifies the oil-drops. The swelling caused by the action of the solution in water is often too great, especially when it is desired to see the cell-walls distinctly; this difficulty may be got over by the use of the alcoholic solution.

After treatment with the aqueous solution of potash, the sections should be washed in distilled water, and after treatment with the alcoholic solution in dilute alcohol; the sections, in either case, may be mounted in glycerine : or the sections may be treated at once with a mixture of potash solution and glycerine, but in any case the potash must be washed out before mounting as a permanent object.

If treatment with potash solution does not readily make the tissues transparent, the action of the reagent may be accelerated and intensified by warming over a spirit-lamp. If the action be too strong, and the tissues become too transparent, this may be corrected by neutralizing with acetic acid. 
Another method which gives good results, especially in clearing growing-points, is by the use of "eau de javelle" (see Appendix A). The object, either fresh, or after hardening in alcohol or picric acid, is mounted under a cover-slip in "eau de javelle" for three or four, to ten or fifteen minutes, according to the rapidity of action of the reagent : very gentle warming over a spirit-lamp will quicken the action : it is then to be carefully washed with water, next with dilute acetic acid, and it may finally be mounted in glycerine.

All the abovemethods involve the partial or complete disorganization of the protoplasmic body: the following method of treatment has the advantage of preserving the structure of the protoplasm and of the nucleus, and it is specially applicable to material in which the protoplasm has been fixed by alcohol, or by picric acid and alcohol. The sections (after staining, if that is considered necessary) should be placed for a few minutes in absolute alcohol; they should then be transferred to a watch-glass, containing either a mixture of turpentine and creosote (four parts of the former to one of the latter), or some oil of cloves ; sections which have been stained with aniline dyes are best cleared by cedar-wood oil ; they should be left in the clearing agent for a short time, until they appear to be quite transparent, and should then be mounted in a drop of Canada balsam or Dammar.

Permanent Mounting.-It was pointed out in the previous chapter that objects mounted in water cannot easily be kept, while the objects do not appear so transparent in water as in some medium of higher refractive index. The media most commonly used are glycerine, glycerine jelly, Canada balsam; and Dammar.

Glycerine.-This may be used for objects prepared from fresh material, or hardened with alcohol, \&c., and is especially suited to objects stained with ammoniacal solution of hæmatoxylin, carmine, and many of the aniline colours : it is also used for objects cleared by potash, or " eau de javelle." Dilute glycerine should be used for this purpose, consisting of a mixture of pure glycerine with an equal bulk of water.

In order to make the preparations mounted in glycerine per- 
manent, the cover-slip should be fixed to the slide by applying a coating of gold size, Brunswick black, or Canada balsam dissolved in benzol, round its edge with a brush. If a circular cover-slip be used, a turn-table will be found to save much time in this process. Care should be taken that no glycerine is on the slide outside the cover-slip; if any is there it should be removed by means of blotting-paper before applying the varnish.

Glycerine Jelly. - Objects which may be mounted in glycerine may equally well be mounted in glycerine jelly, in which case since the jelly sets firmly, it is unnecessary to use any cement or varnish. The sections should be previously soaked for one or two days in glycerine so as to remove water or alcohol from them. A trace of carbolic acid should be added to the glycerine jelly in order to prevent the growth of Fungi.

Canada Balsam.-This is a highly refractive medium, and is thus well adapted for lending transparency to objects. It is specially suited to sections stained with hamatoxylin. Water must be completely extracted from the objects before mounting, by treatment with absolute alcohol, or strong methylated spirit ; they are then to be transferred to oil of cloves, or a mixture of turpentine and creosote, or cedarwood oil, and finally mounted in Balsam.

The stain produced by aniline colours is apt to fade, so that they are not to be recommended for preparations which are to be kept for a long time. The staining of hæmatoxylin also fades, but more slowly. In order to prevent fading, the preparations should be kept in the dark. 


\title{
PHANEROGAMÆ
}

\section{ANGIOSPERMS}

\section{VEGETATIVE ORGANS.-(A) DICOTYLEDONS}

\author{
HERBACEOUS TYPE
}

Observations with the Naked Eye

I. Sone seeds of the Sunflower should be germinated in a pan, and the young seedlings, after forming a few leaves, should be bedded out, and allowed to grow for about three months: examine a well-grown specimen of that age, as a whole. The main axis or stem is stout, herbaceous, and erect: it often develops to a considerable length without branching : it is cylindrical, slightly striated below, while the higher parts of it, where the lateral branches are developed, are polygonal. Its surface is studded by stiff hairs, which are especially obvious on the lower portions of the internodes.

The stem bears laterally numerous leaves, which are simple, petiolate, cordate-acuminate, the margin slightly serrate, venation palmate-reticulate, the surface hirsute. The arrangement of the leaves at the lower part of the plant (and including the cotyledons, which wither at an early stage) is opposite, or in whorls of three; higher up, this arrangement merges gradually into the alternate.

The stem is terminated by a bud, which may consist only of closely aggregated foliage leaves, or it may inclose the repro- 
ductive organs, which are contained in numerous flowers, closely aggregated so as to form a characteristic inflorescence -the capitulum, or head. Similar buds, in earlier stages of development, may be observed in the axils of the leaves (axillary buds).

Wash the roots and examine them. They are fibrous, and branch profusely. The primary (tap) root, and earlier developed lateral roots are thicker than the later developed roots of a higher order, the latter being successively thinner. This is due to the fact that the roots undergo a process of secondary thickening.

\section{* The Mature Stem.}

II. Cut the stem of a well-grown plant transversely at its thickest part, and smooth the surface with a razor.

The most prominent object in the section will be the massive, white, spongy pith which occupies the centre.

Around this will be seen, arranged more or less regularly in a circle, and near the periphery, a series of more solid-looking masses of tissue ; these are the vascular bundles.

III. In order to obtain a clear idea of the course of these bundles along the stem, and of their connection with those of the leaves, cut off a piece of the stem, so as to include the insertion of a leaf or node, and about two or three inches of stem above and below that point. Bisect this longitudinally in a plane perpendicular to the median plane of the leaf, i.e. so that one of the pieces will bear the whole base of the leaf. Clear away the pith with some blunt instrument, taking care not to injure the vascular bundles. This process will be made easier if the stem be previously boiled in water for about ten minutes.

Now dissect out carefully the course of the several vascular bundles, clearing away as much of the internal parenchyma as possible. Treat the whole preparation with acid solution of aniline sulphate for about five or ten minutes. The vascular bundles will be stained yellow, and their course may then be more readily followed. 
It will be apparent that in the internodes the bundles run parallel to one another, and as a rule without lateral fusion. This regularity is disturbed at the nodes by lateral fusions of some but not of all of the bundles, and by the entry of fresh bundles from the leaves (usually three from each leaf), into the vascular ring.

IV. In a longer piece of the stem follow carefully the course of several of the bundles entering from the leaves, as far as they can be traced independently and without fusion. This will be possible at least for one internode, and usually for two or three; but the distance through which this independent course can be traced is variable in this plant. Further, the lateral fusions do not occur only at or near the nodes; instances may not unfrequently be found of fusions occurring at various points in the internodes.

For further description of the rough anatomy of the Sunflower, and of the vascular system in other herbaceous Dicotyledons, see larger edition, pp. 57-61.

\section{Microscopic Observations.}

The material should be kept in spirit for some time, to remove resin and air, and to harden the tissues; but this is not indispensable, and fresh material may be used, though it is not so satisfactory.

I. Cut thin transverse sections of a stem of a well-grown plant of Helianthus, i.e. of a stem more than half an inch at least in diameter.

Mount some of these in glycerine or glycerine jelly (these may be kept as permanent specimens), and others in chlorzinc-iodine. Examine these first with a low power, and observe the following tissues in succession, starting from the exterior:-

1. The epidermis, a single peripheral layer of cells, not very well defined from the underlying tissues: it completely covers the surface.

The margin is not perfectly regular, but is here and there extended outwards at the regions surrounding the bases of the 
large multicellular hairs, which may be recognized as being products of the epidermis.

2. Beneath this single epidermal layer lies a band of tissue, several layers of cells in width, the walls of which are thickened at the angles where three or more cells meet, the cell-cavity being thus made oval or circular in transverse section; this is the chief characteristic of collenchyma, of which this is a good type. Below this lies--

3. A band of thin-walled parenchyma, in which are dotted here and there resin-passages.

Within these tissues of the cortex (a general term including the tissues described under the headings 2 and 3 ) lie-

4. The vascular bundles, which are wedge-shaped, and are arranged in a ring : according to the stage of development of the stem, and the point at which the section is taken, the bundles may be more or less completely joined laterally with one another. In old stems, and at or near the nodes, this lateral fusion is most complete : still under any circumstances, the originally separate bundles can easily be recognized.

5. Centrally, i.e. within the ring of vascular bundles, is the parenchymatous pith, consisting of thin-walled cells, which have for the most part lost their activity, having no protoplasmic contents, and are filled with air : hence the whiteness of the fresh pith. In material which has been a long time in spirit, the air may have been remored by the alcohol, but this is usually a slow process.

II. Choose out the thinnest of the sections, and examine it with a higher power, starting as before from the periphery of the stem.

I. The epidermal layer will be seen to consist of cells contiguous with one another, without intercellular spaces, but with occasional stomata : the structure of these will be studied in detail in specimens where they are more numerous. The walls, and especially the external and internal walls, are thick, highly refractive, and show a stratified structure. In chlorzinc-iodine they show the characteristic blue of cellulose with the exception of the outermost layer-the cuticle: this is a continuous well-defined layer, which stains yellow, and 
may thus be easily recognized (see p. 26 , reactions of corky walls).

The granular protoplasmic contents of these cells (brown, with chlor-zinc-iodine) are not plentiful, but form a thin layer lining the somewhat rounded cell-cavity, Chlorophyll-grains are to be found in these cells : this point is to be noted, since in the stems of many plants chlorophyll is absent from the epidermal cells.

The cells surrounding the bases of the hairs, as well as the underlying tissue, show a luxuriant growth: in fact the hairs are each seated at the apex of an emergence.

2. In the collenchyma the protoplasmic body resembles that of the epidermis: chlorophyll-grains are numerous. The cell-walls also are highly refractive, and stain blue with chlorzinc-iodine (cellulose); they are specially thickened at the angles, where three or more cells meet; in the thickened mass the lines of stratification are well seen. Note that the collenchyma is not continuous below the stomata; also that there is no sharp internal limit to the collenchyma, but it merges gradually into-

3. The thin-walled cortical parenchyma, which differs from the preceding $(a)$ in the thinness of its walls, $(b)$ its less copious cell-contents, $(c)$ the larger size of the cell-cavity, $(d)$ the presence of intercellular spaces, which result from the splitting of the cell-walls at the points where three or more walls meet; in the living state they are filled with air, and even in specimens which have been treated with alcohol, air-bubbles may still be found entangled in them.

Observe carefully the resin-passages, which occur in the cortical parenchyma. The resin, being soluble in alcohol, has been removed. They are intercellular spaces, formed by the splitting of cell-walls. The cavity thus formed is surrounded by small, thin-walled epithelium, the cells of which divide both radially and tangentially as regards the passage.

Note that in the epidermis, collenchyma, and thin-walled parenchyma of the cortex, there occur divisions of the cells in a radial direction. Compare the girth of the stem at the upper with that at the lower part of the plant, or that of a young plant 
with that of an old one. The conclusion will naturally be drawn that the stem increases in girth as it grows older, and since the outer tissues neither peel off, nor do the individual cells increase greatly in width, longitudinal radial divisions of the cells are the only alternative.

Before leaving the cortical tissue it must be noticed that the bundle-sheath or endodermis, which is the inmost layer of the cortical tissue, and which is easy of observation in the younger stem, may be identified in these sections, though with difficulty (see below, p. 45). It lies immediately abutting upon the thickwalled sclerenchyma, but it is often difficult to distinguish it in old stems.

Within this are-

4. The vascular bundles. Select one of the largest of these for more minute examination : it will be found to consist of two well-marked masses of thick-walled tissue, peripheral and central as regards the stem, with a transparent thin-walled portion between them. Further, on examining the latter more carefully, it will be seen that the external part of it has thicker walls, and is less regularly arranged than the central portion, and must accordingly be distinguished from it. We have thus four portions of the bundle which, taking them in succession from the periphery to the centre, are named as follows :-
(i.) Sclerenchyma.
(ii.) Soft Bast or Phloem.
(iii.) Cambium.
(iv.) Xylem.

i. Examine first the sclerenchyma. This appears as a halfmoon-shaped mass of tissue consisting of elements with rounded cavity, in which may be recognized the remnants of protoplasmic contents. The walls are thick, and lignified (yellow with acidulated aniline sulphate, or with chlor-zinciodine, see p. 25). They also show differentiation into layers, of which the most prominent is the bright-looking middle lamella. Perpendicular to the internal surface of the walls pits may be seen. 
ii. The soft bast, or phloem, consists of elements of very different structure and function : these are--

a. Sieve-tubes, which appear in transverse section as the larger cavities of the soft bast : their walls are rather thin and consist of cellulose (blue, chlor-zinc-iodine). Occasionally these cavities will be found traversed by transverse septa, having a punctate appearance. These stain dark brown with iodine solution: they are transverse sieve-plates. (See the description of sieve-tubes in Cucurbita.)

b. Abutting directly on the sieve-tubes, and appearing as though they had been cut off from the sieve-tube by a longitudinal wall, may be seen smaller cells: these are the companion-cells, but they are not readily distinguished.

c. The remaining elements resemble the sieve-tubes in transverse section except in their smaller size, and absence of sieve-plates: these are cambiform cells, or phloemparenchyma.

Passing inwards, the distinction of these several constituents of the soft bast becomes more difficult, while the walls are thinner, and the arrangement of the elements is more regularly in radial rows, till, in the band of thin-walled tissue which borders immediately on the xylem, these characters become very obvious. The band is -

iii. The cambium, or active formative layer. Its constituents are cells arranged in radial rows, with thin cellulose walls (blue, chlor-zinc-iodine), and plentiful protoplasmic contents: the tangential walls are the thinnest, hence we may conclude that the most recent divisions have been in this direction, and have been repeated. Occasionally traces of recent radial division will be found, but this is less common. The form of the individual cells varies from oblong to square, as seen in transverse section : in the former case the longer axis is tangential. Trace the radial series outwards into the phloem, and inwards into the xylem : they may often be followed for a considerable distance with certainty. Note how, in passing from the cambium to the phloem or xylem, the cells divide, and how the form of the individual cells is modified. Hence we may draw conclusions as to the development of the different tissue- 
elements of the mature xylem and phloen from the originally uniform cells of the cambium. For further details see the Elm (pp. 56,63) which, being a woody stem, and having more definite secondary increase, is a better type for the study of cambium. (Compare Fig. 7, A, p. 64.)

iv. The xylem also consists of elements of various structure : of these the most noticeable are-

a. The vessels, easily recognized by their large cavity : they are arranged in radial rows, the individual vessels usually decreasing in size towards the central limit of the bundle. The walls are thick and lignified (yellow with chlor-zinc-iodine, or with acidulated aniline sulphate, see p. 25); they have no protoplasmic contents, their further distinctive characters can only be seen in longitudinal sections. Thyloses may be observed (see below, p. 44), especially in more central vessels. The vessels are embedded in a mass of tissue composed of two tissue-forms, which, however, are not readily distinguishable in transverse sections : they are-

b. Xylem-, or wood-fibres, which appear irregular and polygonal in transverse section, and have thick lignified walls : cell-contents are not prominent, or they may be entirely absent.

c. Xylem-parenchyma-cells which retain their protoplasmic contents; their cell-walls are lignified, or of cellulose : the latter is the case with those cells which surround the more central vessels. This constituent of the bundle is more characteristically represented in the stem of the Elm (see below, p. 56).

5. The pith consists of cells, which have for the most part lost their cell-contents : they have very thin walls; the walls are slightly pitted : intercellular spaces small. The cell cavity is usually filled with air, which replaces the protoplasm ; hence the whiteness of the pith.

III. Cut radial longitudinal sections of an old stem of Helianthus, and choosing such as have passed through a vascular bundle (easily recognized with the naked eye), treat them as above.

Bear in mind the observations already made on the transverse 
sections, and compare those results with the observations about to be made.

Starting as before from the periphery, note successively the tissues already observed in the transverse sections. It is but rarely possible to see all the tissues satisfactorily represented in a single radial section, therefore the study of the tissues and of their relative positions should be conducted by comparison of a number of sections one with another.

I. The epidermis, consisting of oblong cells, whose walls and contents present the appearance already observed in the transverse sections. Note the disturbance of their normal arrangement around the bases of the larger hairs.

2. Beneath the epidermis lies the collenchyma, consisting of oblong cells with thick longitudinal cellulose walls (blue, chlorzinc-iodine), and thin transverse ends : the contents are protoplasm, with a nucleus and chlorophyll-grains. Below each of the larger hairs the collenchyma gives place to short, thinwalled parenchyma, which, together with the epidermis covering it, forms those emergences on the summit of which the hair is seated. Within this is-

3. Thin-walled cortical parenchyma, the cells of which are shorter, but, wider, than those of the collenchyma; there is, however, no sharp limit between them: observe transitional forms. The cell-contents resemble those of (2), but there is less chlorophyll.

Note the resin-passages, the course of which is directly longitudinal: they therefore appear as longitudinal bands of small, oblong, thin-walled cells (epithelium).

The bundle-sheath may occasionally be recognized as the layer of cells immediately outside the bundle. Very commonly starch-grains may be detected in its cells.

4. The vascular bundle. Supposing the section to have been approximately median through the bundle, the following components will be found to be included in it:-

i. Hard bast, sclerenchyma, or bast-fibres, which appear in longitudinal section as long prosenchymatous cells, occasionally divided by more or less oblique septa. Walls thick, lignified (yellow with chlor-zinc-iodine, or with acidulated aniline 
sulphate), and pitted : remnants of the protoplasmic contents may be found, especially if the stem cut be not very old.

ii. The soft bast, or true phloem, consisting of tissues with cellulose walls (blue with chlor-zinc-iodine), and abundant protoplasmic contents : its several constituents are--

$a$. Sieve-tubes, long tubes with thin walls and transverse or oblique septa (sieve-plates), the structure of which is the chief characteristic of the sieve-tubes; they are readily recognized in sections treated with chlor-zinc-iodine (or iodine solution) by the deep brown coloration of the protoplasm, which is collected round the sieve-plates.

Treat some sections with potash: the protoplasm, and mass of callus surrounding the sieve-plates, swells, and the perforated or sieve-like character of the septum, which does not swell, is then easily recognized. The sieve-tubes will be more easily recognized in sections which have been stained with eosin (see Appendix A) which stains the contents of the tubes deeply.

A more detailed study of sieve-tubes, and their structure and contents will be given below in a special section (p. 70).

$b$. Side by side with the sieve-tubes may be found the companion-cells, which are smaller sister-cells of the segments of the sieve-tubes, cut off during development.

c. Bast-parenchyma, or cambiform cells. These are oblong parenchymatous cells with thin, indistinctly pitted, cellulose walls, and protoplasmic contents.

iii. The cambium, a narrow band of oblong cells with very thin walls, and dense protoplasmic contents. As the tissue in this case differs in no essential point from that in other plants treated elsewhere, and as it is here difficult to study, its description will be deferred, though its presence here must not be forgotten (see below, p. 64, Fig. 7, B).

iv. The xylem, consisting of-

a. Vessels, which are its most prominent constituent. They are elements with lignified walls (note reactions as on p. 25), which are variously marked : they have no protoplasmic contents, their wide cavity containing during life water or gases. The cavity is continuous owing to the partial or complete 
absorption of the transverse or oblique septa. Note instances of this partial or complete absorption. According to the various markings, or thickenings of their walls, the vessels may be grouped under the following heads, the first named being the nearest to the periphery of the stem :-

a. Pitted vessels, which are the largest, having very wide cavity : their walls are marked with pits which appear oval in surface view, and which have the same characters as the round bordered pits of Pinus (see p. 138).

Having observed the pits in surface view, focus so as to obtain a longitudinal optical section of one of the walls; or better, find a place where the preparation is so thin as to show this in real section. Compare this with what was seen in surface view.

B. Spiral vessels found in the part of the xylem nearer the pith, those nearest the pith having the spirals less closely coiled. Note transitional forms (irregularly reticulated) between spiral and pitted vessels.

$\gamma$. Annular vessels found at the part of the xylem directly adjoining the pith : the thickening is here in the form of rings; in mature stems these vessels are usually more or less disorganized.

b. Fibrous cells (wood-fibres), which are long and pointed: it is difficult to follow one individual fibre throughout its whole length, owing to its taking a sinuous course, the fibres being interwoven one with another: their walls are lignified and pitted : the cell-contents are reduced or absent.

c. Parenchyma, which is to be found more especially around the vessels near the central limit of the bundle. The phenomenon of thyloses is the result of the encroachment of these cells on the cavity of the vessels. The normal individual cells are oblong with square ends, they have cellulose walls, and retain their protoplasmic contents.

5. The central pith is composed of parenchymatous cells, with thin walls consisting of cellulose : the walls are slightly pitted: these cells have lost their protoplasmic contents in many cases, and especially near the centre of the stem. Occasional resin-passages may be found in the pith. 


\section{* * Young Stem.}

IV. Cut transverse sections of a young branch of the Sunflower about one-eighth of an inch in diameter. The sections may be cut from the hypocotyledonary stem, in which case they will be found to correspond in all important points to the following description, but they will differ in some of the details; thus hairs will be absent, the bundle-sheath will be more obvious, \&c. : it will therefore be best to cut the sections, as directed, from a young branch.

Mount in glycerine, and passing from the periphery inwards observe successively under a low power-

1. The epidermis, as before a single layer, with hairs of various complexity and shape. Beneath this-

2. Cortical tissue, which is more or less differentiated into-

a. Collenchyma.

B. Cortical parenchyma.

$\gamma$. Resin-passages.

$\delta$. Bundle-sheath, or endodermis.

These sevcrally hold the same position, and have the same characters, as were above observed in the older stem, but the tissues are less bulky, and less clearly differentiated from one another.

The bundle-sheath in the young stem is more easily recognized than in the older stem, though it will subsequently be still better seen in roots. It is a continuous layer of cells, which have the characteristic dark dot on each radial wall: this is due to reflection of light from the peculiar sinuous waves of the central part of the radial walls. The oblique part of each wave acts as a reflector, so that the greater part of the light is diverted before it reaches the eye : hence the origin of the dark dot. The bundle-sheath lies immediately outside the vascular bundles, curving slightly towards the centre of the stem in the spaces between the bundles.

Within the bundle-sheath, and arranged in a ring, lie-

3. The vascular bundles, which are of variable number: they are wedge-shaped and of unequal size, and are composed of 
elements essentially similar to those described above in the older stem ; but the bundles are here much smaller, they consist of fewer elements, and the tissues are immature : thus the sclerenchyma which lies directly within the bundle-sheath has its walls as yet thin ; it may already be distinguished from the soft bast by the more uniform character of its elements: the cambium may be distinguished by the regularity of arrangement of its cells in radial rows. Of the wood only the vessels nearest to the pith will be matured, and between them and the cambium various young vessels may be seen, having large cavity, but the walls not yet thickened or lignified.

Note that, if the stem be young enough, the bundles are

$A$

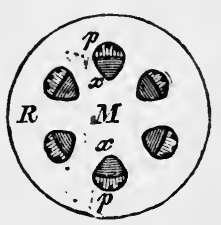

$\boldsymbol{B}$

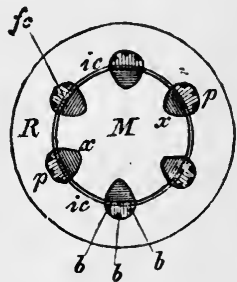

Fig. 2.-A, B. Diagrams illustrating the formation of interfascicular cambium. A shows the primary vascular bundles isolated, and embedded in quiescent ground tissue, before the interfascicular cambium begins to be formed; $B$ shows the interfascicular cambium (ic) forming with the fascicular cambium $(f f)$ a continuous ring: $p=$ phloem ; $x=$ xylem $; b, b$, groups of bast-fibres at the periphery of the phloem. (After Sachs.)

not joined laterally as in the older stem, but are separated from one another by broad bands of ground tissues. In slightly older stems the cells of this tissue may be found actively dividing, by tangential and occasionally by radial walls. An interfascicular cambium is thus formed, and by the tissues derived from it the vascular ring, as seen in the older stem, is completed. Centrally lies-

4. The pith, consisting of thin-walled cells, with sparing cell-contents : thus these cells have not yet lost their activity; 
compare the older stem, where the protoplasmic contents are replaced by air.

Note on Interfascicular Cambium.-It has been seen that in the Sunflower the bundles are quite separate in the young stem, being isolated by masses of quiescent ground tissue. Later, the cells of the latter tissue begin to divide actively as an interfascicular cambium layer, lying between the originally separate bundles. This interfascicular cambium joins the margins of the fascicular cambium, and a complete cambial cylinder is thus formed. But here in the Suntlower, as in most herbaceous annual plants, the interfascicular cambium is not very long active, the product of its activity being but a narrow band of secondary fascicular tissue : the identity of the original bundles can thus be recognized at a glance. These points can be very well observed in the stem of Ricinus and other herbaceous or semi-herbaceous Dicotyledons. (Compare Fig. 2, A, B.)

\section{* * * Apical Bud.}

V. Take the apical bud of a young plant, or of a young lateral branch of the Sunflower, and cut longitudinal median sections ; treat with potash, and mount in glycerine : a better method is to treat with "eau de javelle," and mount as directed on p. 32 : examine with a low power, and then observe-

1. That the axis ends in a naked, broadly-conical apex (punctum vegetationis), which is surrounded and enveloped by-

2. Leaves: these may be observed in various stages of development, the youngest being nearest to the apex : their order of development is thus acropetal. The surfaces of the older leaves are covered with-

3. Hairs, which are absent from the apical cone and the youngest leaves, the hairs being developed subsequently to the leaves themselves.

Note (with a high power) that the apical cone itself consists of thin-walled cells with plentiful protoplasm, which are sinaller than the cells of the mature tissues already studied, and are in a state of active division, i.e. they are merismatic. Observe 
further that the newly-formed cell-walls cut the pre-existing cell-walls at right angles, and that the two parts of the cells thus divided are apparently equal to one another. A comparison of the general arrangement of the cell-walls with the diagram shown in Fig. 3 will help to make clear the arrangement of these cell-walls : in drawing the comparison, however, it must not be forgotten that Fig. 3 is a diagram, and cannot be expected to apply in detail.

The whole merismatic mass is differentiated into parts, which

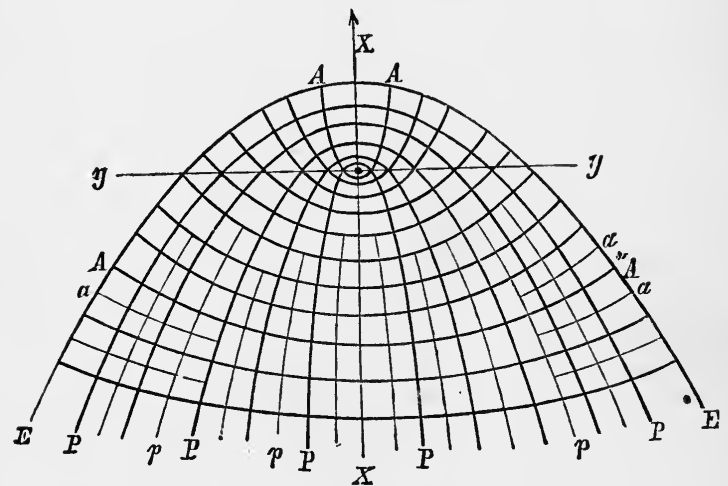

Fig. 3.-Diagram illustrating the plan of arrangement of cell-walls in the apex of the stem of an Angiosperm. $x, x=$ longitudinal axis, which is the organic axis of the stem. E, E=external surface. P,P, P,P, are the periclinal curves. $A, A=$ the anticlinal curves which cut these at right angles. $\not p, p=$ incomplete periclinals. $\boldsymbol{a}, \boldsymbol{a}=$ incomplete anticlinals. The dermatogen is represented by the space between the outer surface, E, E, and the outermost periclinal, P, P. (After Sachs.)

may be distinguished more or less clearly from one another, and it will be easy to trace their continuity with the several tissue-systems of the stem and leaves, of which in fact they are the formative layers. We may thus distinguish the following :-

I. The dermatogen, as a single continuous layer of cells, which divide only in a direction perpendicular to the external surface of the organ (stem or leaf), which it covers completely : it is easily seen to be continuous with the epidermis, of which 
it is the formative layer. Within this is a solid mass of tissue, which looks for the most part dark, owing to its being permeated by intercellular spaces filled with air. It is traversed at a short distance from the external surface by transparent, longitudinal bands of-

2. Procambium, which is the formative tissue of the vascular bundles. Trace its continuity with these. Between the procambial bands and the dermatogen lies-

3. The formative tissue of the cortex (periblem) which is (partially at least) characterized by dark-looking intercellular spaces.

4. Centrally lies a dark bulky cylinder, which is continuous with, and formative of, the pith.

Observe carefully the mode of origin of the leaves. They appear at the periphery of the cone as protuberances of the dermatogen and of the subjacent cells: the divisions in the dermatogen are all anticlinal, those in the lower layer are both periclinal and anticlinal. (Compare Fig. 4.) As they increase in size their internal tissues become differentiated into ( $\mathrm{I}$ ) procambium, which is subsequently connected with that of the stem, and (2) tissue with intercellular spaces, which is continuous with the cortex. At the same time single cells of the dermatogen grow out, and divide, so as to form the conical multicellular hairs, which cover the surfaces of the leaves. In the older leaves of the bud the development of the emergences around and below the bases of these hairs may be traced: these are not represented in the diagram (Fig. 4).

Note on passing back from the apex towards the more differentiated part of the stem a gradual increase in length of the cells, corresponding to the gradual extension of the internodes, while in the first elongated internode of the stem below the bud this is very marked. Observe also the various stages of the process of vacuolization of the protoplasm; this will be best seen in sections stained with hæmatoxylin, and mounted in Canada balsam.

Apical buds of the Jerusalem Artichoke (Helianthus tuberosus) may be used instead of $H$. annuus, and they have the advantage of being vegetative buds. Whereas the Sunflower flowers 
early, the Artichoke does not flower at all in this country : thus the complications which attend the formation of flowers will be avoided.

Buds of the Common Lilac (Syringa vulgaris) also afford good material: various other buds may be used, allowance

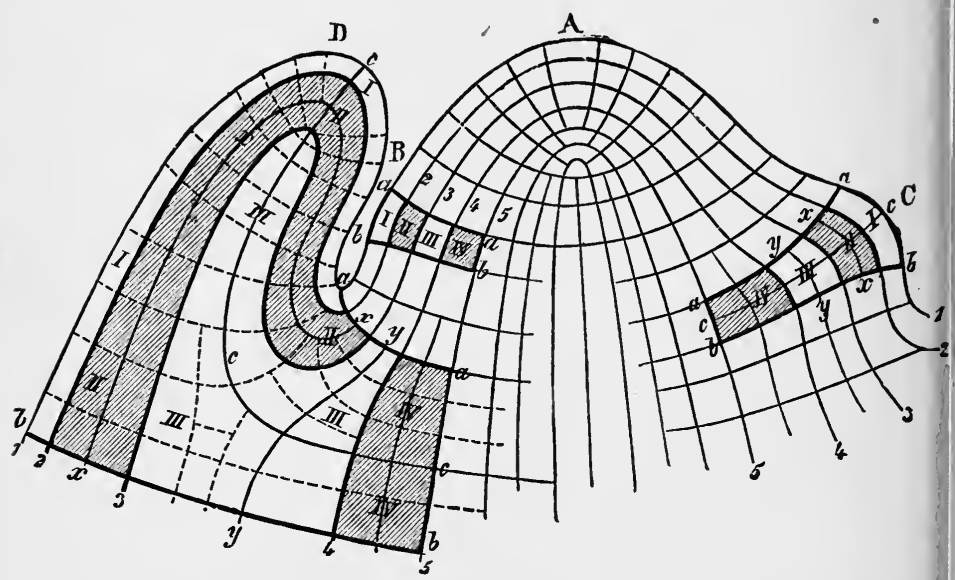

FIG. 4.-Diagram illustrating the mode of origin of leaves (with alternate arrangement) from the growing point of a Phanerogam. A, apex of the growing point. $B, C, D$, various stages in the origin of a new leaf: the arabic numbers, and shading, indicate how the individual layers of cells take part in the origin of the new leaf. It is clearly indicated in this diagram that no periclinal divisions appear in the cells of the dermatogen. (After Sachs.)

being made for difference of detail owing to the various arrangement of the leaves, \&c.

\section{Cell-division.}

Cell-division as it takes places in the multiplication of cells of an ordinary tissue may be observed in the young stems of Sunflower or Elder. On a warm day, cut young shoots of either of these plants, in which the internodes are between one and two inches in length: fix them at once in alcohol for 
twenty-four hours or more, and from the tissue thus hardened cut longitudinal sections so as to traverse the pith. Stain with hæmatoxylin, wash with alcohol, transfer to oil of cloves, and mount in Canada balsam. In sections so prepared, if the staining is not too deep, cells may be found in various stages of division, showing the peculiar nuclear spindle, or the delicate new cell-wall between the freshly formed nuclei. For details of the process of cell-division, see the larger edition, p. 84 . 


\section{STEM-ARBOREOUS TYPE}

I. Note the following external characters of a twig of Elm (Ulmus campestris) of the current year. It is cylindrical, hirsute, green or brown according to age, the latter colour being due to the formation of a superficial layer of cork. Small brown excrescences are scattered over its surface; these are lenticels. The arrangement of leaves is alternate and bilateral, phyllotaxis $\frac{1}{2}$, branching axillary : at the base of each leaf, note on either side a small scar, where the stipule was inserted : the stipules usually fall away soon after the buds open in spring, but they may sometimes be found persistent for a time on strong shoots.

II. Cut thin transverse sections of a twig of the current year ; mount in glycerine, and examine with a low power. Other sections may, for comparison, be treated with chlor-zinc-iodine, others again with aniline sulphate.

Observe the general arrangement of tissues in concentric layers, which will be found to succeed one another in the following order, starting from the outside :-

I. Epidermis : a single layer of small cells : many of them have grown out, as conical hairs, perpendicular to the surface.

2. Cork : consisting of one or more layers of square cells : it will be more strongly developed in older twigs, while it is completely absent in very young twigs : its development is studied below, pp. 54, 55. Here and there a lenticel may have been cut through, in which case it will appear as a lateral extension of the band of cork.

3. Cortical tissue: parenchyma with chlorophyll, having cellulose walls, and intercellular spaces : an outer band of the cortex shows a collenchymatous development, similar to that in Helianthus. The inner part of the cortex is thin-walled : here. 
and there are large transparent areas: these are cells with swollen mucilaginous walls.

4. Thick-walled masses of sclerenchyma (hard bast), which form an irregular broken ring: the walls stain brownish-red with chlor-zinc-iodine.

5. Soft bast : a transparent tissue with cellulose walls, and plentiful protoplasm.

6. Cambium : a misty layer of thin-walled tissue with plentiful protoplasm : cells in radial rows.

7. Xylem : a broad band of thick-walled lignified tissue, with crenated inner margin ; centrally lies-

8. The pith or medulla : round-celled parenchyma, with thin pitted walls : here and there are large, transparent mucilage cells.

The crenated appearance of the inner margin of the xylem is due to the presence of the wedges of primary xylem, forming the so-called medullary sheath : the wedges are separated from one another laterally by parenchymatous bands, which may be followed outwards in a radial direction through the whole thickness of the vascular ring : these are the primary medullary rays: other rays will also be seen following a similar course, but extending only part of the way from the cambium to the centre and periphery of the vascular ring : these are secondary medullary rays.

Examine the several tissues, above enumerated, in detail with a high power :-

1. Epidermis : a single layer of cells, with the outer wall thickened and cuticularized or corky (test with the usual reagents, see p. 26) : stomata will be found in a normal position in young twigs, in older ones they are found at the apices of the lenticels (see below, p. 54). Note the form of the conical hairs, the walls of which are silicified.

2. The periderm (when present) lies immediately below the epidermis : its cells are arranged, in radial rows, without intercellular spaces. Select a thin part of the section for special study of these radial rows, and note in each the following succession of tissues, passing from without inwards :-

a. A series of cork-cells as above described: walls stained yellowish brown with chlor-zinc-iodine. 
b. At least one cell with very small radial diameter, and with protoplasmic contents, and thin cellulose walls: this is the cork-cambium, or phellogen.

c. Cells with thick cellulose walls, and protoplasmic contents with chlorophyll : no intercellular spaces: this is the phelloderm, which is also derived from the cork-cambium.

Treat a thin section with concentrated sulphuric acid: the walls of all the tissues will swell, and gradually lose their sharpness of outline, with the exception of the cuticularized outer wall of the epidermis, and the cork, both of which resist the action of the acid. A similar result may be obtained on treatment with strong chromic acid.

By comparing sections of twigs of various ages, starting from such as have just escaped from the bud, the following facts may be established--

i. The cork-cambium appears in the layer of cortical cells immediately below the epidermis.

ii. These cells divide parallel to the external surface of the stem.

iii. The result of successive divisions in this direction is the formation of secondary tissues, which develop externally as cork, internally as phelloderm.

iv. The true cork-cambium consists of only a single cell in each radial row, from which, by successive division, all these secondary tissues are derived : compare cambium of vascular bundles (see below, p. 63-65, \&c.).

v. The cells of the cork-cambium occasionally divide radially.

The diagram (Fig. 5) will help to make this plain.

Examine points where a lenticel has been cut through, or make median sections through a lenticel.

Note that here the cork layer widens out laterally so as to form a hemispherical mass (semicircular in section), which is covered by the extended epidermis; if the section be median, a stoma will usually be seen at the apex of the lenticel: the whole mass of tissue consists of cells of a corky nature, with intercellular spaces.

3. The cortical tissue is a broad band consisting of 
parenchymatous cells with intercellular spaces: a peripheral part of it may be distinguished as a band of not very definite collenchyma from the thinner walled cortex within. According to their various characters they may be thus grouped :-

a. Ordinary parenchyma cells, with cellulose walls and protoplasmic contents with nucleus, chlorophyll, and starchgranules: the two latter are not constantly present.

b. Cells (idioblasts) with large crystals.

c. Large cells whose mucilaginous walls almost or entirely obliterate the cell-cavity.

Note that the cells $(a)$ are subject to radial division, and

A

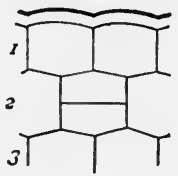

B

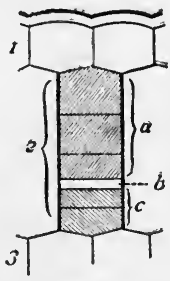

FIG. 5. - A, B, Diagrams illustrating the formation of periderm in the layer of cells

(2) directly below the epidermis (1). A shows the first periclinal division of the hypodermal layer (2). B shows as the result of repeated periclinal divisions a radial row of cells, of which the outer portion $(a)$ is of cork; the inmost portion (c) is the phelloderm: these are separated by a single cell (b), which represents the cork-cambium.

that the whole cortical tissue undergoes tangential extension, so as to keep pace with the increasing bulk of the internal tissues.

In good sections of young material an endodermal layer may be distinguished running peripherally in a wavy line round the outer margin of the series of bundles.

4. The sclerenchyma consists of cells with walls so thickened that the cell-cavity is often obliterated: the walls are differentiated into two or more strata. Reactions with aniline sulphate, light yellow ; with chlor-zinc-iodine, brownish red.

5. The soft bast is, as in the Sunflower, composed of 
several different thin-walled tissue-elements, which are, however, difficult to distinguish in transverse sections: they are-

$a$. Sieve-tubes, which are nearly circular in section, and usually of larger cavity than the other constituents.

b. Bast-parenchyma: cells often arranged in more or less regular radial rows : certain of the cells differ from the rest in containing one or more crystals.

The nature of these several tissues will be more successfully studied in longitudinal sections.

6. The cambium consists of thin-walled cells arranged, as in the Sunflower, in radial rows, which may often be traced outwards into the phloem, and inwards into the xylem: the cells have copious protoplasm, in which an elongated nucleus may often be observed.

7. The xylem also consists of several different tissue-forms, all of which have lignified walls (note their reactions) : they are-

a. Vessels, easily recognized by their large cavity, and by the absence of any protoplasmic body. They occur, singly or in groups, scattered through the xylem.

b. Xylem-fibres or wood-prosenchyma, consisting of elements with much smaller cavity, little or no protoplasm, and thick walls.

c. Xylem-parenchyma, recognized by the presence of a protoplasmic body, and (at all events in winter) of starch grains. The cells of this tissue are usually grouped round the vessels, and often form bands connecting two consecutive medullary rays laterally.

The cells of those parts of the medullary rays which are in the xylem are thick-walled, lignified, and pitted: they have protoplasmic contents and starch: they are elongated in a radial direction. Note that they have special cambium-cells, differing in form from the ordinary cambium (compare Fig. 7, A). In the phloem the cells are thin-walled (cellulose), and have plentiful protoplasm.

8. The pith. In the peripheral part the cells have thick, lignified, pitted walls, and a protoplasmic body with starch (at 
least in winter). Tissue of this nature merges gradually into the central tissue with thin walls (lignified and pitted), and no protoplasm. Mucilage cells occur here and there.

III. Cut a four-year old twig of Elm transversely, and smooth the cut surface with a razor.

The age of a twig may be judged externally by counting backwards the annual increments of growth from the apex. The limits of each annual increment of growth may be recognized by the close aggregation of the scars of the leaves or scales at those points.

Examine with a lens, and observe-

I. The pith, which occupies the organic centre of the stem. Its position does not, as a rule, coincide with the geometrical centre. Externally to this lies-

2. The xylem, which is here a broad yellowish band, clearly marked off into a succession of concentric rings; these, as a rule, correspond in number to the years of the twig (annual rings).

3. The cambium lies at the outer limit of the xylem, but it will hardly be recognized as a definite band of tissue under a simple lens, since it is a very narrow zone: its position may frequently be recognized by the rupture of the tissues, the walls of the cambium being thin and easily broken. Outside this is-

4. The phloem, which is a much narrower band than the xylem, and is also marked off, though less distinctly, into concentric rings of equal number. Outside this lie-

5. The cortical tissue and cork, which are usually of insignificant bulk, compared with that of the vascular tissues : in some cases, however, there is an unusually great development of cork, which then appears externally as longitudinal projecting plates.

Note the medullary rays. Some of these (primary rays) may be traced the whole distance from pith to cortex; others (secondary rays) only part of that distance. The latter have been entirely formed by the cambium.

The general plan of the process of secondary thickening, and the relation of the secondary tissues to the primary 
B

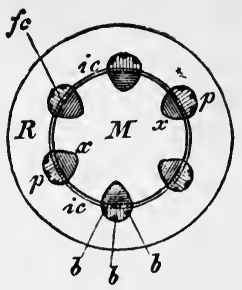

A

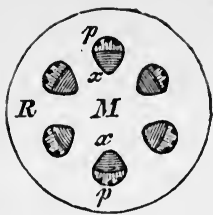

c

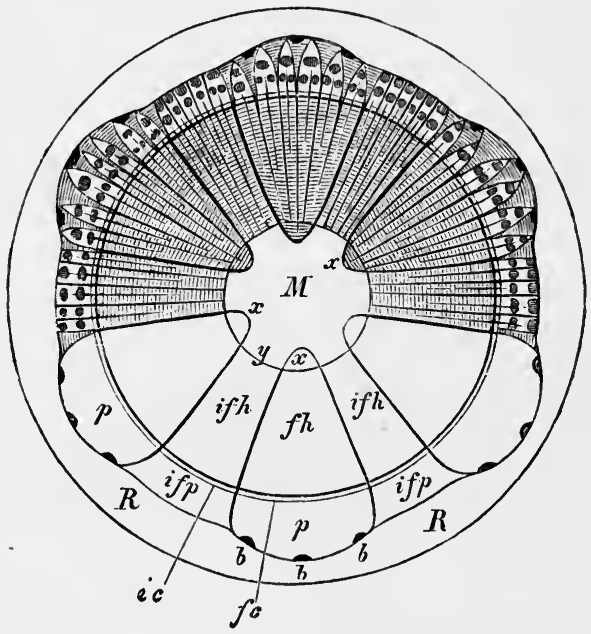

FIG. 6.-Diagrams illustrating secondary growth in thickness in a typical Dicotyledon; the diagrams are based on drawings of transverse sections of the hypocotyl of Ricinus. $A, B, C$ represent the condition of the stem at different stages of development : $A$, before the origin of the interfascicular cambium; $B$, after the interfascicular cambium has been formed; $C$, after the cambium has been active for some time, producing internally a broad ring of secondary xylem, externally a narrow ring of secondary phloem. $K=$ primary cortex : $M=$ pith; $p=$ phloem; $x=$ xylem $; b, b, b=$ three groups of bast fibres at the periphery of the phloem ; $f c=$ fascicular cambium : $i c=$ interfascicular cambium ; $f h=$ wood developed from the fascicular cambium: if $h=$ wood developed from the interfascicular cambium: if $p=$ secondary bast developed from the interfascicular cambium. By the intercalation of the secondary xylem and secondary phloem, the primary groups of bast fibres, $b, b, b$, are removed a considerable distance from the primary xylem, $x, x$, though in the young stem $A$ these are in close proximity to one another. Note also in $C$ the primary medullary rays, which extend the whole distance from the periphery of the ring to the pith, while the second medullary rays only extend through part of that distance. (After Sachs.) 
arrangement are made clear by means of the diagrams $A, B$, $C$ of Fig. 6.

IV. Cut thin sections from the transversely cut surface, so as to include all the bands of tissue from the pith to the cortex : moisten them with alcohol, and mount in water or dilute glycerine. Examine with a low power.

Note that the constituents of the several tissues, produced during the later years, are similar to those already observed in the first year's stem ; also that they are arranged, more or less regularly, in radial rows. This arrangement is best seen in the xylem, and it points to the origin of the tissues from the cambium.

Observe that the constituents of the autumn-formed xylem are smaller, and have slightly thicker walls than those formed earlier in the year, also that vessels of large cavity are absent from it. Hence arises the appearance of the annual rings, which is easily seen in almost any wood of temperate climates, when the transverse section is examined.

In arboreous stems of considerable age a central portion of the woody mass (duramen, or heart-wood) becomes differentiated by texture and darker colour from the more superficial and later formed portion (alburnum, or sap-wood) : this may be seen in old stems of the Elm, but more distinctly in stems of the Laburnum, where the heart-wood is coloured dark brown, while the sap-wood is light yellow. Compare also the black duramen, and light-coloured alburnum of Ebony, and the red duramen of the Logwood, \&c., \&c.

As stems grow older, layers of cork appear successively further and further from the external surface : not only the cortex but also the outer and older portions of the phloem are thus cut off from physiological connection with the inner tissue : the term bark is applied to tissues thus cut off, together with the cork which forms the physiological boundary.

V. Cut radial sections from a four-year-old stem of Elm ; soak them ten minutes or more in alcohol to remove the airbubbles, and mount in glycerine. Other sections may be mounted in Schulze's solution, and these will perhaps be found the most useful ; examine first under a low power.

It will be found difficult to cut good sections so as to include 
the whole radial surface : it is therefore better not to attempt it, but to study the several structures in a number of successive sections, each extending over only a part of the radial surface.

Starting from the outside, observe the same succession of tissues as already seen in the transverse sections, viz. :-

1. Epidermis, which is often dried up and disorganized.

2. Cork (including the cork-cambium and phelloderm), with the short cells arranged in radial rows.

3. Cortical tissue, with large mucilage cells.

4. Hard bast, consisting of long fibres.

5. Soft bast, thin-walled elements with much protoplasm.

6. Cambium, a misty band ; cells not easily defined.

7. Xylem, with thick lignified walls, the vessels appearing as large tubular cavities.

8. Pith, parenchymatous; its appearance as in transverse sections.

Note the medullary rays, which appear as narrow bands of parenchyma, following the plane of section.

Examine these several tissues in detail with a high power.

1. The epidermis, when still persistent, shows the same characters as are observed in transverse sections.

2. The cork is composed of square cells arranged in radial rows, which are continuous through the cork-cambium to the phelloderm, the latter presenting much the same appearance as in transverse section.

3. The cortical tissue, which is parenchymatous throughout, also appears much the same as in transverse section.

4. The hard bast consists of long fibres, with thick walls, and very small cell-cavity: they are distributed in irregular groups among-

5. The soft bast, which is characterized by thin walls and protoplasmic contents, and is composed of -

$a$. Sieve-tubes, which are best seen in the part of the phloem nearest to the cambium : the sieve-plates are oblique, and face the radial planes. The sieve-tubes may easily be recognized in stems cut in autumn by the masses of callus which surround the siere-plates : this stains brown with chlor-zinc-iodine. 
b. Bast-parenchyma : oblong cells with cellulose walls : some contain protoplasm and starch, in greater or less quantity according to the season: others contain crystals : note the medullary rays as before.

Passing inwards the differentiation of tissues of the phloem is lost in-

6. The cambium, which appears here as a narrow band of cells with thin walls, and abundant protoplasmic contents. The form of the cambial cells is difficult to make out, but a careful observation of a good section will lead to the conclusion that the form of the cell as seen in the radial section is oblong and very narrow, with square ends. Compare the diagrammatic figure (p. 64).

7. In the xylem, excluding for the present the medullary rays, observe the following elements, all of which have lignified walls-

a. Vessels of various orders, which may be grouped as-

(i.) Spiral vessels (protoxylem) found at the central part of the xylem, next the pith : they are usually more or less disorganized, being often filled with thyloses.

(ii.) Pitted vessels, the lateral walls of which are crowded with bordered pits of essentially the same structure as those in Pinus. These vessels are usually of large cavity.

(iii.) Vessels with both pitted and reticulate marking, superposed on one another on the same lateral walls: these vessels usually occur in groups, and are of small bore.

Note in all these, but especially in (iii.), points where transverse or oblique septa have been partially or completely absorbed.

b. Fibrous cells, which occur in large groups, between the vessels : they are long, and prosenchymatous, and are intertwined, so that it is difficult to follow them through their whole length. They have little or no cell-contents, and their walls are not pitted.

c. Xylem parenchyma : oblong cells with protoplasmic contents, and starch : walls thick, lignified, and pitted : they occur in longitudinal bands: note their close contact on the one hand with medullary rays, on the other with vessels. 
Examine the medullary rays in the xylem : they are composed of oblong cells, with their longer axes horizontal, arranged like bricks in a wall: in characters they resemble xylemparenchmya.

8. The pith presents in radial section, for the most part, the same characters as those already noted in transverse section.

VI. Treat some small pieces of the wood of the Elm with a small quantity of Schulze's macerating fluid (see Appendix A) in a test tube, and warm gently till the tissues break up, and the several constituents begin to separate: then wash with water, and mount a very small quantity in water or glycerine.

Some at least of the constituents will be found lying separately, or may be detached by slight pressure on the coverslip : the true form of the wood-fibres, as greatly elongated, spindle-shaped cells, will now be seen. Note also vessels of the various types above described, and xylem-parenchyma.

VII. Cut tangential sections through the xylem of a four to five-year-old stem of Elm, treat with solution of iodine, and mount. Observe first with a low power-

I. The medullary rays of lenticular outline, easily recognized as masses of small thick-walled cells of almost circular form, filled with starch, which appears dark blue. This is best seen in stems cut in autumn. Examine the medullary rays closely in the thinnest part of the section, under the highest power, and note the small triangular intercellular spaces, which take a horizontal course along the medullary rays, and are therefore cut here transversely. In close connection with these-

2. The xylem-parenchyma, the cells of which also contain starch, and are thus easily recognized : note that cells of the parenchyma more or less completely surround-

3. The vessels, the walls of which are stained yellow, and present those characters already observed in radial sections. The interspaces are filled by-

4. Masses of xylem-fibres, which appear as before.

VIII. Cut tangential sections of the phloem of a similar stem : treat as before, and observe-

I. The form and arrangement of the medullary rays as in the xylem, but the walls of the cells are thinner, and not 
lignified : intercellular spaces may be noted here also, similar to those above described as occurring in the medullary rays of the wood. The cells contain copious protoplasm.

2. Phloem-parenchyma, the cells of which differ in their cell contents-

a. Some contain crystals.

b. Others have copious protoplasmic contents.

Both forms will be seen to have been derived by division from original elongated cells with pointed ends, since they are arranged in groups of this form. Compare the form of the cambium cell as described below (IX.).

3. Sieve-tubes answering to the description given for radial sections. The sieves are oblique, the form of the successive segments oblong. The sieves are often callous, and are easily recognized in sections stained with iodine or eosin.

4. Bast-fibres as before in radial sections.

IX. Cut tangential sections through the cambium of the stem of Elm : treat with dilute potash or "eau de javelle," and mount in glycerine. Examine first with a low power, and note that the general arrangement is similar to that already seen in tangential sections through the mature tissues, also that the form of the cells, in each part of the cambium-zone, is like or similar to the average form of the elements of the mature portion of wood or bast, which borders on it in a radial direction. Thus the cambium is differentiated into-

I. Cambium, of medullary rays, which appears to consist of roundish cells, resembling cells of the mature medullary rays in form.

2. Cambium, from which all the other tissues are derived, the cells of which have a prismatic form.

To gain a clear idea of the process of secondary thickening the actual form of the cambium-cells and their arrangement must be recognised: as stated above (p. 6), it is necessary, in order to fully realise the form of a cell as a solid body, to cut sections in three directions at right angles to one another : the cambium-cells have now been seen in transverse, radial, and tangential sections, and the results are represented diagrammatically in Fig. 7, A, B, C, which are based upon results of 
Sanio's investigations of Pinus, but the main points are the same for Dicotyledons.

Fig 7, A, shows diagrammatically four radial rows of cambium-cells $(\mathrm{I}, 2,3,4)$ ), as seen in transverse section : of these row (2) is a medullary ray. Note in row (3) the single

A

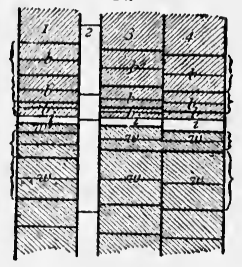

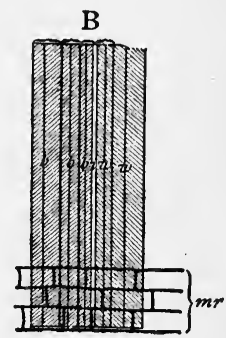

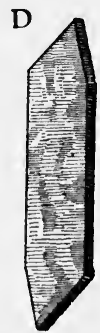

FIG. 7 .

initial cell (i), oblong in transverse section, and the shorter diameter placed radially; according to Sanio's law of cambial division there is only one such initial in each radial row : from this successive segments $(w w)$ which go to form wood have been cut off on the inner side, others $(b, b, b)$ which go to form bast on the outer side : each is represented in the diagram as 
dividing into two by a periclinal wall; this is typically the case in Pinus, but the division is not so regular in Dicotyledons In row ( 1$)$ is represented a segment $\left(w^{\prime}\right)$, recently cut off from the initial cell on the side next the wood, in which this division has not yet taken place ; in row (4) there is a similar undivided segment $\left(b^{\prime}\right)$ which, after division will go to form bast.

Fig. 7, B, shows diagrammatically the arrangement of the cells of one of these rows (3), as seen in radial section : the length of the cells is much greater than their width, and the ends are square : $i$ is, as before, the initial cell of the row : $w w$, pairs of cells formative of wood $: b, b, b$, pairs of cells formative of bast : $m . r$. is a medullary ray put in so as to show the relative position and form of the cells.

Fig. 7, C, represents the appearance of the cambium cells $i, i, i$, in tangential section : they are obliquely pointed, and their width corresponds to that shown in A: $m$. r., as before, the medullary rays.

Fig. 7, D, shows the form of a single isolated cambium-cell as a solid body, drawn to the same scale as the other figures: if such a cell be cut transversely, radially, or tangentially, it would give the appearance presented by the initial cells (i) in Figures $\mathrm{A}, \mathrm{B}$, and $\mathrm{C}$.

Taking cells of this form as a starting point, the several tissues above described are derived from them in the following way :-

(i.) Phloem-a. Sieve-tubes, by lateral distension, and conversion of the oblique walls into sieve-plates.

b. Parenchyma, by division of the cells by transverse septa.

c. Fibres (sclerenchyma), by elongation and interweaving of cells, the width of the cells at the same time being relatively reduced: the end of the cells slide past one another as the cells elongate.

(ii.) $\mathbf{X y l e m}-a$. Vessels, by lateral distension, and absorption of cell-contents, and of the oblique walls. 
b. Parenchyma, by division of the cells by transverse septa.

c. Fibres, by elongation and interweaving of the cells, while the width of the individual cells is relatively reduced.

Observe intermediate stages between cambium-cells and these several mature tissues : this may best be done in sections cut from stems in early summer.

$\mathrm{X}$. To investigate the nature of the crystals, several times observed in the parenchyma of the stem of the Elm, cut tangential sections of the phloem or of the cortical tissue, mount in water, and having found one or more crystals-

(i.) Run some iodine solution under the cover-slip : the crystal is not stained.

(ii.) Acetic acid : it is not attacked.

(iii.) Dilute nitric acid : it is more or less completely dissolved.

These reactions, coupled with what is known from the analysis of ash, point to the conclusion that these are crystals of calcium oxalate. 


\section{STEN-AQUATIC TYPE}

Note the cylindrical smooth stem of the Mares-tail (Hippuris vulgaris), bearing whorls of simple leaves. Cut the stem transversely, and note the central vascular cylinder, which is easily seen with the naked eye, and the broad band of cortex with large intercellular lacunæ.

For the microscopic work fresh material may be used : if the material has been kept in alcohol, the sections should, after being cut, be allowed to swell in water before mounting.

I. Cut transverse sections of an internode of the stem of Hippuris vulgaris: mount in glycerine and examine with a low power. Observe-

I. A well-marked epidermis with cuticle and occasional stomata. Here and there are to be seen radiating scale-hairs. These occur especially in the axils of the leaves.

2. Cortical parenchyma : a broad band consisting of thinwalled, chlorophyll-containing cells, with large intercellular spaces.

3. A well-marked bundle-sheath, with the usual characters which immediately surrounds-

4. The central vascular cylinder. This is composed of-

$a$. A basis of thirtwalled parenchyma, which forms a more or less bulky pith at the centre: towards the periphery are distributed-

$b$. Internally vessels of the xylem with lignified walls.

c. Outside these are are elements with the characters of soft bast; the sieve structure is in this case doubtful.

II. Take a terminal bud of Hippuris: remove from it the largest external leaves, and then dissect off the inner and smaller leaves with needles in a drop of water on a glass slide : 
in the centre of the bud will be found the elongated conical and colourless apical cone. Cover with a cover-slip, and examine it under a low power: the smooth cylindrical apical cone will be well seen, the inner tissues of it being marked by a reticulum of dark lines : these are the intercellular spaces filled with air.

Note especially the leaves, which appear as rounded outgrowths laterally on the axis: the larger ones are seated lower down the axis, and they are successively smaller as the abex is approached.

III. Cut median longitudinal sections of the apical bud of Hippuris, so as to pass through the elongated apical cone; treat with potash, or with "eau de javelle," and mount in dilute glycerine. Examine first with a low power, and observe-

I. The axis, which is wide below, but tapers upwards to the rather elongated apical cone (punctum vegetationis). The axis is composed of the several tissues already noticed. Note especially in the lower part of the section-

$a$. The rectangular intercellular spaces, divided transversely by diaphragms at the nodes.

$b$. The axile vascular cylinder, which may be followed far up into the apical cone, and which gives out lateral branches to the leaves.

2. The reaves, diminishing in size towards the apex. Note the scale-hairs about the bases of the leaves.

Put on a high power, and examine the apical cone. Note-

I. The dermatogen, a continuous layer of cells, which covers the apical cone externally. Trace it backwards from the apex : it will be seen to give rise to the epidermis.

2. The periblem, consisting of 4-5 layers of cells, which may be traced backwards, and be thus shown to give rise to the cortex.

3. A central cylinder of plerome, which is continous with, and gives rise to, the vascular cylinder (compare the diagram Fig. 3, p. 48).

Note that the leaves originate from the outgrowth of the 
dermatogen and periblem, the plerome taking no part in their formation. Also that the vascular system of the stem is already developed at a higher point on the axis than that of any of the leaves. We have thus an instance of cauline vascular bundles, that is such as are proper to the stem, as distinguished from common vascular bundles, which terminate at their upper extremities in the leaves. 


\section{SIEVE-TUBES}

\section{i. Cucurbita}

Though the sieve-tubes of the Sunflower are fairly large, the soft bast does not occur in large masses. In the Vegetable Marrow, however, the sieve-tubes are of extraordinary size, and occur in large numbers : this stem is thus excellently fitted for the study of the sieve-tubes of the type usually found in herbaceous stems.

The material should be hardened in alcohol.

I. Cut transverse sections of the stem of the Vegetable Marrow, stain with eosin, and mount in water or glycerine.

The general arrangement of tissues in this stem differs in several important points from that in the Sunflower: the structure of the individual bundle is also abnormal, being of the bi-collateral type.

In the soft bast, which resembles that of Helianthus but has larger constituents, observe--

(i.) The transverse, circular, punctate sieve-plates, having the same appearance as in Helianthus, and easily recognised by their contents being stained with eosin.

(ii.) The companion-cells, appearing as though cut off from the side of a sieve-tube by a curved wall.

(iii.) Cambiform cells.

Treat some sections with chlor-zinc-iodine : all the walls of the soft bast turn blue (cellulose), but the sieve-plates appear yellow or brown.

II. Cut longitudinal sections through the soft bast : either radial or tangential sections will do. Mount some in iodine solution. The transverse sieve-plates will be brought into prominence by the deep yellowish brown staining of the mass of substance, which surrounds them : this may consist of- 
a. A callus-mass which surrounds, and often completely invests the sieve-plate: the size of the callus-mass is variable according to season, age, \&c., being greatest in autumn, and in old sieve-tubes.

b. Protoplasm, which is usually collected in close contact with the sieve-plate (or with the callus if present), and more especially on its upper side.

Note, i. the oblong form of the segments composing the sieve-tubes.

ii. The companion-cells, short with granular protoplasm, and nucleus.

iii. Cambiform cells of similar form to the segments of the sieve-tubes.

Other sections should be stained with eosin, then washed and mounted in glycerine. The sieve-tubes will be readily seen, as their contents will be stained deeply.

III. Treat some fresh sections with iodine, then dry off the superfluous fluid with blotting-paper, and mount in a single drop of strong sulphuric acid. The cellulose walls and callus will swell ; the protoplasm will contract. Look carefully over the protoplasmic contents of the sieve-tubes for the points where sieve-plates have been; here it will be found that fine strings of protoplasm, which passed through the sieve-plate, connect the protoplasmic masses on opposite sides of the sieve with one another. By this reaction the continuity of protoplasm through the sieve is demonstrated.

It will be noted that the sieve-tubes, of Cucurbita closely resemble those of Helianthus, the sieve-plates being transverse and simple. This is the usual type of sieve-tube to be found in primary phloem, and generally in herbaceous stems of Angiosperms. In the secondary phloem of ligneous stems a more complicated type of sieve-tube is frequently found. This will be studied now in the stem of the Lime.

\section{ii. Tilia (Lime).}

I. Cut radial sections of the phloem of a stem of Lime more than three years old. Stain with eosin, wash, and mount in 
glycerine; examine them with a high power for sieve-tubes. The general arrangement of the phloem is similar to that in the Elm. The sieves, which will appear stained pink, occur on oblique walls facing the radial plane, and are therefore here seen in surface view. Note that they have a similar appearance to those above described, but here three or more sieveplates occur on each oblique wall.

II. Cut tangential sections of the same; stain, and mount as before. The oblique walls are here cut longitudinally; the sieve-plates are often callous, especially in autumn.

Note the form of the segments of sieve-tubes; it is fundamentally the same as that of the cambium cell as seen in tangential section (compare Fig. 7, C, D). 


\section{LATICIFEROUS TISSUES}

The material for the study of these tissues should be prepared by treatment with alcohol to coagulate the latex. Care should be taken to place the material in alcohol directly it is cut, or at least the cut surfaces should be wetted with alcohol so as to check the flow of latex from them. If the latex be allowed to escape, the laticiferous tissues are emptied, and are then much less easily traced than when they are full. The best method is perhaps to preserve the whole plant without injury in alcohol, in which case the latex will not be lost at all.

Draw from a piece of the fresh stem of Euphorbia a drop of latex upon a slide : examine it quickly under the microscope, and observe the fluid is at first almost uniformly milky, but that in a short time a coagulum separates in irregular masses from the more transparent fluid. The coagulation is effected more completely and rapidly on addition of a drop of alcohol.

\section{i. Laticiferous Vessels.}

I. Cut tangential sections from the phloem of the root of the Dandelion (Taraxacum officinale), mount in potash and glycerine, and warm; examine under a low power.

The main constituents of the tissues are parenchymatous cells, with thin walls (phloem-parenchyma) : sieve-tubes are to be met with here and there. The whole mass of tissue is permeated by a ramifying and profusely anastomosing network of laticiferous vessels. The communication of these tubes with one another is demonstrated by the continuity of their coagulated contents (1atex), which appear brown and granular.

The course of the vessels is mainly longitudinal, while 
lateral, horizontal branches frequently connect the parallel tubes.

With a high power make out more accurately the course of a group of the vessels.

II. Cut transverse sections of the same ; mount in glycerine, and examine with a low power.

The laticiferous vessels appear circular in transverse section, and have brown contents : they are distributed in groups, which form more or less regular concentric rings round the central xylem. They may be recognized still more distinctly in sections stained with alkannin, or with potassium bichromate.

Note in these sections the presence of sphere-crystals of inulin : in the former section they will have been dissolved by the treatment with potash. Observe that they are formed quite irrespective of the cell-walls, which are often included in them.

\section{ii. Laticiferous Cells.}

I. Cut tangential sections of the cortex of Euphorbia splendens (other species will do) just outside the vascular ring, and mount in water, or dilute glycerine : or stain with alkannin, and mount in glycerine.

Examine with a low power.

Running through the cortical parenchyma will be seen long tubes, with thick cellulose walls and granular contents. These are the laticiferous cells, which differ from the preceding in being developed, not by fusion of originally distinct cells, but by continued apical growth of single cells.

Note cases of branching of these cells.

Included in the granular contents are starch-grains of pecular dumb-bell form.

Treat sections with iodine solution, and observe the effect on these bodies.

II. Cut transverse sections of the same stem, and note the distribution of the laticiferous cells ; they may be recognized by their walls, which are thicker than those of the surrounding tissues, and appear circular in section. 
III. Separate the whole cortex from a piece of the stem; boil it in potash for about five minutes, and tease out the long laticiferous cells with needles; mount and observe with a low power. They appear as long cylindrical tubes, with thick walls. Observe occasional branching. They are usually broken at the ends, the length of the tubes being greater than that of the parts teased out. 


\section{LEAF}

\section{A.-PETIOLE}

Observe that the mature leaf of the Sunflower consists of an upper, flat, expanded portion - the lamina, and a lower, narrow stalk-the petiole, by which it is inserted on the stem. Note the channelled upper surface of the petiole, and the broad insertion on the stem : in the angle between the petiole and the stem may usually be observed an axillary bud, or shoot.

I. Cut transverse sections of the petiole, and mount in glycerine. The details of structure resemble in many respects those of the young stem, from which the petiole differs in the following points :-

I. The general outline of the section is semilunar, the concave being the superior, while the convex is the inferior surface : thus the petiole is dorsi-ventral whilst the stem is polysymmetrical. This property extends also to the arrangement of the vascular bundles, of which the xylem is as a rule directed towards the upper surface of the petiole.

2. The presence of numerous stomata ; beneath each stoma the collenchyma is replaced by chlorophyll, containing parenchyma with intercellular spaces. Note beneath each stoma an enlarged intercellular space-the air-chamber.

3. The number and arrangement of the vascular bundles. In the petiole there are three main bundles, besides several smaller ones.

4. The absence of interfascicular cambium: the larger bundles are for a short time at least, open bundles, having an active cambium, while the smaller ones are closed, having no secondary thickening by cambium. 
5. No general bundle-sheath is present, though each bundle is surrounded by a layer of colourless cells, without intercellular spaces, which may be regarded as representing the bundlesheath.

\section{B. - LAMINA.}

I. Take a piece of the lamina of the leaf of the Sunflower, including the apex : it is important that it should be previously bleached by treatment with alcohol : warm it gently in a mixture of dilute glycerine and potash, and mount in glycerine : examine with a low power, and observe-

I. The midrib, with its strongly marked vascular bundle, running up to the apex of the leaf, where it terminates abruptly in a mass of glandular tissue.

2. Lateral branch-bundles-the ribs or nerves-passing off from it, and forming a network by frequent anastomoses, while some of them run up into and terminate in the serrate projections of the margin of the lamina.

3. Smaller branch-bundles sometimes showing blind endings in the parenchyma which fills the meshes of the network.

II. Cut off a small square piece of the lamina of a leaf of Helianthus, including one of the main ribs or nerves, and embed in paraffin (see directions, p. 9), so that the rib shall be perpendicular. Cut transverse sections, and mount in glycerine.

Good sections may be obtained even from fresh material by holding the piece of lamina between slices of carrot, or pith ; or by folding the whole lamina repeatedly, and cutting sections from the whole mass.

Note with a low power-

I. The general outline of the section, which is irregular and undulating, though it is in the main of uniform breadth. At the point corresponding to the main nerve the section widens out, the nerve appearing semilunar, as in the petiole. The convex side is the inferior (adaxial or dorsal), and the concave the superior (abaxial or ventral) surface.

2. That the margins of the sections (i.e. the superior and 
inferior surfaces of the leaf) are studded with projecting multicellular hairs.

3. That the arrangement of the tissues in the large nerve resembles that in the petiole, though less complicated. Thus it often has but one large central bundle, with smaller lateral ones. The position of the xylem and phloem relatively to the whole leaf corresponds to that in the petiole, i.e. xylem towards the upper surface, phloem towards the lower

4. Smaller veins, with correspondingly reduced vascular bundles, are found scattered through the thinner part of the section.

Next examine the thinner part of the section with a high power, and, starting the study of them from the upper surface, note successively the following tissues :-

I. Upper layer of epidermis, continuous with that covering the nerve : it is a single layer of cells, covered externally by cuticle. The epidermis bears numerous multicellular hairs, already noted in connection with apical bud. Stomata occur in considerable numbers. Beneath this layer lie-

2. Thin-walled, oblong cells, with copious protoplasm, and chlorophyll-grains; these cells are arranged with the longer axis perpendicular to the outer surface, and form two layers; this tissue, from the form and arrangement of the cells, is called the palisade-parenchyma ; below it is-

3. A mass of parenchymatous cells of irregular form, with large intercellular spaces; in general characters they resemble (2): this is the spongy parenchyma. (2) and (3) are together included under the general term mesophyll. Carefully examine the chlorophyll-grains in this tissue: their form, mode of multiplication by dividing, and their position in the protoplasm.

4. Embedded between (2) and (3) are numerous smaller vascular bundles (nerves) of various size, often reduced to a single pitted or spiral tracheid, surrounded by a colourless sheath of parenchyma similar to those in the petiole. The course of the bundles is diverse, since they form the reticulate system of veins : they may thus be seen in the sections to have been cut transversely, obliquely, or longitudinally,

5. A second layer of epidermis bounds the section on the 
lower side ; it has the same characters as the upper layer, but stomata are more frequent. Note the two small guard-cells of each stoma, and below them the large air-chamber.

Hairs as before seen on the upper surface. Note the mucilaginous walls of these hairs.

Included Starch-grains.-These may be observed in the cells of the mesophyll of any leaf which has been exposed to the light, under conditions suitable for assimilation : but they may be seen with special ease in Fern prothalli which have been thus exposed to bright sunlight for some hours, and then bleached in alcohol.

Mount such a bleached prothallus in water, or in weak glycerine : examine under a high power, and note the bleached chlorophyll-corpuscles, or chloroplasts, in which highly refractive granules may often be seen.

$a$. Stain with iodine solution: the chloroplasts will assume a dusky bluish colour, the blue tint being more or less distinctly localized in the highly refractive granules (starchgrains) above noted.

b. The presence of the included starch-grains may be more clearly demonstrated by causing them to swell : this may be effected in various ways.

i. Mount in glycerine and iodine, and warm: the high temperature will swell the starch, which will at the same time stain with the iodine.

ii. Treat with potash, and, after carefully washing out the alkali, stain with iodine.

iii. The best method is, however, to treat the bleached specimens for some hours with a solution of iodine in chloral hydrate : the included starch-grains are simultaneously swollen and stained blue.

III. Since the structure of the leaf of the Sunflower is not a universal type, it will be well to study also the structure of some other leaves; for instance, the evergreen leaves of the Holly (Ilex aquifolium) : note first the short, almost cylindrical petiole, and the leathery lamina with cartilaginous margin and spines.

Cut transverse sections of the petiole of the Holly : mount 
in glycerine, and note in the slightly oval section under a low power the epidermis, and broad band of cortex : also the large, semilunar vascular bundle which occupies a central position, and has its xylem disposed at the concave side, nearer to the upper surface, and its phloem disposed at the convex side, which is directed towards the lower surface of the petiole. One or two small outlying bundles are also to be seen.

Note that there is a cambium-layer, which shows signs of activity, between the xylem and phloem of the large bundle.

IV. Transverse sections of the lamina of the Holly may be prepared as above directed for the Sunflower, and be mounted in dilute glycerine, others in chlor-zinc-iodine. Starting from the upper surface of the thin lateral portion of the lamina, observe successively the following tissues :-

I. Epidermis, a single even layer of cells, with thick walls, and colourless protoplasmic contents; no hairs or stomata are to be seen; the lateral walls are pitted: note in sections, treated with chlor-zinc-iodine that the outer wall, which is thicker than the rest, is differentiated into-

$a$. Cuticle, a continuous, well-defined and highly-refractive layer, covering the whole epidermis externally: this stains yellow with chlor-zinc-iodine.

$b$. Cuticularized layers, of granular appearance, and stained a deeper colour than $(a)$ with chlor-zinc-iodine : they are intermediate in properties between cuticle and true cellulose.

c. The cellulose-1ayer, which abuts on the cavities of the cells; this stains blue with chlor-zinc-iodine.

2. Hypoderma, a strengthening tissue, which is immediately below the epidermis, and consists of a single layer of cells : at the midrib it may widen into two layers : the walls are pitted, and stain bluish with chlor-zinc-iodine.

3. The palisade-parenchyma, composed of thin-walled, oblong, closely-packed cells, with their longer axes perpendicular to the surface of the leaf; the cells are somewhat irregularly arranged in three layers; observe nuclei and chlorophyll-grains; here and there are cells (idioblasts) with but little protoplasm, in which is inclosed a large crystal. Passing towards the lower surface of the leaf, this tissue merges gradually into- 
4. The spongy parenchyma, the cells of which resemble those of (3) in general characters ; but their shape is various, and large intercellular spaces occur. Idioblasts with crystals are scattered here and there. Embedded between (3) and (4) are-

5. Vascular bundles of various size; the direction in which these run is not uniform, as is naturally the case, since the venation is reticulate: the positions of xylem and phloem with regard to the whole leaf are the same as in the Sunflower : the bundles are surrounded by a continuous colourless sheath of cells (the bundle-sheath or endodermis) without intercellular spaces. At the lower limit of the section lies-

6. The lower epidermis, which resembles ( $I$ ) in general character; but differs in having numerous stomata. Note the appearance presented where the two guard-cells of a stoma have been cut transversely, and observe carefully -

a. The form and position of the two guard-cells

b. The cavity or intercellular space between them (the pore): this leads into-

c. The large, intercellular space (air-cavity) in the tissue beneath the stoma.

$d$. In the sections stained with chlor-zinc-iodine or with fuchsin, note the continuity of the cuticle round the guard-cells, into the pore of the stoma.

V. Cut tangential sections from the upper and under surfaces of the leaf of the Holly, and mount them separately in glycerine with the external surface in both cases uppermost.

The cells of the upper epidermis are tabular, with irregular outline; the surface has a granular appearance, explained by the granular cuticularized layers observed in transverse sections; the lateral walls are pitted, the contents colourless, and there are no stomata.

The cells of the lower epidermis are similar to the above; but stomata are numerous; they have no definite arrangement. Note the two sausage-shaped nucleated guard-cells, inclosing the pore; they contain chlorophyll, and are slightly depressed below the general surface.

N.B.-The Cherry Laurel (Prunus Lauro-Cerasus) may be 
used instead of the Holly, the structure being very similar, with the exception that the hypoderma and marginal sclerenchyma are absent.

Water stomata and marginal glands. Examine leaves of the Fuchsia, and observe that the tips of the leaves and the marginal teeth are terminated by slightly swollen, opaque masses of tissues : these are the marginal glands, and drops of water exuded at those points may be seen in the morning, or on plants, kept during the day in moist atmosphere at a high temperature.

Cut off a piece of the margin of a leaf and examine it under a low power : a large stoma (water-stoma) may be recognised at the apex of each tooth : below it is a pad of opaque tissue (the gland) to which a vascular bundle runs up, and in which it ends.

From material which has been hardened in alcohol, cut off with a razor the extreme tips of several of these teeth : mount with the outer surface uppermost: on examining these, the extreme apex, with the water-stoma will be seen in surface view. Note the size of the stoma, and that the pore is widely expanded.

Cut longitudinal sections so as to follow the vascular bundle up to the marginal gland, and to traverse the gland in a median plane. Selecting a section which is really median, note, in the part of it further from the tip, the epidermis, mesophyll; and the vascular bundle surrounded by a parenchymatous sheath following these up towards the tip, observe the epidermis continuous, with the exception of the widely-gaping water-stoma at the extreme apex : the form of the guard-cells as seen in section is simpler than in ordinary stomata. The vascular bundle widens out towards the tip, and the vascular elements terminate in the pad of closely-packed parenchyma of the gland (epithema): there is a large cavity below the water-stoma.

Special attention should be paid to the chalk-glands of the Saxifragace (e.g. Saxifraga crustata) in which the structure of the marginal gland is extremely well seen, while the accretions of chalk deposited by the evaporating water are easily re- 
cognised with the naked eye. $S$. oppositifolia or $S$. umbrosa (London Pride) will afford excellent material for the study of these glands. Compare also various Crassulacea.

Treat some of the accretions with acetic acid, and note their solution with evolution of bubbles of $\mathrm{CO}_{2}$.

\section{Leaf-scars and Fall of the Leaf.}

On twigs of the Elm cut in winter, note the buds, both terminal and lateral, and below each an oval scar which indicates the surface of separation of a leaf when it fell in autumn: the surface of the scar is brown, and the slightly projecting dots upon it are the broken ends of the vascular bundles which ran out from the stem into the petiole.

Cut longitudinal sections so as to pass through a scar, and select for observation one of those which has followed up the course of one of the vascular bundles to the surface of the scar: mount in glycerine, and observe below the scar the tissues as above described for the stem (p. 6o, \&c.). At the level of the scar the following structural points are to be noted :-

I. The rough and irregular outer limit of the tissues, with dried up remains of cells often projecting beyond the general surface.

2. The dark brown band of cork, without intercellular spaces, which covers the scar, and protects the internal tissues.

3. The projecting end of the vascular bundle : mark especially how the corky formation is continuous into the tissues of the bundle, evidently having there arisen from the division of cells of the parenchyma of the bundle : also note that the vessels of the xylem are laterally compressed by the adjoining cells, and their broken ends are thus closed at the surface of the scar.

Sections should also be made from material taken in autumn just at the period of the fall of the leaf, so as to see the changes in the tissues at the base of the petiole which precede the rupture. These may be particularly well seen in the 
Horse-Chestnut. In longitudinal sections through the base of a leaf, which is almost ready to fall, note that the brown band of cork on the stem stops short at the base of the leaf, and that close to the point where it stops is the starting-point for the similar corky layer which runs directly across the base of the petiole, cutting the vascular bundles at right angles, and continuous through them.

Examine such a section under a high power, and note-

I. The radial rows of cork-cells, with the phellogen on the side next the stem.

2. A band of cells outside the cork, which are of yellowish colour, and the individual cells are rounded, having large intercellular spaces between them; thus this layer, which has been styled the abciss layer, is easily ruptured.

3. The cells of the tissues of the leaf are almost empty with the exception of crystals : those of the stem, below the layer of cork, have plentiful protoplasm, and starch.

Comparisons may also be made of similar material of the Poplar, Ash, or Walnut, which are well adapted for illustrating the process of defoliation. 


\section{ROOT}

\section{i. Herbaceous Type.}

Observations on the structure of the root may be made on the seedling of Helianthus, but as even the tap-root of this plant when young is only of small size, it will be found more convenient, and as a rule more successful, to study the structure of the root in the Scarlet Runner, or the Garden Pea.

\section{Observations with the Naked Eye.}

Germinate seeds of the Scarlet Runner or of the Pea, in wet sawdust, or pure vegetable mould, till the primary root has attained a length of six to eight inches.

Note with the naked eye-

I. The seed, from which the testa can easily be removed, disclosing-

2. The two fleshy cotyledons : between these-

3. The plumule, which develops early as a stem, bearing foliage leaves.

4. Below the cotyledons a short hypocotyledonary stem, not clearly marked off externally, except by colour, from-

5. The primary root, on the upper part of which are-

6. Numerous secondary or lateral roots. These are formed in acropetal order, and are arranged in regular longitudinal rows, usually four in number. On the youngest part of the primary root no lateral roots are to be seen.

Observe that particles of the sawdust, \&c., adhere to the older parts of the roots, while the younger apical parts come out of the soil quite clean: this is due to the fact that root- 
hairs are present on the older parts, but not on the youngest parts close to the apex.

\section{Microscopic Observations.}

Harden the roots in alcohol for two or three days or more. In order to cut the sections it will be necessary to hold the roots between pieces of pith, or, better, to embed in paraffin.

I. Cut transverse sections of the primary root at a point nearer the apex than the youngest lateral roots, i.e. about two inches from the end : clear the sections with weak potash, or "eau de javelle," and mount in glycerine.

Observe the following tissues :-

1. At the centre of the circular section is a mass of parenchymatous pith. At the periphery of this are-

2. Radiating groups of elements of the primary xylem, which are the most strongly marked tissues of the young root. The number of these is most often four, but it is subject to variation, and may be as high as six, while in the Pea it may frequently be only three : the same is the case with the groups of phloem, which alternate with these. The groups of xylem have dark lignified walls (test with chlor-zinc-iodine or aniline sulphate), and resemble the primary xylem of the stem. Note fresh elements in course of formation at their central limit : the development is thus centripetal. Alternating with these may be seen-

3. Four groups of primary phloem, which are not as yet very well marked. These several groups of elements are separated laterally from one another by bands of parenchyma. At the periphery of the central cylinder thus built up is-

4. The pericycle, consisting of thin-walled cells arranged in an undulating band, which is a single layer of cells in thickness peripherally to the phloem, but opposite the xylem it consists of two to three layers of cells.

5. Immediately outside this is the bundle-sheath, or endodermis, consisting of a single layer of cells, having the characteristic dark dot on their radial walls. Then follows- 
6. The parenchymatous cortex, a thick band of tissue, with intercellular spaces, and-

7. The piliferous layer, a single superficial layer, not well marked. Single cells of this layer will be seen to have grown out perpendicularly to the surface as root-hairs, which as a rule are not branched, and are of cylindrical form, with thin cell-walls : particles of soil may be found attached to many of them.

II. Cut sections successively at older points in the same root, treat as before, and observe the mode of origin of the lateral roots, noting more especially the following facts :-

a. The lateral roots arise opposite the groups of primary xylem : this explains their arrangement in four rows as above observed with the naked eye, since the number of groups of primary xylem is usually four.

$b$. The pericycle, endodermis, and a small portion of the cortex, all take part in their formation.

c. In the older lateral roots it may be seen that their vascular system is continuous with that of the main root.

d. The lateral roots, increasing in length, burst through the outer layers of cortex and the piliferous layer: since they originate from deeply seated tissues and rupture the more superficial ones, they are said to be of endogenous origin.

III. Cut transverse sections of the root, six inches or more from the apex, avoiding the lateral roots : take care also to avoid the thick base of the hypocotyledonary stem, which shows a structure characteristic neither of the stem nor of the root: treat as before.

The general arrangement of tissues is the same as has been above described, though there has been increase in bulk, and the xylem and phloem, being now more fully developed, are more easily recognized. Observe especially that the parenchyma, lying centrally to the phloem, has begun to divide repeatedly by tangential walls: in fact, four cambium bands are thus formed, from which is derived the secondary thickening of the root.

IV. Cut transverse sections of an old root of the Scarlet- 
Runner, taking care here also to avoid the base of the hypocotyledonary stem, and treat as before. Observe-

I. Centrally a parenchymatous pith.

2. The primary xylem groups, usually four in number, retain their original position, relatively to the pith.

3. Four large wedges of secondary xylem have originated internally from the four cambium zones. These are separated from one another laterally by-

4. Four broad parenchymatous rays, which lie on the same radii as the primary xylem. Outside the xylem is-

5. The cambium, having similar characters to that of the stem, and giving rise peripherally to-

6. Secondary phloem. Note if possible-

7. The four groups of primary phloem now separated from the primary xylem, but still on radii alternating with the latter. The section is bounded by-

8. A narrow band of cork with a cork-cambium at its inner limit : this originates from the pericycle, and this point should be ascertained by cutting sections successive ly at older points. It is to be noted that the endodermis, cortex, and piliferous layer, are absent in these sections, these being thrown off on the formation of the layer of cork from the pericycle beneath them, which thus cuts them off from a physiological connection with the central cylinder. (Compare Fig. 8, p. 9r.)

\section{ii. Ligneous Type.}

For comparison with the root of Phaseolus, which is characteristic rather of that of herbaceous plants, observations should also be made on the roots of some woody plant. The root of the Elm has its cortex densely crowded with mucilage-cells, and in other respects is not very suitable for work: the HorseChestnut (Assculus Hippocastamum) is a better type of a root of an arboreous plant. Dig up roots of this plant carefully so as not to break off the finer fibrils : wash them gently from the soil, and observe the reddish-brown colour of the thicker and more mature parts, while the ends of the thinner fibrils are pale-coloured. Note also on passing from young portions to 
the older that an outer coating of effete brown tissue is thrown off, and thereby the bulk of the root may be apparently diminished; this is the cortex, which here, as in other cases, is only a temporary covering of the younger portion of the root. The soil will be found in this case also adherent to the fibrils, thus indicating the presence of root-hairs at some distance from the apex, but not at the extreme apex, nor on the older portion of the root where the cortex has been thrown off.

V. Select a strong young fibril : embed a short piece of it, taken about half-way between the apex and the beginning of the red colouring: cut transverse sections, and clear with potash, or "eau de javelle" : mount in glycerine, and examine under a high power : observe-

I. The piliferous layer, a rather irregular layer with slightly thickened outer wall: single cells may have developed as root-hairs:

2. The exodermis showing a thickening of the radial walls not unlike that common in endodermis : this thickening is continued all round the anticlinal walls, and is not uncommon in roots of woody plants.

3. A broad band of ordinary cortex, with large intercellular spaces: the walls are more thickened nearer the central cylinder, and are pitted.

4. The endodermis or bundle-sheath, with the characteristic dot on the radial walls: within this is the central cylinder, composed of-

5. A peripheral layer of the pericycle : occasional periclinal divisions may be seen in the cells of this layer.

6. The groups of primary xylem-usually four in numberwhich will be still separate from one another, or, according to the age of the root, may be united at the centre: note the details of appearance of this primary xylem, so as to be able to recognize it in the older roots.

7. The groups of primary phloem, equalling in number those of the xylem : this tissue is not well marked.

8. Narrow bands of parenchyma separating the successive groups of phloem and xylem : subsequently these cells are the seat of origin of the cambium. 
VI. Cut similar transverse sections from a part of a root which has recently turned brown, and has produced lateral roots: comparing with the above sections, note the following changes :-

I. The piliferous layer and cortex have turned brown, and will often be separated from the central cylinder by rupture of the radial walls of the endodermis.

2. The cells of the pericycle will be found undergoing periclinal divisions, which ultimately result in the formation of a layer of cork.

3. The groups of primary xylem as before, but united at the centre so as to form a star-shaped mass, with no central pith: the groups of primary phloem alternating with those of primary xylem, as before.

4. Divisions may be seen in the cells intervening between the xylem and phloem, which indicate the position of the cambium.

5. If lateral roots be present, they originate from the pericycle.

VII. Cut transverse sections of still older portions of the root, about $\frac{1}{16}$ of an inch or more in diameter : treat with chlorzinc-iodine, which brings the starchy medullary rays into prominence. Now examine carefully the central mass of tissue, and recognize the primary xylem in its original position : the further arrangement of the secondary tissues is as in the Scarlet-Runner, but note these points of difference in the root as a whole :-

I. There is no pith.

2. The primary medullary rays opposite the groups of primary xylem are relatively small and inconspicuous.

3. The xylem is marked off into annual rings, as in the secondary xylem of the stem.

It is further to be observed that the cortex has completely disappeared, and the peripheral layer of cork is the product of the pericycle. Numerous sclerenchyma-fibres are to be found scattered through the secondary phloem.

The diagrammatic Fig. Io will illustrate the mutual arrangement of the primary and secondary tissues of the root. 


\section{Apex of the Root.}

Type I.-Using the fruit of the Sunflower in the dry state, as it may be bought in seedsmen's shops, cut thin median longitudinal sections of the apex of the radicle of the straight

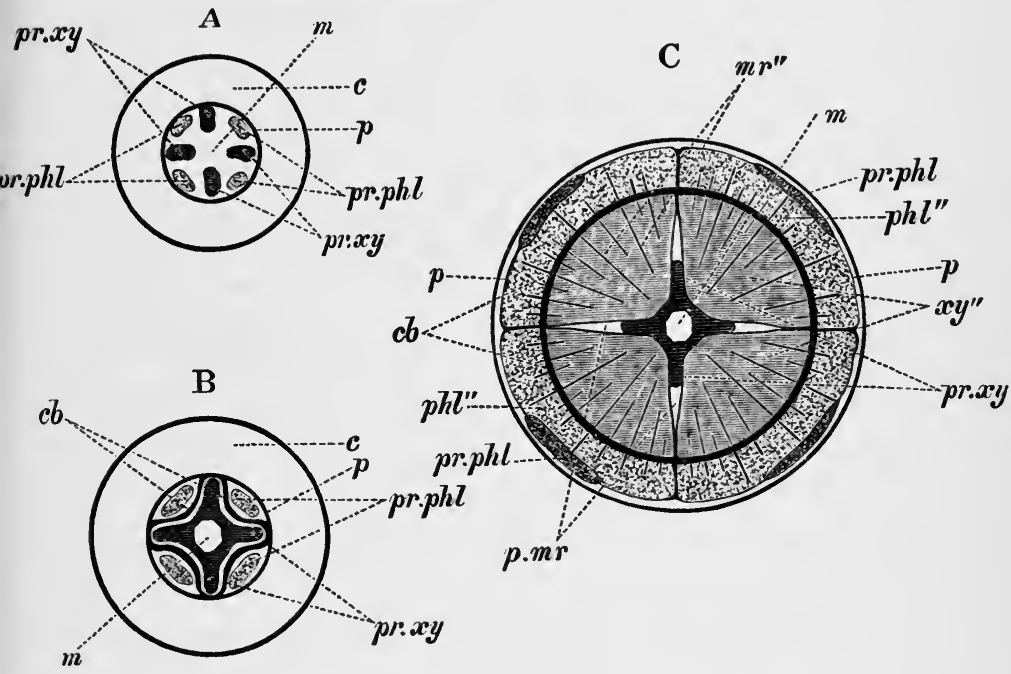

F1G. 8.-A. Diagram illustrating the disposition of tissues in the young root of a Dicotyledon, before the cambial divisions begin.

B. The same at a later stage, when the cambium may be clearly recognized.

C. Diagram of arrangement of tissues in the root, after secondary thickening has been in progress for a considerable time: in such a root the cortex, which is seen as a broad band $(c)$ in Figs. A, B, has been completely thrown off, and the section is now limited by tissue $(p)$ derived from the deeper-lying pericycle.

$c=$ cortex $; p=$ pericycle ; $p r . x y=$ protoxylem ; $p r . p h l=$ protophloem ; $m=$ pith; $c b=$ cambium; $x y^{\prime \prime}=$ secondary xylem; $p h l^{\prime \prime}=$ secondary phloein; $p . m r=$ primary medullary rays $; m^{\prime \prime}=$ secondary nedullary rays.

embryo. The arrangement of the meristem at the apex of the radicle of the embryo is similar to that of the apex of the growing root, and the former is chosen in this case as it is much easier to make preparations from it than from the growing 
root. The sections are of little use unless they are accurately median.

Treat the sections with potash for ten minutes or more; or better, treat with "eau de javelle" as directed on p. 32 : wash with water, and mount in glycerine : examine with a low power, and observe that-

I. The mass of tissue is composed of thin-walled cells, arranged regularly in longitudinal rows.

2. That these rows of cells converge towards a point at some distance below the external apex of the root. This is the centre of construction of the punctum vegetationis.

3. Note also that the vascular cylinder of the root may be traced upwards to the apex as the plerome cylinder, with a dome-like ending.

4. The cortex continues upwards as the periblem: it may be distinguished by its darker appearance owing to the intercellular spaces.

5. The superficial piliferous layer, which curves inwards under-

6. The tissue of the root-cap.

The general scheme of arrangement of the apical meristem of a root is indicated in the diagram, Fig. 11 : but in comparing the sections with the diagram it must be remembered that the figure represents an ideal Dicotyledonous type, and it must not be attempted to trace a correspondence of minute detail of the sections with the diagram : thus in the diagram there is a sharp limit $\mathrm{K} \mathrm{K}$, between the root-cap and the body of the root, whereas in the Sunflower, as will be presently shown, the rootcap and piliferous layer have a common origin.

Examine with a high power : and observe that-

I. At some distance from the apex a definite piliferous layer covers the root externally. Follow this towards the apex : at some short distance from it this single layer splits into two : the inner is the dermatogen, formative of the piliferous layer: the outer is the outermost layer of the calyptra, or root-cap. Following the dermatogen further inwards, it will be seen to split again several times in succession: the dermatogen may be traced as a continuous layer covering the inner tissues. The 
layers thus thrown off externally from the dermatogen form collectively the root-cap, or calyptra. We have in this case a common formative layer for root-cap and piliferous layer.

2. Between the procambium and the piliferous layer lies a broad band of formative tissue of the cortex, or periblem : follow this to the punctum vegetationis: it is also a distinct continuous band, though reduced to a single layer of cells at the apex.

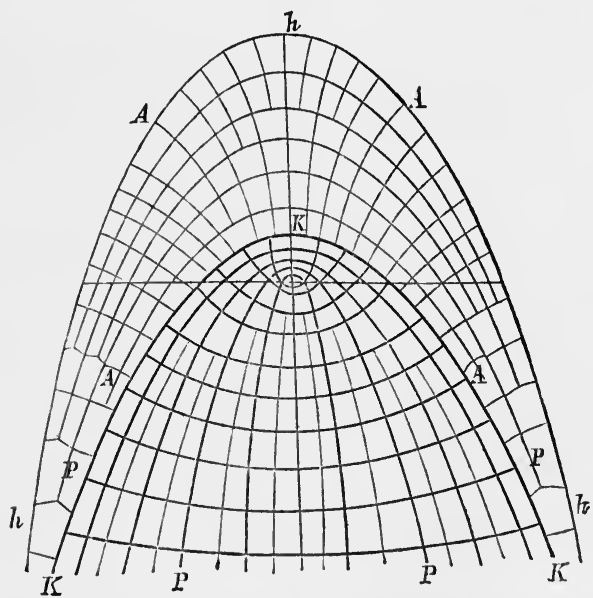

FIG. 9.-Diagram illustrating the arrangement of a meristem which may be found at the apex of a root of a Dicotyledon. $h h h$, the root-cap, limited internally by the line $\mathrm{K} \mathrm{K} \mathrm{K}$, which represents the outer limiting wall of the dermatogen. In the root-cap the letters A A indicate anticlinals; $P$ P, the periclinal curves. (After Sachs.)

3. The plerome, or central procambium cylinder, may also be traced as distinct up to the apical point.

This type of arrangement of tissues of the meristem may then be expressed thus :

Calyptrogen a single layer of cells, i.e. piliferous layer and Dermatogen $\}$ root-cap have a common origin.

Periblem, distinct from the rest.

Plerome, distinct. 
To this type belong most of the Dicotyledons. The work may be equally well done on Linum usitatissimum or Polygonum Fagopyrum.

Type II.-Prepare median longitudinal sections of the apex of the radicle of Phaseolus multiflorus (the Scarlet-Runner), or perhaps better, from the Broad-Bean : in either case the dry seed may be used : treat as the above. Examine with a low power and make out-

I. Calyptra (root-cap).

2. Piliferous layer.

3. Periblem.

4. Plerome, forming the procambium and pith.

But here all the different tissue-systems will be found to originate from a general meristem, the original formative tissue of none of them being distinct from that of the others. This type may be expressed, shortly, thus :-

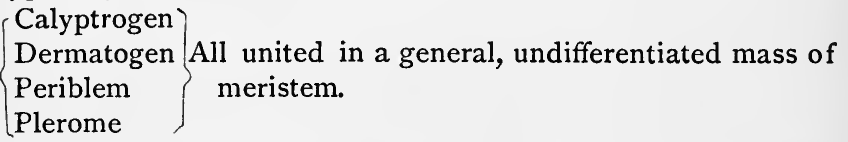
Calyptrogen

Dermatogen All united in a general, undifferentiated mass of $\left.\begin{array}{l}\text { Periblem } \\ \text { Plerome }\end{array}\right\}$ meristem.

As alternative plants of the same type, may be named Cucurbita and Pisum. 


\section{VEGETATIVE ORGANS.-(B) MONOCOTYLEDONS}

\section{i. STEM-HERBACEOUS TYPE}

Fruits of Maize should be sown in pans, in spring, and kept in a cool house or frame : they may be bedded out in early summer, and the plants will be suitable for the observations detailed below in August. Fresh material may be used, but stems preserved in alcohol are preferable.

I. Cut transverse sections from about the middle of an internode of a well-grown stem of Zea Mais : mount in water, or glycerine. The sections should be cut from the upper part of one of the lower internodes, otherwise the vascular bundles may be found to be imperfectly developed.

Examine with a low power, and, beginning the study of the tissues at the periphery of the section, observe-

$a$. A single layer of rather irregular epidermis : immediately below this are-

b. Irregular groups of sclerenchyma with thick lignified walls : internally lies-

c. A mass of parenchyma, which forms the ground-work of the whole section : embedded in this are-

d. Numerous vascular bundles : note that they are smaller, but more numerous near the periphery than at the centre; also that the position of the parts of the bundles relatively to the centre of the section is usually uniform.

Treat a section with chlor-zinc-iodine : put on a high power, and examine in detail the several tissues above named.

$a$. The epidermis appears as a definite layer of cells of unequal size, without intercellular spaces. Note a well-marked 
cuticle (brown). Here and there may be found stomata, with two small guard-cells, and two subsidiary cells.

b. The sclerenchyma consists of cells with thick, highly refractive walls, which stain yellowish brown with chlor-zinciodine (lignified).

c. The parenchyma consists of cells with thin cellulose walls, At the angles where the cell-walls meet are intercellular spaces. The external layers have abundant protoplasm with chlorophyll-corpuscles. These are less frequent in the inner layers, while in the central parenchyma the protoplasm is hardly appreciable.

d. For the minute study of the vascular bundles select one of the largest central bundles. The section must be thin. The most prominent elements in the bundle are-

i. Four large vessels of the xylem, arranged like a $\mathbf{V}$, with the angle towards the centre of the stem : of these the two smaller are developed first. Compare sections of young stems.

The vessel nearest the centre of the stem has usually annular thickening : in old stems it is partially surrounded by an intercellular space, while the rings often become detached, in which case the vessel is not easily seen in transverse sections. Next to this is a vessel which has commonly a spiral thickening: the remaining two have thinner walls with pitted marking, and large cavity.

Surrounding the pitted vessels, and between them, are-

ii. A number of tracheides with pitted lignified walls, and no cell-contents. Surrounding the intercellular space above described is -

iii. A group of parenchymatous cells with thin cellulose walls. These may be regarded as xylem parenchyma.

The phloem portion of the bundle lies between the limbs of the $\mathbf{V}$-shaped xylem, and is easily recognized by the thin cellulose walls characteristic of soft bast. It consists of-

iv. Elements with large cavities, in which transverse septa (sieve-plates) often occur : these elements are the sieve-tubes.

v. Smaller cells (cambiform) between the sieve-tubes.

Surrounding the above tissues of the xylem and phloem is a sheath of sclerenchyma. On its internal side may be found 
tissue-forms which are transitional between sclerenchyma and certain of the constituents of the bundle.

II. Cut radial longitudinal sections of the same, treat as before, and observe-

a. The epidermis, composed of oblong cells.

b. The prosenchymatous cells of the sclerenchyma.

c. The ground-parenchyma, with roundish cells.

d. The vascular bundles, pursuing a longitudinal course parallel to one another, without lateral fusion.

In the xylem observe -

i. The annular, spiral, and pitted vessels, and note, especially in the latter, the clearly-marked joints, pointing to their origin from a succession of cells.

ii. The pitted tracheides.

iii. The thin-walled parenchyma.

And in the phloem, which is easily recognized by its cellulose walls, distinguish-

iv. The sieve-tubes, which have a wide cavity, intercepted here and there by transverse sieves.

If it be found difficult to distinguish the sieve-plates, a fresh section may be treated with potash ; the character of the sieveplate is then more easily seen.

v. The cambiform cells, which are narrow and parenchymatous.

Note the prosenchymatous constituents of the sheath of sclerenchyma, and observe transitional forms between these and the pitted tracheides with square ends, which belong to the xylem.

III. In order to see the fundamental arrangement of the vascular system, cut median longitudinal sections through the apex of a young plant of Maize, or of a foliage-branch of an old plant: treat with strong potash; or, better, with dilute potash for twenty-four hours : examine with a low power, and observe, if the section be median-

1. The apical cone (punctum vegetationis).

2. Leaves, in successive stages of development, seated laterally.

3. In the older leaves, vascular bundles, which enter the stem. 
On following the course of these vascular bundles it will be seen that on entering the stem they proceed at first towards the centre : before reaching it they curve downwards, and finally turning again outwards they approach the periphery of the stem. We thus see that in young stems of Maize the course of the bundles corresponds to the Palm-type, though as the stem grows older, and the internodes develop, the correspondence is less obvious, by reason of the almost straight course pursued by the bundles in the internode, and the complications which arise at the node.

But no student should be satisfied with seeing the typical bundle-system of a Monocotyledon in small microscopic preparations : for it is not difficult to prepare from any of the Palms which have a columnar stem, dissections which shall show plainly to the naked eye the course of the vascular bundles. The spiral lateral curvature of the bundles in their downward course may be readily recognized in such dissections, where the ground tissue has been removed to a sufficient depth. No botanic institution should be without such dissections, which will make more plain to the mind than any description, or any microscopic preparation, the rather complicated bundle-system of the Palm-type.

\section{ii. STEN-ARBOREOUS TYPE.}

I. Examine preparations of the old stem of Yuccia or Dracana, in which the thin-walled parenchyma has been allowed to rot away, while the vascular bundles remain. On comparing transverse and longitudinal sections of such stems, it may be seen, with the naked eye-

I. That the central primary bundles are isolated, and that the course of each bundle may be traced as starting from below at the periphery of the stem, then curving towards the centre as it ascends, and finally turning outwards, and passing into a leaf. These are therefore common bundles.

2. That the peripheral mass of secondary bundles increases in thickness towards the base of the stem, and has no direct 
connection with the leaves. These bundles are therefore cauline.

II. Cut transverse sections of the stem of Dracana immediately below the apical tuft of leaves: mount in glycerine, and examine under a low power. Observe that the arrangement of the tissues, as well as the character of the vascular bundles, is similar to that in the Maize : there is, however, a peripheral cortex, which is not found in the Maize. Note that the cells of the inner limit of the cortex are quiescent, and not undergoing division.

III. Cut transverse sections of the stem of Draccena at a point one foot or more from the apex, and mount in glycerine. Examine with a low power, and observe-

I. A well-marked epidermis. Beneath this-

2. A band of cork.

3. A broad belt of cortical parenchyma many cells of which contain crystals (raphides, \&c.). Here and there a vascular bundle will be seen in the cortex: these are bundles of the leaf-trace, passing inwards from the leaves.

4. At the inner limit of this the cells are not quiescent, as in the younger part of the stem, but there is an actively dividing merismatic ring, which gives rise internally to new vascular bundles, and externally to fresh cortical cells. The new bundles thus formed are cauline, having no direct connection with the leaves, and are embedded in lignified ground-tissue. These together form a dense ring.

5. Centrally, there still remains undisturbed that arrangement of thin-walled parenchyma and vascular bundles which has been above noted in the young stem as being similar to that in the internode of Maize: the primary or common bundles may be distinguished from the secondary or cauline bundles, not only by their arrangement, but also by their structure, the latter having a denser sclerenchymatous sheath and smaller vascular elements than the former.

Note the passage of these central bundles outwards to the bases of the leaves: they are common bundles. Observe also the mode of formation of the cauline bundles. 


\section{LEAF}

Note that the phyllotaxis in the Maize is $\frac{1}{2}:$ the leaf is sessile, and sheathing in its lower half, with a ligule at the upper limit of the sheath; the form of the lamina is lanceolate, margin entire, ciliate, midrib well marked; venation parallel; upper surface hirsute; lower glabrous.

I. Treat a piece of the thin peripheral part of a leaf (which has been previously bleached in alcohol) with potash till it is transparent; mount in glycerine, and examine under a low power. Observe-

I. The parallel course of the vascular bundles.

2. Their frequent lateral fusion, by means of small branchbundles.

3. The absence of stomata above the vascular bundles, and their arrangement in rows in the spaces between them.

4. The various forms of hair ; and especially the conical unicellular hairs, which give the ciliate character to the margin of the leaf.

II. Cut transverse sections of the lamina; mount in water, or dilute glycerine. Other sections may be treated with alcohol to expel the air-bubbles; the chlorophyll will, at the same time, be dissolved out: other sections may be mounted in chlor-zinciodine, and kept for comparison with the above. Examine with a low power.

The section presents a sinuous outline, corresponding to a certain extent to the arrangement of the main vascular bundles: at the midrib the section widens out. Note the following arrangement of tissues :-

I. Covering both surfaces of the leaf is an epidermis, resembling that of the stem, but bearing hairs of various form, mostly simple, conical : the largest of them are surrounded at the base by an outgrowth of the neighbouring epidermal cells.

Note the stomata on both surfaces, with small guard-cells, surrounded by two subsidiary cells: these will be further examined below. 
2. Vascular bundles of various size, which, in the thinner part of the lamina, lie in a median position between the two epidermal layers. The largest of these correspond in structure to those of the internode, the smaller ones are reduced forms of the same type. Note that the spiral and annular vessels of the protoxylem are nearer the upper surface of the leaf.

Between the epidermis on either side, and the larger bundles, are masses of sclerenchyma, which, together with the bundles, form complete bridges of rigid tissue between the two epidermal layers.

3. The spaces between the tissues hitherto considered are filled with parenchyma (mesophyll), which may either be (a) green (containing chlorophyll), or (b) colourless (without chlorophyll).

a. The green chlorophyll-containing parenchyma fills up the greater part of the space ; intercellular spaces occur in it.

b. The colourless parenchyma occurs (i.) as a sheath, without intercellular spaces, surrounding each bundle (endodermis) ; (ii.) as groups of cells immediately below the epidermis : these are more common towards the central part of the leaf. At the midrib this tissue forms the bulk of the structure.

III. Cut thin tangential sections from the under surface of the lamina, so as to remove, if possible, only the epidermis. Treat with potash, and mount in glycerine. Observe-

I. The ordinary cells of the epidermis, of oblong form, and with sinuous outline.

2. Short cells between the ends of these, which often project perpendicularly to the surface as hairs, of various form.

3. The stomata, holding the same position as (2) relatively to the oblong epidermal cells.

Observe with a high power the structure of the stomata. They consist of -

a. Two narrow guard-cells, which inclose the pore.

b. Two triangular subsidiary cells, which completely surround the convex side of the guard-cells.

Compare this view of the stoma with the same structure as seen in transverse sections of the lamina. 
IV. Transverse sections should also be cut from the foliageleaves of the Hyacinth, which, as above noted, grow in an almost vertical position : mount in glycerine, and note under a low power that there is no great difference between the upper and lower surfaces as regards the disposition of the tissues, excepting that the orientation of the collateral bundles is such that the xylem is directed towards the upper surface.

Stomata may be seen both on the lower and upper surfaces : there is no distinctly marked palisade-parenchyma : centrally is a mass of colourless thin-walled parenchyma. Note the absence of strengthening sclerenchyma.

This will be found an excellent opportunity for the study of the details of a simple stoma: observe that the guard-cells are about at the general level of the epidermis: that when fairly cut through the middle they differ in section from the other epidermal cells : the cell-wall separating them from the adjoining epidermal cells is relatively thin, while that adjoining the pore of the stoma is thick, excepting at one point, where the guard-cells are near to, or in contact with, one another. There are external and internal thickened ridges on each guard-cell, which appear in section as sharp projecting teeth : these respectively define and partially inclose the front cavity and back cavity of the pore. The cuticle is seen to be continuous through the pore, to the lower surface of the epidermis. Note also the large air-chamber leading into the system of intercellular spaces of the cortex. The contents of the guardcells are conspicuously stained blue with chlor-zinc-iodine.

$\mathrm{V}$. To observe the stoma in surface view, and in the living condition, take leaves of Hyacinth, or better of some species of Lilium, in which the stomata are of unusually large size : on a bright day, and after full exposure to the light, strip off a piece of the epidermis: mount it in water, with the outer surface uppermost, and examine under a low power. It may then be readily seen that the pores of the stomata are widiely open, the guard-cells being strongly curved.

Having seen this, irrigate with a 2 per cent. solution of common salt, keeping watch upon a stoma which has been seen to be open : when the salt solution reaches it, the stoma will 
be seen to close, the guard-cells straightening themselves as their internal tension is relieved, and finally becoming plasmolysed. The connection between the opening of the stoma and the internal tension of the guard-cells is thus demonstrated.

\section{Note on crystals.}

I. Cut longitudinal sections of the scape or leaves of the Hyacinth or Onion : many other Monocotyledons will do as well : mount in water, and observe the large cells containing numerous needle-shaped crystals (Raphides) arranged in a bundle parallel to one another. In order to investigate their nature the following tests may be applied :-

a. The attempt may be made to stain them with iodine, or other stains which colour crystalloids, but they will not be affected : they are thus distinguished at once from crystalloids.

b. Irrigate a section with acetic acid : they are not affected : they are therefore not calcium carbonate.

c. Irrigate with dilute nitric acid : the crystals are dissolved.

d. Irrigate a fresh preparation with a small quantity of dilute sulphuric acid : the crystals will be dissolved, and crystals of a different form (calcium sulphate, which is not readily soluble) may be seen to be formed in the fluid.

These reactions, coupled with what can be ascertained from analysis of the ash of the plant, point to the conclusion that these crystals consist of calcium oxalate.

II. Cut transverse sections of the petiole of some species of Begonia; mount in water, and examine under a low power. Here and there will be found bodies of a more or less distinctly crystalline form occupying the cavities of certain cells. Their form is very complicated, and their size variable.

The reagents above applied to the Hyacinth are to be used : the results will be similar. Thus they also may be shown to consist of calcium oxalate. Crystals giving the above reactions will be found in the tissues of most plants. 


\section{RooT}

I. Cut transverse sections of the root of the Maize, selecting a well-grown, underground piece of root : mount in glycerine, and examine first under a low power, then under a high power. Starting from the periphery observe-

I. The superficial piliferous layer, consisting of small cells, many of which have grown out into long root-hairs.

2. Immediately below this is a protective layer of exodermis, with more or less cuticularized cell-walls.

3. The cortical parenchyma, a broad band, of which the peripheral part is often sclerenchymatous, and this is especially the case in the aërial prop-roots: observe the regularity of arrangement of the inner part of the cortex, of which the innermost layer is to be recognized as-

4. The endodermis : the cell-walls of this layer are in old roots thickened on three sides, the outer wall remaining thin, and the radial walls in young roots show the usual dark dotted appearance.

5. Within this is the pericycle, a layer of cells with walls thin when young, but they may be lignified when old : the series is interrupted opposite the xylem masses, which abut directly on the endodermis.

6. The vascular cylinder, round the periphery of which are disposed-

A. Xylem-tissues, recognized by their dark-looking lignified walls, especially those of the large vessels: these lie nearer the centre, while the smaller elements of the protoxylem are at the extreme periphery.

B. Phloem-tissues, which alternate with the xylem-groups, and are to be recognized by their brighter cellulose walls. Note that the number of xylem and phloem groups may vary, and is often very large.

7. Centrally lies a bulky pith, in which may be seen one or more irregular groups of sclerenchyma surrounding a vessel or vessels. 
II. Cut transverse sections of the root of Hyacinthus orientalis. An old root must be taken, and the sections should be cut as far as possible from the apex. Treat them with potash, and mount in glycerine. Starting from the outside, note surccessively-

I. The superficial piliferous layer, single cells of which have grown out, here and there, perpendicular to the surface as root-hairs.

2. Beneath this a layer of cells of larger size with clearlymarked, cuticularised cell-walls : this is the exodermis.

3. A thick band of cortical parenchyma, consisting of rounded cells with intercellular spaces : in old roots the outer layers of this tissue become disorganised and distorted. The inmost layer of this tissue differs in structure from the rest, and is called-

4. The endodermis : the radial walls of this layer present the characteristic appearance of a black dot, and are cuticularized.

5. Within this is a layer of thin-walled cells of the pericycle which immediately surrounds-

6. The central vascular cylinder: two kinds of tissue are specially to be distinguished in this cylinder, viz.-

A Xylem-tissues, easily recognised by their dark lignified walls : they are arranged in a series of groups of indefinite number, which abut externally on the pericycle, and extend inwards, till they meet internally, and form a central mass. The chief constituent are vessels of various form. As may be seen in transverse sections of young roots, the smaller peripheral members of each group are formed first (protoxylem), and have spiral or annular thickening; then successively the larger vessels towards the centre.

B. The Phloem-tissues, which are groups of elements with small cavity, and bright cellulose walls : they lie between the peripheral groups of the xylem, and alternate regularly with them.

Apex of the Root.

It is not easy to cut longitudinal sections of the apex of an ordinary fully developed root without embedding. The 
arrangement of the meristematic tissues, is, however, the same in young as in old roots; it is therefore more convenient, and quite as successful, to cut longitudinal sections of the apex of the young lateral roots, which are to be found growing horizontally out of the nodes of the Maize plants. Or, if fitting material for this be not at hand, longitudinal sections may be made of the radicle of the embryo.

Adopting one of the above methods, cut longitudinal median sections of the apex of the root. The section must be accurately longitudinal and median, i.e. the section must include the organic axis of the root, around which the several tissues are symmetrically arranged.

Treat the sections for about ten minutes with dilute potash, or, better, with "eau de javelle" (Appendix A), and mount in glycerine.

In a median section the following arrangement of tissues will be visible :-

I. A central mass of tissue, clearly defined laterally, and rounded off at its apex, which is at some distance below the external apex of the root : this is the plerome-cylinder. If this tissue be traced back into the older part of the root, it will be found that its central part is continuous with the parenchymatous pith, while its peripheral part develops into the vascular ring. Note rows of larger cells, which may be traced back as continuous with the vessels of the xylem. In the central portion of the plerome are intercellular spaces, which appear black in sections from fresh material, being filled with air.

2. Surrounding the plerome is a broad band of tissue with intercellular spaces, which appear as irregular black lines. This tissue is the periblem, which is the formative tissue of the cortex.

3. Outside this is a single layer of cells soniewhat elongated radially, and with a thick outer wall: this is the dermatogen, or formative tissue of the piliferous layer.

If the section be accurately median it will be possible to trace (2) and (3) upwards, till, immediately above the apex of the plerome, they merge into a single layer of cells : thus the formative tissue, from which the piliferous layer and cortex are 
derived, is represented at the apex by a single initial layer of cells.

4. Outside the dermatogen, at the apex of the root, will be found another formative tissue, the cells of which divide parallel to the surface of the dermatogen : this is the calyptrogen-layer, which is formative of the tissues of the root-cap. The latter appears as a mass of parenchyma, covering the whole apex of the root: the outer cells of it will be seen to be undergoing mucilaginous degeneration of the cell-walls. 


\section{REPRODUCTIVE ORGANS}

\section{Observations with the Naked Eye on the Mature Flower}

In order to become acquainted with the external characters of the reproductive organs, it will be well to examine and compare a few common types of flower; and since the sexual reproductive process is essentially the same in Dicotyledons and Monocotyledons, the two may be treated simultaneously.

I. Examine specimens of the common Buttercup (Ranunculus acris): a number of flowers may be found associated together on a single branching system, the inflorescence, which has here the character of a cymose panicle. Recognize in each single flower the following series of parts, which are inserted upon the enlarged apex of the axis or floral receptacle :-

I. The calyx, which is the outermost series of floral leaves, and consists of five sepals, separate from one another (or polysepalous), inserted below the other organs (inferior), greenish yellow, and hairy.

2. The corolla, consisting usually of five yellow petals, separate from one another (polypetalous), and seated below the more central organs (hypogynous) : remove a single petal, and observe the pocket-like gland or nectary on the upper surface, close to the base.

3. The andrœcium, consisting of an indefinite number of stamens, which are separate from one another (polyandrous), and are seated below the central series of organs (hypogynous): each stamen is a club-shaped body, and two parts of it are to be recognized-

a. A thin stalk, the filament.

b. A two-lobed head, the anther.

In a flower fully opened, note with a lens the dehiscence of 
the anthers by two longitudinal slits, through which the powdery yellow pollen may escape.

4. The gynœeium at the centre of the flower, consisting of an indefinite number of carpels, which are separate from one another (apocarpous), and are seated above the other floral organs on the conical receptacle (superior). Each carpel consists of a lower laterally compressed portion, the ovary, and at the apex of a short curved process (the style) is a rough yellow surface, the stigma. Open one of the carpels carefully, and observe an internal cavity, containing a single round body, the ovule.

II. Compare the flower of Caltha palustris, the Marsh Marigold. Here the general arrangement of parts will be found to be the same : but note the following points of difference-that the calyx is here petaloid, consisting of five or more sepals, the corolla is absent, and the carpels are fewer (five to ten), but of larger size. Slit open one of the carpels along the dorsal side, turn back the flaps, and observe the numerous ovules, attached to the ventral side of the carpel, and arranged in two irregular longitudinal rows.

III. For comparison with the above, examine the greater Stitchwork (Stellaria holostea), and note the regular cymose inflorescence (dichasium). The flower is composed of -

I. Calyx, sepals five, polysepalous, inferior.

2. Corolla, petals five, deeply notched, polypetalous, hypogynous.

3. Androcium, stamens ten, polyandrous, or very slightly united at the base, hypogynous.

4. Gynœcium, carpels three, united or syncarpous, superior : styles and stigmas three. Ovary unilocular, ovules numerous, inserted on the prolongation of the axis (central placentation). This affords an example of cohesion of the carpels.

Compare the Rose Campion (Lychnis dioica), which belongs to the same natural order, and shows the same general characters; but the plants are more or less distinctly unisexual, flowers with perfect stamens being borne on some plants, while on others flowers will be found with only the female organs matured : the species is thus diøcious. 
Note the calyx with united sepals, gamosepalous: in the male flowers there are ten stamens slightly united at the base, and centrally a rudimentary gynocium ; in the female flowers, the gynœcium consists of five carpels, syncarpous and superior, while around its base may be seen ten rudimentary stamens: thus this plant illustrates cohesion of the sepals and of the carpels, and a partial suppression of the stamens, or of the carpels.

IV. Examine flowers of the Bird-Cherry (Prunus Padus): they are arranged in racemose manner. Note that each flower consists of-

1. A calyx of five sepals, inserted upon the so-called calyxtube, which may be regarded as an enlargement of the floral receptacle.

2. A corolla of five polypetalous petals also inserted on the margin of the calyx-tube, the petals alternating in position with the sepals.

3. Androcium, composed of indefinite stamens, polyandrous, and perigynous, i.e. inserted on the margin of the calyx-tube.

4. Gynœcium, consisting of one carpel, superior : ovules two.

This is a typical perigynous flower, in which the sepals, petals, and stamens are inserted on the margin of the calyxtube.

Compare flowers of Hawthorn (Cratagus oxyacantha), which belongs to the same natural order : the number of parts is the same as in the above, excepting that the carpels may be one, two, or three. It differs however in the fact that from an early period the calyx-tube is adherent to the ovary, and the ovary accordingly is inferior. Compare the Apple.

V. Examine flowers of the Primrose (Primula vulgaris), or of the hothouse Primula ( $P$. sinensis), and note that it is composed of-

I. Calyx of five sepals, gamosepalous, inferior.

2. Corolla of five petals, gamopetalous, hypogynous, and alternating with the sepals.

3. Androcium of five stamens, which are inserted on the inner surface of the tube of the corolla (epipetalous) : they are opposite the petals. 
4. Gynœcium of five carpels, syncarpous, superior : placentation, free-central, ovules numerous.

This is an example of cohesion of sepals, petals, and carpels, and of adhesion of the stamens to the corolla. Note also that the flowers are of two types, short-styled and. long-styled (dimorphic).

VI. Examine a head or capitulum of the Sunflower: this is an inflorescence, and it is composed of a large number of florets, or small flowers, inserted on a wide disk-like development of the main axis or peduncle. Note the dark green, closely imbricated bracts, which show a gradual transition from the foliage-leaves to a simpler form : these together constitute the involncre, which surrounds the margin of the capitulum. On the upper surface of the flattened receptacle are the numerous, and closely packed florets, of which two types are to be distinguished-

a. Ligulate or ray-florets, with broadly strap-shaped yellow corolla, which are disposed at the periphery.

b. Tubular or disk-florets, which constitute the central part of the head.

In the young inflorescence before flowering, and also later in the fruiting inflorescence, there may be seen opposite, and external to each floret a small leaf (the bracteole), lanceolate above, but broadly sheathing below, in the axil of which the floret is produced.

Remove the bracts from the periphery of the capitulum, and separate a single ligulate floret: examine it in detail, and observe at the base the more or less compressed ovary, which is inferior : at its upper limit is an irregular rim, which may be regarded as representing the calyx: above it is the yellow corolla, tubular in its lower part, broadly ligulate above : on slitting the tubular portion there may be seen a more or less reduced style inserted on the apex of the ovary: the stamens are abortive. These florets are thus neuter.

Examine one of the florets of the disk in detail, noting first its position in the axil of a bracteole : observe-

I. At the base the laterally compressed ovary, which is inferior. 
2. Seated in an antero-posterior position above it are two chaffy scales, which represent the calyx, and it is accordingly superior.

3. Above this is the tubular yellow corolla, with a throat narrowed below, and terminated by five teeth : it thus consists of five petals, gamopetalous and superior.

4. Projecting from the tube of the corolla may be seen a darkcoloured, cylindrical body composed of the coherent anthers, and projecting through the tube is-

5. The bifid and recurved stigma.

Slit the tube of the corolla longitudinally, and note the five separate filaments of the stamens, which insert themselves on the inner surface of the narrow throat of the corolla (epipetalous), while the anthers are united above so as to form a tube (syngenesious),

Remove the corolla and stamens : the long cylindrical style will remain rising from the apex of the ovary, and terminating in a bifid stigma ; thus it is indicated that there are two carpels, syncarpous and inferior.

Open the ovary longitudinally, and note the single cavity (unilocular), and within it a single anatropous ovule attached to the base of the cavity.

As a substitute, or for comparison, the head or capitulum of the Dandelion (Taraxacum officinale) should also be dissected : the general features will be similar to the above, the chief points of difference being that--

I. All the florets are ligulate, and bisexual.

2. The bracteoles are abortive.

3. The calyx is developed as a silky pappus.

For comparison with the above types of flower, which are all Dicotyledonous, examine, as typical of the Monocotyledons, the flowers of the Blue Bell (Scilla nutans), which are borne in simple racemes. Each is composed of-

I. A perianth, consisting of six petaloid segments which are free, or polypetalous, and hypogynous: three composing an outer whorl, overlap the other three which compose an inner whorl.

2. The andrœcium, consisting of six stamens, each being 
opposite one of the segments of the perianth to which it adheres.

3. The gynœeium, consisting of three carpels, syncarpous and superior: the ovary has three loculi, ovules numerous, placentation axile.

For further details as to the various structure and form of flowers, reference must be made to books on Descriptive Botany.

\section{Development of THE Flower.}

In order to trace the development of the flower it is found convenient to use plants with aggregated inflorescences, i.e. those in which the flowers are closely associated together in large numbers. By cutting sections through such an inflorescence many individual flowers, illustrating different degrees of progress, will be traversed, and by comparison of these an idea of the course of development may be gained even from a single section.

I. Examine young capitula of the Sunflower with the naked eye : they occur in the same positions as the vegetative apical buds, but differ externally from these-

I. In their greater bulk, and more especially in their diameter being larger.

2. In their colour, which is usually darker.

3. In being covered externally by a large number of imbricated bracts (or hypsophyllary leaves), which together form the general involucre.

Select a very young capitulum - that is, one in which these characters can be recognized, but are not as yet very pronounced-and, having removed the largest external bracts, cut from it median longitudinal sections : treat with potash and mount in glycerine : observe with a low power-

I. That in outline and general arrangement of parts the sections resemble those of the vegetative bud, but that the apical cone is broader, and more flat.

2. That the surface of the cone has an irregular outline, owing to the formation of a series of appendicular organs, which are developed in acropetal order, i.e. the smallest or youngest 
are nearest the centre or apex, while on passing towards the periphery the size regularly increases.

Put on a higher power, and study these organs in detail, beginning at the centre.

If the capitulum be young enough, there will be found, as in the vegetative bud, a naked apical cone, with a rather flatter form, but a similar arrangement of tissues to that there observed. Passing from the centre, the external surface assumes an undulating appearance owing to the formation of -

I. Bracteoles, or small leaves, which arise similarly to the leaves as above observed (p. 49), by outgrowth of the epidermis and subjacent tissue : as they grow older they curve towards the centre. Note the formation of hairs of various types from single cells of the epidermis, this being a good opportunity for tracing their origin.

2. The rudiments of flowers, which appear in the axils of the bracteoles, i.e. on the side nearer the apex. These are likewise produced from the epidermis and subjacent tissue; they are, morphologically speaking, axillary branches.

The development of the latter into the complete flower must be carefully studied, by comparison of those nearer the centre with older flowers near the periphery of the capitulum, or on capitula of various ages. It is obvious that flowers which have been cut in median section will be best fitted for this study. Note the following successive stages of development-

a. Form of papilla, conical.

b. Apex becomes flattened.

c. Periphery of the flattened apex rises into a whorl of five small lobes; these are the petals, which are in the mature flower united as a gamopetalous corolla.

$d$. Between the corolla and the now depressed apex rises a fresh series or whorl of five lobes; these are the young stamens.

About this stage may be seen externally, below the corolla, a slight protuberance on each side of the flower (as seen in section): this is the first appearance of the calyx, which consists in the mature flower of two scaly sepals. This order of appearance of the floral whorl is not normal but is the rule 
in the order Composita. In the large majority of plants the calyx is developed first, then the corolla, and then the stamens.

e. Within the whorl of stamens there arises, at the margin of the now much depressed apex, the last series of floral organs, viz. two carpels, which arch over the apical depression, and thus close in the cavity of the inferior ovary.

$f$. All the organs increase in size, while from the base of the cavity of the ovary a papilla arises, which develops into a single anatropous ovule, with one integument, and small nucellus.

II. Cut horizontal (i.e. transverse) sections of a capitulum : treat as before : examine with a low power.

Note the arrangement of bracteoles, with young flowers in their axils, round the central naked apex. The youngest flowers will appear simply circular in outline (simple papillæ of stages $a$ and $b$ ) ; older flowers will show successively-

i. The five papillæ of the corolla (petals) uniting at an early stage into the gamopetalous corolla-tube. (Stage $c$.)

ii. Five stamens, alternating with the petals. (Stage $d$.)

iii. Centrally two carpels. (Stage e.)

Other Composita may be taken as substitutes for Helianthus, but some variety will be found in different genera in the character of the bracteoles, and in the calyx: thus in Chrysanthemum Leucanthemum, which is a useful type, the bracteoles are absent, and there is no representative of the calyx.

\section{Calyx and Corolla.}

Mount in glycerine two small pieces of the corolla of a ligulate floret of the Sunflower which has been kept in spirit, the one with the lower, the other with the upper surface uppermost. Examine under a low power and note, the delicate texture and transparency of the whole : the rarity or even entire absence of stomata: the numerous hairs on the lower, and the small projecting papille on the upper surface: and the vascular bundles which do not form a dense network as in the foliage leaf. 
Cut transverse sections of the same, mount in glycerine, and observe that the structure is altogether simpler than that of the foliage leaf. Note the smooth lower epidermis : the upper epidermis, of which each cell has grown out as a conical papina : it is these which give the velvet-like appearance to the corolla: the mesophyll which is very lax, and is not differentiated into palisade and spongy parenchyma.

The bright colours of flowers and fruits may be due either to colouring matter dissolved in the cell-sap, or to small coloured bodies in the cells, or to both combined. They must be studied in fresh material, as the colourings are altered or destroyed by alcohol. As a first example the common scarlet Geranium (Pelargonium) may be taken, in which the petals owe their colour to dissolved matter.

Strip off the superficial tissue from a petal of this plant, and mount in water with the outer surface uppermost: note under a low power the conical form of the superficial cells, and the bright red colour of the cell-sap : chromoplasts or formed granules appear to be entirely absent.

The case of the common red and yellow Tulip is a good example of mixed colouring ; strip off the superficial tissue from the yellow base of one of the segments of the perianth : mount in water, and examine under a high power : observe the very numerous yellow chromoplasts of more or less distinctly crystalline form.

Strip off now a similar patch of tissue from the upper, red portion, mount, and examine as before : here the chromoplasts will be seen as before, but masked by the more prominently coloured red cell-sap.

\section{The STAMEN.}

III. All the following preparations should be made from materials hardened in alcohol, or fixed with saturated solution of picric acid, and then washed, and hardened in alcohol.

A. Cut transverse sections of a flower bud of Caltha palustris, which was just ready to open, taking care that the anthers shall be cut through transversely. Neglecting the other parts, mount 
the sections of the anthers in glycerine, and examine with a low power. Note :-

I. The general outline of the section, and compare it with the form of the bilobed anther as above observed.

2. The two large cavities or pollen-sacs in each lobe.

3. These are surrounded externally by the wall of the anther which consists of at least three layers of cells.

4. The septa, which divide the two pollen-sacs or microsporangia of each lobe from one another; the anther has thus originally four pollen-sacs : these may be found still distinct in almost mature anthers, though as they approach maturity the septa are partially broken down, and the cavities of the pollensacs are thus thrown together: this usually happens before the dehiscence of the anther.

5. A single small vascular bundle slying symmetrically between the cavities in the central part or connective of the anther.

6. Pollen-grains or microspores, mostly to be found lying free in the glycerine.

Put on a high power and make the following observations :-

1. The wall of the anther is composed of-

(a.) A layer of epidermis, with an external cuticle: within this is- -

(b.) A layer of cells with a fibrous thickening of the cell walls.

(c.) Immediately within $(b)$ will be seen a narrow highly refractive band, consisting of the remnants of two transitory layers of cells, the inner of which was the tapetum: this is almost completely disorganized; the outer of the two layers, which abuts on the fibrous layer, is less completely disorganized, and may be seen as an almost continuous layer of thin-walled cells, even in almost mature anthers. Note also that the wall of the anther is thinnest, and its construction most simple at the part most remote from the connective, i.e. where the septum of each lobe meets the wall of the anther, while nearer to the connective it becomes thicker.

2. At the point where the septum meets the wall of the anther the cells are smaller, and of rounded form, owing to the presence 
of intercellular spaces between them, and the inner layer is not spirally thickened : this is the line of dehiscence of the anther, and the lax character of the tissue at this point helps to bring about the rupture.

3. The pollen-grains or microspores, which are almost spherical, with smooth walls and granular protoplasmic contents, in which may be made out, with difficulty, two nuclei.

B. Mount in half glycerine, half alcohol, some almost mature pollen of Fritillaria imperialis, which has been previously preserved in alcohol, and examine with a high power. The grains have a smooth wall, and in the granular protoplasm may usually be seen two nuclei one of which occupies a lateral position, and is surrounded by a definite body of protoplasm. If the grains be stained with hæmatoxylin before mounting in glycerine and alcohol, the nuclei will be more easily made out. Pollen of Iris pseudacorus will also give satisfactory results: it may be treated as above or stained in fresh condition with methyl green and acetic acid : wash in weak acetic acid, and mount in the same, or in very weak glycerine.

C. In order to observe the germination of the pollen-grains, and formation of the pollen-tubes, cultures may be made in a watch glass, or, if it is desired to follow the process in single individual grains, use may be made of the moist chamber described in Appendix A.

Mount some pollen-grains of Helianthus or of Lilium in one hanging drop of a weak solution of cane-sugar in water (about 5 per cent.). Examine them with a high power, and note their form and the external configuration of their walls.

Keep them at an ordinary temperature in the dark for 12 to 18 hours : on again examining them, many will be found to have put out pollen-tubes, filled with granular protoplasm, in which, after suitable staining, two or more nuclei may be detected.

If transverse sections be made from very young buds of Caltha, and successfully from older ones up to the mature flower, the development of the anther and of the pollen may be traced.

The material should be preserved in absolute alcohol (or strong 
methylated spirit), and the sections should be treated with half glycerine, half alcohol : this should be left exposed to the air in a watch-glass, so that the alcohol may evaporate: mount in pure glycerine. Anhydrous staining reagents may be employed, but are not actually necessary.

\section{CARPEL AND OVULES.}

IV. The following preparations must be made from materials hardened in absolute alcohol, or methylated spirit. From an open bud of Caltha palustris which has been thus treated, strip off the outer organs, and cut a large number of transverse sections of the carpels : by so doing the ovules will be traversed in a longitudinal direction. Treat the sections with one-half pure glycerine, one-half alcohol, in a watch-glass, and let the alcohol evaporate gradually: pick out those sections which appear to have fairly traversed one or more of the ovules, and mount them in pure glycerine. Strasburger recommends that in the preparation of such objects the transfer to pure glycerine should be made before the sections are cut.

Examine first with a low power, and observe-

I. The carpel, having a structure not unlike that of an ordinary leaf, and consisting of an upper and lower epidermis with some four layers of mesophyll between them. Note the suture or junction of the two margins of the carpel, which thus encloses a central cavity.

2. The ovules (macrosporangia) seated in this cavity, and attached near the margins of the carpel : it has already been noted that there are two rather irregular rows of ovules in each carpel, therefore at most only two ovules appear in each section.

The form of the ovule is anatropous: it consists of the following parts :-

a. The funiculus, or stalk, which adheres through the greater part of its course (as the raphe) to the body of the inverted ovule. A procambium bundle, connected with a bundle at the margin of the carpel, traverses it longitudinally. 
The body of the inverted ovule consists of -

$b$. Two integuments, each several layers of cells in thickness, the outer being united with the funiculus: the integuments cover the body of the ovule completely, excepting a narrow channel (micropyle) near its apex. Within the integuments lies-

c. The nucellus, an oval mass of cellular tissue in which is embedded-

d. The embryo-sac (macrospore), a large oval cell, situated centrally a short distance below the apex of the nucellus.

Examine the embryo-sac with a high power, and observe-

I. The granular, vacuolated protoplasm which fills it : embedded in this are to be found-

2. A large central nucleus, with highly refractive nucleolus.

3. At the micropylar end of the embryo-sac, three cells, with clearly defined nuclei. Two of these (the synergida) fill the apex of the sac, the third (the ovum) being placed laterally, a little below the apex.

4. At the posterior end of the sac are three cells (the antipodal cells), also with clearly defined nuclei. Divisions of these cells occasionally occur, so that their number may be found to be greater than three.

Note the tapetum, consisting of cells more or less disorganized which partially or completely surround the embryo-sac.

\section{FERTILIZATION.}

I. Remove from flowers of Stellaria media, which have just faded, the three styles : moisten them with alcohol, and mount quickly in water : note the cylindrical colourless styles, curved at their upper ends: the stigmatic surface with its numerous papillose hairs is found on the convex side of the curved part of the style. Note especially the numerous yellow pollen-grains adherent to the stigmatic surface, while it may often be seen that a pollen-tube will proceed from the pollen-grain, and enter the tissue of the style.

II. The style and stigma of flowers of Rhododendron ponticum from which the corolla has already fallen off will also be found 
to be good material for showing pollen-tubes. Cut transverse sections of the style in the fresh state, mount in dilute glycerine and observe-

I. The tissue of the style with small vascular bundles dotted in it.

2. The star-shaped central cavity, filled with mucilage, embedded in which may be seen-

3. The small pollen-tubes cut transversely, and embedded in a mass of transparent mucilage.

Cut longitudinal sections of the same, including the stigma, and mount as before : observe-

I. The irregular stigmatic surface.

2. The numerous pollen-grains (associated in groups of four) attached to the stigma, and often putting out pollen-tubes which penetrate the tissue of the style.

3. The pollen-tubes, often to be seen as a dense sheaf, pursuing their course down the cavity of the style : note their thin walls, and the presence of highly refractive plugs, which, stop their cavities: look for endings of the tubes, in which the protoplasm will be denser, and one or two nuclei may be observed there.

IV. Pick out gently a number of ovules from an ovary of a flower of Datura Stramonium, or of Digitalis purpurca, which has just faded, and mount in dilute glycerine. Observe-

I. The campylotropous ovules, with curved body.

2. Pollen-tubes, which are often to be found with the end applied closely to the micropyle.

Similar observations may also be made on Stellaria media, and many other plants.

\section{RESUlts OF FERTILIZATION.}

A. DEVELOPMENT OF THE EMBRYO.

i. Dicotyledon.

Pick out the ovules from a fresh ovary of Capsella Bursipastoris, which has attained about half the ultimate size of the mature fruit : material kept in spirit will not do well for this 
work. Treat with dilute potash, and examine with a low power. Observe--

I. The form of the ovule (campylotropous, i.e. with a curvature of the body of the ovule).

2. The funiculus, or stalk.

3. The integuments.

4. The micropyle, not very easily seen : a pollen-tube may often be observed entering the micropyle.

5. A large central cavity (the embryo-sac), which is curved like the whole ovule. In this may be seen, more or less distinctly-

\section{The embryo.}

To study the structure of the embryo, either longitudinal sections of the ovule must be cut, and the embryo be thus laid bare, or the embryo must be removed from the ovule. The former is the more accurate method, though the latter is much the easier: the latter will therefore be adopted.

Press gently with a needle upon the cover-slip of the above preparation, so as to burst the ovules : the embryo will escape in some cases without injury; but this will only be the case when fresh material has been used; after hardening in alcohol the embryos will not readily leave the ovule. Neutralize the potash with dilute acetic acid. The structure of the embryos which now lie freely suspended in the fluid, may be easily studied.

Apply the same method for the preparation of embryos, from ovaries of various ages, both younger and older than that first taken. A series of preparations may thus be obtained illustrating various stages of development of the embryo, such as are figured in ordinary text-books.

Note more especially the following successive stages of development :-

I. The suspensor, consisting of one or more cells and terminated by a single embryonic cell.

2. The embryonic cell divided into octants arranged in two tiers : the suspensor is elongated and the cells divided so as to form a series, of which the basal cell (that nearest the micropyle) is usually enlarged greatly, so as to exceed the embryo in 
size, and beginners are apt to mistake it for the embryo: the terminal cell next the embryo (the hypophysis) encroaches between the four lower octants of the embryo.

3. The octants so divided as to form three layers of cells, which have been distinguished as $(a)$ the external dermatogen, $(b)$ the periblem, $(c)$ the central plerome.

4. The two cotyledons formed by lateral outgrowth from the upper tier of octants, the apex of the radicle derived from the hypophysis, the hypocotyledonary stem from the lower tier of octants.

5. Other parts as before. The apical bud or plumule formed between the cotyledons.

\section{ii. Monocotyledon.}

Treat ovules of Alisma Plantago in the same way, and observe the following stages of development :-

J. Suspensor and embryo consist of a single short series of cells, produced by tranverse divisions.

2. The terminal cell divides longitudinally into four (first tier).

3. The second, third, and fourth cells from the end also divide successively (second, third, and fourth tiers).

4. The cells of the body of the embryo divide (as in Capsella) so as to form three layers: (a) external dermatogen, (b) periblem, (c) central plerome.

5. A lateral depression of the surface, at the level of the second tier. At the basal lip of this the apical cone of the plumule is formed.

The single cotyledon is formed from the first tier.

The radicle from the third tier.

The apex of the root from the fourth tier.

Compare these results with those obtained in Capsella.

\section{B. DEVELOPMENT OF THE ENDOSPERM.}

I. This may be traced in the embryo-sac of Caltha palustris in material which has been fixed and preserved in absolute alcohol or strong methylated spirit: it is an advantage 
to collect the material on a hot day, and place it in alcohol without delay; by this means many nuclei may be fixed in various stages of division.

II. Cut transverse sections of the carpels of a flower of Caltha palustris which is full blown, or even beginning to fade, and also sections of successively older specimens up to the almost mature fruit: treat them as before described (p. II9), and compare them : they may illustrate the changes which appear in the embryo-sac subsequently to fertilization, viz. :-

I. The penetration of the micropyle and apex of the nucellus by the pollen-tube.

2. The first stages of development of the embryo, which in this case remains relatively small, the seed being an albuminous one ; the embryo will thus be seen in situ.

3. The division of the central nucleus of the embryo-sac into two, subsequently into four, eight, \&c.

4. The disposition of the nuclei, as they increase in number, as a dense series embedded in the protoplasmic film at the periphery of the embryo-sac.

5. The formation of cell-walls between these nuclei, so that the embryo-sac is lined internally by a single layer of cells of the endosperm.

6. The ingrowth of these cells, and their subsequent division so as to fill the cavity of the embryo-sac with endosperm which embeds the embryo.

7. The great increase in size of the embryo-sac, and of the whole ovule.

8. Note also the changes in the integuments, and the disappearance of the nucellus as the ovules become mature.

On looking over a number of such sections, numerous cases of division of nuclei, illustrating various stages of the process, may be found. These points may be very well studied in the embryo-sacs of Fritillaria impcrialis, \&c.

III. The continuity of protoplasm through cell-walls has been shown in the sieve-tubes (p. 71). Similar observations of fine threads of protoplasm traversing the cell-walls may be made in the endosperm of various seeds, and these are merely prominent examples of a widespread phenomenon. 
Cut thin sections with a dry razor from the endosperm of the dry seed of Strychnos Nux-vomica : first mount a section in glycerine, and observe, under a high power, the dense protoplasmic body of each cell surrounded by a thick cellulose wall.

Mount other sections in tincture of iodine not diluted with water: then place a small drop of water at the edge of the cover-slip, drawing it under by means of blotting-paper: observe the edges of the section where the effect of the dilution will first appear, and as the cell-walls swell, it will be seen that they are traversed by fine threads of protoplasm, which are stained by the reagent.

Another method has been found to succeed well in demonstrating continuity through the cell-walls of the endosperm of various Palms, in which the endosperm has thick pitted walls consisting of reserve cellulose : it is, to immerse the fresh sections in sulphuric acid in which a small quantity of powdered Hoffmann's blue has been dissolved: when the sections are sufficiently acted upon, wash them with water and mount in glycerine. The protoplasm will be stained a deep blue, and the swollen cell-wall is not stained : examine the swollen pitmembranes, and if the treatment has been successful they may be seen to be traversed by fine curved strands of stained protoplasm.

\section{MATURE SEED AND EMBRYO.}

\section{(A) Dicotyledons.}

I. (a) Soak some Broad Beans for 24 hours in water: selecting one which is fully swollen, note its flattened form, and the dark blotch (the hilum) at one edge of it: this is the base of the seed, by which it was attached to the parent plant. Dry the surface of the seed and squeeze it gently, water will be seen to exude from a small hole close to the hilum : this hole is the micropyle, and is a guide to the position of the technical apex of the seed, the whole being of the curved or campylotropous type.

Remove the tough outer seed-coat, derived from the integuments, and the bulky, yellowish embryo, which occupies the 
whole space within the seed-coat, will then be disclosed : it is to be observed that there is here no tissue derived from nucellus, and no endosperm, and the seed is therefore described as exalbuminous : note the following parts of it :-

I. The two fleshy cotyledons, which are attached to one another at their base.

2. The conical radicle, which lies externally, and in the seed has its pointed apex directed towards the micropyle.

3. Separate the two cotyledons, and between them observe a bud, the plumule, composed of numerous small plumular leaves.

(b) Compare with the Bean the flattened seed of the Cucumber or Gourd : the micropyle may be found by the same means as before, at the pointed end of the seed, and close to it is the small scar of the hilum : this seed is of the anatropous type and is exalbuminous. Peel off the leathery seed-coat, and note the parts of the straight embryo, viz. :-

I. The radicle directed towards the micropyle.

2. The two cotyledons; fleshy as before.

3. Between them the very small plumule.

(c) Examine the ripe fruit of the Sunflower (Helianthus annuus). The "seeds" sold for sowing are really fruits (achænia), including the products of development of both ovary and ovule. It is a dry inferior achænium, with narrower basal, and broader apical end: at the latter is a scar, where were inserted the style and other floral organs.

Compare fruits in situ on the floral receptacle.

Dissect off the brittle pericarp, from the anatropous and exalbuminous seed, which it incloses.

Note the deiicate seed-coat, and, within this, the straight embryo, of which the radicle is directed towards the micropyle (i.e. towards the base of the fruit), and the two cotyledons towards the apex of the fruit.

Separate the two cotyledons, and note between them, at their point of attachment together, the minute plumule.

(d) Compare the structure of the albuminous seed of the Castor oil (Ricinus communis), observing externally the hard, bright, variously marked seed-coat, which has attached to it at the basal end a wart-like swelling-the arillus 
Remove the seed-coat, which is brittle and easily cracked; note beneath this a thin papery white layer,-the tegmen of old writers : this closely invests the white oily mass of the endosperm, a tissue which is not present at the period of maturity in any of the seeds above described. Cut this through transversely : and a flattened central cavity will be found, lined on either side by one of the thin flattened cotyledons of the embryo. Lay open the endosperm of another seed longitudinally, by a cut following the plane of the flattened cavity : it will then be clearly seen that the straight embryo is embedded in a mass of endosperm, and that it consists of two cotyledons, radicle, and plumule.

Longitudinal sections should be cut of the mature seed of Caltha for microscopic observation under a low power, and the relative positions of the firm testa, the endosperm, and embryo, are to be observed, together with details of their structure.

\section{(B) Monocotyledons.}

II. Soak fruits of the Maize (Zea Mais) in water for several hours. The fruit is a caryopsis, and results from the development of both ovule and ovary; its form is compressed conical, the apex of the cone being the basal point of attachment of the fruit.

Strip off the external coat of the fruit: this represents both the wall of the ovary and the integument of the ovule.

Distinguish in the body of the fruit which remains-

I. A lateral, smaller, white portion : this is the embryo.

2. A larger yellow part, which forms the greater mass of the fruit : this is the endosperm.

Separate the embryo from the rest, and note its shape.

III. Cut longitudinal sections of the fruit so as to traverse the embryo in a median plane: mount in glycerine, and examine with a low power : observe-

i. The coat of the fruit, consisting of two layers, the pericarp, and seed-coat. Note at the apex of the fruit the remnant of the style, and the scar of attachment at the base.

ii. The endosperm, consisting of thin-walled parenchyma ; the cells contain polygonal starch-grains, embedded in a matrix 
of protoplasm: in the peripheral yellower portion of the endosperm the starch-grains are more closely packed than in the central whiter portion.

iii. The embryo, which is in close apposition to the endosperm : the part which is in contact with it is the scutellum; it extends over the whole surface of contact, and almost completely surrounds the body of the embryo itself. Note the central attachment of the scutellum to the body of the embryo ; the vascular bundles, which form a connection through it ; the epithelium of peculiar structure, which faces the endosperm.

The body of the embryo consists of -

(a) An apical bud, with several sheathing leaves, which surround the apical cone.

(b) A radicle, having similar arrangement of the meristem to that of the older root (compare p. I06). Outside the radicle, and continuous with the root-cap, is a root-sheath, or coleorhiza: note that the body of the radicle is covered externally by a clearly marked series of cells which gives rise to the piliferous layer, and this, being enclosed by the coleorhiza, is not continuous with the superficial epidermis of the shoot.

\section{RESERVE AND TRANSITORY MATERIALS IN SEEDS, TUBERS, \&C.}

I. starch from the potato tuber has already been described with its reactions on p. 28: as further examples of its occurrence in seeds, cut sections of the cotyledon of the Pea or Bean : stain with iodine solution, and observe the large, oval starch-grains distributed through the tissue : note at the same time the protoplasmic matrix, and numerous small aleurone grains, which are stained yellow or brown.

Cut sections also of the endosperm of the Maize, and treat with solution of iodine. Note the polygonal starch grains (blue), and the protoplasmic matrix (brown).

Leukoplasts, or Starch-forming Corpuscies.-These are to be found in colourless tissues, in which a storage of starch is taking place; e.g. a young Potato, the rhizome of Iris, or Canna, \&c. 
Cut up very young Potatoes into small pieces, and treat with picric acid: wash out carefully with dilute alcohol, and harden.

Cut sections parallel to the surface, and not far below it (since the leukoplasts are best seen in the most superficial cells immediately within the corky rind): treat the sections for a few minutes in alcohol with a few drops of iodine solution added ; or in very slightly diluted tincture of iodine, and mount in pure glycerine : examine under a high power, and observe-

I. The cells of the usual parenchymatous type, with protoplasm and nucleus.

2. Numerous spherical bodies, usually aggregated round the nucleus: in some cells these will stain blue (starch), with a small yellowish body attached which is the leukoplast; in other cells, which were nearer the outer surface of the tuber, the bodies will stain uniformly yellowish brown: these are the young leukoplasts which have not yet formed starch.

II. Cellulose occurs as a reserve in the endosperm of the Date, and other Palms : sections should be cut and the reactions noted. Thickened cell-walls will also be found in sections of the cotyledons of Lupinus.

\section{Sugars.}

\section{(a) Grape-sugar.}

I. Cut a transverse section of a ripe grape, of such thickness that some cells at least shall be uninjured : mount in water, and observe under a low power the transparent parenchymatous pulp, consisting of cells with thin walls, very sparing contents, and large central vacuole.

Treat for a few minutes with a relatively large bulk of alcohol in a watch-glass : on re-examining, numerous crystals will now be seen in the cells.

Irrigate thoroughly with water : the crystals may be seen to be re-dissolved : they consist of grape-sugar, which is in solution in the cell-sap of the living cell.

2. Squeeze out the juice of some grapes into a test-tube : add a little of Fehling's solution (see Appendix A), and boil : a bulky yellow precipitate is formed owing to reduction of the copper. 
3. Soak a fairly thin section of a Grape in Fehling's solution: wash quickly with water, mount in water, and boil gently over a spirit-lamp : a precipitate like the above (2) is formed : note under the microscope that the dark-looking granules of the precipitate (cuprous oxide) are to be found actually within the cells of the tissue, thus indicating that the sugar was there.

(b) Cane-sugar.

I. Cut transverse sections of the Beet-root: mount them in water, and note under a low power the transparent tissue, and coloured cell-sap. Treat such a section for a few minutes with alcohol in a watch-glass : on re-examination under the microscope, crystals will be seen in the cells, but of smaller size than in the Grape. Re-dissolve by irrigation with water.

2. Boil some small pieces of Beet-root in a small bulk of water : pour off the coloured extract, add to it a little of Fehling's solution, and boil : no precipitate will be formed.

3. This point may be further verified by testing sections as directed above : no precipitate will be formed either in the cells or in the surrounding fluid.

IV. Oil-drops.

Cut thin sections of the cotyledons of the Almond : mount in water, and note the bright-looking oil-drops, both in and about the section, and dispersed also in the water.

I. Irrigate with alcohol : the drops are not dissolved.

2. Treat a section with a considerable bulk of ether in a watch-glass: wash with alcohol, and mount in alcohol, or in glycerine : on examination the oil will be found to have been dissolved by the ether.

3. Stain a thin section with tincture of alkanet (see Appendix A), the oil-globules stain pink.

4. Treat a section with I per cent. solution of osmic acid : the oil-drops will stain slowly, taking a dusky or black hue.

5. Treat a section with potash solution, and warm : the oil will be partially and slowly saponified and dissolved. This effect of potash is best seen in specimens where the oil is present only in small quantities as isolated globules.

V. Aleurone-grains.

These are found of the largest size in oily seeds : they vary 
somewhat in their characters in different plants: those of Ricinus may be taken as a good type.

Having noted the hard, variously marked seed-coat, with the wart-like swelling (aril) at the basal end, crack and remove it : beneath it will be found the white oily mass of the endosperm. Cut this through transversely, and with a razor wetted with olive oil, or castor oil, cut thin sections from it, and mount in the oil. Examine under a high power, and observe-

I. The thin cell-walls of the oval cells.

2. The numerous highly refractive aleurone-grains in each cell ; each is of oval form, and a less highly refractive area is seen at one end : this is the glaboid.

3. The oily matrix in which the grains are embedded, this being so transparent as to be hardly visible.

Cut other sections with the razor wetted with alcohol, soak them well in alcohol in a watch-glass to remove the oil, which is soluble in alcohol, but more readily in ether: if ether be used, wash it off afterwards with alcohol: mount in pure glycerine : examine them under a high power, and observe the appearance of the aleurone-grains as before when seen in oil.

i. Add water gradually, and watch its effect on the grains.

I. The outer amorphous coat of the grain will swell, and become less highly refractive: thus there will be disclosed-

2. The crystalloids, one, or rarely more, being included in each grain : these do not swell greatly with water, and accordingly they retain their refractive power.

3. The globoid will also be visible as before.

ii. Add dilute potash solution : the amorphous coats and the crystalloids will swell and dissolve, leaving the globoids.

iii. Add strong acetic acid : the globoids will dissolve slowly.

VI. Crystalloids.-Crystalloids of cubical form are to be found in the superficial tissues of the Potato. Cut tangential sections from material hardened in alcohol, or in picric acid and alcohol, and mount in pure glycerine and iodine : the cubical crystalloids will be distinguished by their yellowish brown staining. 
Treat a section, in which one or more crystalloids are under observation, with potash : the crystalloids will be seen to swell and dissolve.

Mount another section in alcohol or in glycerine, and, having observed the crystalloids, irrigate with a saturated solution of common salt : this also will dissolve the crystalloids.

$\cdot$

GERMINATION.

(A) Dicotyledons.

(a) Examine seedlings of Helianthus which have been germinating for different periods from one day to one week, and observe the following points in the process of germination :-

I. The internal parts of the fruit swell, and cause the brittle pericarp to split longitudinally.

2. The radicle protrudes, and curves downwards.

3. The hypocotyledonary stem elongates, so that the pericarp and seed-coat are carried upwards by the cotyledons, which remain inclosed by them for a considerable time.

4. The coats of the fruit fall from the cotyledons, which soon turn green, and expand as assimilating leaves, with the plumule seated between them.

5. The plumule develops leaves, which expand in succession.

6. The radicle has meanwhile elongated, and produced lateral roots.

Notice that when the young root is removed from the soil many particles adhere to it, especially at some distance from the apex : these are held by the root-hairs which attach themselves closely to the particles of soil.

(b) With the above compare seedlings of Ricinus in various stages of germination: in the main features the results are the same, but note especially that the endosperm remains for a long period in close connection with the cotyledons, and that as the seedling grows that tissue loses its firmness and density, owing to the abstraction of the nutritive substances stored in it, and their transfer through the cotyledons to the seedling. 
(c) It will be found useful to compare the germination of other seeds also, e.g. the Broad Bean, Kidney Bean, Cucumber or Gourd, \&c.

\section{(B) Monocotyledons.}

I. Comparing plants of Maize which have been germinating for different periods, the following facts in the history of germination may be observed:-

I. The fruit swells.

2. The outer coat ruptures opposite the apex of the radicle, which soon protrudes, bursting through the coleorhiza also, which appears as an irregular ring round the base of the young root. Since the coleorhiza is thus burst through by the young root, it is clear that the epidermis of the shoot is not continuous with the piliferous layer of the root.

3. The rupture of the coat extends upwards to the point opposite the apical bud, which also emerges.

4. The root elongates, and forms lateral roots : other lateral roots (usually two) burst out above the insertion of the scutellum : these soon equal the primary root in length, hence there is no well marked tap-root.

5. Leaves of the plumule unfold, and gradually turn green : the leaf inserted lowest, which was the outermost of those composing the plumule, remains small and develops no expanded lamina : this is the cotyledon, according to Hofmeister and other writers.

II. From a young plant with leaves about three inches long, cut longitudinal sections so as to traverse the whole fruit and the contiguous part of the seedling in a median plane : mount in water, and irrigate with solution of iodine Observe-

I. That in the neighbourhood of the surface of the scutellum the starch-grains are in course of demolition, and that the central part of each is first attacked.

2. That no starch-grains are to be seen in the epithelium of the scutellum. 


\section{GYMNOSPERMS}

\section{VEGETATIVE ORGANS}

\section{EXTERNAL CHARACTERS}

TAKE a branch of Pinus sylvestris, cut in autumn, including at least four years' growth. The limits of each year's growth may be recognized externally at those points where false whorls of strong lateral axes are developed; and the portion of stem lying between two such whorls may be regarded as roughly representing one year's growth.

I. Consider first the growth of the year in which the branch was cut, i.e. the part above the youngest whorl of lateral axes. At its apex is a large bud, surrounded by a variable number of smaller lateral buds.

From a bud, which has been treated with alcohol to remove the external secretion of the resin, detach some of the brown scale-leaves, which cover it externally. Note-

I. The succulent base of these scales.

2. Buds in their axils.

In studying the growth of the current year, bear in mind that it has been derived from a bud which had a similar structure to that which is now seated at its apex. Examine the stem of the current year externally, and note-

I. The thick main axis, more or less succulent in appearance : its surface is marked by longitudinal grooves.

2. The persistent brown tooth-like bases of the scale-leaves of the bud, the upper part of which had fallen in spring : they are best seen at the lower part of the internode. 
3. In the axils of these, especially at the upper part of the internodes, are axillary buds of two kinds.

(a) Buds with limited growth (bifoliar spurs), each bearing two acicular foliage-leaves, surrounded at the base with numerous scale-leaves. These dwarf foliage shoots occur in the axils of the scales throughout the greater part of the current year's growth : in older parts they may be found to have fallen off, the bifoliar spurs separating as a whole from the parent branch.

(b) Buds with unlimited growth, which are seated close to the apex of the shoot of the current year. They are few in number: their structure has already been observed : each may develop into an unlimited axis.

It may here be observed that $(a)$ and $(b)$ have a similar origin, both being axillary buds in the axils of the leaves of the main axis of the current year. The apparent difference depends upon the fact that the buds $(b)$ are more strongly developed than $(a)$.

II. Passing to the increments of growth of former years, i.e. to the lower and older parts of the branch, in the external appearance and arrangement of parts they resemble that of the current year. The main axis increases in thickness, and is more obviously ligneous, while the bifoliar spurs drop off, leaving scars which mark their former position.

\section{THE STEM.}

It is best to work with material which has been treated for some time with spirit; by this means the resin, which would otherwise clog the razor, is removed.

I. Cut transverse sections of the young elongating shoot of the current year taken in June : mount some in glycerine, others in chlor-zinc-iodine : the sections have a wavy outline, the indentations corresponding to the grooves which may be observed externally. Starting from the periphery of the section, note the following tissues :-

I. Epidermis, a single layer of cells, following the wavy out- 
line of the section: the walls, especially the outer, are much thickened : externally there is a cuticle.

2. Cortical tissue, consisting of cells having rather thick cellulose walls (blue with chlor-zinc-iodine), and protoplasmic contents with chlorophyll. Many cells have recently divided: this is necessary to keep pace with the growth in thickness of the vascular cylinder. Large intercellular spaces (resin-passages) occur here and there, and are lined with small-celled epithelium.

Near the periphery of the cortex may be found a layer of cork and a cork-cambium (compare stem of Elm, p. 54), derived from cells of the cortex by their division by tangential walls. The mature cells of the cork have no cell-contents : their walls are coloured yellowish brown with chlor-zinc-iodine.

3. The vascular system is here a complete ring, though it is composed of separate bundles in the bud, as may be seen if sections be cut from the axis of a dormant winter hud. Distinguish the external phloem, with its bright-looking cellulose walls (blue with chlor-zinc-iodine), the internal xylem, the components of which have thick dark-looking lignified walls (yellow with chlor-zinc-iodine), and the misty layer of cambium between them.

Observe that the internal limit of the vascular ring is sinuous: the convexities mark the position of the primary bundles: at the inner limit of these will be found the protoxylem.

4. The pith consists of parenchyma, having the same characters as in the bud : there are no resin passages.

Put on a high power, and examine the cambium. Note-

i. That the cells are arranged with great regularity in radial rows.

ii. That their watls are thinner than those of the surrounding tissues, and are composed of cellulose (blue with chlor-zinciodine),

iii. That the tangential walls are thinner than the radial.

iv. That the cells have copious protoplasm, in which a nucleus may often be recognized.

These facts point to a repeated division of cells by tangential walls. (Compare Fig. 7, A, p. 64.) 
Observe, here and there, radial rows of which the cells are more elongated in a radial direction than the rest: these may be traced outwards towards the cortex and inwards towards the pith : they are the medullary rays. (Compare Fig. 7, A, row 2.) Some of them may be traced the whole way to the cortex and to the pith (primary medullary rays), others only part of that distance (secondary medullary rays).

The mature cells of the ray usually have cellulose walls (blue with chlor-zinc-iodine), and granular protoplasmic contents with nucleus. In fact the cells of the medullary rays usually retain their cell-nature.

Follow the radial rows of cambium-cells outwards, and note the gradual transition to the permanent tissues of the secondary phloem, the constituents of which are also arranged in radial rows, and have cellulose walls (blue with chlor-zinc-iodine). The ring of secondary phloem is cut up into rectangular areas by the medullary rays, which are easily recognized as above directed. Observe that the tissues filling these areas are of three sorts-

i. Elements with cellulose walls, and no very distinct contents : they are radially compressed: these are the sievetubes, which compose the greater part of the phloem. The walls are differentiated into layers, and have bright globules attached to them.

ii. Here and there the radial rows of sieve-tubes are broken by single large cells of the bast-parenchyma, which resemble in their characters those of the medullary rays.

iii. Towards the periphery of the phloem are elements similar in form to the sieve-tubes, whose cell-contents are brown, and contain crystals.

Note on passing to the periphery of thes phloem an increasing irregularity of form of the tissues, due to distortion, caused by pressure from without by the cortical tissue upon the vascular system as it increases in bulk by secondary thickening.

Follow the radial rows of cambium-cells inwards, i.e. towards the centre of the stem. Note the transition from thin-walled cambium to the thick-walled tissue of the xylem. If the stem 
was cut in winter the transition will appear sudden, if cut in summer it will appear gradual.

Observe that the xylem-ring is cut by the medullary rays into wedge-shaped areas. The chief tissue-elements filling these areas are the tracheides, which present the following characters :-

i. They have approximately the same shape as the cells of the cambium from which they are derived.

ii. Their walls are thick and lignified (yellow with chlor-zinciodine), and are differentiated into layers, distinguished optically and by staining.

iii. They have no cell-contents.

iv. On their radial walls (and rarely on the tangential walls) are found the bordered pits, which are best seen in the xylem formed at the early part of the year.

These appear, when seen in transverse section under a low power, as bi-convex enlargements of the wall, which look darker than the rest of the wall : under a high power it is seen that there is a biconvex-lens-shaped cavity of the pit, overarched on either side by a meniscus-like outgrowth of the wall, which is seen in good sections to be perforated at its centre : the cavity of the pit is traversed by the thin pit-membrane, enlarged at its central point, :and occupying either a median position, or more commonly arched to one side : the wall is thus not perforated at the pits, but they are due to irregularity of thickening of the wall, the thinnest part remaining persistent as the pit-membrane.

Observe near the centre, and bordering on the pith, the protoxylem arranged as above observed in the younger stem. No bordered pits occur in the walls of the protoxylem.

Note the occurrence of resin-passages in the secondary xylem, lined as before by thin-walled epithelium which may be regarded as a form of xylem-parenchyma.

II. Cut transverse sections of a three-year-old-stem so as to include the whole width of the vascular ring ; it is not necessary however to have a complete transverse section of the whole stem. Mount in glycerine. Comparing this -with what has already been observed in the stem of the current year, note the following differences :- 
I. The cortical tissue bears evident traces of tangential extension. This is necessary to keep pace with the increase in bulk of the vascular system.

2. The phloem is thicker, and the constituents of the outer part of it are much distorted and displaced.

3. The xylem has increased in thickness more than any other tissue, so that it is now the chief constituent of the stem. It may be distinguished as being composed of three bands (annual rings), in each of which the more central tracheides have large cavity and thinner walls (wood developed in spring); passing outwards through the annual ring a gradual reduction of the cavity may be seen, and increase in thickness of the walls till a certain limit is reached (autumn wood).

Outside the latter is a sudden transition to the spring wood : at this point is the limit of each year's growth.

III. Cut radial longitudinal sections of a three-years-old stem : mount some in glycerine, others in chlor-zinc-iodine. The section should be accurately radial and longitudinal, otherwise the difficulty of study of the tissues is greatly increased.

Beginning at the centre of the stem and passing outwards, observe successively :

I. The pith, consisting of two sorts of elements, both of which are of parenchymatous form.

a. Cells with pitted cellulose walls, and having protoplasm and nucleus.

b. Elements of similar form with pitted lignified walls, and no cell-contents.

2. The xylem, consisting of-

a. Tracheides with lignified walls, and no cell-contents. Starting from those nearest the pith, and passing outwards, the following forms may be observed :

i. Tracheides with narrow cavity, and more or less regular annular or spiral marking-the proto-xylem.

ii. Elements wider than these, and with bordered pits scattered between the spirals.

iii. Normal tracheides, with bordered pits only : these form by far the greater bulk of the secondary xylem, and 
must be carefully studied. Their form is prosenchymatous. The greater part of the cell-walls is of uniform thickness. On these portions of the wall observe with the high power two intersecting systems of lines of striation. The bordered pits are found in single longitudinal rows: each of these has the appearance of two concentric rings, of which the smaller is more strongly marked, and corresponds to the opening of the cavity of the pit into the cell-cavity, the larger represents the limit of area of the pit. It must be remembered that we are now observing the radial walls in surface view. A careful comparison should be made of the bordered pit as seen here in surface view with its appearance when seen cut through, as in the transverse sections above described.

Note the annual rings recognized here as in the transverse sections, the autumnal wood being distinguished by the smaller size of the cavity and greater thickness of the walls of the tracheides.

b. Here and there the continuity of the mass of tracheides is broken by a longitudinal resin-passage, surrounded by parenchymatous cells, which have cellulose walls and retain their cell-contents.

c. The whole mass of xylem is traversed radially by plates of parenchyma (medullary rays). Note that they extend only a short way longitudinally, but a long way radially; also that they are composed of cells arranged like bricks in a wall, among which may be distinguished-

i. Cells with cellulose walls, and protoplasmic contents : the pits in the walls of the tracheides which abut on these are unusually wide.

ii. Elements with no protoplasm, and with lignified walls marked with bordered pits.

Both tissue-forms may often be found in the same ray, though rays will often be seen consisting of (ii.) alone. Note that between the cells (i.) clearly defined lines running radially may commonly be seen : these are intercellular spaces.

3. The cambium-layer, consisting of elongated thin-walled 
cells, the ends of which are difficult to observe. They have copious protoplasm, and an elongated nucleus. (Compare Fig. 7, B, p. 64.)

Note that the medullary rays are continuous through the cambium, and observe the differentiation from the uniform cambium of the ray to the forms $(a)$ and $(b)$.

4. The phloem tissues, which are best studied in sections which have been treated for some hours with chlor-zinc-iodine, consist of-

$a$. Sieve-tubes, elongated structures with cellulose walls, those which are radial being marked by numerous circular sieve-plates, here seen in surface view : these sometimes stain a sherry brown with chlor-zinc-iodine. The ends of the tubes are difficult to observe : their protoplasmic contents are transparent and sparing.

b. Phloem-parenchyma, cells arranged in longitudinal rows, with cellulose walls, and copious protoplasm.

c. Occasional elements (prosenchymatous or parenchymatous) with brown cell-contents, in which crystals are embedded: these are found towards the periphery of the phloem.

Medullary rays will be seen with a similar arrangement to that seen in the xylem. Their cells, which resemble those of the phloem-parenchyma in character, are all alike.

5. Externally to the phloem is the cortical parenchyma, which requires no further notice here. Outside this is cork, and at certain points a little sclerenchyma. At the periphery of the section is the epidermis.

V. Cut tangential sections of a three- or four-years-old branch, and bear in mind that as a rule the central part of the sections is the most accurately tangential, i.e. that the plane of section is there most accurately perpendicular to the radius of the stem. (See p. 6.) Sections should be cut at different depths in the tissues, so that the middle of the plane of section shall traverse (a) the peripheral part of the xylem, (b) the cambium, and $(c)$ the inner part of the secondary phloem. Mount as before.

(a) In sections which pass through the peripheral part of the xylem observe-

i. The tracheides, of prosenchymatous form. No bordered 
pits (or very few) are seen in surface view, but they may be seen in large numbers in the radial walls (here cut longitudinally), presenting a similar appearance to that seen in transverse sections.

ii. Medullary rays, which resemble a section of a biconvex lens. Note that each ray extends only a short distance in a longitudinal direction : in some cases rays consist of only a single radial series of cells, of which only one lenticular cell appears in this section. In those rays which consist of several rows of cells, note the small triangular intercellular spaces which intervene between the cells : these are only seen in thin sections. Occasionally a resin-passage is included in a ray.

iii. Longitudinal resin-passages.

(b) In sections passing through the cambium will be seen-

i. The cambium-cells, resembling the tracheides in form (prosenchymatous): the cell-walls are thin, and the protoplasm granular, with elongated nucleus.

ii. The cambium of medullary rays is similar in shape to the cells of the rays : it is thin-walled, with granular protoplasm and nucleus. (Compare Fig. 7, C, p. 64.)

If these sections be treated with dilute potash, and mounted in glycerine, their structure may be more easily made out.

(c) In sections passing through the phloem will be seen-

i. The medullary rays as before, but their form is more convex: all the tissues between the medullary rays are derived from cambium-cells of the form above observed. These are-

ii. Sieve-tubes, which retain the form of the cambium-cells : the cellulose walls seen in surface view are smooth : those cut longitudinally appear of wavy outline (sieves) : the structure of the latter is well seen after treatment with chlor-zinc-iodine for twenty-four hours.

iii. Bast-parenchyma, derived from cambium-cells by their division by transverse walls.

iv. Some few cells, especially towards the periphery containing crystals which give the reactions of calcium oxalate. 


\section{THE LEAF.}

Examine the bifoliar spur of Pinus sylvestris as a whole: it consists of a very short axis, at the base of which are borne membranous sheathing scales, and at the apex two long needleshaped foliage-leaves : in other species of Pinus the number may be larger. Note that the inner, or morphologically upper surface of the leaf is flat, while the outer or lower surface is rounded, and the whole leaf is traversed from end to end by two sharp marginal ridges which are slightly rough to the touch.

Cut transverse sections of a foliage-leaf taken from a stem of the current year. It may be found convenient to embed in paraffin, or to hold the leaf between pieces of pith, or carrot. Mount some in glycerine, others in chlor-zinc-iodine, and examine with a low power. Note the semilunar form of the section : the flat side is the upper, the convex side the lower. Starting from the periphery observe successively the following tissues :-

I. A single layer of epidermal cells with very thick walls : enlarged cells are to be found at the two corners, and since these cells project slightly they cause the roughness above noted.

2. A narrow band of thick-walled hypoderma.

3. A broad band of chlorophyll-containing mesophyll, with resin-passages.

4. A bundle-sheath or endodermis, consisting of oval cells.

5. A broad band of tissue without chlorophyll (the pericycle), which surrounds-

\section{Two central vascular bundles.}

Study these several tissues under a high power.

I. The epidermal cells have their thick walls differentiated into three layers. These may be recognized without staining, or better after treatment with chlor-zinc-iodine, as-

i. A thin external cuticle, not very deeply stained : it extends as wedge-like processes between the cells. 
ii. The cuticularized layers, forming a thick band, which stains a deep brown. Immediately surrounding the cell-cavity is-

iii. A broad pitted band, not deeply stained.

Here and there depressions of the external surface may be observed. These indicate the position of the stomata. Observe the two guard-cells, which are seated some distance below the surface of the leaf : an intercellular space (respiratory cavity) is to be seen immediately below each stoma.

2. The hypoderma (sclerenchymatous) varies in thickness from a single layer of cells to several layers. It is thickest at the corners of the section : the cells are thick-walled, and lignified. Note that it is absent below the stomata.

3. The mesophyll consists of thin-walled, chlorophyll-containing parenchyma : the cellulose walls (blue with chlor-zinciodine) show a peculiar in-folding. Resin-passages occur in it: their cavity is lined with thin-walled epithelium, which is immediately surrounded by a layer of thick-walled sclerenchyma.

4. The endodermis has its walls stained brown with chlorzinc-iodine.

5. The tissue immediately within this, which may be called the pericycle, consists of two elements-

i. Parenchymatous cells, with thin cellulose walls (blue with chlor-zinc-iodine), and protoplasmic contents.

ii. Elements having lignified walls, with bordered pits, and no cell-contents (tracheides, or "transfusiontissue").

6. The two central vascular bundles, the constituents of which resemble those of the stem. Note that the xylem is directed towards the upper surface. Thick-walled sclerenchyma is scattered irregularly round the bundles.

A description of the root is given in the larger edition. 


\section{REPRODUCTIVE ORGANS}

It has been above noted (p. 134) that at the apex of the ordinary vegetative branch in spring there is an apical bud surrounded by a number of lateral buds, all of which normally develop into vegetative axes of the type above described. The reproductive organs of Pinus are produced on buds corresponding in position to these : they are easily distinguishable, even at an early stage of development, with the naked eye, as male and female, which are borne on separate axes (declinous), but may be upon the same tree (diœcious). The following observations should be made upon specimens preserved in alcohol, otherwise they could only be made at intervals, according to the period of development of the organs in question.

A. Male inflorescence. - Note that the inflorescence while young appears as a bud covered with brown scale-leaves, in the axils of which are lateral axes easily seen on removing the scales. Of these lateral axes-

$a$. Those nearest the apex of the bud develop as lateral foliage-shoots, as is the case on the ordinary vegetative axis.

$b$. Below these, a number bear, in place of the two foliageleaves, numerous staminal leaves: to each one of these axes the term flower may be applied.

I. Separate a single male flower, and cut it longitudinally in a median plane: it will be found to consist of -

1. An axis, which bears-

2. At the base of it several small scale-leaves.

3. A number of staminal leaves are inserted above.

Detach some of these staminal leaves with a needle : each consists of - 
a. A short stalk, or filament, which bears at its apex-

b. An expanded anther, with two swellings on the lower surface (pollen-sacs, or microsporangia).

II. Cut longitudinal sections of the male flower in which the pollen is not yet ripe, and mount in glycerine : examine with a low power. Note the arrangement of the parts as above described: in the pollen-sacs note the pollen-grains in situ (microspores).

III. Mount ripe pollen-grains (i.e. such as may be collected by shaking a male branch in June) in dilute glycerine, having previously wetted them with alcohol. Observe-

I. The two large lateral wings, usually filled with air, which facilitate the transfer of the pollen by the wind: these are extensions of the outer coat (extine).

2. The central body of the pollen-grain, consisting of-

a. A large cell, which constitutes the greater part of the grain, and from which the pollen-tube springs.

$b$. A series of one or more smaller cells affixed laterally to the wall of the pollen-grain at a point between the wings: they are placed on the convex side of the grain, which is not so completely covered by the wings. These take no direct part in the formation of the pollen-tube.

B. Female branches or cones - Observe on a Scotch Fir, towards the end of June, that there are cones to be found in three different stages of development, the position of which is constant.

a. Small green cones, one or more of which occur close to the apex of the shoot of the current year. Note that the basal part, or stalk, bears brown membranous scales, while the upper part is globular, and is marked out into numerous square areas, which are the apices of the ovuliferous scales. Comparing a shoot, which bears such young cones, with an ordinary vegetative shoot, it will be seen that the cones correspond in position to the lateral buds, of which they are the morphological equivalent.

b. Larger green succulent cones, which occur laterally at the apical part of the shoot of the previous year : the arrangement of parts on these corresponds to that on $(a)$. 
c. Cones larger than $(b)$, brown and with lignified tissues : on these the scales are usually more or less separated from one another, so as to disclose the seeds, two of which are borne at the base of each of the ovuliferous scales. These ripe cones are seated laterally near the apex of the two-years-old shoot.

I. Cut median longitudinal sections of a cone corresponding to stage $(a)$. It should previously have been hardened with alcohol for some days : mount in glycerine, and examine with a low power. Observe-

I. The central axis, not differing essentially from the young vegetative axis: on this are borne scales of two orders easily distinguished by their size.

2. The smaller of these are the leaves borne by the axis of the cone, and the morphological equivalents of the brown scaleleaves which cover the winter buds.

3. In the axil of each of these is borne one of the larger or ovuliferous scales, which are longer and more bulky than $(b)$ : they alone can be seen externally. On the upper surface of each of these, close to the axis, are borne-

4. Two ovules or macrosporangia, which are anatropus, so that the micropyle is directed towards the base of the scale : if cut in a median plane, each ovule will be seen to consist of-

i. One integument, several layers of cells in thickness, with a widely open micropyle facing the axis : this surrounds-

ii. The nucellus, a mass of parenchyma, near the centre of which is-

iii. The embryo-sac or macrospore, a cell much larger than those of the surrounding tissue, and lying some distance below the apex of the nucellus.

Pollen-grains may often be found seated on the apex of the nucellus : one or more of these may throw out pollen-tubes, which penetrate into its tissue.

Dissect off one whole ovuliferous scale, and observe on its upper surface, close to the base, two ovules, which are anatropous. Note also the relative positions of the two sets of scales.

II. Take cones of the stage above described as $(b)$. The 
material should be collected about the middle of June, and must be hardened in alcohol.

Strip off the ovuliferous scales of such cones : the ovules will remain adherent to the base of each. Cut longitudinal sections of the scales so as to pass through the median planes of the ovules: mount in pure glycerine, and examine with a low power. Observe-

I. The structure of the ovuliferous scale, which is traversed by vascular bundles, and resin-passages.

2. The ovule, which is united with the scale, and consists, as in the younger stage, of-

$a$. An external integument : note the wide micropyle.

$b$. The nucellus as before, but larger.

c. The embryo-sac, filled with the thin-walled tissue of the endosperm. All the parts of the ovule are larger than in the younger stage, but retain the same relative positions. Note carefully that pollen-grains (one or more) are usually to be found lying on the apex of the nucellus, and that from the larger cell of each of them arises a cylindrical pollen-tube, which traverses the tissue of the nucellus as far as the apex of the endosperm, where it widens out into a large sac.

Observe near the apex of the endosperm, and embedded in it, one or more large vacuolated protoplasmic bodies: these are the egg-cells, or ova. From the apex of each a small cell is cut off shortly before maturity : this is the ventral canal cell. Leading upwards from this (i.e. towards the micropyle) may be traced a narrow neck or channel, inclosed by smaller cells than those of the surrounding endosperm. The neck, ventral canal cell, and ovum, together form the archegonium.

III. Remove ovules from cones of the second year, taken and preserved in alcohol about August r. Dissect off from them the now hardened integument or seed-coat : note within this the delicate remnant of the nucellus, which covers the mass of endosperm. Soak the latter in water, and dissect from it with needles the numerous embryos, which lie in the central cavity of the endosperm : treat them with potash, and mount in dilute glycerine. Examine with a low power, and observe- 
I. The suspensors, coiled filaments consisting of numerous transparent thin-walled cells. At the ends of the suspensors are borne-

2. The embryos : they are more or less elongated, almost cylindrical bodies : in some cases (only one as a rule in each seed) they may have already formed-

a. An apical cone, which terminates the free, anterior end of the embryo ; this being surrounded by-

$b$. A whorl of cotyledons of variable number.

c. The apex of the radicle, directed towards the suspensor (i.e. towards the micropyle of the ovule), and imbedded in the tissue at the posterior end of the embryo.

Note that there is no definite boundary between the suspensor and the embryo. Also that though polyembryony is the rulethat is, a number of embryos are at first formed simultaneouslyone of these supersedes the rest, and that one alone becomes differentiated as above described.

\section{Ripe Seed.}

Examine the ripe seed of $P$. sylvestris, and note the external hard and thick seed-coat : within this the endosperm, which incloses the single embryo. It has numerous cotyledons, and a radicle, the apex of which is directed towards the micropyle.

\section{Germination.}

Compare plants in different stages of germination, and observe the following points in the process :-

I. The endosperm swells, and bursts the testa.

2. The radicle protrudes, and curves downwards.

3. The cotyledons elongate, and push out the stem and their own basal portion from the cavity of the endosperm.

4. The rest of the seed is usually carried upwards on the apex of the cotyledons, which, with the hypocotyledonary stem, elongate greatly.

5. The plumule develops, forming numerous acicular leaves.

Note that the cotelydons turn green while still protected from the light, below the soil, and within the testa. 


\section{PTERI DOPHYTA}

\section{A.-LYCOPODIN $Æ$}

\section{Heterosporous Type}

\section{SELAGINELLA MARTENSII}

SPOROPHYTE

I. This plant is commonly grown in green-houses, and specimens can be readily obtained from nurserymen. In a wellgrown plant note with the naked eye the following external characters :-

I. The stem ascending, frequently branched, apparently in a dichotomous, but really in a monopodial manner : the branching occurs only in a single plane.

2. The leaves, of small size, and simple in form, with a ciliate margin, and arranged in alternating pairs : each pair consists of a dorsal and a ventral leaf, the whole series thus forming four orthostichies : note the two different sizes of leaves-

$a$. The larger ventral leaves, arranged in two orthostichies, and without terminal awns.

$b$. The smaller dorsal leaves, also arranged in two orthostichies, each leaf being terminated by a fine awn.

Each leaf has a single central nerve or midrib. Turn back one of the leaves, and observe with a lens the small scale-like ligule.

3. The rhizophores, long cylindrical branched organs, which arise at the points of branching of the obliquely ascending stem, and grow vertically downwards : note their frequent bifurcations. 
Remove a rhizophore, which has grown down so as to reach the soil, and wash it : observe-

4. The delicate roots, which rise at the point where the rhizophores touch the soil, and branch in a monopodia! manner; and though they often seem to bifurcate it appears not to be a case of true dichotomy.

Observe further that many of the branches of the stem may have a symmetrical arrangement of the leaves close to the apex: these are the branches or cones, which bear the sporangia : note that on these cones-

i. The leaves are all similar to one another and of small size.

ii. That they are arranged in four symmetrical orthostichies.

iii. That on turning the leaves back, one sporangium will be disclosed in each case. On comparing a number of sporangia which have been exposed in this way, it may be seen that there are two sorts of them-

a. Macrosporangia, which are of a green or light-brown colour, and appear to be of rounded tetrahedral form.

b. Microsporangia, which are more nearly spherical, and of a reddish-brown colour.

Note in older cones that the sporangia are already open, dehiscence having taken place in a plane parallel to that of the leaf.

II. Cut out as thick a piece of the stem as can be found, and about one inch in length : note a central white dot on the transversely cut surface: this is the single central vascular bundle. Slice off the upper surface of the stem with a razor till the whole course of the vascular bundle is laid bare, and observe with a lens-

I. The course of the central vascular bundle, which is directly longitudinal and median.

2. The smaller lateral bundles, which pass from the central bundle without branching into the leaves, and traverse the midribs of the leaves.

III. Cut transverse sections of a well-developed stem : mount some in glycerine, others in chlor-zinc-iodine : others again may be mounted in acid solution of aniline sulphate. Examine first 
under a low power, using a high power when necessary, and observe the following tissues in succession, starting from the periphery of the section :-

I. At the periphery a layer of small, thick-walled cells, forming an ill-defined epidermis, with no stomata : it is covered externally by a continuous cuticle. Beneath the epidermis, and not clearly marked off from it, is-

2. The cortical tissue : the cells of the peripheral part of it have thick stratified and lignified walls, with no intercellular spaces. Passing inwards there is seen a gradual decrease in thickness of the walls, and increase in size of the cells, till an abrupt limit is reached at-

3. The lacunar tissue, consisting of thin-walled cells, which form irregular trabeculæ traversing the intercellular cavity in a radial direction: this tissue may be regarded as the equivalent of the endodermis.

4. By means of these trabeculæ the single central vascular bundle is suspended in the middle of the large air-cavity: the bundle is of elliptical outline, as seen in the transverse section, and is built upon the concentric type : it is composed of the following tissues:-

$a$. The pericycle, an irregular band of comparatively large, thin-walled cells, which completely surround the central tissues, and abut externally on the intercellular cavity, and the trabeculæ. The cells of this layer, in common with all the outer tissses, including the epidermis, may contain chlorophyllcorpuscles.

$b$. The phloem, recognised as a tissue with thin cellulose walls, small cavities, and sparing protoplasmic contents : though reduced in bulk at the poles of the elliptical bundle, it forms a continuous band surrounding-

c. The central xylem, which appears as a spindle-shaped mass of tissue when seen in transverse section, and consists of elements with lignified walls, and no cell-contents.

Small vascular bundles of rounded outline, as seen in the transverse section, may be found opposite or near to the ends of the spindle-like vascular bundle; these are bundles of the leaf-trace cut through on their course inwards from the leaves : 
thus the whole bundle-system of this shoot consists of a single central bundle, which traverses the axis longitudinally, and gives off smaller branch-bundles, which pass outwards into the leaves, one of them entering each leaf.

Note with a higher power-

I. The general appearance of the phloem, with its highly refractive cellulose walls, and scanty protoplasm.

2. Between this and the xylem is a somewhat irregular series of cells of the conjunctive parenchyma, with thin cellulose walls and plentiful protoplasm.

3. The chief constituents of the sylem are large prismatic tracheides, with peculiarly marked, lignified walls.

4. At the poles of the spindle-shaped xylem note tracheides of smaller size : these compose the first-formed protoxylem : the development of the xylem thus starts from the periphery and proceeds towards the centre of the oval xylem.

IV. Cut transverse sections of fresh leaves held in a piece of pith : mount in water or weak glycerine, and observe-

I. The epidermis of the upper surface consists of conical cells, each of which contains a single large chlorophyll corpuscle. Stomata are absent.

2. Beneath this is the spongy parenchyma, which incloses centrally-

3. A single vascular bundle.

4. The epidermis of the lower surface consists of smaller cells containing chlorophyll, and with stomata opposite the midrib.

V. Cut longitudinal sections through fertile branches similar to those cut from the vegetative bud, and examine them under a low power. In the lower part, if the section was median, the same succession of tissues may be recognised, as has been already described in the transverse section (III.) Starting from the outside, they will be as follows :-

I. Epidermis \} these are hardly to be distinguished one

2. Outer cortex $\}$ from another: the cells of both are prosenchymatous, and thick-walled, and show a gradual transition to-

3. The inner cortex, in which the walls are thinner, and the form of the cells parenchymatous. 
4. The lacunar tissue, the cells of which are elongated in a radial direction.

5. The pericycle, consisting of elongated parenchymatous cells, with cellulose walls, and often containing chlorophyll.

6. The phloem, the most prominent elements of which are long narrow elements with cellulose walls and sparing contents : these are regarded as the representatives of the sievetubes.

7. The xylem, the most prominent elements of which are spiral and scalariform tracheides, similar to those to be described below as composing the xylem of the bundle in the Ferns.

Observe the general arrangement of the stem, leaves, and ligules.

In the lower part of the sections a mature sporangium may be found in the axil of each leaf. The sporangium may have lost its spores partially or entirely during the preparation of the sections. It will consist of -

a. A short massive stalk.

b. A wall inclosing the central cavity : the wall will be found under a high power to consist of three layers of cells-

i. The outer consisting of thick-walled cells, more or less elongated radially.

ii. A layer of small, compressed cells.

iii. A layer of thin-walled cells, elongated radially : this is the tapetum, which is here persistent until the spores are ripe.

Surrounded by the wall will be found-

c. Spores of two sorts, contained in different sporangia-

i. Microspores of relatively small size : these will be found in large numbers in certain sporangia, which will accordingly be recognized as microsporangia. When ripe they may be still seen to cohere in groups of four : each spore is a single cell with a brown wall.

ii. Macrospores of relatively large size : four only of these will be found inclosed in a single sporangium, which is accordingly termed a macrosporangium. Each spore consists of a thick wall, with numerous external projections, surrounding a large cavity filled with protoplasm, \&c. 


\section{THE GAMETOPHYTE OR OOPHYTE}

VI. Spores of both kinds may be obtained free by drying branches which bear sporangia on sheets of paper. Pick out the macrospores, and mount them in olive-oil: dissect off the brittle outer coat of the spore with needles, and examine under a high power. It will be seen that the chief contents of the ripe spore are a protoplasmic matrix inclosing oil-globules and aleurone-grains, while traces of the cells of the prothallium may be recognized even in these preparations.

If plenty of spores are to be had, embed a quantity of them, and to cut sections, mounting them in glycerine. Observe-

I. The character of the wall, consisting of-

a. An outer thick, yellow exospore.

$b$. An inner thin endospore.

2. The contents as above described: the natural position of the cellular tissue of the prothallium may be seen to be at the apex of the cavity of the spore.

VII. Spores of both kinds should be collected in considerable quantity by drying on paper, and then be sown on moist soil or sand, and left to germinate. In a few weeks young seedlings will be seen with an erect axis, bearing small leaves. Note that the axis of the seedling branches at an early period.

Remove some of these seedlings from the soil, and note the monopodial branching of the root, and the macrospore still attached laterally to the axis.

Longitudinal sections should be made through the young seedling, so as to traverse also the macrospore attached to it: in such sections it will be readily seen that a lateral outgrowth (the foot) projects from the base of the axis into the cavity of the macrospore: also that the latter is filled with a cellular tissue of the prothallus, from which the nutritive substances above noted in the mature macrospore will have been removed.

A detailed description of work to be done on Lycopodium clavatum, as a homosporous Lycopod, is given in the larger edition. 


\section{B.-FILICINEA}

\section{Homosporous Type}

\section{NEPHRODIUM FILIX-MAS (The Male Shield Fern)}

\section{A.-MATURE SPOROPHYTE \\ I.-External Characters}

I. Taking a well-grown plant of the common Male Fern in summer, wash the soil away from the roots, and observe the following external characters :-

A. The stem is oblique and ascending: it is not branched at its apex : its surface is covered by the persistent bases of the leaves, which are densely covered by numerous brown scaly hairs (paleæ or ramenta).

B. The leaves, the most prominent of which are-

i. The fully developed green leaves of the current year: of these the following parts may be recognized :-

$a$. A long almost cylindrical leaf-stalk, which is traversed by two longitudinal, lateral ridges or reduced wings. This leafstalk supports-

$b$. The numerous pinnæe, which are arranged in two lateral rows, corresponding in position to the lateral ridges above mentioned: note that the arrangement of the nerves in the segments of the pinnæ is based upon repeated bifurcation of the stronger nerves. On the under side of the pinnæ will frequently be found-.

c. Sori, which are roundish brown groups of small stalked bodies (sporangia), covered by a kidney-shaped indusium. 
ii. The bases of the leaves of previous years will be seen, covering the lower part of the stock or stem externally: observe that lateral buds are frequently to be found connected with these, being attached to their ab-axial side, near to their point of junction with the stem.

iii. Nearer the apex of the stem than the expanded leaves of the current year, and completely covering it, are young leaves, densely covered with ramenta: these, together with the axis, constitute the apical bud. Note that the apex of each such leaf is rolled up like a crozier (circinate vernation).

C. The roots are rather thin and brown, with transparent apices: they are inserted on the bases of the leaves, close to their junction with the stem : the branching of the roots is monopodial, and their branches appear in acropetal succession.

\section{II.-Anatomical Characters to be observed with the naked eye.}

II. Having observed the above external characters, remove the roots, keeping the transparent apices of the young roots, as well as the thickest parts of the old roots : these should be preserved in alcohol for further treatment.

III. Remove from the apical bud the large quantities of scaly hairs (ramenta), so as to lay bare-

I. The young leaves, with their circinate vernation.

2. The broad apex of the stem with leaves in various stages of development around it.

3. The young roots which will be found already present on the bases of the young leaves.

4. The young buds which may be observed at a very early stage on the posterior side of the leaves.

Starting from the older end of the stock, cut off successively the persistent bases of the old leaves about half an inch above their insertion on the stem. Observe the lateral bud borne by some of the leaves on the ab-axial side of the leaf-stalk near its base : observe also that the roots spring from the bases of the leaves, close to their insertion on the stem.

If the specimen be a large one, with a stock 5 or 6 inches in length, cut off about 2 inches of the older end of the stem 
exposed as above, and boil it in dilute hydrochloric acid till the parenchyma is soft : for further treatment of this see below. Meanwhile smooth the cut end of the remainder of the stock with a razor, so that it may present an even surface of transverse section, and observe-

$a$. The great irregularity of outline, due to the close crowding of the bases of the leaves.

b. The dark brown band of sclerenchyma bordering the periphery of the section.

$c$. The great bulk of the stem consisting of yellowish parenchyma, with very bulky central pith,

d. Round the latter are a number of isolated, large vascular bundles, forming an interrupted ring.

$e$. Outside these, and running out into the leaves, are numerous smaller bundles of the leaf-trace, which appear to be less regularly arranged.

IV. Divide the stock, including the apical bud, into two symmetrical halves by cutting it in a median longitudinal plane: smooth one of the cut surfaces with a razor, and observe--

$a$. That the stem is of almost equal thickness throughout its length, i.e. it is roughly cylindrical.

$b$. That its external conformation is very irregular by reason of the closely crowded insertion of the leaves.

c. The bulky central pith as before.

$d$. The large vascular bundles ( $d$ above), which are not continuous in direct longitudinal lines, but form an interrupted series.

$e$. The smaller bundles of the leaf-trace ( $e$ above), which in some cases may be followed, after a little careful dissection of the parenchyma which surrounds them, from one of the larger bundles of the central system into the base of one of the leaves.

Slice away carefully the external tissues of the posterior part of the stock, so as to lay bare the central system of larger bundles: it will then be seen that these form a continuous network with large meshes, and that each mesh is opposite the point of insertion of one of the leaves, hence it is called a 
follar gap. Observe also that the vascular bundles, which pass out into any individual leaf, are given off from the margin of its own mesh.

Confirm these observations by the dissection of the stock: the parenchyma may be easily removed, leaving the vascular system as a network of stronger bundles, which gives off nume-

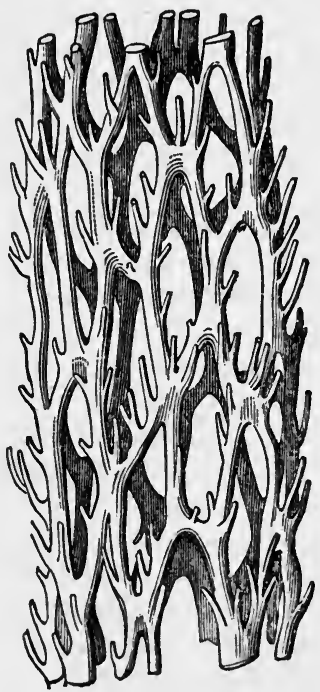

Fig. 10.-Vascular skeleton prepared by maceration and dissection from the stem of Nephrodium Filix mas. (After Reinke.) (2: r.)

rous weaker bundles from the margins of its meshes; these weaker bundles run out into the leaves.

By careful dissection a skeleton may be prepared similar to that shown in Fig. Io.

\section{III.-Microscopic Investigation.}

V. Cut transverse sections of the stock of Nephrodium : it is hardly to be expected that a transverse section of so bulky a 
stem as this could be cut so uniformly thin that the structure of all the tissues could be well seen ; it is better therefore to cut a number of sections, each extending over a comparatively small area, and to study the various tissues separately. Mount some in glycerine or glycerine jelly, others in chlor-zinc-iodine. Examine under a low power, and observe successively the following tissues, starting from the periphery of the stem :-

a. An epidermis, consisting of a single, somewhat irregular and ill-defined layer of cells, with dark brown outer walls : their arrangement is disturbed at the point of insertion of the scaly hairs, which appear as plates of cells one layer of cells in thickness, rising obliquely from the epidermis. Beneath this is-

b. The ground-tissue, which is differentiated as-

i. An outer narrow band of tissue, with rather thick, colourless, pitted walls, and cell-contents with much starch : there are no intercellular spaces.

ii. A band of sclerenchyma with thick, yellow, lignified, obviously stratified, and pitted walls, cell-contents as in (i.), and no intercellular spaces. This merges gradually into-

iii. The bulky central mass of ground-tissue, in which the vascular bundles are embedded. It consists of cells with comparatively thin, pitted, cellulose walls, protoplasmic contents with much starch, and with intercellular spaces. Internal glandular hairs are also found in the intercellular spaces.

c. The vascular bundles of elliptical outline: they are embedded in the ground-tissue, and are sharply circumscribed by a narrow, light brown layer of cells without intercellular spaces : this is the bundle-sheath or endodermis. Among the tissues inclosed by this sheath, note that a large central mass may be distinguished as consisting for the most part of elements with large cavity, no cell-contents, and rather thick walls with a peculiar marking: this is the xylem. Between this and the bundle-sheath is a broad band of tissue with thin, bright-looking walls, and with protoplasmic contents: this is the phloem. Since the xylem is surrounded by the phloem, this bundle is said to be of the concentric type.

In the sections treated with chlor-zinc-iodine note that the 
walls of the inner ground-tissue stain blue, and that starch is found in the cells; that the bundle-sheath appears browner than before; that the walls of the phloem stain blue (cellulose), and the contents yellowish; that the walls of the chief constituents of the xylem stain yellow (lignified).

VI. As the vascular bundles of the leaf-stalk are better fitted for minute observation, and are better types of the concentric bundle of the Fern than those of the stem, cut thin transverse sections of the lower part of the petiole. Having previously noted with a low power that in their main features the tissues resemble those above observed in the stem, examine the structure of one vascular bundle under a high power, and starting from the periphery of it, note successively-

I. The bundle-sheath or endodermis, a single layer of cells, with yellowish walls, and yellow granular contents: there are no intercellular spaces in this layer, nor in any of the tissue surrounded by it.

2. The phloem-sheath or pericycle, which is a band of tissue of varying thickness at different parts of the bundle, being thin at the poles of the elliptical bundle, and thicker at the sides : it consists of cells of roundish form, with cellulose walls, and protoplasmic contents, and starch.

3. At the inner limit of the pericycle are found elements with thick cellulose walls and narrow cavity, these constitute the protophloem.

4. Internally lies the broad band of true phloem, which is composed of two tissue-forms-

a. Sieve-tubes, which appear polygonal in the transverse section, with thin cellulose walls which are lined by a delicate protoplasmic membrane dotted with numerous highly refractive granules.

b. Cells of the conjunctive parenchyma, with thin walls and protoplasmic contents.

5. Centrally lies the $\mathbf{x y l e m , ~ i n ~ w h i c h ~ a l s o ~ t w o ~ c o n s t i t u e n t s ~}$ may be recognized -

a. Tracheides, which appear polygonal in section, and have large cavities, with no cell-contents: the walls are thick and lignified, and show a peculiar structure 
which will be better understood on comparison of their appearance in longitudinal sections.

b. Conjunctive parenchyma with cellulose walls, and protoplasmic contents with starch: these cells are distributed evenly throughout the xylem, and also form a band surrounding it completely.

VII. As a preliminary to the study of longitudinal sections, separate some pieces of the vascular bundles of Pteris or Nephrodium from the surrounding tissue, and warm them gently in a test-tube with a little potassium chlorate and nitric acid, till the elements of the bundle may be separated easily one from another; then stop the action by diluting with water, and mount in water or glycerine. By preparing them in this way the tracheides, \&c., may be subjected to separate examination, and their form and structure may be more exactly made out.

Apply the same process to the sclerenchyma, and observe the form and marking of the walls of its constituent elements.

Cut longitudinal sections of the stem of the Male Fern : first take radial sections of the peripheral tissues, and treat as above : note-

I. The epidermis with scaly out-growths.

2. The subjacent ground tissue, and especially the sclerenchyma consisting of cells of short prosenchymatous form, with brown pitted walls. and cell-contents : note the gradual transtion from sclerenchyma to-

3. The colourless ground tissue, with short parenchymatous cells, and large intercellular spaces.

VIII. Cut longitudinal sections so as to pass tangentially through the central network of bundles: treat some sections with chlor-zinc-iodine, and mount others in glycerine. Note the several tissues observed in the transverse sections, and they will show here the same position relatively to one another. By reason of the frequent splittings and fusions of this bundlesystem the several elements will appear contorted and twisted, but this does not materially affect their general arrangement, which will be seen under a high power as follows :- 
A. In the xylem of the bundle-

a. The scalariform tracheides, which are the main constituents of the xylem : they are elongated, prosenchymatous elements, with ladder-like marking of the lateral walls : this is due to the presence of regularly arranged, transversely elongated, bordered pits. (Compare those of the pine, p. 138.) Take especial notice of the appearance of the lateral walls as seen in longitudinal section, where two tracheides are contiguous with one another, and compare them with parts of the wall which adjoin.

b. Cells of the conjunctive parenchyma interspersed among the tracheides.

c. Tracheides with spiral marking: these are the firstformed wood, or protoxylem.

B. In the phloem observe-

a. The sieve-tubes, which are also elongated elements with pointed ends; the surfaces of the walls which separate contiguous sieve-tubes are covered with numerous sieve-plates (best seen in sections treated with chlor-zinc-iodine), to which round, highly refractive granules adhere: these stain yellow with chlor-zinc-iodine. Note also the irregular beaded appear. ance of the walls when seen in longitudinal section.

b. Cells of the conjunctive parenchyma, interspered among the sieve-tubes.

As the vascular bundles of the rhizome of Pteris the (common Bracken) are more regularly typical of the concentric bundle of the Fern than those of Nephrodium, thin transverse sections should also be prepared from the rhizome of this plant; mount some of the sections in glycerine, others in chlor-zinc-iodine ; or these sections may be stained with hæmatoxylin and mounted in Canada balsam.

First examine the whole section under a low power, and note its oval form, the upper and lower surfaces being flattened. It is composed of the following tissues :-

I. A peripheral band of brown sclerenchyma, outside which is a scarcely distinguishable epidermis. 
2. Colourless, parenchymatous ground-tissue, in which are embedded successively the following :-

3. An outer series of relatively small, sharply circumscribed vascular bundles, arranged in an irregular ring : one larger bundle is usually to be found opposite the lower flattened surface.

4. An incomplete ring of dark brown sclerenchyma, com. posed of two parts which are usually distinct, viz. an upper strongly curved portion, and smaller flat portion which is nearer the lower surface: small isolated patches of brown sclerenchyma may also be seen dotted about in the ground. tissue.

5. A central series of bundles, usually two or three in number, and of larger size : they may sometimes be found to be connected at their margin into one irregular ring-like mass.

Examine the sclerenchyma under a high power, and note the thick, brown, stratified walls : the cells contain a somewhat reduced protoplasmic body.

Examine also the parenchymatous ground-tissue, which will be found to consist of cells with thin cellulose walls, and mucilaginous protoplasmic contents, with much starch. Note especially small pegs and rods, which appear as superficial outgrowths from the walls adjoining the intercellular spaces.

Select a single elliptical vascular bundle for detailed observation under a high power, and recognize-

I. The bundle-sheath or endodermis, which is a definite, but narrow layer of cells, with brown coloured contents.

2. The phloem-sheath or pericycle, which is not quite so definite a layer of deeper cells, with cellulose walls, and plentiful protoplasm.

3. Within this is a band of phloem, which is wider at the flattened sides of the bundle, but narrower at the two poles : it consists of-

a. Sieve-tubes, which may be recognized by their large cavity, sparing contents, and cellulose walls: note where two sieve-tubes are contiguous that bright yellow granules may be seen adhering to the wall : these indicate the position of the sieve-plates. 
b. Parenchymatous cells, which fall under the general term conjunctive parenchyma.

4. An elliptical area of $x y l e m$ occupies the centre of the bundle, it is composed of-

a. Tracheides, which are large and of circular or polygonal outline, with highly refractive lignified walls, and no cellcontents. Towards the poles of the elliptical area tracheides of small size, and circular outline may be seen: these are the protoxylem.

b. Conjunctive parenchyma, distributed irregularly among the tracheides.

Longitudinal sections should also be cut, so as to traverse the vascular bundles of the central series : they may be treated as above directed. Note in these the thin-walled groundparenchyma, and the brown sclerenchyma; the latter consists of fibrous cells with peculiar crossed pits in their walls.

a. The bundle-sheath, or endodermis, consists of narrow oblong cells with square ends, and with brown contents.

$b$ The phloem-sheath, or pericycle, is composed of wider oblong cells, with colourless protoplasic contents : the ends are square or oblique.

c. The sieve-tubes appear as wide tubes, with pointed ends, and cellulose walls : the surfaces of the walls which separate contiguous sieve-tubes are covered with numerous sieve-plates (best seen in sections treated with chlor-zinc-iodine), to which round, highly refractive granules adhere : the sieve-tubes are in fact essentially similar to those of Nephrodium (p. 163). Note especially the irregular outline of the wall when seen in longitudinal section: this will be best seen in sections which have been cut so as to pass through the phloem in a plane parallel to the flattened side of one of the larger bundles.

d. The scalariform tracheides, which are the main constituents of the xylem: they are similar in all their main characters to those of Nephrodium (see p.:163), being elongated and pointed, while the walls are marked by transversely-extended bordered pits, arranged regularly so as to give the ladder-like appearance; but they differ from them in one point, for by a careful examination of fine sections it may be ascertained that 
the pit-membrane which remains permanently in Nephrodium, is often broken down on the oblique terminal walls in Pteris : this is, however, exceptional for Ferns.

$e$. The conjunctive parenchyma, distributed among both sieve-tubes and tracheides.

IX. From around the apical bud of a well-grown plant of the Male Fern remove successively the bases of the leaves of previous years, those of the current year, and finally the larger circinate leaves, which would have unfolded in the following year. Carefully remove the smaller ones with a scalpel, and then with forceps gradually pull off the large mass of brown scales, which completely cover the extreme apex. With a stiff camel's-hair brush remove the bases of these scales, together with the youngest of them, which will still remain round the punctum vegetationis : after this treatment it will be easy to observe with a pocket lens-

I. The apical cone (punctum vegetationis), a rounded papilla, occupying a central and terminal position in the flattened apical region.

2. The young leaves, situated round the apical cone, and successively larger the further they are from the apex. Note the circinate curvature which appears at an early period in their development.

$\mathrm{X}$. With a sharp razor, wet with water or with very weak spirit if the material be fresh, or with strong spirit if it has been previously hardened in alcohol, remove the extreme apex of the punctum vegetationis, taking care to cut accurately in a transverse plane : mount in water or in weak glycerine, and examine with a low power. If the section be thin enough, it will be seen that a large cell of triangular outline occupies the centre of the apical cone, while the cells immediately surrounding it are arranged in more regular order than those at a greater distance. This cell is the apical cell, and the cells surrounding it have been derived by cell-division from it, by mean of walls parallel to its three sides : they are called the 
segmental cells, and it may readily be seen that these again undergo subdivision. If the section be not sufficiently transparent, it may be treated with very dilute potash and weak glycerine, or, better, with "eau de javelle," which will clarify the tissues, and make the cell-walls more distinct.

The form of the apical cell, and of the segmental cells which surround it, will be readily appreciated on comparison of Fig. I I .

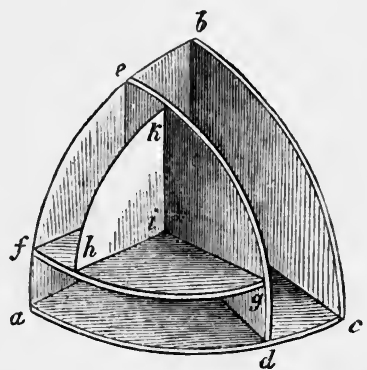

Fig. 11.-View of a model of a three-sided pyramidal (or tetrahedral) apical cell, as seen from above; the walls $d \ell, f g, h k$, denote successive walls by which segments have been cut off from the growing apical cell $: i$ is the apex of the pyramidal cell, at which point the three youngest segmental walls cut one another. (After Sachs.)

XI. From the apex of another plant cut median longitudinal sections : mount in weak glycerine : a very little dilute potash may be added if the sections are not transparent enough, or they may be treated first with "eau de javelle," and then be mounted in glycerine.

If any one of the sections has passed through the apical cone, in a median plane, the apical cell will be seen presenting a wedge-like appearance, and the cells around it will show, in the regularity of their arrangement, that they have been derived from segments successively cut off from the apical cell. (Compare Fig. 12.) It may be concluded from the observation of transverse and median longitudinal sections that the form of the apical cell is that of a three-sided pyramid. 
The structure and mode of origin of the young leaves should also be observed in the median longitudinal sections.

\section{The Root.}

XII. Cut transverse sections of the root of the Male Fern, selecting for that purpose the thickest part of an old root : mount in glycerine, and observe-

I. The piliferous layer : certain cells of this superficial layer

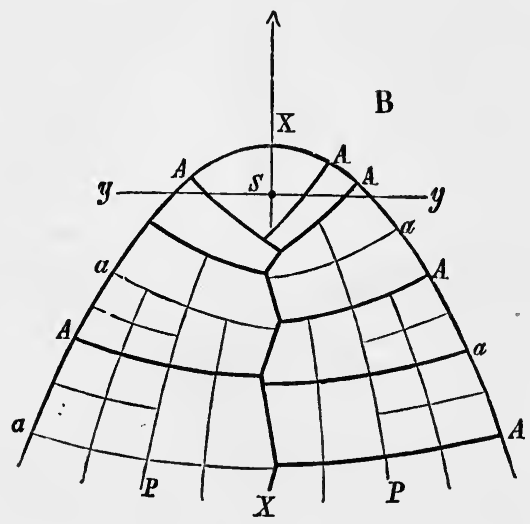

FIG. 12.-Diagram showing the arrangement of cell-walls as seen in a median longitudinal section through an apical cone with a pyramidal apical cell. $A A$, are the segmental walls, which form part of the system of anticlinals; $a, a$, walls by which each segment is cut into two equal halves: these complete the anticlinal curves ; $P P$, periclinals, which are not completed up to the apex. (After Sachs.)

have grown out as root-hairs, remnants of which may still be seen.

2. The greater part of the section consists of the bulky, brown-walled cortex, of which the outer parts are thin-walled; but, passing inwards, there is a sudden increase in thickness of the wall, so as to form a dense sclerenchymatous ring; this surrounds-

3. The endoderms, which consists of a single layer of cells 
flattened tangentially, and having the usual dot-like marking of the radial walls : this may be difficult to observe, as the radial walls are often pressed out of shape. Within this layer lies-

4. The pericycle, which usually consists of two layers of cells with thin walls, and obvious protoplasmic contents. The vascular tissues inclosed within these layers are arranged according to the ordinary radial type: thus there will be seen :-

5. Two groups of $x y l e m$ abutting on the pericycle and composed of tracheides of various size, the largest being near the centre of the root ; as the root develops, the two originally separate groups of xylem unite at the centre by formation of fresh tracheides, and together form a flat band which traverses the root longitudinally. Alternating with the groups of primary xylem at the periphery of the vascular cylinder are-

6. Two groups of phloem, consisting mainly of sieve-tubes having the same characters as those of the stem. Scattered among the vascular elements are cells of conjunctive parenchyma.

XIII. Cut median longitudinal sections of the apex of a root which has been hardened in alcohol: at most only one absolutely median section can be obtained from a single root: it will be found convenient to embed the apex of the root in paraffin, or to hold it between pieces of pith or carrot. Mount in glycerine, and examine first with a low power: choose out those sections in which there is a symmetrical arrangement of tissues around a single, large, apparently three-cornered apical cell, which lies at some distance from the extreme apex. (Compare Fig. 13.) Note-

I. That the orientation of the apical cell is constant, i.e. one corner is directed towards the older part of the root, while the side opposite that corner, i.e. the anterior face or base of the cell, is perpendicular to the axis of the root.

2. That around the apical cell are regularly arranged segmental cells, which have successively been cut off from it by walls parallel to the sides of the apical cell. Of these-

$a$. Those successively cut off from the base form the root- 
cap, dividing up by regularly arranged walls into a mass of regular cells.

$b$. Those cut off from the sides of the apical cell form the body of the root: these also divide by walls in regular succession. Observe carefully the arrangement of these walls, and by comparison of several sections ascertain their order of

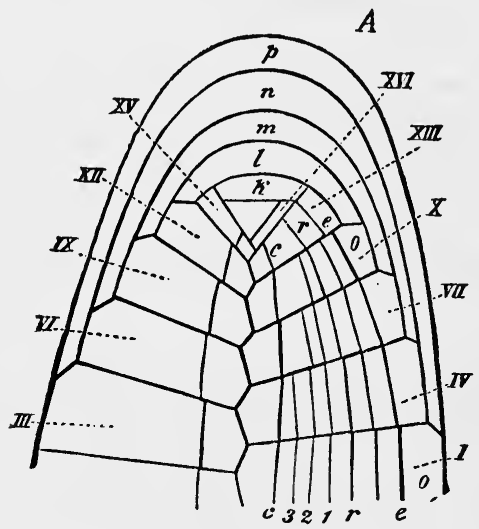

FIG. 13.-Diagram illustrating the arrangement of cell-walls as seen in a median longitudinal section through the apex of the root of a Fern. I. III. \&c. indicate segments cut off from the sides of the apical cell, which go to form the body of the root ; $k, l, m, n, p$, are successive segments from its base, which go to form the root-cap. (After Goebel.)

succession, and their relation to the various tissues of the root above described.

XIV. Cut successive transverse sections of the apex of a root which has been hardened in alcohol: this may easily be done if the root be held between pieces of pith, or better by embedding in paraffin. If possible, keep all the sections in their proper order of succession, and mount in glycerine. Examine with a low power, and choose out those in which the large apical cell is to be seen. Observe carefully-

I. The form of the apical cell, apparently three-sided: 
combining this result with that obtained by examination of the longitudinal sections the form of the whole cell must be a three-sided pyramid. (Compare Fig. II.)

2. The segments are arranged in regular order round it, and are cut off successively from the three sides.

3. Note the mode in which the several segments are further divided.

Next examine a section which has passed through the rootcap immediately above the apical cell : this will include the young segments cut off from the base of the apical cell by transverse walls, and destined to form the root-cap. Note the first divisions of these segments by walls arranged crosswise : it may be seen that these walls do not coincide in position in successive segments.

\section{The Leaf.}

XV. Cut transverse sections of a pinna of a leaf of the Male Fern which has no sori upon it : mount in weak glycerine, and observe with a low power that the outline of the section shows the leaf to be of equal thickness throughout, except where traversed by vascular bundles: at those points the pinna is thickened, the lower surface projecting convexly.

Examine with a high power, and observe successively the following tissues, starting from the upper surface :-

I. A regular epidermis with a thin cuticle: the epidermal cells contain chlorophyll : there are no stomata.

2. The mesophyll consists in its upper part of thin-walled cells containing chlorophyll, and with small intercellular spaces ; this passes by gradual transition into the lower part, where the intercellular spaces are larger, and the form of the cells less regular. Internal glandular hairs are frequently to be found in the intercellular spaces of the mesophyll.

3. The lower epidermis, the cells of which also contain chlorophyll : numerous stomata are present : note the form of the two guard-cells as seen in transverse section, and their position in relation to the epidermis.

4. Here and there vascular bundles, of circular appearance 
in transverse section, will be found embedded in the mesophyll : the larger of these correspond in position to the swollen ribs of the pinna.

Note the endodermis as a continuous layer of cells, which completely surrounds the circular bundle, and within this the xylem and phloem elements, similar to those of the stem : the bundles show an approach to the collateral type, the xylem being nearest to the upper surface of the leaf.

XVI. Cut tangential sections (or strip off the epidermis) from the upper and the lower surface of the leaf : mount as before, and compare them.

$a$. The epidermis of the upper surface will be found to consist of cells with sinuous outline, and protoplasmic contents, with chlorophyll : no stomata will be found.

$b$. The epidermis of the lower surface consists of cells similar to the above : there are stomata with two guard-cells.

\section{The Sporangia.}

XVII. Having examined the sori as directed on p. 156 with the naked eye or with a lens, cut transverse sections through pinnæe of leaves which bear sori, taking care that the sections shall pass through one or more of them : mount as before, and examine with a low power. Note-

I. The structure of the pinna, as above described.

2. Opposite to, and seated upon a rib will be found the membranous indusium, which, like an umbrella, covers over-

3. The sporangia, which are biconvex-lens-shaped, brown stalked capsules, attached to the rib and filled with-

4. Numerous roundish, brown, unicellullar spores.

Observe more closely the structure of the single sporangium. It is composed of-

i. The stalk, which is of considerable length, and usually consists of three rows of cells. Stalked glandular bodies are often found as lateral branches on the stalk of the sporangium in this species.

ii. The capsule, which has the form of a biconvex lens, and consists of a marginal series of cells with peculiarly thickened 
walls, which constitute the ring, or annulus; and thinner-walled, flattened cells, which together form the lateral walls of the completely closed sporangium.

Place a number of mature, but not yet ruptured sporangia upon a dry slide : warm them very gently over a spirit-lamp, and observe quickly under a low power: note the sudden explosive rupture of the sporangia, so as to eject and scatter the spores : this is due to the straightening of the annulus or ring. Similar results may be obtained by mounting in water, and subsequently adding glycerine ; in fact, on the removal of water by evaporation into the air, or by a reagent such as glycerine, the curved annulus tends to straighten itself, and then ruptures the thin wall of the sporangium.

Note sporangia in which the thin lateral walls have been ruptured transversely, the ring having straightened itself out : now breathe on the sporangia, and note that on being thus moistened by the breath the annulus becomes more curved, while on being left exposed to the dry air for a few minutes it again becomes straight.

Examine single spores under a high power: they are unicellular bodies, having a brown wall, with external bandlike outgrowths of the exospore or outer layer of the wall. All the spores are alike (Homosporous).

The various stages of development of the sporangium may be found in any sorus in which only the first sporangia have come to maturity: treat the sections previously with weak potash; if this makes them too transparent, neutralize with weak acetic acid, and mount in glycerine ; or the sections may be treated at once with "eau de javelle," and then be mounted in glycerine.

\section{B.-THE GAMETOPHYTE, OR OOPHYTE.}

I. Dry some of the leaves of the Male Fern, which bear sori, on a piece of paper: the spores will then be set free by the rupture of the sporangia, and they may thus be collected in large quantities. Sow some of them on damp earth : keep 
them moist, and sheltered from direct sunlight ; they will then germinate, and after a few weeks the surface of the soil will be found to be covered with small, green, flattened bodies, each of which is an individual prothallus.

From time to time, pick off some of the young prothalli with a needle from the surface of the soil : by this means a series of observations may be made which will illustrate successive stages of development of the prothallus.

II. Examine a single, fully-grown prothallus with the naked eye, and observe-

I. The form, which is flattened, and more or less kidneyshaped, with a depression of the margin, at the base of which is the organic apex of the prothallus. Note that the central part of the prothallus is often perceptibly thicker than the periphery : this thicker part is called the cushion.

2. The position of the prothallus while growing : it is usually oblique to the surface of the soil.

3. The root-hairs, which spring from the under surface of the cushion, and run downwards into the soil.

4. The green-colour, due to the presence of chlorophyll: the prothallus is thus capable, under suitable circumstances, of carrying on the process of elaboration of fresh organic substances.

III. Wash a fresh, well-developed prothallus carefully in water, so as to remove the soil from the root-hairs : mount it whole in water, with the lower surface directed upwards, and examine it with a low power. Observe again the chief points seen above with the naked eye, which are now more plainly visible, and note especially-

I. The form and structure of the cells in the lateral, thinner portions of the prothallus; they are polygonal, and have thin cellulose walls, and protoplasm containing a nucleus and numerous chlorophyll-corpuscles : the cells at the margin are often extended as hair-like outgrowths.

2. The cells composing the cushion are of similar structure, but are aggregated in a mass more than one layer of cells in thickness : many of the cells will be seen to have grown out as root-hairs. : 
3. The depressed apex of the prothallus, which is occupied, not by a single wedge-shaped cell, as is the case in early stages of development, but by a closely aggregated series of marginal cells, with thin cell-walls, and every appearance of recent and, repeated cell-divisions.

4. The antheridia, which are hemispherical outgrowths, situated chiefly on the posterior and lateral portions of the under side of the prothallus.

5. The archegonia, which are situated on the cushion near to the organic apex of the prothallus; the multicellular neck of the archegoniun projects from the surface of the prothallus as an elongated cylindrical structure.

Under the low power select one mature antheridium, and, without moving the slide, adjust the higher power so as to observe the structure of the same antheridium in detail. It will then be seen that it consists of-

a. A wall, composed of a single layer of narrow cells; this completely surrounds-

b. The spermatocytes, or mother-cells of the spermatozoids, which are small, and not very numerous.

Other antheridia may be found which have already burst the outer wall : in these the contents of the mother-cells may perhaps be seen escaping from the ruptured antheridium as spiral spermatozoids, endowed with active movements. If a preparation showing motile spermatozoids be treated with a weak solution of iodine, the movements will cease with the deatb of the spermatozoids, which will assume a brown staining, while the cilia attached to the anterior ends of them will then be clearly seen.

Select under the low power one mature archegonium, and then observe it in detail under the higher power. If the neck be vertical, which would under the circumstances be the natural position, since the prothallus was mounted with the lower surface uppermost, there will then be seen, on focusing down upon it, four rows of cells composing the wall of the neck, and surrounding one cell, the canal-cell.

IV. Harden some prothalli with alcohol, or with picric acid and then with alcohol. The preparations described below may 
also be made from fresh material, but the results will not be nearly so good as if one of the above methods of fixing and hardening be adopted.

Hold a prothallus thus prepared between pieces of pith, or embed as directed on p. 173 : then cut sections perpendicularly to the surface of the prothallus, so as to pass through the cushion, following the organic axis from base to apex. Mount in glycerine, and examine first with a low power.

The lower surface may easily be recognized by the presence of root-hairs : on this lower side, chiefly near to the apical end of the section, which is characterized by its small cells with thin walls, will be found archegonia: these may be recognized by the multicellular neck, which projects beyond the surface of the section. In some cases the canal of the neck may appear of a deep brown colour: this is the case in old archegonia which have not been fertilized, and they should be disregarded. Select one archegonium of full size and healthy appearance, and examine it under a high power.

Observe that it consists of-

A. The central series of three cells, which may be distinguished as-

a. The canal-cell; this is oblong in form, and its walls are subject to mucilaginous degeneration : it occupies the channel of the neck, and has been above alluded to as being visible when the neck of the archegonium is seen from above.

b. The small ventral canal-cell, which lies immediately below the oblong canal-cell, and is of rounded form.

c. The oosphere, or ovum, which is of relatively large size, and roughly spherical form : it is embedded in the tissue of the cushion, and consists of a dense mass of granular protoplasm.

B. The neck, which is composed of cells arranged in four rows, constituting together a cylinder or tube, one layer of cells in thickness : this projects from the surface of the prothallus, and incloses the cells $(a)$ and $(b)$ of the central series, while $(c)$, the ovum, is embedded in, and surrounded by, cells of the cushion.

At the end of the section more remote from the apex may be found antheridia. Select one fully developed, and 
it will be seen to consist essentially of an outer wall one layer of cells in thickness : this incloses a central mass of cells, the contents of which may be seen to be rounded off, and to have assumed the form of a closely coiled spiral: these are the spermatocytes or mother-cells of the spermatozoids.

The dehiscence of the antheridia, the escape of the spermatozoids, and their movement, should be observed with particular attention in fresh prothalli mounted in water ; also the opening of the apex of the neck of the archegonium ; in both cases the process depends upon a mucilaginous degeneration of cell-walls of the inner cells, and a subsequent swelling by taking up water, and consequent rupture of the outer walls. Further, the movements of the living spermatozoids may be followed, and the act of fertilization observed : the spermatozoids pass through the mass of mucilage which fills the neck of the archegonium, and finally coalesce with the ovum.

\section{C.-THE YOUNG SPOROPHYTE, OR FERN-PLANT.}

I. The result of the process of fertilization of the ovum by the spermatozoids is the development of a riew Fern-plant (the Sporophyte), and in cultures which have been continued for some months such young Fern-plants may be clearly seen attached to the prothalli, but one prothallus produces only one young Fern-plant.

Select a prothallus to which a young Fern-plant is thus attached, and wash from it the soil which adheres to it. Examine it with a lens, and observe-

I. That the prothallus itself is similar in form and structure to those before observed.

2. That the young Fern-plant is firmly attached to its under surface by a lateral protrusion (foot).

3. That the young Fern-plant consists of the following parts :-

a. A root, which turns downward into the soil.

b. A lateral protrusion, the foot, which maintains a close 
physiological connection between the prothallus and the Fern. plant.

c. A first leaf, or cotyledon, with an elongated petiole, and bifurcating, expanded, upper part : this usually grows upwards through the depression at the apex of the prothallus.

$d$. Between the base of the cotyledon and the foot is the apex of the stem, which continues its growth, and produces new leaves. 


\title{
BRYOPHYTA
}

\author{
A.-MUSCI
}

\section{POLYTRICHUM COMMUNE, $L$.}

\section{A.-GENERAL EXTERNAL CHARACTERS}

I. Observe in well-grown specimens of this Moss taken in spring or early summer-

1. The erect stem, ${ }^{1}$ which may attain a considerable length, branching but rarely :

2. The leaves, ${ }^{1}$ of relatively small size, and simple form; their arrangement is on a complicated plan : at the base of the stem note-

3. A dense mat of rhizoids of brownish colour.

At the apex of some specimens will be found merely a bud, composed of young leaves of the vegetative type; other specimens will bear at their apex-

4. Perigonia, or perichætia; cup-like rosettes of leaves, which assume a bright reddish or orange colour, and protect the antheridia; other specimens again may bear at their apex-

5. The mature sporogonium or spore-capsule, of which the

1 Though the terms "stem" and "leaf" are used here, it must be distinctly borne in mind that the members thus named, being parts of the oophyte generation are not homologous with, but at most only analogous to the stem and leaf of vascular plants, which are parts of the sporophyte generation. 
head or theca is supported on a long stalk, or seta. Note in specimens which are not too ripe-

a. The calyptra, a dry fibrous hood, covering the apex of the sporogonium : beneath this is-

b. The lid-like operculum with its terminal beak: this lid may be easily detached, disclosing-

c. The pale-grey epiphragm, which appears as-a transverse membrane, attached at its margin to the capsule by a number of short teeth of the peristome.

$d$. At the base of the theca observe a swelling called the apophysis.

$e$. By carefully removing the leaves from the apex of a plant which bears a sporogonium, it may be seen that the base of the seta is enveloped by a closely fitting sheath, the veil or vaginula, the origin of which will be explained later.

\section{B.-MICROSCOPIC INVESTIGATION.}

\section{Oophyte Generation.}

II. Cut transverse sections of a mature stem of Polytrichum: mount some in glycerine, others in chlor-zinc-iodine, or in iodine solution: examine them first under a low power, and observe in those mounted in glycerine-

I. The outline of the section, which is usually more or less clearly triangular.

2, The dense reddish-brown band of peripheral sclerenchyma, which passes over gradually into-

3. A broad, thinner-walled band of tissue, which may be termed the cortex : this finally surrounds-

4. A central mass of firm, yellow-walled tissue.

Examine these several tissues in detail, under a high power, and observe that-

I. At the extreme outer limit is a thin cuticle, with small and irregular outgrowths : there is no clearly defined epidermal layer.

2. The peripheral sclerenchyma consists of cells with clearly stratified red walls, which are of such thickness as almost to obliterate the cell-cavity. 
3. The broad band of tissue of the cortex has relatively thin, yellowish or colourless walls, and protoplasmic contents with starch-granules, and globules of oil (compare sections treated with iodine).

4. The central mass of tissue, which may be compared to a vascular bundle, is not sharply limited from the cortex : it consists of -

a. A peripheral, small-celled, and thin-walled portion, the walls of which do not stain blue, but light yellow with Schulze's solution.

b. A central, thick-walled part, without cell-contents : the thick walls stain dark brown with Schulze's solution: the elements are often divided by delicate septa, which are not stained by Schulze's solution. This tissue may be compared to the xylem of true vascular plants.

Here and there small groups of tissues similar to the above may be seen in the cortex; these are the strands which enter the stem from the leaves, and pass inwards towards the central bundle.

III. Cut median longitudinal sections of the mature stem of Polytrichum: mount as before, and note that the peripheral sclerenchyma consists of elongated prosenchymatous elements, while the cells of the massive cortex are of a parenchymatous form. The elements of the central strand are elongated, and their lateral walls smooth, without pits : they are separated one from another by thin oblique septa. Observe that where the median plane of a leaf has been cut through longitudinally, a strand of tissues similar to those constituting the central strand may be traced, passing obliquely through the cortex towards the central strand.

IV. Strip off a few mature leaves : mount one of them in water, with the upper surface uppermost, and observe under a low power that the narrow, linear upper portion is marked on its upper surface by longitudinal striæ (the lamellæ), and has a minutely serrated margin : the basal portion of the leaf, which is closely applied to the stem, is broad, but thin and membranous, and is not marked by longitudinal striæ. 
V. Cut transverse sections of leaves : this may easily be done by holding the terminal bud of a mature plant between pieces of pith, or by embedding in paraffin, and then cutting transverse sections of the whole bud. Mount all the sections as before, and examine first with a low power. Neglecting the almost circular transverse sections of the stem, recognize-

I. Those transverse sections which have passed through the sheathing basal portions of the leaves : these may be readily distinguished by their broad lateral wings, only one layer of cells in thickness.

2. Those which have been taken from the upper part of the leaf : these may'be distinguished by their more bulky appearance.

Having recognized these sections, put on a high power and examine them in detail :-

I. In the section of the sheathing base of the leaf observe-

$a$. The two lateral wings, consisting of a single layer of cells, with thickened outer walls, and but little chlorophyll.

b. The more bulky central portion consisting of-

i. An irregular layer of superficial cells with thickened outer walls, covering both upper and lower surface: beneath these are-

ii. Bands of sclerenchyma, in which the lumen is almost obliterated.

iii. Within these lies a "vascular bundle" consisting of elements essentially similar to those composing the central bundle of the stem.

2. In the sections of the upper part of the leaf note that the arrangement of the tissues is for the most part similar to that in the above sections, but rather more bulky, while opposite each of the cells at the upper surface is seen to be attached a series of three to six chlorophyll-containing cells, which represent transverse sections of those longitudinal plates or lamellæ above observed on the upper surface of the leaf; the uppermost cell in each lamella is enlarged and forked. It is obvious that these chlorophyll-containing lamellæ are separate laterally from one another : they constitute the chief assimilating tissue of the plant. 


\section{Sexual Organs}

VI. Take a mature antheridium-bearing axis of Polytrichum, and dissect it with needles in a watch-glass, keeping all the detached parts. Examine them carefully with a lens, and observe the following categories of organs-

I. The perigonial leaves, which are widened laterally into very broad membranous wings, with a clearly-defined central midrib.

2. The white, club-shaped antheridia.

3. The paraphyses, which will often be found associated with the antheridia: some of them are simply filamentous, others are more or less clearly spathulate.

VII. Cut median longitudinal sections of a male axis : mount in weak glycerine, and with a low power recognize the several organs above described, and their relative positions: note especially the antheridia in the axils of the perigonial leaves. Observe under a high power the structure of a single antheridium : it consists of a short stalk, and a club-shaped body, composed of (i) a wall a single layer of cells in thickness, and (ii.) a central mass of cells of more or less clearly cubical form : these are the spermatocytes or mother-cells of the spermatozoids.

VIII. Take fresh antheridium-bearing specimens of Polytrichum, after some days of dry weather (or keep them rather dry for some days, carefully preventing any access of water from above): squeeze one of them between the finger and thumb: the antheridia will thus be easily forced from their position, and may be mounted in water. If they were properly mature, it may then be seen that on contact with water the antheridia burst, and the spermatocytes escape, aggregated in a mass. In each cell of this mass a spiral filament may be seen, in active movement : ultimately it will escape, owing to mucilaginous swelling of the wall of the mother-cell, as a free spermatozoid of spiral form, having two cilia.

IX. Take a sod of Funaria ${ }^{1}$ with no sporogonia as yet visible

1 Since Funaria hygrometrica produces sporogonia at all times of the year, and is very common, while Polytrichum commune is reproduced sexually only in the 
upon it, but which bears antheridia : these will be situated at the apices of the shorter axes : many of the longer axes will appear to be terminated by ordinary vegetative leaves, and it is on these axes that the archegonia may be found.

From such buds, after hardening in alcohol, cut median longitudinal sections : if not transparent enough treat with dilute potash solution, and mount in weak glycerine: subsequently the sections may be transferred to glycerine jelly. Examine first with a low power, when the usual arrangement of axis and leaves may be observed; between the youngest leaves an archegonium (or several) may sometimes be detected. If mature, it will be seen to be a flask-shaped organ, seated on a short massive stalk : it consists of-

I. An elongated neck, more or less contorted, composed of a single layer of cells arranged in four to six rows : these surround a central canal, which is filled with mucilage at the time of fertilization, but before maturity there may be seen within it a series of canal cells.

2. A lower, enlarged ventral portion, consisting of two layers of cells, which constitute the wall, and inclose a central space, in which may be seen the naked spherical oosphere or ovum, and above it the smaller ventral canal cell.

\section{Sporophyte Generation.}

\section{The Sporogonium.}

$X$. Having noted the external characters of the sporogonium of Polytrichum, as above described, cut transverse sections of the mature seta : mount in glycerine or glycerine jelly. Being a cylindrical organ the transverse section is circular. Note-

I. The superficial layer of cells with a definite cuticle and thick yellow walls.

spring and early summer, it will be convenient in most cases to use the former in examining the archegonia. In either case, however, it is a matter of some experience and expenditure of time to get a good series of preparations illustrating the development and structure of the archegonium, and the early stages of the production of the sporogonium. Various other Mosses might be used for the purpose of this work, especially such as grow in tufts, and produce their sporogonia almost simultaneously. 
2. A band of brown sclerenchyma, which graduates internally into-

3. A thin-walled parenchyma with large intercellular spaces, and containing chlorophyll.

4. Centrally is a strand of denser tissue without intercellular spaces.

XI. Cut median longitudinal sections of the base of the seta, which is inserted on the apex of the Moss-plant or oophyte : mount as before, and note in the upper part of the seta the superficial layer, brown sclerenchyma, thin-walled parenchyma, and central strand, as above described. Following the seta down to the base, it will be seen that the cuticle and brown sclerenchyma stop short, and are replaced by thin-walled parenchyma with plentiful protoplasm; this tissue of the sporophyte is in close connection with the inner surface of the vaginula, which belongs to the oophyte generation. With this close physiological connection of the sporophyte and oophyte in the Moss compare the connection by means of the foot in Ferns.

XII. Passing now to the apex of the sporogonium of Polytrichum, remove the calyptra: mount it in water or weak glycerine, and examine under a low power. It consists externally of dry, branched, hypha-like filaments, loosely matted together : the neck of the archegonium may often be recognized at its extreme apex. Open the calyptra with needles in a drop of water on a slide, and observe the firm inner cap-the calyptra proper-which is covered externally by the hairy indumentum : the latter is the result of outgrowth of superficial cells of the calyptra.

XIII. After having noted the external form of the capsule, and of its operculum, transverse and longitudinal sections should be cut. For this purpose it will be well to select young specimens, in which the capsule has not attained more than half its full girth : after hardening in alcohol they may be embedded in paraffin, or held in pith, and the sections be cut : mount in glycerine or in glycerine jelly.

Taking first transverse sections cut from the middle of the capsule, examine them under a low power and observe the 
circular or, according to age, slightly quadrangular outline of the section; its constituent parts may be recognized as follows :-

I. The wall of the capsule consisting of several layers of chlorophyll-containing cells, of which the outermost has its external wall thickened and cuticularized like a typical epidermis.

2. Within this is an air space, traversed in a radial direction by filaments of cells, containing chlorophyll : these are connected internally with :-

3. The spore-sac, which is limited internally by-

4. An inner air-space : this also is traversed by filaments, which connect it with :-

5. The central columella.

Examine the spore-sac under a higher power, and, if the sporogonium be of the right age, it will be seen to consist of usually five layers of cells.

$a$. Two external layers of thin-walled cells :

b. A central layer of cells with dense protoplasmic contents : this is the archesporium, which is originally a single layer, but may undergo divisions as it grows older: ultimately by division of each of the resulting mothercells into four, and their separation from one another, the spores are produced.

c. The archesporium is sheathed again on the inner side by two internal layers of thin-walled cells.

According to the age of the sporogonium various conditions of the spore-sac may be observed, from the single archesporial layer, to the condition of mature spores.

XIV. Examine median longitudinal sections of a similar young sporogonium, and recognize in it the several parts above noted.

The outline of a median section will show at the base the narrow seta : passing upwards to the capsule, it will be found to consist of-

I. The apophysis, which appears as a basal swelling limited by a definite epidermis with stomata : internally is a mass of lax, chlorophyll-containing tissue. 
2. Above this is the real capsule in which will be recognized as before in the transverse section :-

$a$. The wall of the capsule.

b. The outer air-space traversed by filaments.

c. The spore-sac with structure as before described.

d. The inner air-space.

$e$. The central columella.

These severally terminate below in the tissue of the apophysis : above they may be traced to a point close below-

3. The operculum, which appears as a conical lid, at the apex of the capsule.

4. Note carefully a transverse band of tissue of pale, compressed cells at the base of the columella : this is the epiphragm mentioned on p. 180 , which remains after the operculum is removed. At the margin of it, will be seen-

5. The peristome, consisting of a series of curved cells with their walls more or less thickened according to age.

In order to see the condition of the epiphragm in the mature capsule, and its connection with the teeth of the peristome, take a ripe specimen from which the operculum has dropped off. With a sharp razor cut transversely through the capsule so as to remove the epiphragm : mount in water and examine under a low power. Note that the epiphragm is a thin papery tissue, without intercellular spaces. The peristome consists of 64 teeth, connected below with the wall of the capsule, above with the margin of the epiphragm. By drying up of thinner walled cells between the teeth, spaces are formed through which the spores can escape. The capsule becomes inverted at the period of ripeness, and the dry spores are dusted out through these spaces.

In many respects Polytrichum is more complex than other. Mosses, and differs from most in the characters of the peristome. Other examples of Mosses are described in the larger edition pp. $342-355$.

XV. Scatter spores from the ripe sporogonium of Polytrichum or of some other Moss over moist soil, and keep them at a moderately high temperature, under a bell-glass, for a few days. The surface of the soil will soon be seen to be over- 
grown by numerous fine green filaments. Having carefully removed some of these with a needle, and having washed the soil from them, mount them in water, and examine them under a high power. Note-

i. The dark-coloured exospore, which may be found still attached to the filaments after they have attained a considerable length.

ii. The fine filamentous protonema resulting from outgrowth of the endospore : observe especially the septa, which are often oblique; the branches, usually arising immediately below a septum ; the various development of these branches, either-

$a$. As relatively thin filaments with brown cell-walls, and no chlorophyll : these are the rhizoids, and they penetrate the soil.

$b$. As relatively thick filaments, with colourless cell-walls, and containing chlorophyll : these constitute the true protonema.

$c$. As solid buds, which are usually situated at the base of one of the branches such as $a$ or $b$ : in these solid buds of various ages may be traced the successive stages of development of the moss-plant, which is thus produced as a lateral bud on the protonema.

Cultures of protonema, showing all the most important characters above noted, may be obtained at any time of year by cutting fine sods of Funaria or other Mosses, inverting them under a bell-glass, and growing them in moist air and at a moderate temperature for two or two weeks.

It will also be found possible, by culture of detached leaves and portions of the stem of the Moss-plant on moist soil, and under other favourable conditions, to induce a formation of protonemal filaments by direct outgrowth of cells of those parts.

Observations should also be made on the rhizoids, and protonema of various Moss-plants, by removing them from the soil, and washing them gently with water and mounting in water: examination will show the brown underground rhizoids, with oblique septa and no chlorophyll : these may rise to the surface of the soil, and develop as a branched, green protonema : or such protonemal filaments may spring from superficial cells of the stem or leaves. 


\section{B.-HEPATICÆ}

\section{MARCHANTIA POLYMORPHA, $L$.}

\section{A.-GENERAL EXTERNAL CHARACTERS}

I. Taking a fresh growing sod of Marchantia, observe the following external characters with the naked eye or by help of a pocket lens :-

I. The flattened form, sinuous margin, and prostrate position of the branched, green thallus.

2. Its dull, dark green upper surface, marked by diamondshaped areas, and in the middle of each of these a dot, which is a single stoma.

3. Projecting from the upper surface there are in most cases small circular cups, with a finely crenate margin, in which may be seen numerous dark green flattened bodies, the gemmæ : these may be easily detached by slight mechanical disturbance.

4. Note the organic apex of the thallus, situated at the base of a terminal depression (compare the prothallus of Ferns) : also that the branching is dichotomous, though the ultimate development of the originally similar branches is unequal, so that the result is a sympodium.

5. In some cases the branches of the thallus may have assumed peculiar forms, together with an erect position : these are the branches which bear the sexual organs, and two different types may be easily recognized as borne upon different individual plants, viz.- 
a. Branches with a relatively thin stalk, bearing a terminal disk with crenate margin, and having numerous dot-like markings on the upper surface : these are the male-branches, having the antheridia on their upper surface.

b. Branches, also with thin stalks, bearing a terminal star about $\frac{1}{4}$ inch to $\frac{1}{2}$ inch in diameter: these are the female branches, which produce the archegonia on their under surface, and ultimately the sporogonia and spores.

II. Remove a thallus carefully from the soil, and wash with water, taking care not to injure it: examine the organs on its lower surface with a pocket lens, and note especially-

I. The numerous rhizoids or root-hairs, attached chiefly to the central midrib.

2. The amphigastria, white or purple lamellæ attached to the lower surface of the thallus, and most clearly seen in the regions near the apex, where they are closely aggregated so as to protect the young tissue.

\section{B.-MICROSCOPIC OBSERVATIONS.}

III. Cut transverse sections of the vegetative thallus of Marchantia, avoiding at first the cups bearing the gemmæ, and the sexual branches. It is easier to use material hardened in alcohol, and to embed it in paraffin, or to hold it between pieces of pith : but if sections be cut from fresh green material the presence of chlorophyll will be found to be an advantage in distinguishing the tissues. Mount some sections in weak glycerine, others in chlor-zinc-iodine, or in iodine solution: examine under a high power, and, starting from the upper surface, observe-

$a$. The superficial layer, or so-called "epidermis," consisting of a continuous layer of cells of small size which contain chlorophyll : the continuity of the layer is broken here and there by the so-called "stomata": these, however, differ from the true stomata of the higher plants in the mode of their development. This layer may be seen to be attached to the lower-lying tissues at points between the "stomata," and the lines of attachment 
thus cut through correspond to the limits of the diamondshaped areas above noted.

$b$. Beneath the "stomata" are large areas, the air-cavities, in which are seen numerous round or oval cells, grouped in simple or branched series, and attached to the lower surface of the cavity : their cell-walls are thin, and consist of cellulose : these cells contain chlorophyll, and are the chief assimilating tissue of the plant.

c. Below this is a massive tissue, which constitutes the great bulk of the section : it consists of oval cells : the walls are thin, and marked with shallow pits : the protoplasmic contents are scanty: in the cells nearer the upper surface there are often numerous starch-grains. Individual cells here and there in this tissue have peculiar mucilaginous, or highly refractive, yellowish or brown, oily contents.

$d$. Attached at the lower surface of the thallus may be seen organs of two kinds-

i. Hairs, or rhizoids, which are long and unicellular, and are inserted deeply in the tissues of the thallus: they often show dotted or peg-like ingrowths of the cell-wall of various form.

ii. The amphigastria, which may now be seen to be plates of tissue one layer of cells in thickness : their cell-walls are often coloured violet or brown.

Returning now to the "stomata," note under a high power their structure as seen in a good transverse section : each will appear as consisting of tiers of small cells (four or more in depth), which surround a large central cavity.

IV. Cut tangential sections so as to strip off the so-called "epidermis": mount with the outer surface uppermost in weak glycerine: observe under a low power the diamondshaped areas above described, and a single large "stoma" in the middle of each. Under a high power note-

1. That the cells of the "epidermis" contain chlorophyll.

2. That each "stoma" is bounded by four or five of the tiers of cells above described.

3. That these cells contain but little chlorophyll.

4. That on focusing downwards it becomes apparent that the 
lowest cell of each tier projects into the cavity of the "stoma," so that the channel at that point presents a stellate appearance in surface view.

V. Remove a number of the rhizoids : mount them in water or glycerine, and examine under a low power: two types of these elongated unbranched hairs may be recognized-

a. Those with smooth walls : these are the more numerous :

$b$. Those with peg-like projections of the wall into the cavity of the hair : the protoplasmic contents are very scanty.

\section{Gemma.}

VI. Remove from one of the cups on the upper surface of the fresh thallus of Marchantia some of the gemmæ: mount them in water, and note under a low power-

1. The flattened disk-like form of the gemma, with two lateral indentations, and a scar at the base where it was attached to the thallus which produced it.

2. The ordinary chlorophyll-parenchyma of which it is mainly composed.

3. Superficial hyaline cells, from which the rhizoids are subsequently derived.

4. The single cells containing oil-bodies.

It may further be observed that the gemma is in its peripheral part only one layer of cells in thickness, while the central part is a solid mass : also that the structure is alike on both sides of the gemma, i.e. that it does not as yet show any trace of a dorsiventral character.

VII. Cut transverse sections of a thallus so as to pass through the middle of one of the cups : mount in very weak glycerine, or in water, and examine under a low power : note-

I. The two lips of the cup, which appear as outgrowths from the upper surface of the thallus, and show more or less clearly the same structure, especially in the lower part.

2. The numerous gemmæ, in various stages of development, which are attached to the base of the cup by unicellular stalks.

3. Two involutions of the margin, corresponding to two channels, which traverse the stalk longitudinally. 
Removing some gemmæ from the cups, germinate them on clean moist sand under a bell-glass at a medium temperature, and exposed to moderate light : on examining them after five or six days, they will be seen to be elongated transversely to their original axis of growth, the base of each of the lateral indentations serving as an organic apex : from the lower surface roothairs have been formed, by simple outgrowth of single cells. After growth has been continued for a longer time the differentiation of tissues characteristic of the mature thallus, with "stomata" and air-cavities, becomes apparent on the upper surface, the thallus thus assuming a dorsiventral character.

\section{The Male Branch (Antheridiophore).}

VIII. Cut median vertical sections through the terminal disk : mount in weak glycerine, and examine first under a low power : observe-

I. The general outline of the section, with its flat upper surface.

2. The amphigastria and rhizoids attached to the lower surface.

3. The cavities in the tissue, of two sorts, both opening by narrow mouths on the upper surface-

a. Air-cavities fundamentally similar to those of the vegetative thallus.

$b$ Flask-shaped cavities each containing one antheridium: these also open by a narrow channel on the upper surface of the disk.

Look for a single ripe antheridium which has been cut through longitudinally : having found one, examine it in detail under a high power, and observe-

I. The short stalk by which it is attached to the base of the cavity.

2. The wall of the antheridium, consisting of a single layer of thin-walled cells.

3. The mother-cells of the spermatozoids of cubical form, and small size, which together constitute a dense central mass. 


\section{The Female Branch (Archegoniophore)}

IX. Remove the star-shaped head of a female branch which has attained a considerable length, and examine first the upper surface : with the naked eye or with a lens note the rounded arms, usually nine in number, and the diamond-shaped areas, each having a single central stoma.

Turn the head upside down, and observe on its lower surface-

I. The central attachment or stalk.

2. The radiating arms, usually nine in number.

3. The curtain-like perichætia, which alternate in position with the arms : the archegonia are enveloped by these, and if the branch be an old one-

4. The nearly spherical sporogonia may be observed protruding from them : if these be fully ripe, they may have burst, in which case a yellow flocculent mass may be seen protruding from them, consisting of the spores and elaters.

$X$. Select a female branch which has not yet grown more than a quarter of an inch in height,- - cut rather thick transverse sections (i.e. in a horizontal plane) through the head of it, mount in glycerine, and examine under a low power: observe-

I. The central stalk cut through transversely, and presenting characters similar to those above described.

2. The arms, usually nine in number, radiating from that central point.

3. The numerous archegonia, each of which presents a circular outline from this point of view : they are disposed in groups alternating in position with the arms, each group being surrounded by the perichætium.

Under a high power the following points may be ascertained-

$a$. That the most mature archegonia are those nearest the periphery, while those of each group are successively younger the nearer they are to the central stalk.

$b$. That each mature archegonium as seen in section consists 
of a wall, one layer of cells in thickness, which surrounds and incloses a large, naked, nucleated ovum.

XI. Cut vertical sections through a female branch of like age to the above: treat as before, and observe in median sections-

I. The stalk, on which is borne-

2. The terminal stellate head.

3. That the latter consists of tissues similar to those of the vegetative thallus : thus there may be seen-

a. The superficial "epidermis," and "stomata."

b. Air-cavities with chlorophyll-parenchyma.

c. Large mucilage-cells.

4. The archegonia, which are flask-shaped bodies suspended in an inverted position : note in a mature archegonium-

$a$. The long neck, consisting of many tiers of cells, which together form a single-layered cylinder surrounding the channel of the neck: when mature the neck will be seen to be open at its apex.

$b$. The more distended lower ventral part of the archegonium, also surrounded by a single-layered wall, and attached by a short massive stalk to the receptacle.

c. Pay special attention to the contents of the ventral portion : in the mature archegonium the cavity will be seen to be occupied by a single primordial cell-the ovum or oosphere-to which access is gained from without through the channel of the neck.

XII. Keep some specimens of Marchantia, having mature male receptacles, protected for some days from access of water from above : then place a drop of water on the upper surface of a receptacle, and after a short time transfer it to a glass slide, and examine under a high power; there will then be seen numerous motile spermatozoids of elongated, slightly curved form, and they are kept in active motion by two cilia attached to the anterior end. In order to make them clearly visible they should be killed and stained by adding a small quantity of iodine solution, or of osmic acid.

XIII. Add a drop of water containing living spermatozoids to a fresh preparation of a female receptacle containing mature 
archegonia: note the directive influence of the archegonia in attracting the spermatozoids to the neck, which they enter, and are lost to sight in the mucilage which fills it.

\section{MARCHANTIA.-SPOROPHYTE.}

XIV. Cut median longitudinal sections of a female receptacle bearing almost mature sporogonia : mount as before, and note under a low power that the parts of the receptacle remain as before : but observe especially-

I. The perigynium, a loose sac-like coat, which arises from the receptacle after fertilization, and envelops the archegonium during its further growth.

2. The wall of the archegonium, now consisting of two layers of cells, and still bearing at its apex the neck, which shows signs of withering.

3. The sporogonium, an almost spherical body inclosed by the enlarged venter of the archegonium : the following parts of it are to be recognized-

$a$. The massive conical foot or seta at the end remote from the neck, i.e. directed towards the base of the archegonium.

b. The wall of the remaining portion of the sporogonium (capsule), consisting of a single layer of cells.

c. The hemispherical sporogenic mass, with no central columella : in it may be recognized (i.) the elaters, long spindle-shaped cells, arranged in a fan-like manner as seen in section; and (ii.) the spores.

Mount a small portion of the yellow flocculent mass which escapes on the rupture of a mature sporogonium, and breathe gently on it, observing it the while under a low power: note the hygroscopic movements of the spirally thickened elaters, and the consequent separation and scattering of the spores. 


\section{THALLOPHYTA}

\section{FLORIDE $Æ$}

\section{POLYSIPHONIA FASTIGIATA, Grev.}

I. This seaweed is found on all our coasts, growing in dense reddish-brown tufts, which are fixed firmly on to the thallus of Ascophyllum (Ozothallia) nodosum, Le Jolis. It grows to a length of about two inches, and the thin cylindrical thallus is frequently branched in an apparently dichotomous manner: on some of the plants taken in autumn, roundish bodies are borne laterally (cystocarps); on others irregular yellowish tassels at the ends of the branches, these are the antheridia, and they are best seen on specimens taken in early summer; on others again dark irregularly disposed swellings may be recognized in the substance of the thallus, these are the organs of vegetative reproduction (tetraspores).

II. The material to be used for microscopic investigation should be either quite fresh, and be kept and mounted in salt water, or better in weak glycerine ; or it should be treated while quite fresh with a solution of picric acid in salt water (see p. 5), and after washing with sea-water, be hardened in successively stronger alcohol from 40 to 90 per cent.

From material thus treated, select a thallus which does not apparently bear any of the reproductive organs above mentioned ; mount a piece of it, including the tips of some of the branches, in 50 per cent. glycerine and water, and observe under a low power- 
I. The cylindrical form of the thallus, and the slight inequality of the apparently dichotomous branching.

2. The general structure of the mature parts of the thallus, consisting of-

a. A series of large central cells, with dark reddish-brown contents : these are surrounded by-

b. A single layer of pericentral or cortical cells, which are arranged with considerable regularity in rings, each ring corresponding to, and surrounding one of the central cells : the whole thallus is thus built up of successive tiers of cells.

3. Observe also the apices of the branches, which taper off to fine points, each terminating in a single dome-shaped apical cell.

Select a good specimen of an apex, and examine it in detail under a high power : observe-

i. The conical ending of the branch, covered by a thick mucilaginous wall, which extends backwards over the more mature parts, and is covered externally by a definite and continuous cuticle.

ii. The single dome-shaped apical cell, with highly refractive protoplasmic contents, and more or less obvious nucleus.

iii. The successive segments which have been cut off from its base by parallel transverse walls.

iv. The subdivision of the segments by longitudinal walls, so that each segment ultimately forms one of those tiers of cells of which the whole thallus is built up.

In mature parts of the thallus, as also near the young apex, note carefully under a high power the fine protoplasmic strands, which extend through the swollen cell-wall, connecting the protoplasmic body of the various cells of the thallus one with another : for further study of these recourse must be had to sections of the thallus.

III. Embed, and cut transverse sections of the thallus of Polysiphonia, selecting such a part of it as is not too old, i.e. about half-way between the apex and the base: mount in glycerine and examine under a high power : it may then be seen in those sections which pass through the middle of one of the tiers of cells above noted that- 
I. The section is circular, since the thallus is cylindrical.

2. That it is limited externally by a clearly marked cuticule, and it will be remembered that as Ascophyllum, on which it grows, is found about half-tide mark, the plant is exposed to the air for several hours in each tide.

3. The series of pericentral cells, of variable number.

4. The single large central cell.

5. Note especially the protoplasmic strands, which run from the central cell to the several pericentral cells, traversing the cell-wall.

IV. Cut transverse sections of the frond of Ascophyllum, so as to pass through the insertion of one of the tufts of Polysiphonia: mount as before, and observe under a low power that elongated, thick-walled cells produced from the base of the Polysiphonia plant penetrate deeply into the thallus of the host, and thus obtain a firm hold upon it, while their own strongly thickened walls will explain further the strength of attachment.

V. Having distinguished with a lens, or under a low power, a specimen bearing tetraspores, mount a portion of it as before directed (taking care that young branches as well as mature ones are represented), and examine under a medium or high power. Note-

1. That the regularity of the tissues of the thallus is disturbed at certain points by dark spherical bodies, which lie embedded in the tissue below the pericentral cells : these are the tetraspores.

2. That they decrease in size as the apex of the branchlet is approached.

3. That they have no clearly definite arrangement.

4. That each undergoes a division into four, hence the term "tetraspore."

5. That they escape by rupture of the layer of pericentral cells: note in older parts the vacant cavities whence tetraspores have escaped.

6. That the mature tetraspores are naked, spherical, and motionless protoplasmic bodies.

VI. Mount as before a small piece of a male plant taken in April, and observe under a medium power- 
I. The normal structure of the main thallus.

2. The club-shaped antheridial branches, often associated together in groups : each consists of -

$a$. A unicellular pedicel, by which it is attached to the thallus.

b. A central linear series of cells, which is almost entirely hidden by-

c Numerous, closely aggregated, and small antheridial cells.

Mount specimens of antheridial branches from fresh living material in sea-water, and having found an antheridial branch exactly at the period of maturity observe the partial disorganization of the walls of the antheridial cells and consequent liberation of their protoplasmic contents, without subdivision, as round non-motile spermatia.

VII. Having recognized a female plant by observations with a lens on specimens taken in late summer or autumn, mount a portion of it in glycerine, and, examining it under a low power, observe-

I. The normal structure of the thallus, which bears-

2. Cystocarps of ovate form : these consist of closely aggregated, small-celled tissue : they occupy the same position as the lateral branches in a vegetative thallus.

3. Compare numerous specimens, and note cystocarps in various stages of development.

VIII. Embed mature cystocarps of $P$. fastigiata in paraffin, and cut from them median longitudinal sections : mount in glycerine, and observe-

I. The short thick stalk of the cystocarp.

2. Its wall, consisting of small, closely aggregated cells, and with an opening or ostiole at the apex.

3. The central cavity, surrounded by the wall, and filled more or less completely, according to age, with elongated, club-shaped cells, having dark protoplasm, and swollen walls; these are the carpospores.

The artificial germination of the spores is a matter of difficulty, but a rough idea of the germination of the spores of red seaweeds may be gained by observing the numerous young plants, of various genera and species, which are to be found attached to the outer surface of almost any one of the larger seaweeds. 


\section{PHÆOPHYCEA}

\section{FUCUS SERRATUS, L. (Wrack)}

\section{OBSERVATIONS WITH THE NAKED EYE}

I. Of the various species of Fucus which are to be found on our shores, the best adapted for laboratory work is Fucus serratus: it is to be found near or below mid-tide level, and may be distinguished from other species by its dark olive colour, the flattened form and serrate margin of the branches of the thallus, the absence of swollen "bladders," and the presence of numerous dot-like conceptacles, crowded together on the ends of branches which show no special swelling.

Having recognized the species by these characters, examine a well-developed plant with the naked eye, and note that the thallus as a whole shows no differentiation of stem, leaf, and root, as in vascular plants ; it consists of the following parts-

I. The flattened disk, of irregular outline, by means of which the plant is firmly attached to the substratum.

2. The stalk, which in old plants is of compressed cylindrical form, but in young plants it may be clearly seen that it is originally a broad flattened expansion, with a more or less thickened midrib : a comparison of plants of successive ages will demonstrate that the compressed cylindrical stalk results from the thickening of the midrib, and decay of the lateral wings.

3. If this stalk be traced upwards it will be seen to branch repeatedly, while on tracing the branches also upwards they gradually assume the flattened form with serrate margin, thus 
confirming the conclusions which may be drawn from a comparison of younger plants, that the whole thallus when young was of a flattened form.

The following observations are also to be made-

A. Examine the apices of young, actively-growing branches : those branches which bear conceptacles must be carefully avoided, as they do not show such characteristic appearances: the extreme apex is emarginate, or depressed, the base of the depression being somewhat flattened, and marked by a slight groove running in the plane of the thallus.

B. Compare a number of apices: in some only a single emargination will be seen, in others two, similar to one another, each having the groove at the base, while others again will show an intermediate appearance: from this it may be concluded that the single apical point divides into two of equal strength, each of which may develop into a branch of the thallus similar to the original: thus the branching is a dichotomy.

C. On comparison of a number of branches it may be seen that the development of the two branches of a dichotomy is not equal, one being usually stronger than the other: this leads to a sympodial development of the dichotomous branchsystem.

D. Observe the less regular outline of the ends of those branches which bear conceptacles, the latter being seen in large numbers on those branches: note with a lens the round orifice or ostiole in the centre of each conceptacle. When mature, two kinds of conceptacle may be recognized in this species : they are borne on different plants, and this species may accordingly be recognized as diœcious : they are-

$a$. Conceptacles the contents of which are of a dark olivegreen : these contain the oogonia, and are the female conceptacles.

b. Others with yellow or orange contents : these are the male conceptacles, and contain the antheridia.

E. If those flattened parts of the thallus be examined which do not bear sexual conceptacles, there will be found, scattered here and there, organs of somewhat similar structure, which 
contain only barren hairs, and they may be termed sterile or neutral conceptacles.

\section{MICROSCOPIC EXAMINATION.}

II. As it is almost impossible to make satisfactory preparations of the tissues of Fucus from fresh material, it will be found a great advantage to fix and harden them: the material is to be fixed by treatment with a solution of picric acid in seawater, and after washing, to remove excess of picric acid, it is hardened in successive strengths of alcohol. An alternative method, which gives good results, is to treat the specimens first with I per cent. chromic acid, wash with water, and harden in successive strengths of methylated spirit.

From material thus prepared select a young flattened branch of the thallus in which the midrib is but slightly marked : cut transverse sections from it, mount in pure glycerine, and observe under a low power--

I. The elongated elliptical outline of the section.

2. The more or less enlarged midrib.

3. The grouping of the tissues exposed: recognize especially-

a. A compact marginal band of tissue of a yellowish-brown colour, the cortical band : this graduates off into-

b. The less compact central mass of the medulla, consisting of a web of interlacing filaments.

Put on a high power, and examine the tissues in detail. Starting from the periphery, observe that the cortical band consists of -

I. A superficial or limiting layer of cells, regularly arranged, and elongated radially; the cells are not of uniform depth, and examination will show that they divide by periclinal, as well as by anticlinal walls ; in fact they constitute an active, continuously meristematic layer, and accordingly the term "epidermis" cannot be applied to it in the strict sense. With the exception of the outer wall, which is thick and cuticularized, the walls of these cells are thin, and the protoplasm plentiful, with a nucleus. 
2. Immediately below the limiting layer, and separated from it by an irregular line, is a parenchymatous tissue, consisting of cells which appear nearly square in the transverse section; each cell has plentiful protoplasm, a nucleus, and several chlorophyll corpuscles : the walls are more or less thickened, swollen, and stratified : here and there are to be seen pits closed by a thin, highly-refractive pit-membrane. These two tissues, (I) and (2), together constitute the cortical band above recognized under a low power.

3. The above tissue graduates off without definite limit into the medulla, of which the chief characteristic is the excessive bulk of the swollen cell-walls: here and there "trabecular" filaments will be found running in the plane of section. If sections be stained with Schulze's solution the firmer cell-wall stains pale blue, but the swollen matrix does not stain.

Occasionally a section may be found which has passed through one or more of the sterile or neutral conceptacles. If the conceptacle was young, it would be found to be a still closed cavity of considerable size, filled with mucilage, and with hairs, which originate from single cells of the tissue lining the cavity ; in sections of older parts the ostiole would be found widely open, and the hairs much longer.

III. Cut longitudinal sections of a young part of a thallus (i.e. close to the apex of a branch), mount in pure glycerine, and examine under a high power : recognize, as in the transverse sections, the cortical band, consisting of-

I. The limiting layer, which presents similar characters to those seen in transverse sections.

2. The inner parenchyma : note that the cells of the inner part of this tissue are arranged in longitudinal rows, having relatively thick, occasionally pitted, lateral walls, and thin transverse septa : this tissue merges gradually into-

3. The medulla, which consists of "trabecular" tissue : here longitudinal rows of cells constitute filaments resembling the hyphæ of Fungi, with numerous thin transverse septa, to which the protoplasmic contents closely adhere.

IV. In order to study the process of thickening of the midrib, cut transverse sections successively of older (i.e. lower) parts of 
the stalk : treat as before, and compare them. It will then be recognized that, as the thallus grows older, the cells of the limiting layer cease to divide by periclinal, and later also by anticlinal walls: it becomes a quiescent tissue, and is ultimately thrown off; the inner cortical tissue however remains active, the cells increase in size, dividing periclinally, and form a massive band, easily recognized by the naked eye. The medulla also increases greatly in bulk, many new hyphal filaments being formed, while they differentiate into two series : $(a)$ smaller ones, with sparing protoplasm ; $(b)$ others of larger size, with a granular protoplasmic lining.

V. Sections should be cut through the organ of attachment. Take plants grown on wooden piles, or on limestone rock: in the latter case the lime may be dissolved by dilute hydrochloric acid, and the tissue then hardened in alcohol. Cut vertical sections, and mount as before : note under a low power the irregularity of the surface of attachment, which closely follows that of the substratum, hence the firmness of its hold. Foreign bodies may often be seen embedded in this part of the thallus, and this finds its explanation in the fact that the tissue here consists of hyphæ similar to those of the medulla, and each appears to grow in an independent manner. Examine the section under a high power, and it will be seen that the mass of tissue resolves itself at the surface of attachment into a number of separate filaments, each of which applies itself separately to the surface of the substratum.

VI. Cut thin longitudinal sections through the apex in a plane perpendicular to that of the flattened thallus: treat those sections which are median with glacial acetic acid, and mount in a mixture in equal parts of pure glycerine and glacial acetic acid ; examine under a medium power, and observe-

I. The outline of the section, showing a depression of the apex corresponding to the groove already recognized with the naked eye.

2. That from their arrangement it may be concluded that the various tissues of the thallus are derived from an initial point at the base of the depression.

3. Examining the tissue at the base of the depression, if the section be median, a single large cell having the form of a 
truncated pyramid may be recognized in a central position : this is one of the initial cells.

VII. Cut successive transverse sections of the apex, so as to pass immediately below the base of the depression : one of these sections will include the initial group, which will then appear to be composed of some four or five cells, of oblong form, placed in a row, side by side.

VIII. Cut transverse sections through the fertile branches of the thallus, so as to traverse the mature conceptacles: mount in glycerine, and examine under a low power. First take sections of the male thallus, and having found a point where a male conceptacle has been cut in median section (i.e. so as to traverse the ostiole) note-

I. The spherical or flask-shaped cavity.

2. The ostiole, by which the cavity communicates with the exterior.

3. The hairs, which almost fill the cavity, and may even protrude through the ostiole.

4. The antheridia, which are single oval cells, borne often in large numbers on these hairs.

It may further be noted that the cavity is lined by a smallcelled tissue, from which these hairs arise, and that this graduates imperceptibly into the other tissues of the thallus, which are similar to those of the vegetative parts.

IX. Tease out with needles the contents of a male conceptacle in glycerine, mount, and observe under high power: note-

I. The thin, colourless, branched hairs, which bear the oval cells (antheridia) with their yellowish granular contents.

2. The mode of branching of the hairs which bear the antheridia.

3. Long hairs, branching less frequently, or not at all : these do not bear antheridia.

$X$. With the above compare sections cut through female conceptacles, mounting as before : in its form, and also in its relation to the tissues surrounding it the female conceptacle is similar to the male; the difference is in the contents, which may be seen to consist of- 
I. Barren hairs, which are usually unbranched.

2. Oogonia, bodies of relatively large size, and oval form, with a thick transparent wall, and dark granular protoplasm : each of these is seated on a unicellular pedicel.

Observe in the largest of the oogonia that the protoplasmic body may be seen to have undergone division into eight parts (ova), the surfaces of separation being visible as transparent lines.

XI. Observations on the extrusion of the spermatozoids and ova, and on the process of fertilization in Fucus must be made with fresh material, and will be most successfully carried out on the coast, the best season for it being winter or spring. Those who have not opportunity for this may succeed in making the observations on fresh material sent from the coast, using a solution of Tidman's sea-salt, 5 ounces to the gallon, in place of fresh sea-water.

If specimens of Fucus serratus be kept exposed to the air for some hours (the period of one tide will suffice), an exudation may be observed from the ostioles of some of the conceptacles : on male plants it will be of an orange colour, on female plants of a dark olive green.

Taking first the male, mount a small quantity of the orange exudation in a drop of fresh sea-water, and examine it under a high power : it will be found to consist of numerous antheridial cells, separated from the hairs which bore them : they will be seen to be bursting, and setting free their contents, and the following stages of the process are to be noted-

I. The antheridial cell is completely closed, the contents are already divided into numerous elongated bodies (said to be sixtyfour in number), each having one or sometimes two brightly orange-coloured globules (chromatophores): these are the spermatozoids, and they may be seen to be in motion before the antheridium bursts.

2. The wall of the antheridium consists of two layers, the outer more firm layer (extine) and the inner mucilaginous layer (intine): observe the extine to burst at one end, usually at the apex, and the contents inclosed in the intine escape from it.

3. The intine gradually swells, loses its contour, and the 
spermatozoids separate, as actively motile bodies of elongated pear-like form. Observe their movements.

To a drop of water containing motile spermatozoids add a little iodine solution, put on a cover-slip, and examine under a high power : the two cilia may be observed on each spermatozoid attached laterally.

Mount in a drop of fresh sea-water some of the darker-coloured exudation from the female conceptacles, and examine under a high power : observe the numerous oogonia, with the pedicel often attached: note the thick limiting wall, consisting obviously of two layers, an outer (extine) more highly refractive, the inner (intine) having the characteristic optical appearance of a mucilaginous wall : a shallow pit is to be seen on the wall adjoining the pedicel. The contents will be seen in most cases or in all to be divided, as above described, into eight cells-the ova. Some of the oogonia will be seen to burst on exposure to the water: watch the process and note the following stages-

I. A slight convexity appears usually near the apex, the extine having there ruptured, and the intine beginning to protrude.

2. The rupture extends, and the extine gradually shrivels back so as to leave the intine fully exposed, though it usually remains still attached to the extine at the base.

3. The intine swells, and ultimately loses its contour at the apex, and the oospheres, which had meanwhile separated and rounded off, escape into the water as eight naked, non-motile spheres of dark granular protoplasm : in each may be recognized a central clearer area-the nucleus.

Into a drop of sea-water in which are free and mature ova, introduce a small number of mature spermatozoids, and watch their movements : they may be seen to approach the ova, to apply themselves closely to their surface, along which they creep : if present in considerable numbers, they give to the ova an irregular rotating movement.

XII. On stones, in districts where Fucus abounds, there may be found earlyin summer olive-brown velvety patches : on examining these with a lens, small club-shaped bodies may be distinguished, attached by their narrower end to the substratum, and with 
their broader, free end crowned by a tuft of hairs : these are young plants of Fucus, or of one of the allied genera.

Having collected such material, and treated it as above directed, tease it out with needles, in glycerine, and examine the plants thus separated under a low power : the following points are the most worthy of note-

I. The nearly spherical form of the very young plants, which consist of but one, or of relatively few cells, and are limited externally by a definite cell-wall, the formation of this wall is the first obvious change after fertilization.

2. The elongated club-shape of the older plants.

3. Their terminal depression, from which numerous hairs protrude.

4. The mode of attachment by means of hypha-like threads of independent growth, similar to those seen in the older plants : some of these threads may be seen quite young, and not yet attached to the substratum.

From such plants as a starting-point, intermediate forms will lead on to the mature Fucus plant. 


\section{CHARACE $Æ$}

Various members of this family are found growing in stagnant, or slowly flowing fresh water : they are green, but owing to superficial lime incrustations, they may appear white and chalky, especially when dry: they are brittle in texture, and are commonly called Stone-Worts. They grow rooted in mud, and put up into the water a branched shoot, which may be a foot or more in length: this bears at intervals whorls of lateral appendages-the "leaves." In summer and autumn these bear the sexual organs in large numbers, the antheridia being specially prominent owing to their bright red colour. The odour of these plants is characteristic, being like that of onions.

There are two chief genera of the family, viz., Chara and Nitella (besides other subgenera) : the most obvious difference between these is that Chara is more robust, the stem and leaves having a peripheral cortex, while Nitella has none. A large number of species are distinguished, and as it might be difficult for beginners to recognize any one definite species with certainty from others, the description given below will be confined to the more essential characters of the genus Chara, while Nitella will be dealt with only incidentally. Fresh material should be used if possible; most of the structural points can, however, be successfully observed on material preserved in alcohol.

I. Examine a mature specimen of Chara with the naked eye, or with a pocket lens, and note-

I. The stem, which is as thick as coarse pack thread, and is marked off into internodes of length varying from $I$ to 3 or 4 inches : this axis is of unlimited growth, and is terminated by an apical bud. 
2. The "leaves" or branches of limited growth, which are arranged in whorls, the point of insertion of each whorl being recognized as a node: the number in each whorl may vary. Examine the leaves with a lens, and observe that they also show a distinction of nodes and internodes; in some species whorls of small unicellular outgrowths (leaflets) may be seen at the nodes: thus the leaves repeat the characters of the axis on a smaller scale.

3. In the axil of one leaf in each whorl is usually found a branch of unlimited growth, which repeats all the characters of the main axis.

4. Examine the base of the plant where it is fixed in the mud: very long transparent rhizoids may be seen to be inserted at the nodes.

5. On the inner side of the leaves of plants taken in summer or autumn the sexual organs will be found, viz., the antheridia, which are globular and of a red colour, and the oogonia, which are of a dark olive colour or brown: these sexual organs are seated, in the monœcious species, in pairs, at the nodes of the leaves, and on the inner, adaxial, side of them.

II. Mount a young part of a plant, including at least one whole internode and two nodes, in water : examine under a low power, and observe-

I. The cylindrical stem; the internode is covered externally by a small-celled cortex, which surrounds one very large internodal cell. Note that the cortex is composed of (a) elongated cells, and (b) short cells which project as hemispherical bosses, the whole being disposed in spirally curved rows.

2. The leaves, which are also covered in their basal part with cortex, but the cells are straight or only slightly curved. Note that the nodes of the leaves may be seen to be marked by cells which project as round bosses (leaflets), or in some species they are elongated. The cortex stops short below the apex of the leaf, which is accordingly terminated by a series of naked cells.

3. Follow the leaves down to their base of insertion at the node, and observe a series of short cells which project more 
or less below the point of insertion : these are the so-called "stipules." The axillary bud will also be seen inserted in the axil of the oldest leaf of the whorl.

III. Remove and examine a whole bud under a low power : either an apical or an axillary bud will do. It may be necessary to treat with acetic acid to remove the lime, which is often present in considerable quantity : the bud may be subsequently cleared with potash, and mounted in glycerine. The outer and older leaves will show the characters above noted, but more clearly, since they are younger, and their internodes shorter: the structure of the cortex will thus be better understood in the young than in the mature leaves.

Examine also the cortex covering the short, young internodes of the stem, and recognize the regular arrangement of the cells : the cortex of each internode is composed of two series of lobes, the one ascending from the lower node, the other descending from the upper : these are in contact at the middle of the internode, and elongate with it as it grows. Each lobe is composed of nodes (3-celled), and unicellular internodes, which alternate in a manner similar to that of the stem itself : compare this arrangement with that of the mature cortex.

Having thus examined the bud, remove the outermost whorls of leaves with needles: then add a little potash and cover the remaining central part of the bud with a cover-slip; press gently with a needle upon the cover-slip, watching the effect under a low power. The outermost remaining leaves will be pressed aside, and the apex of the stem will be exposed.

Observe the terminal dome-shaped, apical cell, from which segments are cut off by transverse walls. By comparison of the terminal series of cells from several apices it may be concluded that each segment cut off from the apical cell divides again transversely into two, of which the lower cell without further division develops directly into an internode, the upper divides to form the numerous cells of the node from which are derived the leaves, and the cortex.

Compare this result with the appearance of the leaves when young.

Note that each cell contains a single nucleus. 
IV. The cells of the Characeæ are well known as good material for showing the movements of protoplasm in the living cell : observations of this are to be made on living specimens mounted in water. Nitella may be used, or the naked terminal cells of the leaves of Chara. Note that the chlorophyll granules, which lie in the outer band of protoplasm, are stationary : the colourless protoplasm below shows however movements by which the granules and clots are carried along, so that a rotation takes place round the large central vacuole. If the movements be sluggish they may be accelerated by gently warming the slide. Note especially the movements in opposite directions on either side of the neutral line, also the relative movements of the contents of adjoining cells.

V. In order to see the rhizoids, which fix the plant at its base, remove one of the lowest nodes of an old plant : wash it gently from mud, \&c., and mount in water : numerous long, transparent threads will be seen to spring from the node: these are the rhizoids. Observe their smooth wall, and granular protoplasm with central vacuole, and the more or less obvious nucleus. Here and there they branch, the point of branching being marked by an oblique, and peculiarly curved cell-wall : from a swelling above the septum the branch-rhizoids spring.

VI. The sexual organs are first to be examined in the mature state : mount a leaf, bearing the bright scarlet antheridia, in water, and examine under a low power. Note the position at the node and below the oogonium : the spherical form, and attachment by a very short stalk. Observe also the surface markings, which indicate that the whole spherical wall is made up of eight unicellular shields, of which the four upper are triangular, but the four lower, adjoining the stalk, are fourangled.

Press gently on the cover-slip : the antheridium will burst, and disclose numerous closely packed antheridial filaments; each of these is partitioned transversely into numerous disc-shaped cells, and contains at maturity a single spiral spermatozoid : the form of the latter can be clearly seen under a high power, and under favourable conditions their escape as free, spirally coiled bodies, with two cilia. 
Attention should be paid to the mode of attachment of the filaments to the shields : in a mature antheridium which has been burst by very gentle pressure, observe that an elongated cell, the manubrium, rises from the centre of the inner surface: this is terminated by a head-cell, which supports six secondary heads, and to each of the latter are attached four of the antheridial filaments : their total number is therefore about 200.

VII. Mount in water a leaf bearing one or more mature but unfertilized oogonia or "nucules" as they are sometimes called, and examine under a low power. Observe their position, directly above an antheridium : their oval form, and insertion by a short pedicel. Each consists of an outer coat, composed of five spirally twisted cells, a crown or apical rosette of five cells, and a large central ovum : at the base of the latter when young, or after treatment with potash, a short cell is to be seen. Note that a narrow lateral slit may be seen between the cells of the crown at the receptive period, through which the spermatozoids may pass to the ovum. Attempts may be made to see the entry of the spermatozoids by adding a drop of water containing motile spermatozoids to a preparation in water of a mature oogonium.

VIII. Examine mature oogonia and note the dark colour, and the thickened, lignified wall of the spiral cells, while the oospore itself is surrounded by a thick, colourless wall. Burst one by pressure upon the cover-slip, and it will be seen that the contents consist largely of starch and oil.

IX. The results of germination may be readily observed in Chara or Nitella, if specimens with mature oospores be kept in water in a bell-glass through the winter: in the spring the oogonia which had settled to the bottom may be found in various stages of germination. Some may be seen still closed at the apex : in others the spiral cells may have ruptured at the apex and two or more transparent filaments project : one of these develops more strongly as the proembryo, it divides by transverse walls, and assumes a green colour: the other remains colourless and develops into rhizoids. In one of the filaments which is far advanced observe a narrow, disc-shaped cell, two or three cells short of the apex-this is the stem-node: from it 
a pseudo-whorl of leaves arises, and, as a lateral bud, the new Chara plant, which at once shows the characteristic alternation of nodes and internodes: observe its position, and successive stages of development.

Lower down is a second node-the root-node, which gives rise to rhizoids; these may branch and fix the young plant in the mud. 


\section{CONFERVOIDE}

\section{EDOGONIUM}

Various species of plants belonging to this genus are to be found growing in fresh water : they are green, filamentous, unbranched Algæ, and are attached at the base to the external surface of submerged plants, stones, \&c. The apex of the filament is in some species extended into a thin, hair-like process : there is often considerable irregularity in the thickness of the filament, by which character, as well as by the peculiar transversely striated markings of the cell-walls, these plants may be distinguished.

I. Mount filaments of $E$ dogonium in fresh water, having gently scraped them off from the surface to which they were attached, and examine them under a low power : observe-

I. The long unbranched filament, of uneven thickness, terminated at the apex either by a rounded cone, or by an attenuated process : note also at the base the irregularly lobed disk of attachment.

2. The septa, dividing the filament into a series of cells, with green-coloured contents.

3. At the upper ends of many of the cells transverse striæ are to be seen : these are indications of past cell-divisions.

Examine the filaments under a high power, and pay special attention to these striæ and other irregularities of the otherwise smooth cell-walls. It will then be seen that the striæ are small, sharp-edged, ring-like projections on the outer surface of the wall : also that a single corresponding stria is to be found, more or less distinctly marked, at the base of each cell.

In some cells an annular ingrowth of the cell-wall may be 
seen immediately below the striæ : note its form and connexion with the cell-wall; also, when seen in optical section, a central, dark mark : it is here that the ring splits, and by stretching of the ring the well-known process of intercalation of a new zone of cell-wall follows. Examine actively-growing filaments, and try to observe various stages of this peculiar process, noting also any indications of the cell-division which follows it, the new septum being formed immediately below the thin-walled intercalated zone.

Passing to the examination of the cell-contents, observe-

I. The colourless protoplasmic basis, in which are embedded-

2. The chromatophores, which appear as elongated and branched rod-like bodies, more or less closely and irregularly connected together: here and there will be seen highly refractive pyrenoids attached to the chromatophores: these are clearly to be distinguished by their dusky purple staining on treatment with iodine solution.

3. A single nucleus which is, however, difficult to recognize in well-nourished cells.

\section{A large central vacuole.}

II. An examination of fresh filaments may result in the observation of the reproductive organs, and numerous specimens should be looked over with the object of finding them. Thus the reproduction by swarm-spores may be seen, especially in the morning : without the cell having undergone any change of form the cell-wall ruptures by a transverse split, and the protoplasmic body, having previously contracted, escapes through the slit as a motile pear-shaped, primordial cell, the anterior end of which is surrounded by a fringe of cilia. After a motile period these attach themselves by the anterior end to some firm body, and, forming a cell-wall, develop into new filaments. Note young plants in early stages of germination : they may be found in numbers attached to submerged plants or stones in waters where $\mathscr{E}$ dogonium grows.

III. There is some variety in the details of development of the sexual organs in different species of CEdogonium: some species are monœcious, others diœcious. 
The oogonia, or female organs, are most easily observed, being spherically enlarged cells of the filament, borne singly or several together : in such oogonia note-

i. The rupture of the cell-wall at the period of maturity by a transverse slit.

ii. The beak-like canal, which projects in some species from the slit.

iii. The hyaline receptive spot.

iv. In old oogonia the mature oospore with thick wall, and dense contents.

The antheridia, which are smaller and shorter cells than those of the normal filament : each divides into two cells, the contents of which, without further division, escape as a motile yellow spermatozoid similar in form to the swarm-spore. Attempts should also be made to observe the germination of the oospore. 


\section{SIPHONEÆ}

\section{VAUCHERIA SESSILIS, Vauch.}

I. This Alga is to be found growing as a lax green felt on the surface of moist soil (frequently on the soil in pots in greenhouses): it is of so coarse a texture that the separate filaments can readily be recognized with the naked eye, having a somewhat dull-green, glassy appearance. Kemove a small portion of this felt : tease it out as gently as possible in water, and examine it under a low power : observe-

I. The coarse, green, cylindrical tubes which constitute this Alga.

2. The absence of septa as a rule, though septa may be present occasionally in unhealthy specimens, and are formed in connexion with the reproductive processes.

3. The very irregular monopodial branching.

4. Some branches may develop as rhizoids, ramifying in the soil, but these are frequently absent altogether.

5. There may be present lateral outgrowths of peculiar form, which are the organs of sexual reproduction (gametangia), viz.-

a. Curved cylindrical bodies, which are the antheridia.

b. Obliquely oval, sessile bodies which are the oogonia.

In this species the sexual organs are associated together in groups of two or three, each being inserted separately upon the thallus : a single antheridium is usually associated with one or two oogonia.

II. Put on a high power, and examine the structure of the thallus in detail. Note-

I. The smooth continuous external cell-wall : this may be 
made more apparent by plasmolysing some filaments with a 2 per cent. solution of common salt.

2. The protoplasmic membrane, which lines the wall, and incloses a large central vacuole which runs the whole length of the filament: this membrane may also be more readily distinguished in plasmolysed specimens. In the membrane are embedded-

3. Numerous oval, or spindle-shaped chlorophyll corpuscles : look for some of these undergoing division.

4. Round highly refractive oil globules, which are more or less numerous according to the condition of the plant as regards nutrition.

III. On specimens which have been kept under conditions favourable for strong growth, the sexual organs (gametangia) are usually to be found in greater or less numbers. Having found a specimen with mature sexual organs, examine first the antheridium under a high power.

I. The lower straight portion, or pedicel, rises vertically from the main filament.

2. The curved portion, or antheridium proper, differs from the pedicel in the contents being for the most part colourless : it is separated by a septum from the pedicel. When mature the contained protoplasm forms a large number of small spermatozoids, which escape through an opening at the apex.

Next examine a mature oogonium in detail : note its sessile position, and the septum which separates it from the main filament: its oblique form and green-coloured, granular contents : when actually mature an obliquely lateral beak is formed, the apex of which becomes gelatinous, so that the motile spermatozoids can gain access to the ovum.

IV. Observe the changes which succeed fertilization, resulting in the formation of the ripe oospore: the chief are-

I. Formation of a firm wall completely surrounding the fertilized ovum, and fitting closely within the wall of the oogonium.

2. An increase in the size and number of the oil globules : no cell-division takes place.

V. The reproduction by means of zoogonidia may readily be 
observed in specimens grown under favourable conditions in water : a considerable mass of the Alga is to be placed in a porcelain bowl, in water, and exposed in a window : after a few days, numerous small plants of Vaucheria will he found floating on the surface of the water, or disposed along the submerged surface of the bowl : these have resulted from vegetative reproduction by zoogonidia. In order to see the process observations must be made in the early morning, or else the culture must be kept in the dark till shortly before the observations are to be made. Shortly after dawn (or soon after the specimens have been exposed to light) some filaments may be seen with a lens to have dark-coloured and slightly swollen ends : these are about to form zoogonidia : mount some specimens without a cover-slip, taking care to avoid injuring them; and examine under a low power : observe-

1. The swollen end of the filament, with dark, densely aggregated protoplasm, surrounding a vacuole.

2. The transverse septum dividing the swollen end from the rest of the filament.

If such specimens be kept under observation the escape of the zoogonidium may be observed : the following points are to be specially noted-

I. Various changes in the protoplasmic body and vacuole, terminating in the formation of a transparent, and radially striated, outer protoplasmic coat (ectoplasm), which lines the cell-wall, while darker, more granular protoplasm (endoplasm), including the chlorophyll corpuscles, collects towards the centre.

2. The rupture of the cell-wall by an irregular slit near to the extreme apex of the filament : before the rupture the septum may be seen to present a convex surface to the rest of the filament, indicating greater internal tension in the "zoosporangium ": on rupture, this is relieved, and the septum then projects convexly into the cavity of the empty zoosporangium.

3. The passage of the protoplasmic mass through the opening, by a streaming movement, assisted by more or less marked, screw-like rotation of the whole body: the protoplasm may undergo division at the time of escape, and two zoogonidia may thus be formed. 
4. The rapid movement of the large zoogonidium when free, which may be followed with the naked eye, and under the microscope is seen to be rotatory. The motile period lasts but a short time, and varies in different species.

Treat a zoogonidium, which has just escaped and is in rapid motion, with a solution of iodine : put on a cover-slip, and examine under a higher power: no cell-wall will be visible, though the solution will in some measure plasmolyse the cell. Turning more especially to the ectoplasm, there will be seen numerous cilia, arranged in pairs, projecting from the surface of the zoogonidium, while in the transparent ectoplasm will be seen numerous highly refractive bodies, which stain with iodine : these are nuclei, and a careful observation will show that their position is exactly opposite the insertion of the pairs of cilia.

Treat a zoogonidium, which has come to rest, with a plasmolysing agent such as 2 per cent. solution of common salt, watching it meanwhile under a high power: the protoplasm will contract, and a fine cell-wall will be seen. This result may also be obtained by pressure on the cover-slip.

Mount and examine zoogonidia which have already come to rest, and by a comparison of them the process of germination of the zoogonidia, and the development of new plants from them may be deduced. 


\section{CON J U GAT $Æ$}

\section{SPIROGYRA}

I. In summer, in stagnant or slowly-flowing waters, flocculent freely-floating masses of a vivid green colour, and slimy to the touch, may frequently be found : with the naked eye it may be seen that the masses consist of coiled and tangled unbranched filaments, in which there appears to be no distinction of apex or base.

Mount a few of them in water, and examine them under a low power: note that the simple unbranched filaments are partitioned off by transverse septa into a number of relatively short cells. It will usually be obvious that the filaments are not all alike, and two chief types will frequently be found present-

$a$. Those with two star-like green bodies in each cell : these belong to the genus Zygnema, and, as these Algæ are not so well fitted for a detailed observation, they may be neglected.

$b$. Others will be seen to have one or more spirally coiled green bands in each cell : these belong to the genus Spirogyra.

A superficial observation of specimens collected at the same time and place will usually show that in different filaments there is considerable variety in size, form of the cells, thickness of the walls, and in the number and arrangement of the spirals : according to these characters (together with those of the zygospore) a large number of species of Spirogyra are distinguished. It will be found convenient to select for observation specimens of the largest size, and with the coils of the green spirals furthest apart. Examine such filaments in detail under a high power, in the living state, mounted in water, and observe- 
I. That the whole filament is covered externally by a transparent gelatinous sheath, with a somewhat irregular outer surface, and showing a radial striation. It is to this layer that the Alga owes its slimy character. It is to be noted, however, that this sheath is almost entirely absent in some species.

2. A firm cell-wall, which is more highly refractive : it immediately surrounds the protoplasmic body, and is continuous with the transverse septa.

3. The protoplasmic body, which consists of -

a. A colourless membrane (primordial utricle) which lines the cell-wall internally, and surrounds the large central vacuole.

b. The green spiral chromatophores (one or more) embedded in the protoplasm: note their irregular outline, and the numerous highly refractive lenticular bodies (pyrenoids) which are contained in them.

c. A bi-convex lens-shaped nucleus, suspended in the centre of the vacuole by fine colourless strands of protoplasm, which run to the primordial utricle, attaching themselves to points opposite the pyrenoids.

Stain with an iodine solution, and observe that the colourless protoplasm stains pale yellow, the nucleus a deeper yellow, and it will thus be more clearly seen, as well as one or sometimes two nucleoli which are deeply stained: the pyrenoids stain a dusky purple.

II. The process of cell-division may be very well observed in the filaments of Spirogyra; the chief difficulty is however that the process normally takes place at night, beginning about io to 12 P.M. If the Spirogyra be placed in a flat plate upon a block of ice during the night, and on the following morning the plants be exposed to a higher temperature, the cell-division which had been previously retarded will begin, and the successive stages may be followed.

The following points in the process should be specially noted-

I. The disappearance of the nucleolus.

2. The formation of the striated nuclear spindle and of the equatorial nuclear disk.

3. Division of the chromatin which constitutes the disk, and 
the collection of the two halves at the poles of the spindle as the new nuclei, which are still connected by fine threads.

4. The subsequent dilatation of the spindle, the threads becoming more curved, while from it new connecting threads pass to the peripheral protoplasm.

5. Meanwhile microsomata collect at the equator of the dividing cell.

6. Note also the involution of the chromatophores and their subsequent division.

7. The gradual formation of the septum, beginning at the periphery and proceeding towards the centre.

III. In summer or autumn the process of conjugation and formation of the zygospores may frequently be observed in Spirogyra: filaments which are about to conjugate assume a position parallel to one another, and on them the following observations are to be made-

1. Cells opposite one another put out rounded processes, which meet.

2. The wall at the point of junction is absorbed, and thus the canal of communication is formed.

3. Meanwhile the protoplasm of the two cells has rounded off, one (the male) usually doing so earlier than the other (the female).

4. The protoplasm of the male cell passes through the canal, and coalesces with the female to form the zygote.

5. The zygote surrounds itself with a thick stratified cell-wall, which is smooth or shows various markings of the surface according to species. 


\section{FUNGI}

\section{BASIDIOMYCETES}

\section{AGARICUS CAMPESTRIS, $L$. (The Common Mushroom)}

I. Examine a brick of "mushroom spawn," such as is sold in the shops for the artificial culture of the Mushroom (Agaricus campestris). It will be found to consist of a compost of dried cows'-dung, loam, and clay, in which numerous very fine microscopic filaments are present, or irregularly branched white bands which may be easily recognized with the naked eye: this is the mycelium.

Tease out with needles in water some of the mycelium, mount in water, and examine under a low power : note that the white bands recognized with the naked eye are composed of numerous colourless filaments (mycelial hyphæ), associated together in a parallel course, while here and there single hyphæ diverge from the rest, and ramify through the compost.

II. In order to obtain an actively growing mycelium, bearing "mushrooms," the brick is to be broken into pieces, and these must be buried a few inches deep in a compost of similar nature to that of the bricks : the whole is to be kept moist, at a moderately high temperature, and in the dark. After a period of a few weeks, the compost will be found to be permeated by a mycelium, similar to that in the brick of "spawn," while numerous mushrooms of various sizes will be found connected with it: such a culture as this will suffice for the study of Agaricus campestris in the laboratory. 
III. Remove a small piece of the mycelium, of an actively growing culture, mount it in water, and having teased it out carefully with needles, examine it in detail under a high power, and observe-

I. The hyphæ, of cylindrical form, and with rounded free ends.

2. The irregular branching of the hyphæ.

3. The septa, which are transverse, and situated at irregular intervals.

4. Hyphæ may frequently be seen to be incrusted by numerous rod-like crystals.

IV. Examine a portion of the mycelium which has begun to produce "mushrooms" : with a little care the compost may be entirely removed from considerable tracts of the branched mycelium, and then the relation of the latter to the young mushrooms may be clearly seen. If a series of specimens illustrating the development of the mushroom be examined with the naked eye, the following observations may be made :-

r. That the mushrooms arise from the mycelium itself.

2. That they appear first as irregular rounded, or oval, upward growths, of denser texture than the mycelium itself.

3. That on cutting one of the smaller mushrooms longitudinally it appears to the naked eye to be of homogeneous structure.

4. That older mushrooms acquire an enlarged head (the pileus), which is supported on a cylindrical stalk (the stipe). In this state they are termed "button mushrooms."

5. That as the pileus dilates horizontally, a rupture of a veil of tissue (velum partiale) about its lower margin exposes a complicated laminated structure formed internally (the gills, or hymenial lamellæ).

6. Note further the ring or annulus, which remains persistent on the stipe of the mature mushroom, and marks the line of rupture of the velum : the corresponding, irregular fringe at the margin of the pileus is also to be recognized.

7. Removing the mature pileus, examine its lower surface, and note the radiating, more or less darkly coloured lamellæ, some of which extend the whole way from the margin to the insertion of the stipe, others only a part of that distance. 
Lay the pileus of a mature mushroom with its lamellæ downwards on a sheet of white paper for a few hours : on removing it there will be seen on the paper a sort of print of the configuration of the under surface of the pileus, produced by the fall of the minute, dark-coloured spores.

V. In order to study the structure of the mushroom by means of sections, it is a great advantage to harden the material, and the following treatment has been found to produce good results : treat the fresh material for about twenty-four hours with I to 5 per cent. chromic acid; wash with water, and then successively with 50,70 , and 90 per cent. methylated spirit : the tissues will assume a cartilaginous character, which makes it possible to cut fine sections: in preparing large specimens it is an advantage to cut them up into pieces of moderate size, so that the reagents may gain more ready access to the internal parts.

From material thus treated cut longitudinal sections of the stipe so as to include both peripheral and central tissues : mount in glycerine, and examine first with a low power: observe-

I. The whole is a spurious tissue, composed of elongated septate tubes (hyphæ), which are closely interwoven.

2. The diameter of the individual hyphæ is less, and they are more closely packed towards the periphery than near the centre of the section.

Examining the sections under a high power it will further be observed-

I. That the hyphæ are branched, while occasionally their endings are to be seen.

2. That they are thin-walled, the transverse or oblique septa being so disposed that the cells are not much longer than broad.

3. The protoplasmic contents of the hyphæ which make up the bulk of the tissue are far from being copious, while no single, well-marked nucleus is to be found in the individual cells.

VI. Cut transverse sections of the stipe, and, treating as before, observe that the hyphæ appear circular in section, that they are more loosely packed towards the centre than at the 
periphery, and that throughout, intercellular spaces are to be recognized.

VII. Passing to the pileus of the mature mushroom, cut tangential vertical sections through it in such a way as to traverse the vertical gills at right angles to their surface : great care must be taken that the surfaces of the gills shall not be injured in the process of preparation, otherwise the basidia and spores which project from their surfaces cannot be observed. Mount in glycerine and examine under a low power : the chief bulk of the section will consist of the massive tissues of the pileus, which show little or no differentiation; passing downwards to the lower surface where the gills or lamellæ have been traversed, the sections of these will be seen as fringe-like projections from the lower surface : occasionally branching of the gill may be recognized.

Examine the sections in detail under a high power: the following observations are to be made-

I. The mass of tissue of the pileus consists of a plexus of much-branched hyphæ, with large intervening spaces: it is composed of short cells, similar in their characteristics to those which compose the stipe: the chief difference lies in their arrangement. This spongy tissue becomes denser about the insertion of the lamellæ.

2. The sections through the lamellæ show a differentiation into-

a. The central portion (trama), in which the septate hyphal filaments are easily recognized running longitudinally down the middle of each lamella, and curving outwards at their ends towards the free surface.

b. The sub-hymenial layer, composed of shorter, closelypacked cells, constituting a pseudo-parenchyma : this consists of the short-celled, terminal parts of the hyphal filaments which compose the trama.

c. The hymenial layer, consisting of oblong, closely packed cells, having their longer axes perpendicular to the outer surface : of these cells two types are to be distinguished-

i. The paraphyses, which are somewhat narrower and have smooth rounded ends. 
ii. The basidia, which are more bulky, and longer : each bears on its end two fine processes (sterigmata); at the extreme tip of each of these there appears a swelling which develops into the mature spore. Note various stages of development of the sterigmata, and spores.

VIII. Remove a whole gill carefully from a fresh mushroom, mount it on a slide, without any reagent or cover-slip, and examine its surface with a medium power : it may then be seen that the dark colour is due to the dusky spores, which are thickly distributed over the surface of the gill in pairs, two being produced from each basidium: note further the pale colour of the tissue of the hymenium, and the rounded ends of the paraphyses, and of those basidia which are young, or have already produced mature spores. 


\section{II. ÆCIDIOMYCETES}

\section{PUCCINIA GRAMINIS (Æcidium Berberidis), Rust of Wheat}

\section{A. Puccinia Stage.}

I. On the stems and leaves of wheat and others of the Gramineæ in winter, dark oblong patches may often be found, which owe their origin to a Fungus (Puccinia graminis) that infests the tissues, and produces the disease called Rust.

Examine one of these patches with a lens, and note that the superficial tissues of the wheat are ruptured by a longitudinal slit, and the torn edges are turned back, so as to expose a dense, dark-coloured mass, which protrudes from within: the nature of this mass must be studied by means of sections.

II. Cut transverse sections of the leaf-sheath, or other diseased part of the Grass plant, taking care that the section shall traverse one or more of the dark patches of Rust: mount in glycerine, and examine under a low power. Observe that the structure of the greater part of the section is normal : each dark patch will be seen to be opposite one of the spaces between the vascular bundles, while the epidermis, which normally covers over the tissues, is ruptured. In case it is the leaf which has been cut, dark patches may be observed as rupturing and projecting through the epidermis of both the upper and lower surfaces.

Put on a high power, and in a thin section observe-

I. The thin hyphæ of the branched mycelium of the parasite (Puccinia), which ramify in the softer, succulent tissues, but do not as a rule attack the sclerenchyma, or vascular bundles: they may be traced up to the dark patches above noted. 
2. The masses of dark brown teleutospores or winter spores, which are produced by this mycelium, each spore being borne on a thin pedicel: each consists of two cells, with thick walls, differentiated into two layers, the exospore and the endospore. In the protoplasmic contents of each cell is a clear spherical body, which may be the nucleus, but this is not certain.

III. If pieces of a Grass plant bearing teleutospores be kept in a moist atmosphere (on wet blotting-paper, under a bell glass) in the spring-time, a fine, white, semi-transparent growth will be produced from the teleutospores: this is the promycelium. Remove some of these germinated teleutospores carefully with a needle, and mount in water: if this be done without injuring the promycelium, it will be seen under a high power that one or both of the cells of the teleutospore have put out a germinal tube (the promycelium) by rupture of the exospore, and protrusion of the endospore : this promycelium divides into four or five cells, each of which (excepting the basal one) produces a conical process (the sterigma): the end of each of the sterigmata swells into a small irregularly roundish body (the sporidium), which ultimately becomes detached.

\section{B. Acidium Stage.}

IV. Note in early summer on the leaves of Berberis irregular bright yellow or red blotches, the tissues of the leaf appearing swollen at those spots, and projecting convexly on the lower surface, while the upper surface of the blotch is usually concave: on the lower surface numerous irregularly distributed yellow cups (æcidium cups) may be seen projecting slightly beyond the surface, while on the upper surface also projecting organs of smaller size, and irregular distribution (spermogonia) may be seen.

V. Cut transverse sections of a diseased leaf, so as to pass through one of these blotches: mount some in glycerine, others in chlor-zinc-iodine, and examine under a low power: observe-

I. That in the thinner normal part of the section, between the upper and lower epidermal layers there is a mesophyll consist- 
ing of a single palisade layer, and five or six irregular layers of spongy parenchyma.

2. That the greater bulk of the infected part is due not so much to increased number of the cells as to the larger size of the individual cells and of the intercellular spaces.

In the sections prepared with chlor-zinc-iodine, if a good staining has been effected, note with a low power that the fungal tissues are but slightly stained yellow, while the tissues of the host are stained in the usual way, chiefly a dark blue. Recognize as the most prominent parts of the parasite-

I. The æcidia, cup-like structures, containing a closely packed mass of spores, and opening by rupture through the lower epidermis of the host.

2. The spermogonia, relatively small, flask-shaped organs opening on the upper surface of the leaf.

Having thus gained a general idea of the sections, examine them in detail under a high power, and note that in the infected patch the cells of the host are apparently embedded in a felt of mycelium, consisting of septate and branched hyphæ, which traverse and completely choke up the intercellular spaces : they are but slightly stained with chlor-zinc-iodine, while the cellwalls of the host plant assume a dark colour : they are for the most part confined to the intercellular spaces, and especially those round about the æcidia ; but it is stated that occasionally they penetrate the cells of the host, and though this is not easy to see, examples of it should be looked for. Turning to the æcidium observe-

I. Its cup-like form.

2. The dense felt of hyphæ at the base of it.

3. Immediately above this is the hymenium, a layer composed of closely packed, parallel, rod-like cells (basidia), arranged perpendicularly to the outer surface of the leaf.

4. The rows of spores, which have been successively abstricted from the basidia : observe the hexagonal form, thickened wall, and orange colour of the spores, and the way in which the spores of contiguous rows fit together.

5. The peridium, consisting of a single layer of cells enveloping the mass of spores : the form and arrangement of the 
cells resemble that of the spores themselves though not so regular: note the thickened and striated outer wall.

Returning to the spermogonia, observe-

I. The closely packed, parallel, rod-like hyphæ converging to the centre (sterigmata).

2. The minute oval bodies (spermatia) abstricted from them, and escaping through the narrow pore on to the outer surface of the leaf.

3. The brush of hyphæ which protrude through the narrow pore.

VI. It is known that the æcidium-spores of this fungus will not infect the Barberry plant afresh, but will only germinate so as to infect a Grass plant; thus the fungus is an example of "Heterœcism." The spores retain their germinating power only for a short period.

Take some fresh spores from an æcidium, and place them in a drop of water on the surface of a fresh leaf of some Gramineous plant : after keeping it in moist air for about $48-60$ hours, strip off a part of the epidermis, or better, cut tangential sections of that part on which the spores have been placed : mount in water with the outer surface of the epidermis uppermost, and examine under a medium power : observe that the æcidium spores have produced tubular hyphæ, which make their way, through the pores of the stomata, into the tissues of the Grass plant.

VII. Infect a Grass plant with æcidium spores and keep it in a moist atmosphere : in about a week reddish swellings will appear about the points infected, and the epidermis will be ruptured.

Cut transverse sections so as to traverse one of these ruptured spots: mount in water, and observe under a medium power : note-

I. The branched mycelium ramifying in the tissue of the Grass.

2. The ruptured epidermis.

3. The closely packed uredo-spores of simple oval form, borne on thin pedicels (basidia). Observe further the exospore, rough with small outgrowths: the endospore, with four 
germinal pores, arranged equatorially; here the inner wall is wanting: note the protoplasmic contents with reddish granules.

The infected Grass plants which have produced uredo-spores should be kept till the autumn, when the patches which before produced uredo-spores only will, on investigation as above directed, be found to bear teleutospores intermixed with them, and finally to assume the winter condition of containing teleutospores or winter-spores only, in which condition the winter is passed: with this stage the study of the Fungus, as above directed, was begun. 


\section{CLEISTOCARPOUS ASCOMYCETES}

\section{EUROTIUM ASPERGILLUS GLAUCUS}

I. Keep a slice of dry bread under a bell-glass, until it becomes mouldy. Even a superficial examination of it will show in most cases that more than one kind of Mould is present. Among the rest the most prominent will probably be one which bears roundish, white or pale green heads closely aggregated, and borne on stalks of about one-sixteenth of an inch in length : this is the conidial form of Eurotium Aspergillus glaucus, and the branches bearing the heads are styled the conidiophores.

Shake some of these gently with the point of a needle : numerous minute powdery bodies (the conidia) will be liberated, and will float away as a fine cloud.

II. From a pure patch of this green Mould remove a' small portion with a needle, avoiding mechanical roughness as much as possible : lay it on a slide, moisten with a single drop of alcohol, then add water, and cover gently with a cover-slip. Examine it under a low power, and observe-

I. The stalked conidiophores, with large, mop-like heads.

2. Attached to these, the colourless tangled mycelium from which they spring.

3. The innumerable detached conidia which will be found thickly distributed throughout the preparation.

Having selected one of the largest of the conidiophores, examine it in detail under a high power, noting especially-

I. The robust stalk, usually without septa : its wall is clearly defined, and the protoplasmic contents granular and vacuolated. 
2. The transversely septate, branched mycelium, from which the conidiophores arise as vertically growing branches, usually from a point immediately behind one of the septa : in this as in other cases of branching of the mycelium, the branch grows out at right angles from the hypha which bears it.

3. The swollen spherical head of the conidiophore, with its conidia in radiating rows inserted upon it. Examine carefully the way in which the conidia are produced, noting-

a. The sterigmata, which are peg-like radiating outgrowths from the head of the conidiophore.

$b$. The series of conidia, in successive stages of development, which have been successively formed by abstriction from the sterigmata.

c. The oval form, and spiny surface of the mature conidium.

In order to observe the successive stages of development of the conidiophore, small portions of the Fungus should be taken from the white patches, where the growth is younger, and be treated as before. In these specimens the following points are to be observed-

I. The conidiophore as a club-shaped thick erect hypha.

2. The swelling of the head, though it at first remains quite smooth.

3. Minute papillar outgrowths appear on the surface of the head-these are the young sterigmata.

4. The sterigmata elongate, and become attenuated at the tips.

5. The successive stages of abstriction of the conidia from the apices of the sterigmata.

III. In order to trace the germination of the conidia, they should be cultivated under microscopic observation on the slide. For this purpose a moist chamber is to be prepared as directed in Appendix A. It will be necessary to take certain precautions to reduce the probability of access of foreign spores to a minimum, and so insure as nearly as possible a pure culture. Prepare a nutritive solution by boiling French plums in water : this decoction is to be used very dilute, and is to be boiled immediately before starting the culture, so as to kill any foreign spores which may be already present: with the 
same object, the glass slide, cover-slip, and needles are all to be heated in a spirit-lamp, and the porous pad for the moist chamber is to be well boiled in water.

Having made these preparations, place a single drop of the clilute, sterilized decoction on the cover-slip: then with a needle, moistened with the sterilized fluid, remove from as pure a tuft of Eurotium as can be found a small number of conidia, and place them in the single drop on the cover-slip : examine under a low power to see that the number of conidia is small, then quickly invert the cover-slip and place it over the round hole punched in the porous pad. Keep the preparation thus made under a bell-glass, and observe it from time to time under the microscope: if the culture be successful, the successive stages of germination and of further development of the Mould may be watched in detail.

IV. The perithecia, and the archicarps (female organs) which give rise to them, are to be sought for on a mycelium which has already produced mature conidia : the ripe perithecia (Eurotium fruits) may be readily recognized in old cultures on dry bread, as minute yellowish spherical bodies, easily distinguished by the naked eye.

A. Remove a small piece of mycelium which has already borne mature conidiophores, and is thus likely to bear young archicarps : moisten it with alcohol, and then wash off in a watch-glass in water as many of the conidia as possible : tease it out with needles, and, mounting in water, examine under a high power. Observe-

I. That the same mycelium which bears the conidiophores also produces relatively thin whip-like branches, with highly refractive contents.

2. That some of these branches become coiled, at first loosely, but later in a tightly packed spiral of four or five coils, and consisting of several cells : these spirals are the archicarps.

3. That first one, and subsequently several hyphal branches appear below the closely coiled archicarp, forming an investment round it : the first formed branch is called the pollinodium (male organ), and comes in close contact with the apex of the coiled archicarp. 
B. From a culture of some six weeks' duration on dry bread pick off with a needle some of the minute spherical perithecia : mount them in water and examine under a low power; observe-

r. The round or oval form of the perithecia.

2. That they are composed of a small-celled pseudo-parenchymatous tissue.

3. Their yellow colour.

4. Their insertion, each being borne on a single filament of mycelium.

The yellow colour is due to an oily substance, which is soluble in alcohol, or in potash solution.

Treat some perithecia with a weak potash solution, mount them in glycerine, and examine under a high power : note-

I. The wall of the perithecium, consisting of a single layer of somewhat flattened cells.

2. The cavity surrounded by that wall, filled with bodies of oval form - the asci.

In order to be able to examine the asci in detail, mount fresh perithecia in glycerine, press with a needle on the cover-slip so as to burst them, and note-

1. The ruptured wall, as before.

2. The oval asci, each of which contains eight ascospores, of oval shape when young, and biconvex-lens shaped when mature.

3. Other cells may also be found which belong to the pseudoparenchyma; this is derived by ingrowth from the wall of the perithecium, and is only to be found in young perithecia : at the period of maturity it is completely absorbed.

Among the Moulds which appear with constancy on bread kept under a bell-glass, as also on other organic bodies, is Penicillium : it may be readily distinguished from Aspergillus by its lower growth, more velvet-like appearance, and blue-green colour, while the latter shows a higher growth, so that the individual conidiophores may be seen with the naked eye, and its colour is an olive-green.

Remove a small piece from a pure patch of Penicillium which has been recognized by the above characters : tease it out with 
needles, then moisten it with alcohol, and mount in water. Examine it under a high power, and observe the branched, septate mycelium, which frequently forms a very dense mat: this is especially the case if it be grown on Pasteur's solution with sugar. Note that certain branches, which grew up from the substratum, end in a brush of closely arranged parallel branches, and that each branch is terminated by a string of conidia : these are formed by basipetal abstriction, in the same way as in Aspergillus.

The conidia may be germinated in the same way as those of Aspergillus, and with suitable precautions pure cultures may be grown on various nutritive substrata. 


\section{PERONOSPORE $Æ$}

\section{PYTHIUM DE BARYANUM}

I. Sow seeds of the common garden Cress (Iepidium sativum) thickly in a flower-pot: cover it over with a glass plate, and keep it well watered, so that the young seedlings grow up in an atmosphere saturated with water. After a few days the head of some of the seedlings may be seen to have bent over, owing to insufficient support of the stem : examination will show that the curvature is a sharp one, so that it is not due to general weakness : further that the stem is thin and flabby at the point of curvature : while fungal filaments may be observed in close contact with the stem at that point, and it is this Fungus (Pythium de Baryanum) which is the cause of the disease termed by gardeners "damping off": it is of common occurrence in propagating pits which are kept too warm and moist.

If the Cress cultures be kept damp for some days longer, a thick felt of hyphæ will be formed, which will bind the seedlings together : and finally the disorganization, which usually begins near the base of the hypocotyledonary stem, will spread throughout the seedlings, causing complete rotting.

II. Mount part of a stem of one of the collapsed seedlings in water, and examine under a low power : observe-

I. That the tissues show an abnormal appearance at the point of curvature, their colour is yellowish, and the individual cells show signs of having lost their turgidity.

2. That numerous colourless branched hyphæ extend along the surface of the seedling, being most numerous at the point of curvature, and less frequent further up. 
III. Tease out a portion of the infected part, as well as of the healthy part above, with needles in water, and mount so that a part at least of the epidermis shall be seen in external surface view; or sections may be cut, the infected part being held between pieces of pith : in such preparations observe-

I. The healthy part of the epidermis with elongated cells, and occasional stomata.

2. The branched, highly refractive, and for the most part nonseptate hyphæ, running with an irregular, but mostly longitudinal course along the outer surface.

3. Mark especially the points of entry of the Fungus into the host-plant : this may be either-

$a$. By perforation of the outer wall of a cell of the epidermis ; and this is by far the more common: or-

$b$. By passage of the hypha through the pore of a stoma: this is the less common mode.

4. Trace the further course of the hypha through the transparent tissues of the host-plant, noting the rarity, or complete absence of septa.

IV. Place an infected seedling in fresh water, in a flat watchglass, and examine it at intervals for a day or two under a low power. Many of the filaments will be seen to form swellings at certain points, which assume a spherical form, are filled with granular protoplasm, and are divided off by a septum from the parent filament, while the thin outer wall assumes a darker colour: these swollen bodies are the asexual reproductive organs, or resting conidia. Two types are to be distinguished-

I. Terminal conidia, at the ends of the filaments.

2. Interstitial conidia, which may appear at any other point on the filament.

It is characteristic of this species that the hypha should be partially or completely emptied of protoplasm for a short distance below the conidium.

These conidia are capable of withstanding drought, or a temperature below freezing, without losing their vitality.

V. From a culture containing numerous conidia, separate a small portion, and expose it in a watch-glass to a relatively con- 
siderable bulk of fresh water : examine the culture at intervals under a low power. Some of the conidia will be seen to germinate by the formation of tubular hyphæ similar to those which produced them.

VI. Continue at intervals the observation of those cultures which have already produced conidia: the formation of the sexual organs will frequently be seen to succeed that of the conidia.

$a$. The oogonium resembles at first the conidium in being spherical, and about of equal size with it, and is partitioned off by a septum; a central spherical mass of protoplasm (the ovum) is to be recognized.

b. The antheridium arises as a branch, either from the same filament as the oogonium, or from another : its apex is cut off by a septum, and it comes in close contact with the oogonium : a cylindrical process from it passes through the wall of the oogonium, and gains access to the ovum.

c. In more mature specimens the oogonium contains a single round, distinctly walled cell (the oospore), which lies freely within it.

Observations may also be made on the Potato Fungus (Phytophthora infestans) the mycelium of which permeates the tissues of the Potato plant, while its branched conidiophores project through the stomata. 


\section{MUCORINEÆ}

\section{MUCOR MUCEDO, Fres}

I. If a slice of bread be soaked in water, and kept under a bell-glass, various moulds will make their appearance upon it : about the fourth or fifth day there will be seen a mould, which at first appears white and flocculent, producing long unbranched stalks, which terminate in round heads, white at first, and subsequently becoming black : this will be Mucor Mucedo. It may also be obtained on horse-dung kept under a bell-glass, and on various other substrata.

II. Remove a very small piece of the bread bearing the mould, and tease it out gently in water : mount and examine under a low power : note-

I. Relatively thick, non-septate hyphæ, which ramify in the substance of the bread.

2. Relatively thin branches, which are produced from the thick ones, and themselves, branching repeatedly, produce a very extensive system of minute fibrils.

3. Hyphæ similar to (I), which however grow erect in the air (gonidophores), each bearing at its summit one spherical sporangium : this will certainly have been damaged in the process of preparation.

III. Cut off a number of mature sporangia with scissors from the flocculent growth, treating them very gently, so as to avoid damage: mount them in alcohol, and examine them quickly under a low power : observe-

I. The cylindrical gonidiophores, terminated by-

2. The spherical and dark-coloured sporangium, with its 
dense contents, and its very thin limiting wall, often bearing small radiating projections.

3. Towards the point of attachment to the stalk a clearer space may be recognized in the contents; this indicates the position of the columella.

Add a drop of water, and draw it under the cover-slip with blotting-paper, watching the effect upon the sporangia : as the water gains access to the sporangia, they burst suddenly, and the wall may be torn to fragments so minute that it cannot be recognized again. Meanwhile the contents, the swelling of which caused the rupture, gradually distend, and may be recognized as consisting of-

4. Numerous oval spores, with smooth walls.

5. An intermediate mucilaginous substance which is capable of swelling, and thus effects not only the bursting of the sporangium, but also the dispersal of the spores.

6. After the swelling and dispersal of the spores are complete, there will be seen remaining a spheroidal body (the columella), which is the distended septum of separation of the sporangium from the gonidiophore : round its base the remains of the wall of the sporangium may often be traced as a ragged fringe.

IV. With similar precautions to those taken in the case of the spores of Eurotium Aspergilluss (p. 237), sow spores of Mucor in a drop of a sterilized decoction of horse-dung, or of French plums, or other suitable solution: the swelling and germination of the spores and the formation of the branched, non-septate mycelium are to be watched; and drawings may with advantage be made at intervals, so as to record the progress of the cultures.

\section{SPORODINIA GRANDIS, Link}

V. Mucor mucedo also reproduces itself by means of zygospores, which are of such size that they may be detected with the naked eye as black bodies which project slightly from the substratum; but they are not of constant occurrence, and may frequently be looked for in vain. Accordingly it will be found 
more convenient and successful to study the development and structure of the zygospores in an allied form, in which they are produced in profusion, viz. in Sporodinia grandis, Link. (= Syzygites megalocarpus, Ehr.).

Sporodinia is a fungus which may frequently be found in autumn, growing parasitically on many of the larger, fleshy Hymenomycetes, especially on Russula, or Boletus : it appears as a greyish or brown flocculent growth, and the zygospores are of such a size that they can readily be seen as reddish-brown bodies with the naked eye. While a part of the mycelium ramifies in the tissue of the host, the zygospores are borne on aërial branches : they may thus be easily recognized as brown bodies, visible to the naked eye.

Tease out a small piece of the flocculent mycelium gently in water : examine under a low power, and observe-

I. The branched hyphæ, which are light-coloured, and rarely septate when young, but assume a brown colour, and form numerous transverse septa at irregular intervals as they grow old.

2. The large brown zygospores, each supported by two thicker, club-shaped hyphæ (Syzygites form).

3. The relatively small sporangia borne on branched gonidiophores, and having a structure similar to those of Mucor (Sporodinia form).

Compare a number of zygospores in various stages of development, and observe in them the following points-

I. The swelling of two neighbouring mycelial filaments (suspensors), and their assumption of a position with their two swollen ends opposite one another.

2. The formation of transverse septa cutting off the apical part of each suspensor, thus forming the two gametes.

3. The two gametes in close contact with one another, while the walls at the point of contact are gradually absorbed, the absorption beginning at the central point : the two protoplasmic bodies thus coalesce to form the zygote or zygospore.

4. The increase in size of the zygospore, its contents becoming dense and oily, while the wall at the period of maturity consists of the following successive layers- 
a. The primary membrane of the gametes, which remains thin, but persistent as an external covering.

$b$. The epispore, which is a dark-coloured firm or brittle layer with hemispherical wart-like outgrowths from the surface.

c. The endospore, which is thicker and more transparent.

Note how numerous though irregular are the septa in the mycelium which has produced zygospores.

It is not an uncommon thing in Sporodinia to find that the two gametes may not come in contact, and no zygote be found ; but still each gamete may develop into a body resembling a zygospore in the character of the wall, the contents, and in the mode of germination. These bodies are called azygospores. 



\section{APPENDIX A.}

THE following list of reagents is not intended to be an exhaustive catalogue of the various substances in use in the Botanical Laboratory: it includes, however, those reagents which are considered to be of the greatest importance, in elementary teaching, together with notes on their proper preparation, and uses.

Acetate of Potash. A strong solution in water is used as a mounting medium for preparations of green parts of plants: in this solution they retain their green colour for a long time. Aluminium acetate may also be used for the same purpose.

Acetic Acid. This is usually used as a dilute solution in water (I per cent.) : it dissolves calcium carbonate with evolution of bubbles of $\mathrm{CO}_{2}$ : it brings out the nuclei very clearly, and with this object in view it is used with methyl-green : it may also be employed as a corrective after treatment of a preparation with potash, if the tissues have become too transparent. Glacial acetic acid is also sometimes used in the preparation of the apex of Fucus.

Alcohol is of universal use as a solvent, precipitant, and hardening agent. Absolute alcohol is the best, but for most ordinary work strong methylated spirit will do. It dissolves chlorophyll and other colouring-matters, resins, ethereal oils, and some fixed oils : wax is soluble in hot alcohol. It precipitates some substances, such as sugars, inulin, and asparagin. It coagulates proteids, and has a peculiar action on some crystalloids. It acts as a hardening agent on cell-walls, sometimes rendering them too brittle : this may be overcome by soaking 
the material, before cutting sections, in a mixture of equal parts of alcohol and glycerine.

Alkanna (the root of Anchusa tinctoria) is used as a test for resin, caoutchouc and oils. The alcoholic solution of alkannin, as supplied by the dealers, may be used for this purpose ; but it is found better to use sections of the dry alkanna root.

Ammonia. The solution in water is often used for clearing preparations instead of potash, as its action is less intense. It is used with nitric acid as a test for proteids, and with copper sulphate as a solvent for some forms of cellulose (see below, Copper Sulphate).

Ammonium Molybdate, used, dissolved in a strong solution of ammonium chloride, as a reagent for the detection of tannin, with which it gives a voluminous yellow precipitate.

Aniline Sulphate and chloride are used as reagents for lignified cell-walls, which they stain yellow, while no other parts of the tissue are coloured by them. A saturated solution of either of these substances is made in distilled water, filtered, and a few drops respectively of sulphuric or hydrochloric acid are added, so that the solution shall give a distinctly acid reaction : or a solution may be made in alcohol, and then be diluted with water.

Asphalte is used for sealing up slides in which glycerine has been used as a mounting medium : it is liable to become very brittle after a time, and, to prevent the cement breaking away, it may with advantage be covered with a layer of gold-size. It may be obtained ready for use from the dealers.

Benzol, used as a solvent for various substances, e.g. the coagulum of latex, ceric acid, \&c.

Brunswick Black may be bought ready prepared from dealers in microscopic requisites : it is used for sealing up slides.

Callus-reagent of Russow is prepared by mixing equal volumes of chlor-zinc-iodine, and of the solution of iodine in potassium iodide : it stains the callus of sieve-tubes a deep brown.

Canada Balsam is to be used dissolved in benzol and in such quantity that it shall have the consistency of syrup. It is used as a mounting medium for sections previously treated with alcohol, 
and then, with either oil of cloves, turpentine and creosote, or cajeput oil ; it is also used for sealing up slides.

Cane-sngar. The concentrated solution in water is sometimes used, together with strong sulphuric acid, as a test for proteids. A dilute solution ( 1 per cent., or more) is useful for mounting living cells for observation under the microscope.

Carbolic Acid (see Phenol).

Carmine. The two best preparations of carmine are those of Beale and Thiersch.

I. Beale's Carmine.-To prepare this, 0.6 gramme of carmine is dissolved in 2 c.c. of boiling solution of ammonia ; the solution must then stand for an hour or so to cool, and to allow of the escape of the superfluous ammonia; to the solution are added 60 c.c. of distilled water, 60 grammes of glycerine, and I 5 grammes of absolute alcohol. The mixture must be allowed to stand for some time; it is then to be filtered.

2. Thiersch's Carmine. -4 grammes of borax are dissolved in 56 c.c. of distilled water ; to this I gramme of carmine is added, and then twice its volume of absolute alcohol is added to the liquid. After filtration the liquid is ready for use.

Carmine has but little differentiating power : it readily stains the protoplasm and the nucleus ; Thiersch's preparation is especially useful for bringing out the structure of the nucleus. It can very well be used for sections which have been previously treated with picric, chromic, and osmic acids. The time during which the section is to be exposed to its action varies very much ; the rule is that the most satisfactory results are obtained by a prolonged immersion in a dilute solution. In case of overstaining, the section may be washed for a moment in water to which a trace of ammonia has been added.

Preparations stained with carmine are best mounted in glycerine. (See also Picro-carmine.)

Chloral Hydrate is used, together with iodine, for the detection of starch-grains included in the chlorophyll-corpuscles. Dissolve 8 parts chloral hydrate in 5 parts of water, and add crystals of iodine, which will dissolve slowly and colour the solution. The material to be tested should be bleached with alcohol, and then be laid in the solution for twelve to twenty-four hours. 
Chloroform is used as a solvent for various substances, e.g. oils, coagulum of latex, \&c.

Chlor-Zinc-Iodine (Schulze's Solution) is the best differentiating reagent, and the one most generally used, but the chief objection to it is that, as in the case of other preparations of iodine, the stain is not permanent. There are various ways of preparing it, but the best is as follows :-

I. Dissolve 1 ro grammes of zinc in 300 c.c. of pure hydrochloric acid, and evaporate to 150 c.c. (sp. gr. r.8).

2. Dissolve 12 grains of potassium iodide in as little water as possible, and add $O 15$ grammes of crystals of iodine.

3. $\operatorname{Mix}(1)$ and (2).

This reagent may however be obtained ready prepared from dealers in microscopic requisites. It may be used either for fresh material, or after treatment with picric acid, or alcohol : the colouring of cellulose walls is intensified if the objects have been previously treated with potash, and the alkali thoroughly washed out.

Under this reagent cellulose walls turn blue, or violet, lignified walls yellow, or various shades to a sherry brown, corky walls yellow or brown, protoplasm brown, while starch-grains swell and turn blue.

Chromic Acid. A strong aqueous solution of this acid, ro per cent., dissolves lignified and cellulose cell-walls : cuticularized cell-walls resist its action; but they become very transparent, and may be easily overlooked. A dilute solution brings out the stratification of cell-walls very clearly. A one per cent. solution may be used in the preparation of Seaweeds.

clove-oil is used as a clearing agent before mounting specimens which have been treated with alcohol in Canada balsam.

Copper Sulphate is used in the preparation of Fehling's fluid (see below), and the preparation of ammoniacal solution of cupric hydrate (see below).

Corallin (Rosolic Acid). A solution of corallin in a 30 per cent. solution of sodium carbonate colours lignified tissue, the callus of sieve-tubes and starch-grains pink.

Creosote is used together with turpentine as a clearing agent before mounting in Canada balsam : I part of creosote and 4 
parts of turpentine are to be shaken well together, and set aside till the cloudiness formed on their first mixing disappears.

V Cupric Hydrate. The ammoniacal solution of cupric hydrate is used as a solvent for pure cellulose. To a solution of copper sulphate in water add dilute potash : collect the precipitate on a filter, wash with water, and then dissolve it in a little strong ammonia : this solution, which is of a dark blue colour, must be prepared fresh each time it is required for use.

Dammar, dissolved in warm turpentine, and evaporated to the consistency of syrup, is sometimes used as a mounting medium instead of Canada balsam : it does not set so firmly as balsam, and it is well to seal up slides in which it has been used.

Ether is used as a solvent for wax, oils, \&c. When very small objects have been embedded in paraffin or cocoa-butter, it may be convenient to dissolve off the fragments of embedding material with ether : the small sections will then be readily found, and collected.

"Eau de Javelle" is recommended as a clearing agent for growing points, and other merismatic tissues : the cell-contents swell under its action, and the cell-walls which remain may then be easily seen. It is prepared by adding to 2 pints of water 2 ounces of chloride of lime, and 4 ounces of carbonate of potash or of soda. Objects treated with it are to be washed with water, then with dilute acetic acid, and should be mounted in glycerine.

Eosin is used in strong solution in alcohol, or in water, for demonstrating the structure of sieve-tubes.

Fehling's Fluid is used as a test for grape-sugar : the following directions for its preparation are given in Foster's Practical Physiology :-

a. Dissolve $34^{\circ} 65$ grammes of pure crystallized cupric sulphate in about 160 c.c. of distilled water.

b. Dissolve also I 73 grammes of pure crystallized potassicsodic tartrate in 600 to 700 grammes of sodic hydrate (sp. gr. I'12).

Add $(a)$ to $(b)$, stirring well to cause a thorough mixture, and dilute with distilled water to a litre.

Fehling's fluid should be fresh made whenever it is required, 
since it decomposes on keeping ; it will keep some little time if kept in a cool place in the dark, and in completely filled, wellclosed bottles (Hoppe-Seyler).

The solution $(b)$ may be prepared, and kept for adding to (a) freshly prepared when required.

Before using a kept solution to test for sugar, always boil a little of it by itself to see if any reduction will take place.

From I c.c. of this solution the copper is completely reduced by 0.005 grammes of grape sugar.

Ferrous sulphate is used in dilute solution in water, to which a drop of nitric acid has been added, as a test for tannin.

$x$ Fuchsin is used in solution in alcohol, for bringing out the structure of thickened cell-walls, and especially the outer walls of the epidermis, and corky walls : the sections should have been previously treated with alcohol. When a section has been stained with fuchsin, and washed in absolute alcohol, the colouration is removed from all parts excepting the corky and cuticularized walls.

Glycerine is the most generally used medium for mounting, as it has the advantages of a high refractive index, and of not being subject to evaporation. It may be applied either pure or diluted : pure glycerine is to be used, after hardening in alcohol, when it is desired to observe the details of the protoplasm, e.g. in the preparation of the contents of the embryo-sac; dilute glycerine (I part glycerine, I part water), is however, of most general use.

Glycerine Jelly is a suitable mounting medium for many objects : it may be bought ready for use from dealers in microscopic requisites: or it may be prepared according to Kaiser's receipt, as follows :- I part by weight of finest French gelatin is to be soaked for about two hours in 6 parts of distilled water : 7 parts of chemically pure glycerine are added, and to about 100 grammes of this mixture I gramme of carbolic acid is added. The whole mixture is to be warmed and continually stirred for IO-I 5 minutes, till the fluid is clear, and then to be filtered through glass-wool.

Gold Chloride is sometimes used in a $1^{\circ} \circ$ per cent. or $0^{\circ} 5$ per cent. solution in water as a delicate stain for protoplasm. 
Gold-Size is to be obtained from dealers in microscopic requisites : it is used for sealing up slides, and a layer of it may with advantage be applied after sealing with asphalte, or Brunswick black.

Gum Arabic is occasionally used as an embedding medium for very small objects.

Hæmatoxylin. A number of preparations of this colouringmatter are in use; of these the following are those generally employed for vegetable tissues :-

I. Alum Solution of Hæmatoxylin.-Dissolve o'35 gramme of hæmatoxylin in 10 c.c. of water, and add to it a few drops of a solution of alum consisting of I gramme of alum to Io c.c. of water.

2. Kleinenberg's Hæmatoxylin.-Saturate some 70 per cent. alcohol with calcium chloride; let the mixture stand for twelve to twenty-four hours over alum, shaking occasionally; add 8 parts of 70 per cent. alcohol ; filter, and then add a solution of hæmatoxylin in absolute alcohol until the liquid has a purple-blue colour; let it stand in a corked bottle exposed to sunlight for about a month ; it is then fit for use. The liquid is to be diluted as required with alum solution. This preparation is most generally employed, and it may be bought from the dealers ready for use.

3. Expose a few crystals of hæmatoxylin to the action of gaseous ammonia in a watch-glass under a bell-jar: then add water, and a good colouring fluid is obtained. The disadvantage of this is that it has to be freshly prepared every time it is required.

The alum solutions will stain all parts of the cell, including the cell-wall. Their special uses are (a) to make the cell-walls more evident when they are naturally transparent and colourless; (b) to stain the protoplasm, so as to make its intimate structure apparent ; (c) to stain the nucleus, so as to demonstrate its presence and to show up its structure.

The ammoniacal solution is especially adapted for differentiated staining. If a dilute solution be used, the first thing to become stained is the chromatin of the nucleus, then, after a time, the rest of the nucleus (achromatin), then the protoplasn. 
The cell-walls do not stain with this fluid, or only slightly. Kleinenberg's hæmatoxylin stains in a few minutes, whereas the alum solution is much slower in its action.

Hæmatoxylin may be used either for fresh material, or for sections which have been previously hardened with alcohol, or with picric or chromic acid. In the latter case the sections must be washed repeatedly in distilled water to remove every trace of the acid, which, if present, would interfere with the proper action of the hæmatoxylin. If the section becomes too deeply stained, as sometimes happens when the alum-hæmatoxylin is used, the excess of colouring-matter may be removed by washing with a solution of alum in water.

Sections stained with alum, or with Kleinenberg's hæmatoxylin, are to be mounted in Canada balsam, or Dammar; those stained with the ammoniacal solution are to be mounted in glycerine.

Hoffmann's Blue. Used in solution in dilute alcohol slightly acidified with acetic acid : it is a useful reagent, inasmuch as it stains the protoplasmic cell-contents and not the cell-wall : it stains also the callus which closes the perforations of the sieveplates during the winter in perennial plants. It is also used, together with sulphuric acid, for demonstrating the continuity of protoplasm through cell-walls : in order to do this a small quantity of the dry substance is dissolved in strong sulphuric acid in a watch-glass : sections, preferably of fresh material, are then immersed in it for a short time, then washed with water, and mounted in glycerine.

Hydrochloric Acid. Used, in very small quantity so as to give an acid reaction, with aniline chloride, phloroglucin, or carbolic acid, as a test for lignin. By itself the acid turns lignified cell-walls yellow; when its action is prolonged, the cell-walls become violet, owing to the presence of various substances such as phloroglucin, coniferin, and pyrocatechin.

Iodine is one of the most useful reagents : it is prepared in various ways. The most important are the following :-

i. Make a strong solution of potassium iodide in distilled water, add to this crystals of iodine and set it aside for some hours, shaking it occasionally : dilute this solution with distilled 
water to the colour of brown sherry. The reagent may also be prepared by diluting the liquor iodi of the Pharmacopœia. This is the ordinary jodine solution in common use in the laboratory.

ii. The alcoholic solution may be prepared by dissolving crystals of iodine in alcohol, and diluting with alcohol to a dark sherry colour ; also by diluting the tinctura iodi of the Pharmacopœia : in the absence of water this solution does not give the blue reaction with starch.

iii. A solution of potassium iodide and iodine in pure glycerine is sometimes used in the treatment of crystalloids.

iv. The solution of iodine in chloral hydrate is used for detection of included starch-grains (see above, Chloral Hydrate).

v. For the solution in chloride of zinc (Schulze's solution), see above, Chlor-Zinc-Iodine.

The ordinary solution of iodine (i) stains proteid substances, and especially the nucleus, brown; cellulose faintly yellow; cuticularized and lignified walls yellow; gum purple and starch blue. Together with sulphuric acid, iodine colours cellulose blue, a reaction similar to that with chlor-zinc-iodine.

Methylene Blue is used in solution in water : it stains the cellwall, but not the protoplasm.

Methyl-green. A tolerably strong alcoholic solution of this is used. The sections of the object, which must have been previously kept in absolute alcohol, are to be treated with the staining-fluid for from 5-25 minutes, then quickly washed with distilled water, and mounted in glycerine. The nucleus stains of a green or bluish-green colour, the protoplasm remaining uncoloured. It is especially good for staining nuclei which are dividing, and for bringing out the nuclei in the cells of Fungi and of the Siphoneæ, for which purpose Strasburger recommends the following method :-The fresh object or section is mounted in 2 per cent. acetic acid, to which a little methyl-green has been previously added : the nuclei are fixed almost instantaneously and at the same time stained. These preparations may then be washed in I per cent. acetic acid, and be mounted in weak glycerine and acetic acid. Objects stained with methylgreen fade very rapidly. 
Methyl-violet. This is used in concentrated alcoholic solution. It is especially useful for staining Bacteria. A few drops of the solution are added to I 5-20 c.c. of distilled water, and a drop or two of the mixture should then be placed on the Bacteria-membrane (zooglœa), and be allowed to remain there for a short time until the membrane appears to be coloured; if the solution used be too strong, the substance between the Bacteria will become stained. The colouring matter is then washed off with distilled water, or better with a ro per cent. solution of acetate of potash. The preparation may then either be allowed to dry in the air and be then mounted in Canada balsam, or it may be mounted in a 50 per cent. solution of potassium acetate in water.

A useful preparation of methyl-violet is the following :Some of that substance is dissolved in strong sulphuric acid, forming a brownish-green solution: on the gradual addition of water the violet colour reappears. This is especially useful for sieve-tubes. If a section be treated with this fluid for a short time, and be then washed with water, it will be found that the cell-walls have become swollen and transparent, that the protoplasm has become deeply stained, and that the sieve-plates are very well brought out. Lignified tissues treated with this fluid assume a yellow colour, as they do when treated with aniline sulphate.

Moist Chamber (see Water).

Nitric Acid colours cuticularized cell-walls and proteids yellow ; it also causes swelling up of cellulose and of lignified cell-walls. When diluted with water it is useful for dissolving the crystals of calcium oxalate which are frequently present in the cells. It is used with ammonia as a test for proteids (xanthoproteic reaction); with potassium chlorate as a test for suberin, and as Schulze's macerating fluid.

olive oil is used as a medium for mounting aleurone-grains, so as to see them unaltered.

orcin. A solution in alcohol is used as a test for inulin. Sections are to be soaked in the solution and subsequently warmed with strong hydrochloric acid : an orange-red colour shows the presence of inulin. 
Osmic Acid is used in $0^{\circ} \mathrm{I}-\mathrm{I}^{\circ} \mathrm{O}$ per cent. solution in water, for fixing and hardening protoplasm : it also stains fats black. The solution should be kept in a well-stoppered bottle in the dark.

Paraffin is used as an embedding medium for small or delicate objects. Paraffins of varying hardness and temperature of melting-point may be obtained : the best for ordinary use is a mixture which shall melt at a temperature of $50^{\circ}$ to $60^{\circ} \mathrm{C}$.

Phenol (Carbolic Acid). Used, together with hydrochloric acid, as a test for lignin. The best preparation of it is its solution in hydrochloric acid ; this is prepared by dissolving carbolic acid in warm hydrochloric acid, adding, whilst the mixture is cooling, sufficient hydrochloric acid to dissolve any precipitate that may be formed. Lignified cells, treated with this mixture and exposed to sunlight, assume a bright green colour in consequence of the presence of coniferin. It may also be used, instead of creosote, together with turpentine, as a clearing agent, before mounting in Canada balsam. A small quantity is to be added to glycerine jelly to prevent the growth of Fungi.

Phloroglucin. Dissolve some phloroglucin in methylated spirit, and gradually add strong hydrochloric acid till precipitation begins; the liquid is then ready for use : in sections treated with it lignified walls assume a bright red colour.

Picric Acid. A saturated solution in water is very generally used for fixing the protoplasm of the cell as nearly as possible in the form which it held during life. It is, however, objectionable, owing to the difficulty in completely washing it out from the specimens before hardening in alcohol, and in most cases treatment at once with absolute alcohol is to be preferred. In some cases, such as delicate Algæ, it is well to dilute the saturated solution with an equal volume of water.

Picro-carmine (or ammoniun picro-carminate) is prepared by adding a strong ammoniacal solution of carmine to a quantity of concentrated solution of picric acid in water, until a precipitate begins to be formed; it is then evaporated to about onefifth of its bulk, filtered, and the filtrate is evaporated to dryness. The crystalline residue is dissolved in water so as to make a 5 per cent. solution, and this may be diluted as occasion requires. 
Another method (Gage) is to dissolve a quantity of picric acid in 100 parts of water, and an equal quantity of carmine in 50 parts of solution of ammonia; these are then mixed, filtered, evaporated to dryness, and the residue dissolved in 100 parts of water.

Picro-carmine is used especially for staining nuclei, the staining being more uniform than when carmine alone is used ; it has this further advantage, that a prolonged exposure to it does not produce overstaining, as is the case with the other preparations of carmine. The objects should be previously kept for some time in absolute alcohol. If it be desired to retain the double staining which this reagent produces, the sections must be mounted at once in glycerine; but if the carmine staining only is required, the sections must be washed in water, which will dissolve out the picric acid. When stained sections are mounted in glycerine, a small quantity of picrocarmine must be added to the glycerine in order to preserve the colours.

The various preparations of carmine can be used as well for tissues which have been hardened in chromic, picric, or osmic acid, as for fresh tissues, but the former stain less readily.

Picro-nigrosin : make a saturated solution of picric acid, add crystals of nigrosin, and allow them to dissolve : steep the specimen in it, and allow time for slow staining; this reagent may be used for simultaneous fixing and staining of delicate tissues, and is especially recommended in the preparation of Spirogyra and other Algæ, and for Fungi.

x Potash may either be used in a dilute solution ( $\mathrm{I}-5$ per cent.) or in a strong solution of water. A dilute solution is commonly used as a clearing agent : it causes cell-walls and starch-grains to swell, especially when heated, and it dissolves sphere-crystals of inulin, crystalloids, and most aleurone-grains, and saponifies fats. It gives a reddish colour to cells in which tannin is present. A strong solution may be used as a test for suberin : when sections of cork are boiled in strong potash, the suberin escapes in the form of yellow viscid drops; when the sections are only slightly warmed in the solution, the cuticularized walls assume a yellow colour. 
A concentrated solution of caustic potash in alcohol is sometimes used with good effect in the preparation of apical meristems, but specimens so treated cannot be permanently kept.

Potassium Acetate (see Acetate).

Potassium Bichromate is used in dilute solution in water as a test for tannin, which it colours dark brown : the I per cent. solution in water may also be used for hardening tissues.

$\times$ Potassium Chlorate is used together with nitric acid as a macerating agent, and as a test for suberin (see below, Schulze's Macerating Fluid).

Russow's Callus-Reagent (see above, Callus-reagent).

Safranin. This may be used in solution in absolute alcohol. It is especially adapted for staining sections which have been previously hardened with chromic or picric acid; it is not so good for those which have been treated with osmic acid. The sections must be well washed in distilled water, and then placed in a small quantity (I c.c.) of the saturated alcoholic solution mixed with an equal volume of distilled water; they require to be left for several hours in the staining fluid. They must then bc removed, and washed for a short time in alcohol ; then they must be placed in absolute alcohol, and kept there until they appear transparent. The sections can now be mounted in distilled water in order to see if the results are satisfactory, or, if they are to be preserved, they must be cleared with oil of cloves, and mounted in Canada balsam or Dammar.

By this means very successful preparations of the structure of nuclei can be obtained.

Schulze's Macerating Fluid. One gramme of potassium chlorate is dissolved in 50 c.c. of nitric acid; or crystals of potassium chlorate may be left to dissolve to saturation in a small bottle of nitric acid. This reagent is to be used only in small quantities, and the process of maceration should not be conducted in near proximity to microscopes, or other metallic apparatus.

It is used as a macerating fluid for separating the constituents of woody tissues from one another, this result being obtained by the solution of the middle lamclla. The tissue to be macerated is cut into small chips, and boiled in the fluid for a short time in 
a test-tube; the fluid is then poured off and the residue collected on a filter, and well washed with water; the specimens may then be mounted in glycerine.

Schulze's Solution (see above, Chlor-Zinc-Iodine).

Sodium Chloride is used as a ro per cent. solution, or as a saturated solution in water, as a solvent for proteid-crystalloids.

A more dilute solution ( $\mathrm{I}-5$ per cent.) is used for inducing plasmolysis.

Sulphuric Acid. This is used either concentrated, or dilute (I to 3 of water). It causes, in either case, the swelling up of cellulose cell-walls, starch grains, \&c.; when cellulose cell-walls which have been previously saturated with solution of iodine are treated with sulphuric acid, they turn blue.

Concentrated sulphuric acid dissolves cellulose and starch, but cuticularized or corky cell-walls and the middle lamella of lignified cells resist its action. It is used with cane-sugar, as a test for proteids, and a few drops of it are added to a solution of aniline sulphate as a test for lignin.

It may also be used as a solvent for crystals of calcium oxalate.

Turpentine is used with creosote, or carbolic acid, as a clearing agent before mounting in Canada balsam.

water may be used as a mounting medium, and as a solvent for various reagents; it may also be used for the cultivation of small organisms, or pollen-grains, spores, or Fungi, under the microscope, and for this purpose a moist chamber is to be constructed as follows :-

A piece of thick rough cardboard is cut to the size of the glass slide, and a circular hole is punched out of the middle of it of such a size as to be completely covered by a cover-slip. The piece of cardboard is then soaked in water (or boiled in water when pure cultures of Fungi are to be made), so as to saturate it, and placed on the glass slide. A drop of water (or solution as described below) is placed on the cover-slip, the object is immersed in it, and the cover-slip is then inverted over the hole in the piece of cardboard. Thus the object is suspended in a drop of liquid on the under surface of the cover-slip. Any loss from the chamber by evaporation is prevented by 
occasionally wetting the cardboard on the slide with freshly boiled, distilled water.

The liquid to be used will of course vary with the nature of the object to be observed. In the case of Algæ, water may be used ; in the case of Fungi, decoctions of various organic substances (fruits, animal tissues, \&c.), or a solution of sugar, according to the habit of the Fungus. For observing the germination of the spores of Mosses and Ferns, water will suffice ; but in the case of pollen-grains a solution of sugar is necessary $(\mathrm{I}-2 \mathrm{O}$ or even 30 per cent., the concentration being different for different plants); for observing the process of cell-division in the hairs on the stamens of Tradescantia, a 2 per cent. sugarsolution may be used. 


\section{APPENDIX B}

THIS appendix includes in a tabular form, as being convenient for reference, the more important reactions of the parts of the vegetable cell, and of bodies commonly contained in it.

\section{Cellulose Cell-walls.}

i. Coloured faintly yellow by iodine.

ii. Swollen and ultimately dissolved by sulphuric acid.

iii. Coloured blue with iodine and sulphuric acid.

iv. Coloured blue or violet with chlor-zinc-iodine.

v. Swollen and dissolved by ammoniacal solution of cupric hydrate.

vi. Stained by solutions of carmine or of hæmatoxylin which contain a mordant, by methylene blue, and in various degrees by other aniline colours.

\section{Lignified Cell-walls.}

i. Coloured distinctly yellow by iodine, and by chlor-zinciodine, but in the case of bast-fibres the tint may vary to sherry brown, or even pink.

ii. Coloured brown and swollen by iodine and sulphuric acid.

iii. Coloured bright yellow by acidulated solution of aniline sulphate.

iv. Coloured red with acid solution of phloroglucin (see Appendix A).

v. Coloured green when exposed to light after treatment with carbolic and hydrochloric acids (see Appendix A). 
vi. Stained slightly or not at all by solutions of carmine, and hæmatoxylin, but readily by aniline colours.

\section{Cuticularized or Corky Cell-walls.}

i. Coloured yellow by iodine.

ii. Coloured yellow or brown by chlor-zinc-iodine.

iii. Coloured yellowish by strong potash : on gradually warming (without boiling), they become bright yellow : on boiling, yellow drops of suberin escape.

iv. They resist the action of sulphuric acid, retaining their clearly-marked outline.

v. On treatment with Schulze's macerating fluid, the cuticularized cell-walls become conspicuous : on boiling in it, their substance escapes as viscid drops of ceric acid.

vi. They are dissolved slowly by strong chromic acid, but resist its action for some time.

vii. They are not stained by solutions of carmine or hrematoxylin, but are coloured by aniline stains.

Mucilaginous walls, resemble cellulose in many of their reactions.

i. They swell with water.

ii. They swell to a greater extent with potash.

iii. They do not stain with iodine.

iv. They stain pink with corallin soda.

v. They stain red with Hanstein's aniline-violet, blue with methylene blue; some kinds of mucilage also stain with Hoffmann's blue.

Callus is found on the plates of sieve-tubes.

i. It is soluble in sulphuric acid.

ii. It is stained by Hoffmann's blue, and by hæmatoxylin.

iii. Brown by Russow's callus-reagent.

iv. Pink with corallin-soda.

v. It is largely swollen by potash.

Mineral Deposits in cells or cell-walls.

A. Silica. If a tissue be ignited on platinum foil (after soaking in nitric acid, or Schulze's macerating fluid), and the ash, after being treated with acetic or nitric acid, shows an insolublc residue, the residue is silica.

b. Calcium Oxalate occurs in the form of crystals. 
i. Insoluble in acetic acid.

ii. Soluble without evolution of gas in nitric acid.

iii. Soluble in sulphuric acid, with formation of fresh crystals of calcium sulphate, if only small bulk of fluid be present.

iv. Are not stained with iodine, \&ec.

C. Calcium Carbonate occurs as incrustations, or crystals : it is soluble in acetic acid with evolution of bubbles of gas $\left(\mathrm{CO}_{2}\right)$.

\section{Protoplasm or Proteids generally.}

i. Coloured yellow or brown by preparations of iodine.

ii. Coloured yellow by nitric acid : on the addition of potash or ammonia a bright yellow colour is produced (xanthoproteic reaction).

iii. Swells and loses details of structure on treatment with potash, ammonia, or "eau de javelle."

iv. Stains readily with solutions of carmine, hæmatoxylin, or Hoffmann's blue ; bright red with Hanstein's aniline violet.

The best stains for the nucleus, and for showing the details of its structure, are hæmatoxylin, safranin, and methyl-green.

Plastids show under favourable circumstances the same reactions as other proteid bodies.

Aleurone-grains and crystalloids give also the characteristic reaction of proteids. There is a considerable variety in the solubility of these bodies in water, or in salt-solution, in different seeds : the following will serve as types :-

I. Grains without crystalloids.

a. Soluble in water : peony, almond, cherry, apple.

b. Partially soluble in water; more or less readily soluble in Io per cent. solution of common salt.

a. Soluble in saturated solution of common salt ; lupine, pea, bean, scarlet runner.

$\beta$. Soluble in saturated solution of common salt only after treatment with alcohol : sunflower, turnip, cress.

2. Grains containing crystalloids.

a. Partially soluble in water; more or less readily soluble in Io per cent. solution of common salt.

a. Soluble in saturated solution of common salt : Brazil nut, pumpkin. 
B. Soluble in saturated solution of common salt only after treatment with alcohol: castor-oil plant, walnut.

In all cases a mass (globoid) of mineral matter remains behind after the solution of the grain : this is soluble in acetic acid. The sections should be examined in alcohol.

Starch-grains.

i. Coloured blue with solutions of iodine in presence of water.

ii. They swell in solution of potash.

iii. They swell in water above $65^{\circ} \mathrm{C}$.

iv. They swell in dilute sulphuric acid.

v. They swell and are coloured blue with iodine in chloralhydrate.

vi. They stain pink in corallin-soda solution.

\section{Inulin.}

i. Soluble, but not readily, in cold water.

ii. Precipitated as sphere-crystals on extraction of water by alcohol or glycerine.

iii. Not appreciably coloured with iodine.

iv. Soluble, without colouration, in potash.

v. Coloured an orange-red with alcoholic solution of orcin, after warming with hydrochloric acid.

\section{Grape-Sugar.}

i. Soluble in water.

ii. Less soluble in alcohol.

iii. Gives a bulky yellow precipitate with Fehling's solution.

Cane-Sugar differs from the above in giving no precipitate with Fehling's solution.

\section{Asparagin.}

i. Soluble in water.

ii. Precipitated by alcohol.

iii. Distinguished from other bodies which give the above reaction by insolubility in a saturated solution of asparagin.

\section{Fixed oils.}

i. Coloured black with osmic acid.

ii. Saponified more or less readily by potash.

iii. Soluble in ether.

iv. Stained pink by alkanna. 
v. Some fixed oils are soluble in alcohol : e.g. oil of Ricinus. Caoutchouc.

i. Swollen, but not dissolved, by potash.

ii. Stained with tincture of alkanet.

iii. Soluble in chloroform or benzol.

\section{Tannin.}

i. Coloured deep brown by potassium bichromate, or chromic acid.

ii. Coloured greenish-blue by solution of ferrous sulphate and nitric acid.

iii. Gives a bulky yellow precipitate with solution of ammonium molybdate in strong solution of ammonium chloride.

\section{Resin.}

i. Soluble more or less readily in alcohol, or ether.

ii. Coloured red by alkanna.

iii. Coloured blue by Hanstein's aniline violet. 


\section{INDEX}

A BCISS LAYER, 84

Achromatin, 28

Adhesion, I I I

Æcidiomycetes, 23 I

AEcidium, 232

Acidium-spores, germination of, 234

Ascullus, leaf-scar of, 83 ; root of, 88

Agaricus, 226

Air-bubbles, II

Air-cavities, Marchantia, I9I

Alburnum, 59

Alcohol, 5

Aleurone-grains, 130

Almond, seed of, 130

Amphigastria, I9I

Amorphous coat of aleurone-grains, I3 I

Anatropous ovule, I I9

Andrœcium, 108

Angiosperms, 34

Annual rings, of Elm, 57 ; of Pine, I 39

Annulus of fern, 173 ; of Mushroom, 227

Anther, 108, II 7, 146

Antheridia of Fern, I75; of Moss, 179, 183; of Marchantia, 193; of Polysiphonia, 200; of Fucues, 206; of Chara, 213; of EEdogonium, 21 8 ; of Pythium, 243

Antheridiophore, I93

Antherozoids, see Spermatozoids
Antipodal cells, 120

Apex, of stem, Sunflower, 47 ; of stem, Hippuris, 67; of root, Maize, I06; of stem, Nephrodium, 157, 166; of root, Fern, I69; of prothallus, Fern, I75 ; of Polysiphonia, 198; of Fucus, 205; of Chara, 212

Apophysis, I8o, I86

Apparatus, I

Arboreous type of Dicotyledon, 52 ; of Monocotyledon, 98

Archegoniophore, 194

Archegonium, of Pine, 143; of Fern, I75, I76; of Moss, I84 ; of Marchantia, 195

Archesporium, I86

Archicarp, 238

Arillus, 126

Ascophyllum, 197

Ascospores, 239

Ascus, of Eurotium, 239

Azygospores, 247

BARK, 59

Basidia, 230

Basidiomycetes, 226

Bast-parenchyma, 56, 61, 137, \&c.

Beet-root, plasmolysis, 21 ; sugar of, I 30

Begonia, crystals of, 103

Bordered pits, 138 , 163

Bracken, rhizome of, 163

Bract, I I I 
Bracteole, II 4

Bryophyta, I 79

Bundle-sheath, Sunflower stem, 39, 42, 45, see also Endodermis

Bundle-system, of Monocotyledon, 98 ; of Ferns, I 59

Buttercup, flower of, 108

Calcium Oxalate Crystals, 103

Callus, 43, 60, 70

Caltha, flower of, 109; stamen of, 116; carpel and ovules of, II9; development of endosperm of, I 24

Calyptra, of Mosses, 180, 185

Calyptrogen, 107

Calyx, 108, II 5

Cambiform cells, 40, 43, 7o, 96

Cambium, of Sunflower stem, 40 ; of Elm, 56, \&c.; of Pine, I36, 142

Campylotropous ovules, 122

Canada balsam, 33

Canal cell, I 75, I76

Cane-sugar, I 30

Capitulum of Sunflower, II 3

Capsella, embryo of, I 2 I

Carpels, 109, II 9

Cauline bundles, 69, 99

Cell-division, 50 ; of Spirogyra, 224

Cell-walls, 18, 24

Cellulose-walls, reactions of, 24, I 29

Ceric Acid, 26

Chara, 2 ro

Cherry Laurel, leaf of, 8I

Chlorophyll-corpuscles, 30,38

Chloroplasts, 30, 79

Chlor-zinc-iodine, 26, 29

Chromatin, 28

Chromatophores, I8; of EEdogonium, 21 7 ; of Spirogyra, 224

Chromoplasts, 116

Circinate vernation, 157

Circulation of protoplasm, 23

Clearing preparations, $3 \mathbf{I}$

Cleistocarpous Ascomycetes, 236

Cohesion, I09, I I I

Coleorhiza, I 28, 133

Collenchyma, 37, 42

Columella, of Mosses, I86 ; of Mucor, 245
Common salt, i9

Companion cells, 40, 43, 70

Concentric bundles, 69, I52, 160

Conceptacle, 206

Confervoideæ, 216

Conidia of Aspergillus, 236

Conidiophores, 236

Conjugation, of Spirogyra, 225

Conjunctive parenchyma, 153, 161

Connective, I 17

Continuity of protoplasm, 71, 124

Cork, 52

Cork-cambium, 54, 60, 136

Corky walls, reactions of, 26

Corolla, I08, II 5

Cortex, 37, 42, 60, 136, of Chara, 2 II

Cotyledons, 85,126

Crystals, 55, 66, I03, I4I

Crystalloids, I3 I

Cucurbita, sieve-tubes of, 70

Culture of Fungi, 237

Cupric hydrate, 25

Cuticle, 8o, 143

Cuticularized layers, 8o, 144

Cutting sections, 6

Cystocarps, 200

\section{DAMPING OFF, 24I}

Dandelion, 73

Date, endosperm of, 129

Datura, I 21

Dehiscence, of anther, I1 8

Dermatogen, 48, 68, 92, I06

Diaphragms, Hippuris, 68

Dicotyledons, vegetative organs of, 34, \&c.

Dracana, stem of, 98

Drawing, 15

Duramen, 59

Eau de Javelle, 32

Egg-cell, see Ovum

Elaters, 194, 196

Elder, pith of, 8, 28

Elm, external characters of shoot, 52 ; stem of, 52

Elodea, 23

Embedding, 8 
Embryo, development of, in Angiosperms, I21 ; in Pinus, 149

Embryo-sac, I 20, 122, 147

Embryonic cell, 122

Emergences 38, 42

Endodermis, 39, 86, 104, I61, I64 ; see also Bundle-sheath

Endosperm, 123, 127, 131; of Maize, of Pinus, 147

Epidermis of Sunflower, 36, 42, 78 ; of Holly, 80 ; of Maize, IOO; of Pine, 135

Epiphragm, 180, 187

Epispore, 247

Epithelium of resin-passages, 38,42 Euphorbia, laticiferous cells, 73

Eurotium, 236

Exospore, 155

Exodermis, 89, IO 4

Extension of internodes, 49

Female cones, Pine, i 46

Fertilization, 120, \&c.

Fibrous cells or fibres, 44, $6 \mathrm{I}$

Fibrous thickening of wall of anther, 117

Filament, 108, I46

Filicineæ, 156

Florideæ, 197

Flower, 108; origin and development of, I I 3

Foliar gap, I59

Foot of Fern, 176

Fritillaria, mature pollen of, 118

Fuchsia, water stomata of, 82

Fucus, 201

Funaria, 183

Fungi, 226

Funiculus, II9

GAMETANGIA, 219

Gametes, 246

Gelatinous sheath, Spirogyra, 224

Gemmæ, 192

Germination, of Helianthus, I 32 ; of Pine, 149; of Fucus, 208; of Chara, 214

Gills of Mushroom, 227
Glandular hairs, internal of Fern, 160

Globoid, I 3 I

Glycerine, 19 ; permanent mounting in, 32

Glycerine jelly, 33

Gonidiophore, of Mucor, 244

Gossypium, 24

Grape-sugar, 129

Guard-cells of stoma, 100, 144, I 7 I

Gymnosperms, I 34

Gynœcium, I09

HAIRS, 42, 78

Hardening, 4

Helianthus tuberosus, 49

Helianthus anmuss (Sunflower), vegetative organs, 34, \&c.

Hepatica, 189

Hilum, 125

Hippuris, stem of, 67 ; apex of, 67

Holly, leaf of, 79

Hyacinthus, protoplasm and nucleus, 27

Hydrocharis, 22

Hymenial layer, 229

Hypoderma, 8o, 143

Hypophysis, I 23

IDIOBLASTS, 8o

Included starch-grains, 79

Indusium, 156, 172

Initial cells of Fucus, 206

Integument, 1 20, 147

Intercalary growth of $Q$ Edogonium 217

Intercellular spaces, $38,67,140$

Interfascicular cambium, 47

Involucre, I I I

Iodine solution, 19

Irrigation, I I

LACUNAR TISSUE, I 52

Lamellæ, of leaf of Moss, I8I ; of Mushroom, 229

Lamina, 76, \&c.

Lateral roots, 85

Latex, reactions of, 73 
Laticiferous cells, 73 ; vessels, 73

Leaf-scar, 83

Leaf-trace of Fern, 158

Leaves, origin of, $47,49,68$; of Dicotyledons, 76 ; of Pinus, 143 ; of Fern, 156, 171 ; fall of leaf, 83

Lenticels, 52

Lepidium, 24I

Leukoplasts, I 28

Lignified walls, reactions of, 25

Ligule, 150

Lilac, apex of, 50

Lime, sieve tubes of, 71

Limiting layer of Fucus, 203

Linum, 94

Lupinus luteus, 129

Lychnis, flower of, I09

Lycopodinæ, I5O

MACROSPORANGIA, I I 9, I47, I 5 I

Macrospores, I2O

Maize, see Zea

Male branches, Marchantia, 193

Male inflorescence, Pine, 145

Male Shield Fern, 156

Manubrium, 214

Marchantia, 189, \&c.

Mares-tail, see Hippuris

Measurement of objects, 15

Medullary rays, Elm, 56, \&c. ; of Pine, I 37, \&c.

Mesophyll, 78 ; Maize, Ior ; Pine, I 43 ; Fern, I 7 I

Micrometer, 15

Micropyle, I 20, 125, 147

Microsporangia, I17, 146, I 51

Microspores, I I 7, I 46

Monocotyledons, vegetative organs of, 95

Mounting objects, 9

Mucilaginous walls, 55

Mucor, 244

Mucorineæ, 244

Musci, I 79

Mushroom, 226

Mycelium, of Mushroom, 226 ; of Aspergillus, 236
Neck of archegonium, Pinus 148 ; Fern, I76 ; of Moss, 184 ; of Marchantia, 195

Nectary, 108

Nephrodium, I 56, \&c.

Nerves, 77

Nitella, 23, 2 10

Nucellus, I 20, I 47

Nucleus, I 8, 27, 28

Edogonium, 216

Oil, 130

Oogonium, of Fucus, 207 ; of Chara, 214; of AEdogonium, 218; of Vaucheria, 220; of Pythium, 243

Oophyte, of Selaginella, I55 ; of Fern, I73; of Moss, 180

Oosphere, see Ovum

Oospore, of Vaucheria, 220 ; of Pythium, 243

Operculum, I 80,187

Ostiole of Futus, 206

Ovary, 109

Ovule, of Angiosperms, I09, I19; of Pine, 147.

Ovuliferous scale, 146

Ovum of Angiosperms, I20 ; of Pine, I48; of Fern, I76; of Moss, 184 ; of Marchantia, I95 ; of Fucus, 207

Palisade parenchyma, 78,80

Paraffin, 9

Paraphyses, of Mosses, 183 ; of Agaricus, 229

Perianth, I 2

Periblem, 68, 93, 106

Pericambium, see Pericycle

Pericarp, 126

Perichætia, I 79, 183, 194

Pericycle, 86, 104, I44, I52, I6I, 164

Periderm, 52

Peridium, 233

Perigonium, I 79, 183

Perigynium, 196

Peristome, I8o, 187 
Perithecium, $23^{8}$

Permanent mounting, 32

Peronosporex, 24I

Petiole, 76

Phæophyceæ, 20I

Phanerogamæ, 34

Phaseolus, root of, 94

Phellogen, 54, 60

Phelloderm, 54, 60

Phloem, of Sunflower, 40, 43 ; of Elm, $57,60,65$; of Cucurbita, 70 ; of Pine, 136

Phloem-parenchyma, 40

Phytophthora, 243

Piliferous layer, 87,89 , I04, I68

Pinus sylvestris, I34, \&c.

Pith, of Sunflower, 37,44 ; of EIm, 56

Pits, bordered, 44

Pitted vessels, 44, 6r, 96

Plasmolysis, 2 I

Plerome, 68, 93, 106

Plumule, 85, I 23, 126

Pollen, 109, I 18

Pollen-grains, germination of, I I 7, 146

Pollen-sacs, I1 7, 146

Pollen-tube, i 18, I 20, 147

Pollinodium, 238

Polyembryony, 149

Polysiphonia, 197

Polytrichum, I79

Potash solution, 19, 29; clearing by, 3 I

Potato, starch of, 28, 129

Primary root, 85

Primrose (Primula), flower of, I IO

Procambium, 49

Proembryo, 214

Promycelium, 232

Prothallus of Fern, 19, 174

Protonema of Moss, I 88

Protoplasm, 18, 27; continuity of, I99; movements of, 22

Protoxylem, 61, 104, 136, 153, I63

Prunus Padus, flowers of, I Iо Pteridophyta, I50
Pteris, stem, 163

Pleccinia, 231, \&c.

Punctum vegetationis, see Apex

Pyrenoids, of Spirogyra, 224; of Edogonium, 2 I 7

Pythium, 24I

RADICLE, I 23, I 26

Ramenta, I 56

Ranunculus, flower of, 108

Raphides, IO3

Razor, 7

Reagents, 2, and Appendix A.

Reproductive organs, of Angiosperms, I08; of Gymnosperms, 145

Resin-passages, 37, 42, \&c., I38, \&c.

Resting conidia, 242

Rhizoids, I79, 189, 191

Rhizophores, 150

Rhododendron, style and stigma of, 120

Ricinus, seed of, 126 ; seedlings of, 132

Root of Dicotyledons, 85 ; of Monocotyledons, I04; of Fern, I68

Root, apex of, 9I, I05

Root-cap, 92

Root-hairs, 22, 87, I 74

Rotation of protoplasm, 22, 213

Rust of Wheat, 23 I

Saxifraga, chalk glands of, 82

Scalariform tracheides, 163

Scale-hairs, 68

Scale-leaves, Pine, 134

Schulze's solution, see Chlor-zinciodine

Schulze's macerating fluid, 26

Scilla (Blue-bell), flower of, I 12

Sclerenchyma, of Sunflower, 39, 42 ; of Elm, 55 ; of Ferns, $15^{8}$, \&c.

Scutellum, 128, 133

Secondary thickening of root, 87 ; of Monocotyledons, 99

Seed coat, 125 
Seed, of Dicotyledons, 85,125 ; of Pine, 147

Segmental cells, 167, 169, 198

Selaginella, 150

Seta, 180, 196

Sexual organs, of Ferns, I75; of Mosses, 183 ; of Liverworts, I93; of Characeæ, 213; of Florideæ, 200 ; of Fuculs, 206; of Vaucheria, 220; of Pythium, 243 Sieve-plates, see Sieve-tubes

Sieve-tubes, Sunflower, 40, 43 ; of Elm, 56, 60; of Cucurbita, 70 ; of Maize, 96; of Pine, 137, \&c. ; of Ferns, 16r-164, \&c.

Siphoneæ, 219

Soft-bast, see Phloem

Sori, 156

Spawn of Mushroom, 226

Spermatia, 200

Spermatozoids of Fern, 175, \&c.; of Moss, 183 ; of Marchantia, 193; of Fucus, 207 ; of Chara, 213; of Vaucheria, 220, \&c.

Spermogonia, 232

Sphere -crystals of inulin, 74

Spiral vessels, of Sunflower, 44 ; of Elm, 6I

Spirogyra, I 7, 223

Spongy parenchyma, 78, 8I

Sporangium of Selaginella, $15 \mathrm{I}$; of Fern, I 56, I 72

Spores, of Selaginella, 154 ; of Fern, I 72, of Moss, 186, of Marchantia, r94; of Mushroom, 228, 230; of Mucor, 245

Spore-sac (Moss), I 86

Sporidium, 232

Sporodinia, 245

Sporogonium, of Moss, I79, I84; of Marchantia, I94

Sporophyte, of Selaginella, 150; of Fern, 156 ; of Moss, 184

Spurious tissue, 228

Staining, 30

Stamen, I08, I16, 145

Starch, structure and reactions of, 28 ; optical properties of, 128 Starch-forming corpuscles, 128
Stellaria, flower of, I09; pollen. tubes of, 120

Stem, herbaceous Dicotyledon, 35 ; arboreous Dicotyledon, 52 ; aquatic Dicotyledon, 67 ; of Pine, 1 35 ; of Selaginella, 1 51 ; of Fern, 156

Sterigmata, 230, 232, 237

Stigma, I09, I 20

Stipe, 227

Stomata, 76, 81 ; of Maize, Ioo ; of Pine, I 44; of Fern, I 7 I ; of Moss, I86; of Marchantia, 190

Stratification of cell-walls, 38

Striation of cell-walls, I40

Strychnos, $\mathrm{x} 25$

Style, 109, 120

Subsidiary cells, ror

Sub-hymenial layer, 229

Sugar, I 29

Sunflower, see Helianthus

Suppression, I ro

Suspensor, 122, 149

Swarm spores, 217

Synergidæ, 120

Tapetum, II 7, I20, 154

Taraxacum, 73, II 2

Teleutospores, 232, 235

Tetraspores, 199

Thallophyta, 197

Thyloses, 4I, 44

Tilia, sieve-tubes of, $7 \mathrm{I}$

Trabeculæ, 152

Trabecular tissue, 204

Tracheides, of Pine, I3 8 , \&c. ; of Fern, $161-165$

Tradescantia, 23

Trama, 229

Trianea, 22

Ulmus, see Elm

Uredospores, 234

VACUOLE, I 8

Vacuolization, 49

Vaginula, I8o 
Vallisneria, 23

Vascular bundles, systems of, 35 ; of Sunflower, 37, \&c. ; of Maize, 96 ; of Ferns, I60

Vaucheria, 219

Velum partiale, 227

Ventral canal-cell, I48, I 76, I84

Vessels, 4I, 44

Water stomata, 82

Wood, see Xylem

XYi.em, of Sunflower, $4 \mathbf{I}$, \&c. ; of Elm, 56,65 ; of Pine, I 36
$\mathrm{X}$ ylem fibres, $4 \mathrm{I}, 56$, dic.

Xylem parençyma, 4r, 56, \&.c.

Yucca, stem of, 98

Zea, 95

Zoogonidia, 22I

Zygnema, 223

Zygospores, of Sporodinia, 245

Zygote, of Spirogyra, 225;

Sporodinia, 246 
<smiles>C1=CC=1</smiles> 



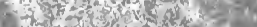
-

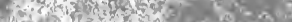

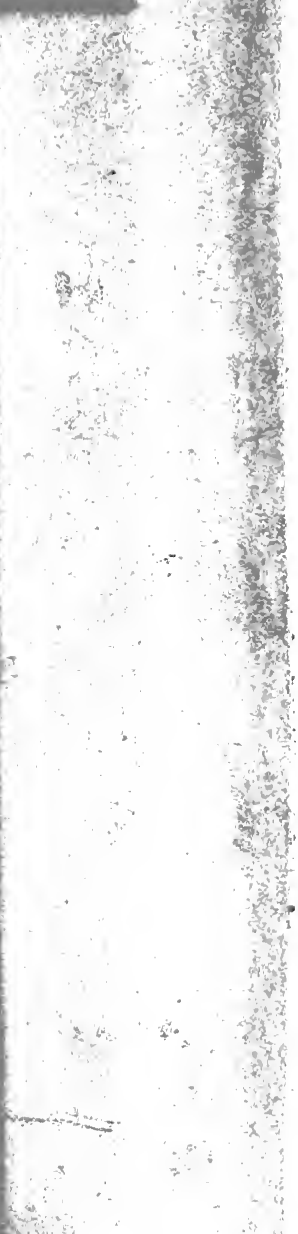




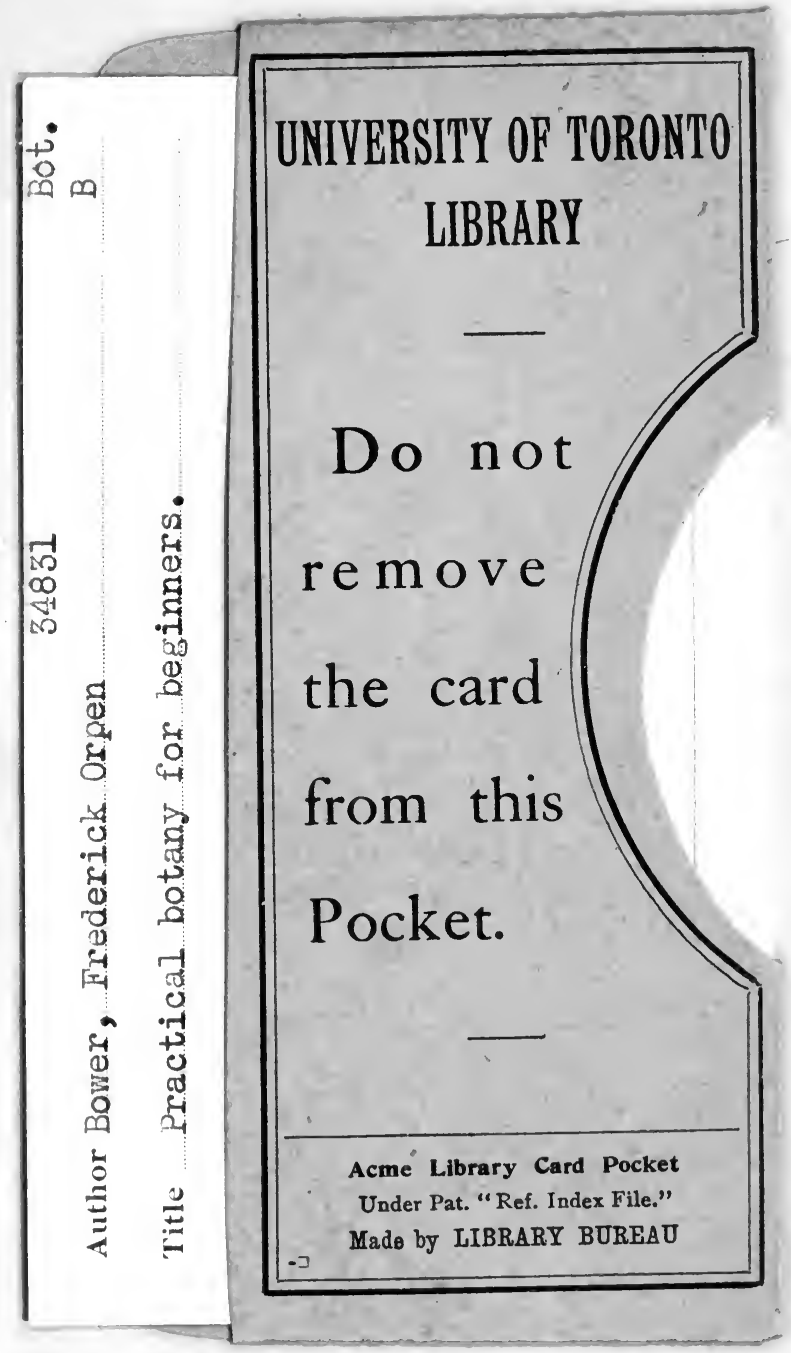


